\title{
In Silico STUdy OF CALCIUM HANDLING IN THE HUMAN FAILING HEART
}

Valencia, September 2020

Author

María Teresa Mora Fenoll

Supervisors

Beatriz Trénor Gomis

José María Ferrero De Loma-Osorio 

This doctoral thesis was carried out in the Centro de Investigación e Innovación en Bioingeniería (Ci2B) from the Universitat Politècnica de València and it belongs to the doctoral program Technologies for Health and Well-Being.

External Evaluators

Dr. Pablo Laguna Lasaosa

Universidad de Zaragoza

Dr. Michelangelo Paci

Tampere University of Technology

Dr. Stefano Severi

Università di Bologna

Reading Committee

Dr. Esther Pueyo Paules

Universidad de Zaragoza

Dr. María Salud Guillem Sánchez

Universitat Politècnica de València

Dr. Stefano Severi

Università di Bologna 

- ¿Me podrías indicar, por favor, hacia dónde tengo que ir desde aquí?

- Eso depende de a dónde quieras llegar - contestó el Gato.

- A mí no me importa demasiado a dónde... - empezó a explicar Alicia.

- En ese caso, da igual hacia dónde vayas - interrumpió el Gato.

- ...siempre que llegue a alguna parte - terminó Alicia a modo de explicación.

- ¡Oh! Siempre llegarás a alguna parte - dijo el Gato - si caminas lo bastante.

A Alicia le pareció que esto era innegable, de forma que intentó preguntarle algo más: “Qué clase de gente vive por estos parajes?”.

- Por ahí - contestó el Gato volviendo una pata hacia su derecha - vive un sombrerero; y por allá - continuó volviendo la otra pata - vive una liebre de marzo. Visita al que te plazca, ambos están igual de locos.

- Pero es que a mí no me gusta estar entre locos - observó Alicia.

- Eso sí que no lo puedes evitar - repuso el gato - todos estamos locos por aquí. Yo estoy loco; tú también lo estás.

- Y ¿cómo sabes tú si yo estoy loca? - le preguntó Alicia.

- Has de estarlo a la fuerza - le contestó el Gato - de lo contrario no habrías venido aquí.

Lewis Carroll, 'Alicia en el País de las Maravillas' 



\section{ABSTRACT}

Heart failure, a cardiomyopathy that produces mechanical dysfunction and sudden cardiac death following fatal arrhythmias, is one of the main causes of mortality worldwide that also causes elevated morbidity rates. Current clinical therapies are challenged by the complexity of this cardiac pathology, in which many factors are involved in the electrical instabilities that lead to an altered function. The electrical activity of the heart comprises a wide range of spatial and temporal scales. Ion transport across transmembrane proteins initiate the cellular depolarization that is propagated cell to cell through the myocardium depolarizing and then repolarizing the entire heart in an orchestrated manner. The electrical excitation of cardiomyocytes triggers the cellular contraction, a process in which $\mathrm{Ca}^{2+}$ ions are the main mediators. $\mathrm{Ca}^{2+}$ dynamics plays a relevant role in controlling excitation-contraction coupling and consequently, investigations have focused on $\mathrm{Ca}^{2+}$-handling proteins and the regulation of $\mathrm{Ca}^{2+}$ homeostasis to elucidate the causes of impaired contractility and pro-arrhythmic conditions in cardiac diseases.

This thesis takes advantage of the existence of mathematical models with detailed representation of the subcellular processes to perform computational simulations of cardiac electrophysiology and understand the altered mechanisms that govern heart failure, especially those related with intracellular $\mathrm{Ca}^{2+}$ cycling.

It is known that failing myocytes undergo a specific remodeling of ion channels and $\mathrm{Ca}^{2+}$ handling proteins that lead to an impaired excitation-contraction coupling. Initially, it was analyzed, in the human action potential model of ventricular myocytes selected for the whole study, the effects of modulating ionic mechanisms on the electrical activity and $\mathrm{Ca}^{2+}$ dynamics. In tissue, heart failure induces additional changes affecting cellular coupling. The development of fibroblasts and impact on myocyte electrophysiology was investigated, including the vulnerability to generate alternans, a common precursor to arrhythmogenesis. Finally, the $\beta$-adrenergic signaling model was integrated with the action potential model because of the electrophysiological modulation exerted by the sympathetic nervous system, which is aggravated under heart failure conditions.

Results highlighted the need of studying heart failure therapies on failing cells because of the different response of ion channels and membrane proteins to drugs. Functional $\mathrm{Ca}^{2+}$ proteins were important to maintain $\mathrm{Ca}^{2+}$ homeostasis and to avoid malignant electrical consequences, being SERCA pump the most critical factor. Apart from the electrophysiological remodeling, fibroblast interaction contributed to alter $\mathrm{Ca}^{2+}$ dynamics in myocytes and, when analyzing $\mathrm{Ca}^{2+}$ alternans, spatial electrical discordances predominated in failing tissues. The inclusion of $\beta$-adrenergic stimulation showed that the inotropic response was diminished in heart failure as well as the antiarrhythmic benefits provided by catecholamines in the normal heart.

These findings contribute to gain insight into the pathophysiology of heart failure and the development of new pharmacological agents targeted to restore $\mathrm{Ca}^{2+}$ dynamics. The control of intracellular $\mathrm{Ca}^{2+}$ cycling is crucial to ensure both the mechanical force and the electrical activity that lead to a rhythmic contraction of the heart. 


\section{RESUMEN}

La insuficiencia cardíaca, una cardiomiopatía que provoca disfunción mecánica y muerte súbita tras arritmias cardíacas letales, es una de las principales causas de mortalidad en todo el mundo que además causa tasas de morbilidad elevadas. Las terapias usadas actualmente en la clínica están comprometidas por la complejidad de esta patología cardíaca, ya que son muchos los factores que están implicados en las inestabilidades eléctricas que conllevan a alteraciones funcionales. La actividad eléctrica del corazón abarca un amplio rango escalas espaciales y temporales. El transporte de iones a través de las proteínas transmembrana inicia la despolarización celular que se propaga de célula en célula a través del miocardio, despolarizando y luego repolarizando todo el corazón de manera sincronizada. La excitación eléctrica de los cardiomiocitos desencadena la contracción celular, un proceso en el que los iones de $\mathrm{Ca}^{2+}$ son los principales intermediarios. La dinámica de $\mathrm{Ca}^{2+}$ tiene un papel relevante en el control del acoplamiento excitación-contracción y, como consecuencia, las investigaciones se han centrado en las proteínas que controlan el ciclo del $\mathrm{Ca}^{2+}$ y la regulación homeostática para encontrar las causas que empeoran la contractilidad y conducen a condiciones proarrítmicas en casos de insuficiencia cardíaca.

Esta tesis hace uso de la existencia de modelos matemáticos con una representación detallada de los procesos subcelulares para realizar simulaciones computacionales de electrofisiología cardíaca y comprender los mecanismos que están alterados y predominan en insuficiencia cardíaca, especialmente aquellos relacionados con el ciclo intracelular de $\mathrm{Ca}^{2+}$.

Se sabe que los miocitos dañados por insuficiencia cardíaca experimentan un remodelado específico en los canales iónicos y en las proteínas partícipes en el ciclo de $\mathrm{Ca}^{2+}$, ocasionando fallos en el acoplamiento excitación-contracción. Inicialmente, se analizaron, en el modelo de potencial de acción humano de miocitos ventriculares seleccionado para todo el estudio, los efectos de la modulación de los mecanismos iónicos sobre la actividad eléctrica y la dinámica de $\mathrm{Ca}^{2+}$. En los tejidos, la insuficiencia cardíaca induce cambios adicionales que afectan el acoplamiento celular. Se ha investigado la presencia de fibroblastos y su impacto en la electrofisiología de los miocitos, incluida la vulnerabilidad para generar alternantes, un precursor común de la arritmogénesis. Finalmente, se ha incluido el modelo de señalización $\beta$-adrenérgica integrado con el modelo de potencial de acción debido a la modulación electrofisiológica ejercida por el sistema nervioso simpático, que se agrava en condiciones de insuficiencia cardíaca.

Los resultados han destacado la necesidad de estudiar las terapias de insuficiencia cardíaca en células de estos corazones debido a la diferente respuesta de los canales iónicos y las proteínas de membrana a los medicamentos. El buen funcionamiento de las proteínas reguladoras del $\mathrm{Ca}^{2+}$ es importantes para mantener la homeostasis del $\mathrm{Ca}^{2+} \mathrm{y}$ evitar consecuencias eléctricas malignas, siendo la bomba SERCA el factor más crítico. Además del remodelado electrofisiológico, la interacción con fibroblastos contribuye a alterar la dinámica de $\mathrm{Ca}^{2+}$ en los miocitos y, al analizar los alternantes de $\mathrm{Ca}^{2+}$, predominan las discordancias eléctricas espaciales en los tejidos de corazones con insuficiencia cardíaca. La inclusión de la estimulación $\beta$-adrenérgica ha mostrado que la respuesta inotrópica disminuye en insuficiencia cardíaca, así como los beneficios antiarrítmicos proporcionados por las catecolaminas en un corazón normal.

Estos hallazgos contribuyen a obtener información sobre la fisiopatología de la insuficiencia cardíaca y el desarrollo de nuevos agentes farmacológicos destinados a restaurar la dinámica de $\mathrm{Ca}^{2+}$. 
El control del ciclo de $\mathrm{Ca}^{2+}$ intracelular es crítico para garantizar tanto la fuerza mecánica como la actividad eléctrica que conducen a una contracción rítmica del corazón. 


\section{RESUM}

La insuficiència cardíaca, una cardiomiopatia que provoca disfunció mecànica i mort sobtada després d'arrítmies cardíaques letals, és una de les principals causes de mortalitat a tot el món que a més causa taxes de morbiditat elevades. Les teràpies utilitzades actualment en la clínica estan compromeses per la complexitat d'aquesta patologia cardíaca, ja que són molts els factors que estan implicats en les inestabilitats elèctriques que comporten a alteracions funcionals. L'activitat elèctrica del cor abasta un ampli rang d'escales espacials i temporals. El transport d'ions a través de les proteïnes transmembrana inicia la despolarització cel·lular que es propaga de cèl·lula en cèl·lula a través del miocardi, despolaritzant i després repolaritzant tot el cor de manera sincronitzada. L'excitació elèctrica dels cardiomiòcits desencadena la contracció cel·lular, un procés en el qual els ions de $\mathrm{Ca}^{2+}$ són els principals intermediaris. La dinàmica de $\mathrm{Ca}^{2+}$ té un paper rellevant en el control de l'acoblament excitació-contracció $i$, com a conseqüència, les investigacions s'han centrat en les proteïnes que controlen el cicle del $\mathrm{Ca}^{2+}$ i la regulació homeostàtica per a trobar les causes que empitjoren la contractilitat i condueixen a condicions proarrítmiques en casos d'insuficiència cardíaca.

Aquesta tesi fa ús de l'existència de models matemàtics amb una representació detallada dels processos subcel·lulars per a realitzar simulacions computacionals de l'electrofisiologia cardíaca i comprendre els mecanismes que estan alterats i predominen en insuficiència cardíaca, especialment aquells relacionats amb el cicle intracel-lular de $\mathrm{Ca}^{2+}$.

Se sap que els miòcits danyats per insuficiència cardíaca experimenten un remodelat específic en els canals iònics $\mathrm{i}$ en les proteïnes partícips en el cicle de $\mathrm{Ca}^{2+}$, ocasionant fallades en l'acoblament excitació-contracció. Inicialment, es van analitzar, en el model de potencial d'acció humà de miòcits ventriculars seleccionat per a tot l'estudi, els efectes de la modulació dels mecanismes iònics sobre l'activitat elèctrica i la dinàmica de $\mathrm{Ca}^{2+}$. En els teixits, la insuficiència cardíaca indueix canvis addicionals que afecten l'acoblament cel·lular. S'ha investigat la presència de fibroblasts i el seu impacte en l'electrofisiologia dels miòcits, inclosa la vulnerabilitat per a generar alternants, un precursor comú de l'arritmogènesi. Finalment, s'ha inclòs el model de senyalització $\beta$-adrenèrgica integrat amb el model de potencial d'acció a causa de la modulació electrofisiològica exercida pel sistema nerviós simpàtic, que s'agreuja en condicions d'insuficiència cardíaca.

Els resultats han destacat la necessitat d'estudiar les teràpies d'insuficiència cardíaca en cèl·lules d'aquests cors a causa de la diferent resposta dels canals iònics i les proteïnes de membrana als medicaments. El bon funcionament de les proteïnes reguladores del $\mathrm{Ca}^{2+}$ és importants per a mantindre l'homeòstasi del $\mathrm{Ca}^{2+} \mathrm{i}$ evitar conseqüències elèctriques malignes, sent la bomba SERCA el factor més crític. A més del remodelat electrofisiològic, la interacció amb fibroblasts contribueix a alterar la dinàmica de $\mathrm{Ca}^{2+}$ en els miòcits $\mathrm{i}$, en analitzar els alternants de $\mathrm{Ca}^{2+}$, predominen les discordances elèctriques espacials en els teixits de cors amb insuficiència cardíaca. La inclusió de l'estimulació $\beta$ adrenèrgica ha mostrat que la resposta inotròpica disminueix en insuficiència cardíaca, així com els beneficis antiarrítmics proporcionats per les catecolamines en un cor normal.

Aquestes troballes contribueixen a obtindre informació sobre la fisiopatologia de la insuficiència cardíaca i el desenvolupament de nous agents farmacològics destinats a restaurar la dinàmica de $\mathrm{Ca}^{2+}$. El control del cicle de $\mathrm{Ca}^{2+}$ intracel·lular és crític per a garantir tant la força mecànica com l'activitat elèctrica que condueixen a una contracció rítmica del cor. 


\section{Contents}

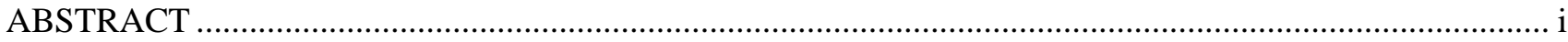

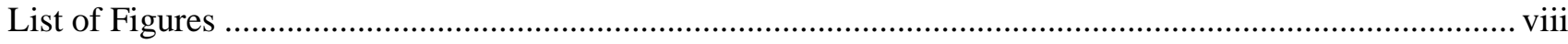

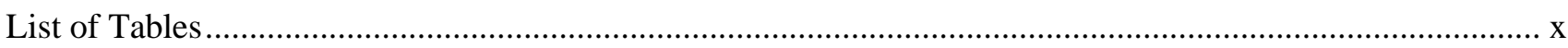

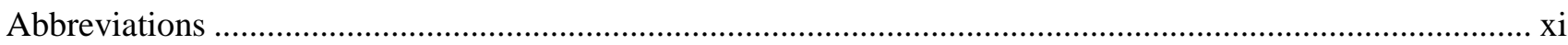

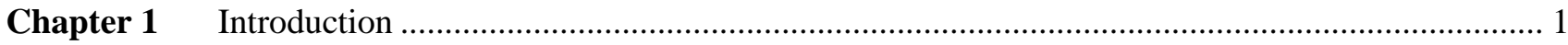

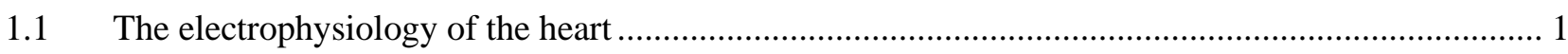

1.1.1 From cardiac physiology to an in silico heart..................................................................... 1

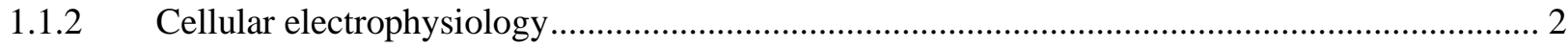

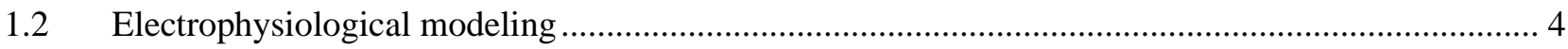

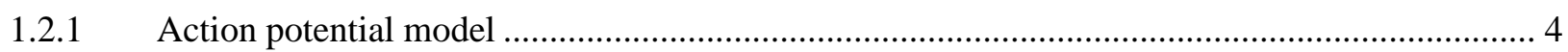

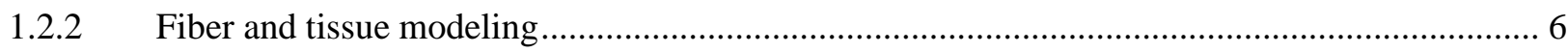

$1.3 \quad$ Heart failure

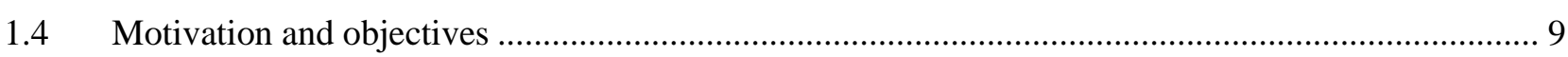

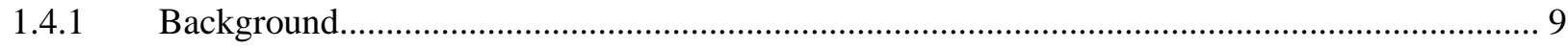

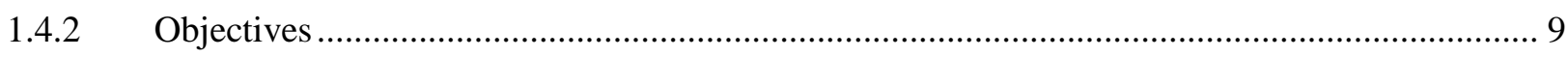

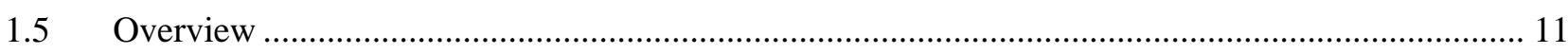

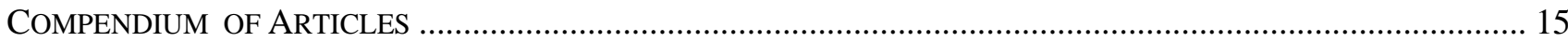

Chapter 2 Sensitivity analysis revealing the effect of modulating ionic mechanisms on calcium dynamics

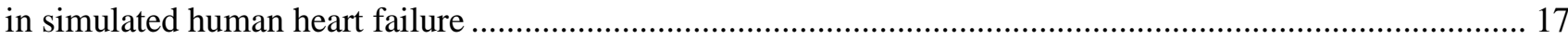

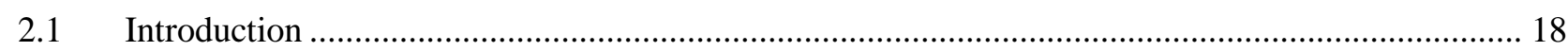

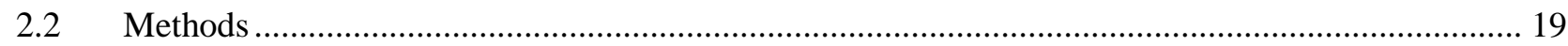

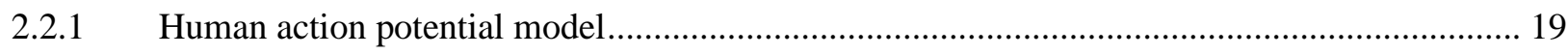

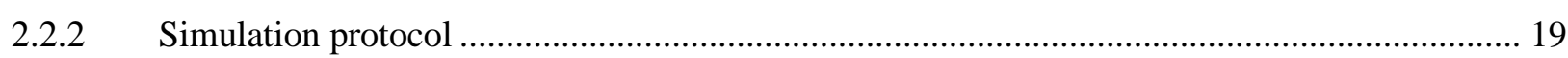

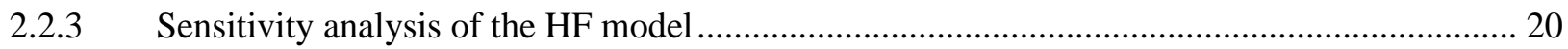

2.2.4 Sensitivity analysis of the effects of potential drugs ........................................................ 21

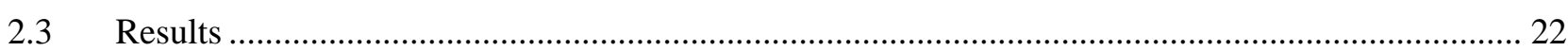

2.3.1 Impact of HF remodeling variability on $\mathrm{Ca}^{2+}$ dynamics.................................................... 22

2.3.2 Sensitivity of the normal and the HF model to potential effects of drugs ............................... 25

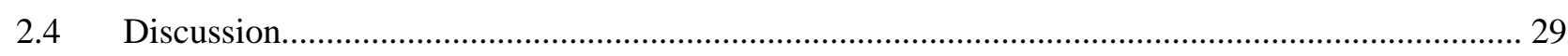

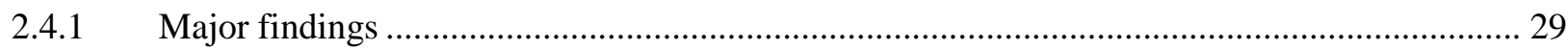

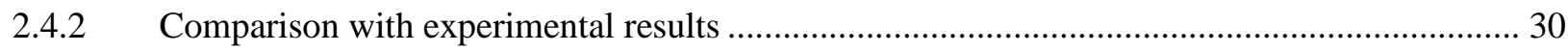

2.4.3 Benefits and predictions from systematic sensitivity analyses ............................................. 31

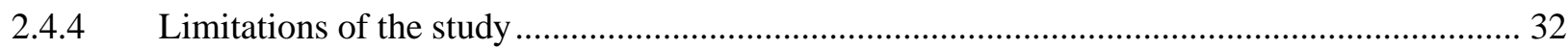

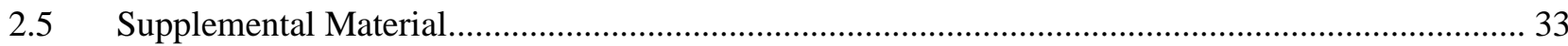

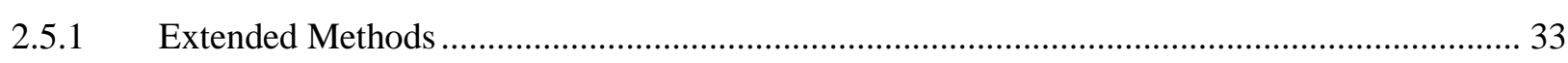

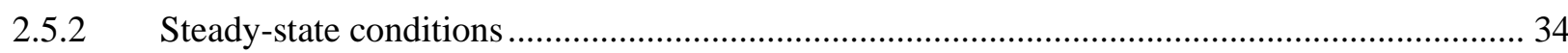


Chapter $3 \mathrm{Ca}^{2+}$ cycling impairment in heart failure is exacerbated by fibrosis: Insights gained from

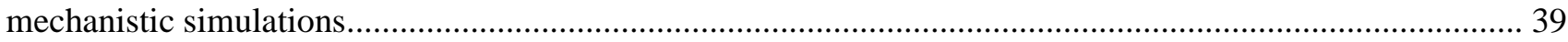

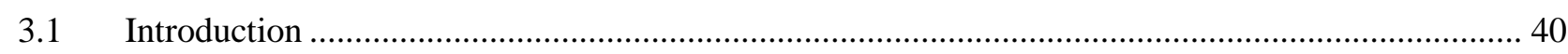

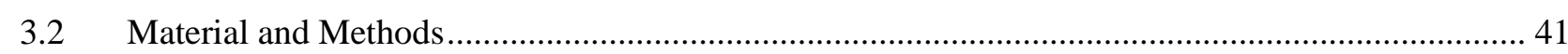

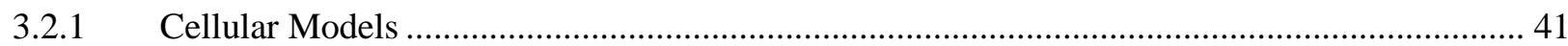

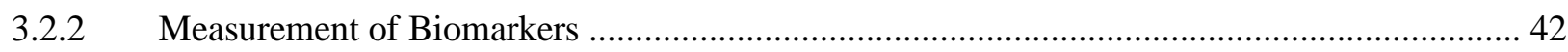

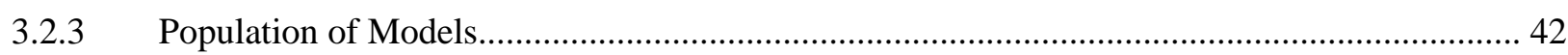

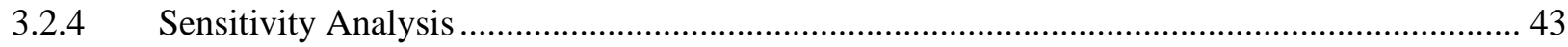

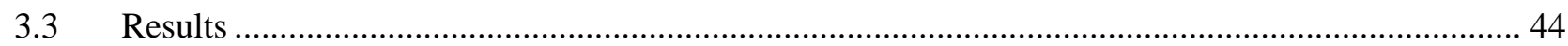

3.3.1 Comparison of univariate and multivariate sensitivity analyses in normal and failing conditions 44

3.3.2 Effects of fibroblast-myocyte coupling in normal and failing conditions .............................. 47

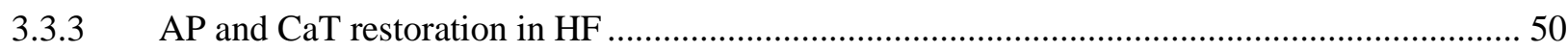

3.3.4 Mechanistic analysis of calcium dynamics impairment in fibrosis ....................................... 50

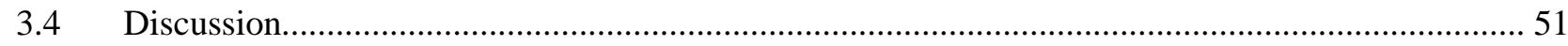

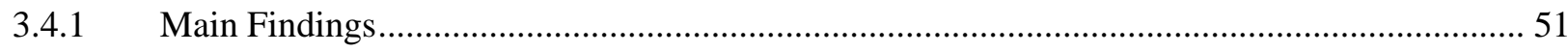

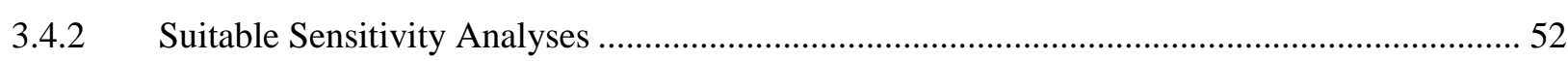

3.4.3 Fibrosis exacerbates $\mathrm{Ca}^{2+}$ transient impairment in heart failure .............................................. 53

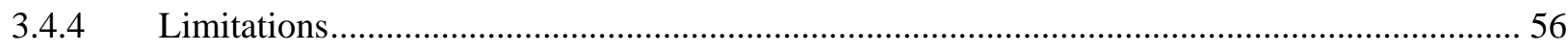

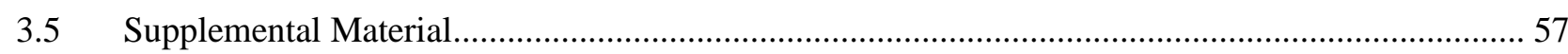

Chapter 4 Mechanistic investigation of $\mathrm{Ca}^{2+}$ alternans in human heart failure and its modulation by fibroblasts $\quad 67$

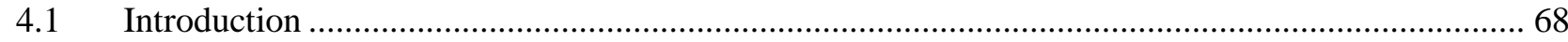

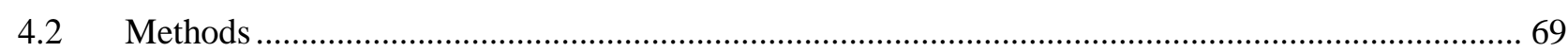

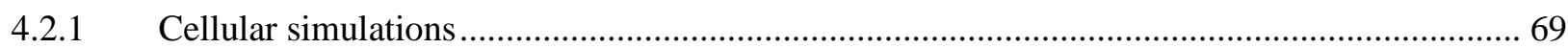

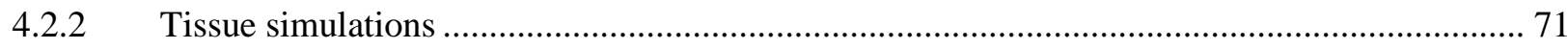

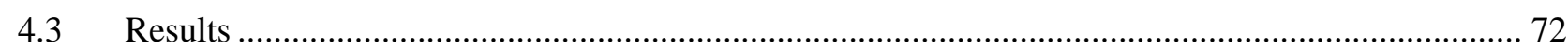

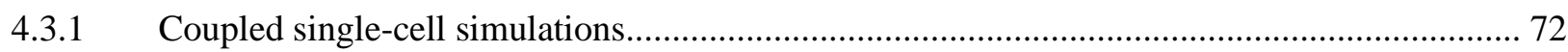

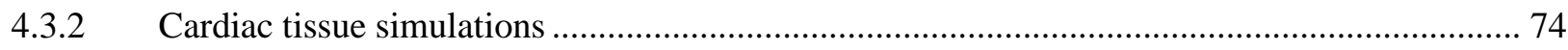

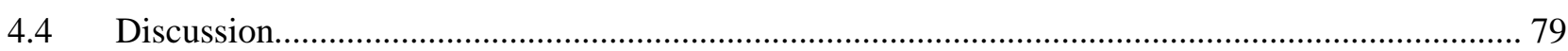

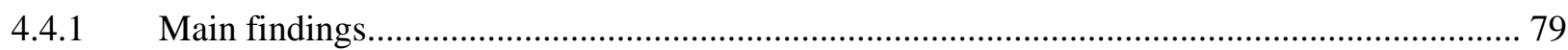

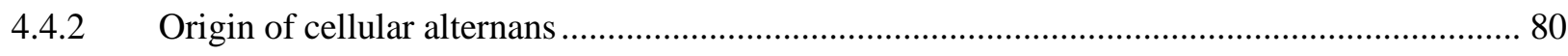

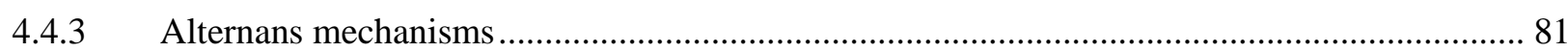

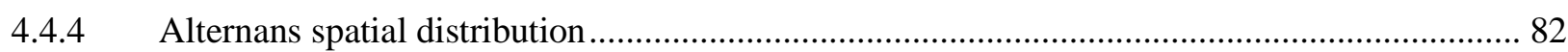

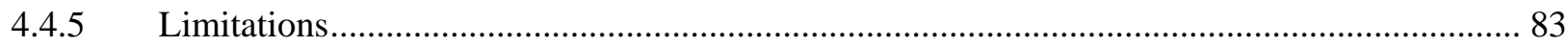

Chapter 5 The role of $\beta$-adrenergic system remodeling in human heart failure: A mechanistic investigation 87

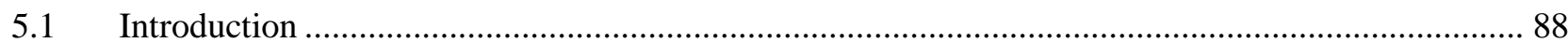

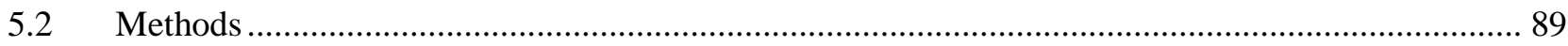

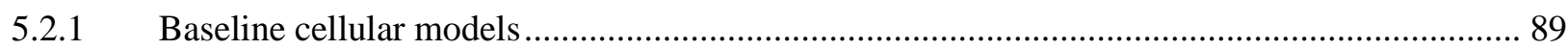




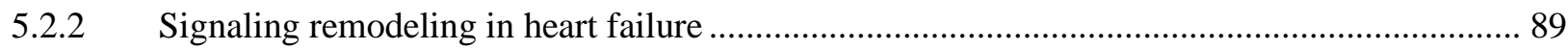

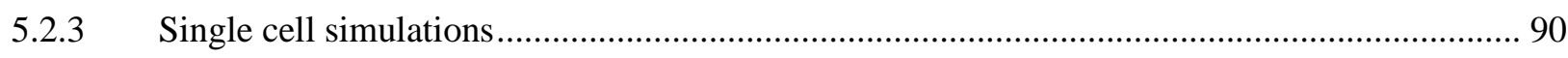

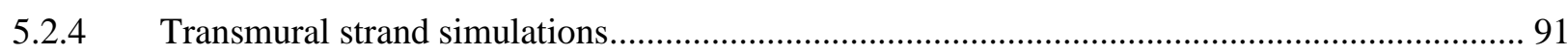

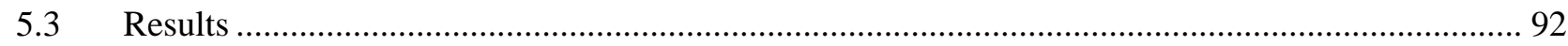

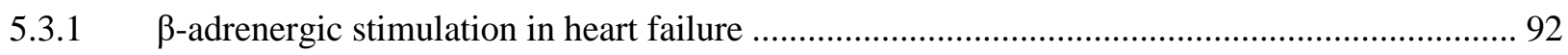

5.3.2 Comparison of $\beta$-adrenergic stimulation in normal and failing myocytes ............................. 93

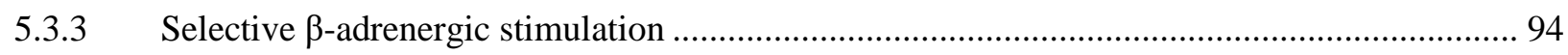

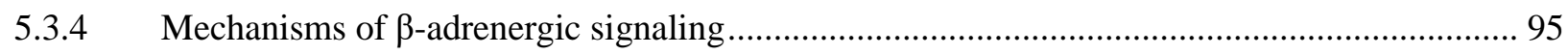

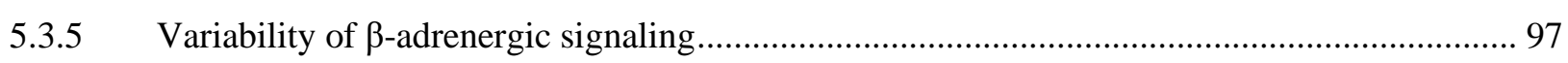

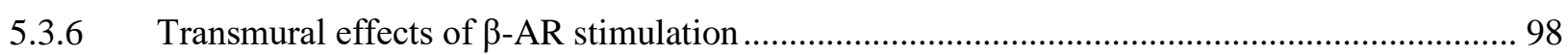

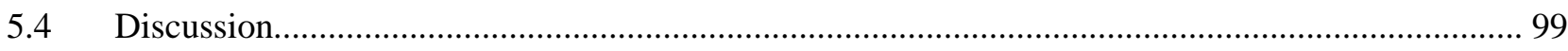

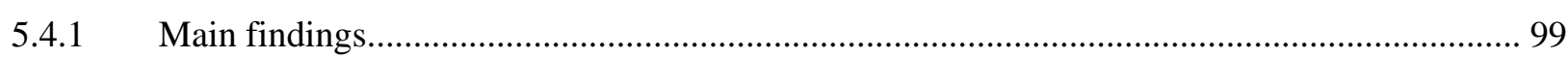

5.4.2 Compartmented PKA-phosphorylation activated by $\beta$-adrenergic stimulation modulates action

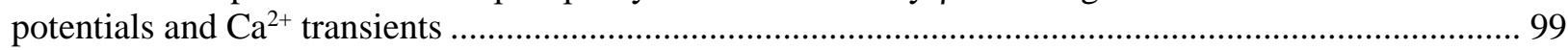

5.4.3 Adverse $\beta$-adrenergic remodeling effects in HF. Desensitization and detubulation ............... 100

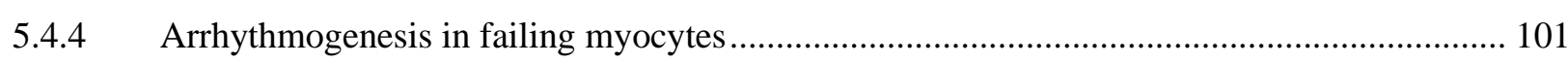

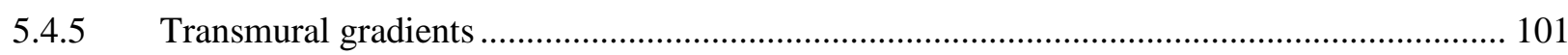

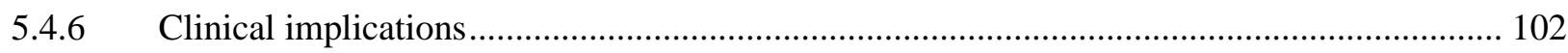

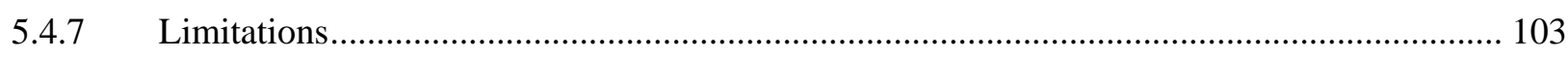

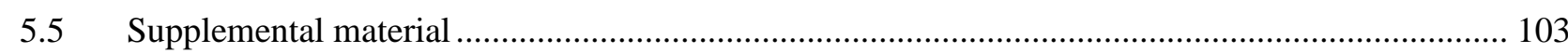

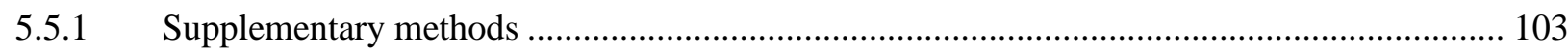

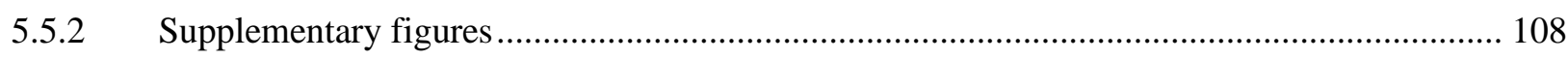

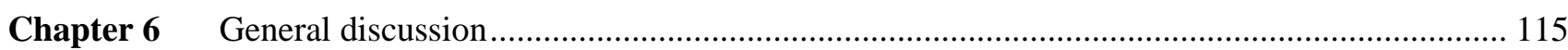

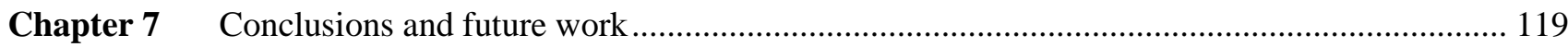

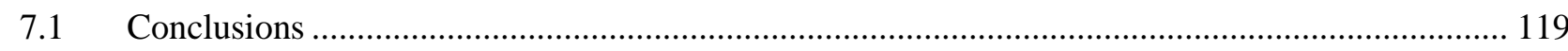

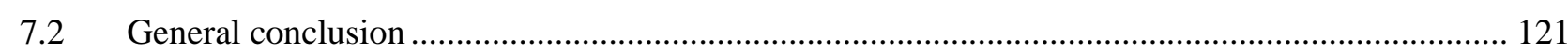

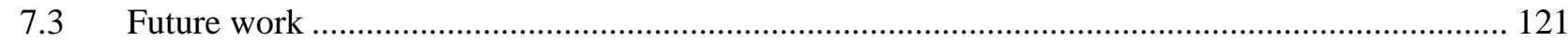

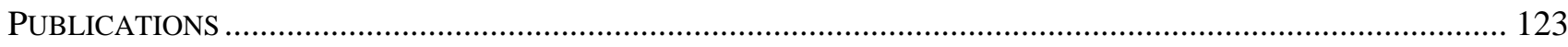

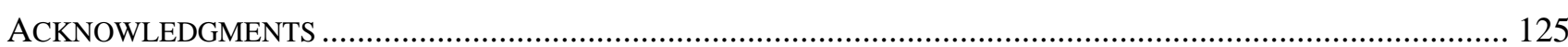




\section{List of Figures}

Figure 1.1. Cardiac conduction system, activation times (in ms), action potential waveforms from different heart

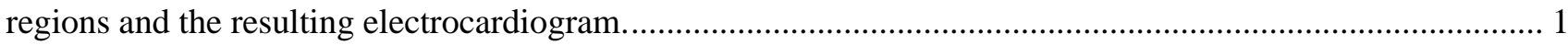

Figure 1.2. Action potential and main ionic currents in an endocardial cell. .............................................. 3

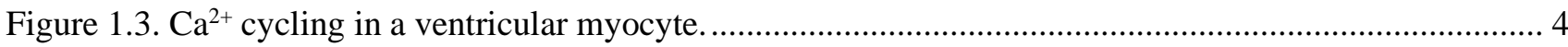

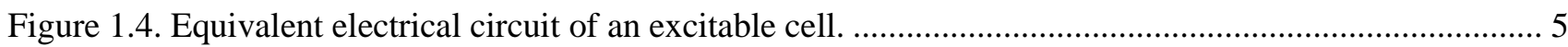

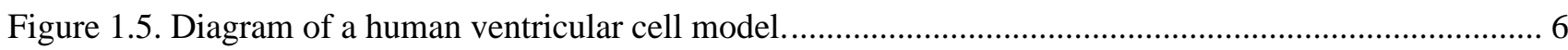

Figure 2.1. Steady state activation (left) and inactivation (right) gates of the fast $\mathrm{Na}^{+}$current in the different

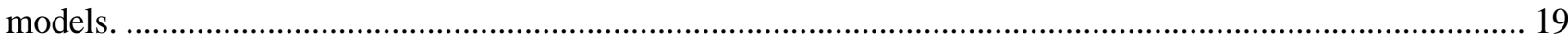

Figure 2.2. Time course of a steady state $\mathrm{Ca}^{2+}$ transient (CaT) and its electrophysiological characteristics.... 20 Figure 2.3. Relative sensitivities of the electrophysiological properties to changes in electrophysiological

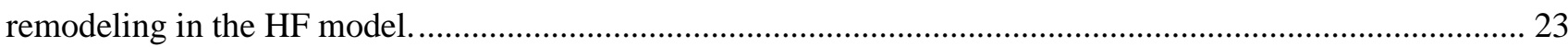

Figure 2.4. Sensitivity of electrophysiological properties to changes in ionic current parameters in the HF model. 24

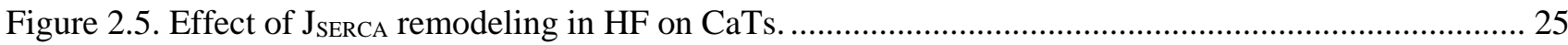
Figure 2.6. Relative sensitivities of the electrophysiological properties to modulating effects of potential drugs.

Figure 2.7. Sensitivity of $\mathrm{APD}_{90}, \mathrm{APD}_{30}$ and $\mathrm{CaTD}_{80}$ to the effects of drugs in normal $(\mathrm{N})$ and failing (HF)

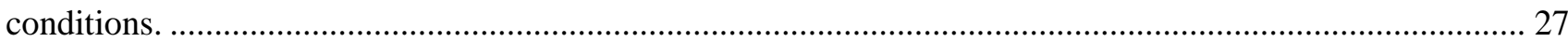

Figure 2.8. Sensitivity of $t_{10-90}$, systolic and diastolic $\left[\mathrm{Ca}^{2+}\right]_{i}$ to the effects of drugs in normal $(\mathrm{N})$ and failing

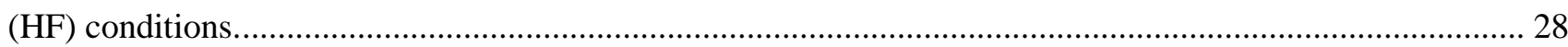

Figure 3.1. Population of normal (N, blue) and heart failure (HF, red) human ventricular cell models.......... 44

Figure 3.2.Comparison of univariate and multivariate relative sensitivities in normal $(\mathrm{N})$ and heart failure (HF)

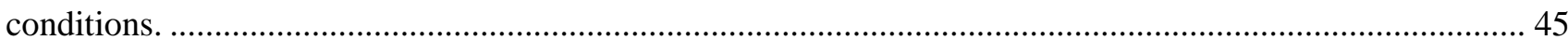

Figure 3.3. Effect of fibrosis on action potential (A) and $\mathrm{Ca}^{2+}$ transient (B) ............................................. 47

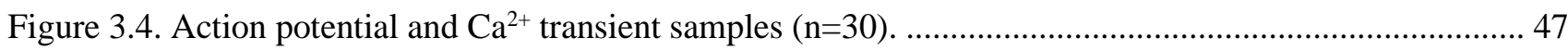

Figure 3.5. Comparison of sensitivities obtained from 4 multivariable regression analyses. ........................ 48

Figure 3.6. Restoration of normal action potential (AP) and calcium transient (CaT) in a population of failing

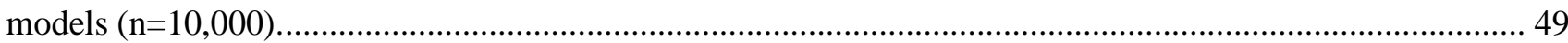

Figure 3.7. Main ionic properties and mechanisms in steady state of a failing myocyte interacting $(\mathrm{M}-\mathrm{Fb})$ or not

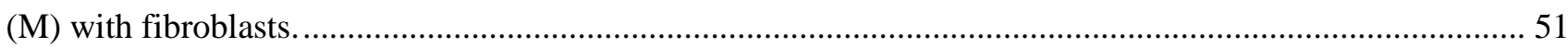

Figure 3.8. Transient state of ionic mechanisms and $\mathrm{Ca}^{2+}$ concentration in cellular compartments of a failing

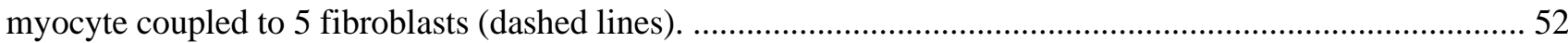

Figure 3.9. Univariate and multivariate sensitivities in normal conditions with high and low parameter

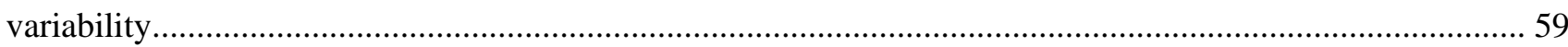

Figure 3.10. Univariate and multivariate sensitivities in heart failure with high and low parameter variability. 60

Figure 3.11. Comparison of sensitivities obtained from 4 multivariable regression analyses: normal (N) and heart failure (HF) conditions with or without coupled fibroblasts $(\mathrm{Fb})$.

Figure 3.12. Comparison of the effects of coupling fibroblasts $(\mathrm{Fb})$ and myofibroblasts $(\mathrm{MyoFb})$ on action potential and $\mathrm{Ca}^{2+}$ transient of a myocyte $(\mathrm{M})$ in normal $(\mathrm{N})$ and heart failure (HF) conditions..................... 62 Figure 3.13. Comparison of the effects of coupling fibroblasts $(\mathrm{Fb})$ to epicardial and endocardial cells $(\mathrm{M})$ on

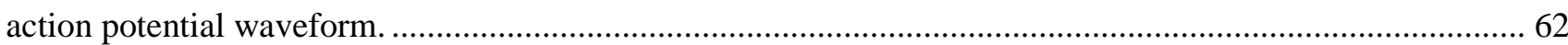

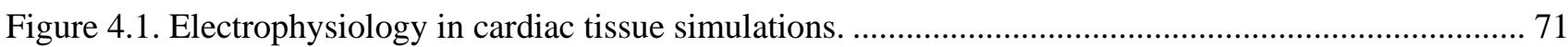

Figure 4.2. Restitution curves of baseline coupled single-cell models.......................................................... 73

Figure 4.3. Parameter distribution according to alternans occurrence in coupled single-cell populations. ....... 74 


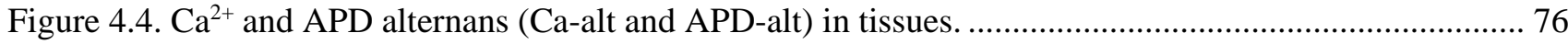

Figure 4.5. Relation between SR Ca ${ }^{2+}$ content, $\mathrm{Ca}^{2+}$ peak and alternans. .................................................... 77

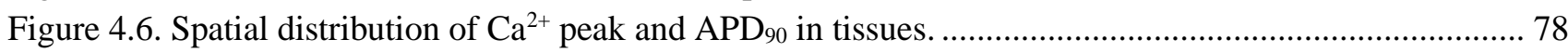

Figure 4.7. Spatial concordance of alternans (Ca-alt and APD-alt) along the tissue. ....................................... 79

Figure 5.1. $\beta$-adrenergic signaling remodeling in heart failure (HF) ...................................................... 90

Figure 5.2. Experimental calibration of a $\beta$-population of failing (HF) myocytes stimulated with isoproterenol

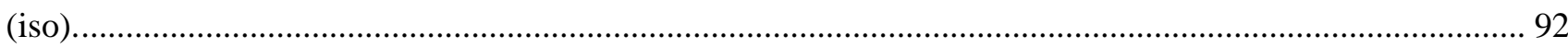

Figure 5.3. $\beta$-adrenergic modulation of action potential (AP) and $\mathrm{Ca}^{2+}$ transient $(\mathrm{CaT})$ in normal $(\mathrm{N})$ and failing (HF) myocytes

Figure 5.4. Selective $\beta$-adrenergic modulation of action potential (AP) and $\mathrm{Ca}^{2+}$ transient (CaT) in heart failure

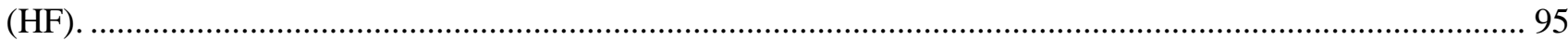

Figure 5.5. Sensitivity analysis of $\beta$ AR-mediated PKA-phosphorylation...................................................... 96

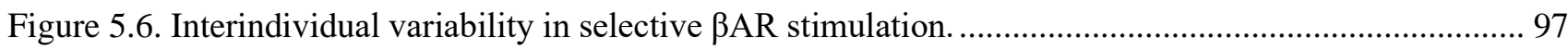

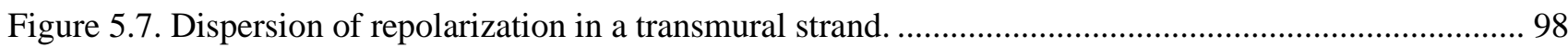

Figure 5.8. Population of cells with $\beta$-AR stimulation in HF with iso..................................................... 108

Figure 5.9. Remodeled signaling parameters contribution to APD and $\mathrm{CaT}_{\max }$ modulation in heart failure

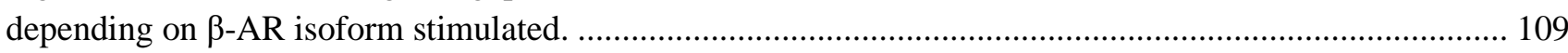




\section{List of Tables}

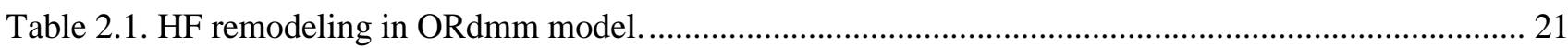

Table 2.2. Individual modulation of heart failure (HF) electrophysiological remodeling ............................... 33

Table 3.1. Biomarkers ranges for normal electrophysiological activity.................................................... 43

Table 3.2. Coefficients of determination $\left(\mathrm{R}^{2}\right)$ of the multivariable regression analyses in normal $(\mathrm{N})$ and heart

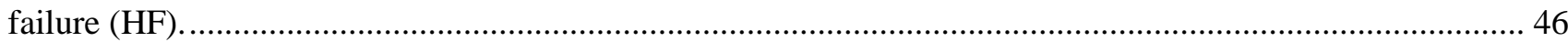

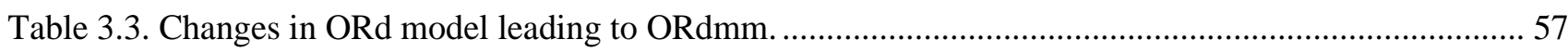

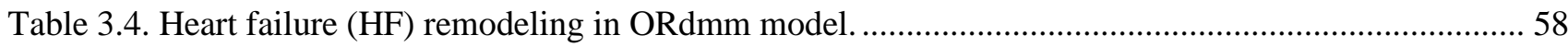

Table 4.1. Electrophysiological remodeling in HF applied to the basic ORd model..................................... 70

Table 4.2. Alternans occurrence in four subpopulations of cardiac tissue. .................................................... 75

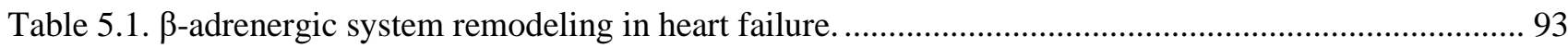

Table 5.2. Mathematical models and modifications described in previous studies used as a basis for the implementation of a heart failure (HF) model in human ventricular myocytes. ............................................ 104

Table 5.3. Variability range of $\beta$-AR remodeling in heart failure ........................................................... 104

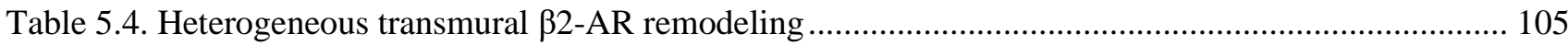




\section{Abbreviations}

$\beta$-AR

Alt

AP

APD

CaT

CaTD

Cav

CICR

Cyt

Ecav

ECC

ECG

$\mathrm{EF}$

EP

$\mathrm{HF}$

Iso

$\mathrm{I}_{\mathrm{x}}$

LTCC

$\mathrm{N}$

NCX

RyR

SERCA

SR

TDR $\beta$-adrenergic receptor

Alternans

Action potential

Action potential duration

$\mathrm{Ca}^{2+}$ transient

$\mathrm{Ca}^{2+}$ transient duration

Caveolar

$\mathrm{Ca}^{2+}$-induced $\mathrm{Ca}^{2+}$ release

Cytosol

Extracaveolar

Excitation-contraction coupling

Electrocardiogram

Ejection fraction

Electrophysiological

Heart failure

Isoproterenol

current of ion ' $\mathrm{x}$ '

L-type $\mathrm{Ca}^{2+}$ channels

Normal

$\mathrm{Na}^{+} / \mathrm{Ca}^{2+}$ exchanger

Ryanodine receptors

Sarco/endoplasmic reticulum $\mathrm{Ca}^{2+}$-ATPase

Sarcoplasmic reticulum

Transmural dispersion of repolarization 



\section{Chapter 1 Introduction}

\subsection{The electrophysiology of the heart}

\subsubsection{From cardiac physiology to an in silico heart}

The heart is a muscular organ that pumps the blood through the circulatory system by rhythmic contraction and relaxation. This mechanical function results from the orchestrated contraction of cardiomyocytes in response to their intrinsic electrical activity. Each beat corresponds to an electrical impulse originated in the sinoatrial node and propagated through the atria. Then, the electrical wave is rapidly conducted to the ventricles via the His-Purkinje conducting system and excites the endocardium surface, activating first the ventricular apex. Propagation spreads cell-to-cell transmurally to the epicardium and from apex to base of the heart. During the cardiac cycle, multiple cellular electrical waveforms combine and lead to an extracellular potential that can be measured with electrodes placed on the body surface. The resulting signal is known as electrocardiogram (ECG), and it is one of the simplest tests clinically used to evaluate heart condition. The ECG shows heart rate, the rhythm of the heartbeats, and the strength and timing of electrical impulses in right and left atria and ventricles, although ventricular excitation predominates in the signal.

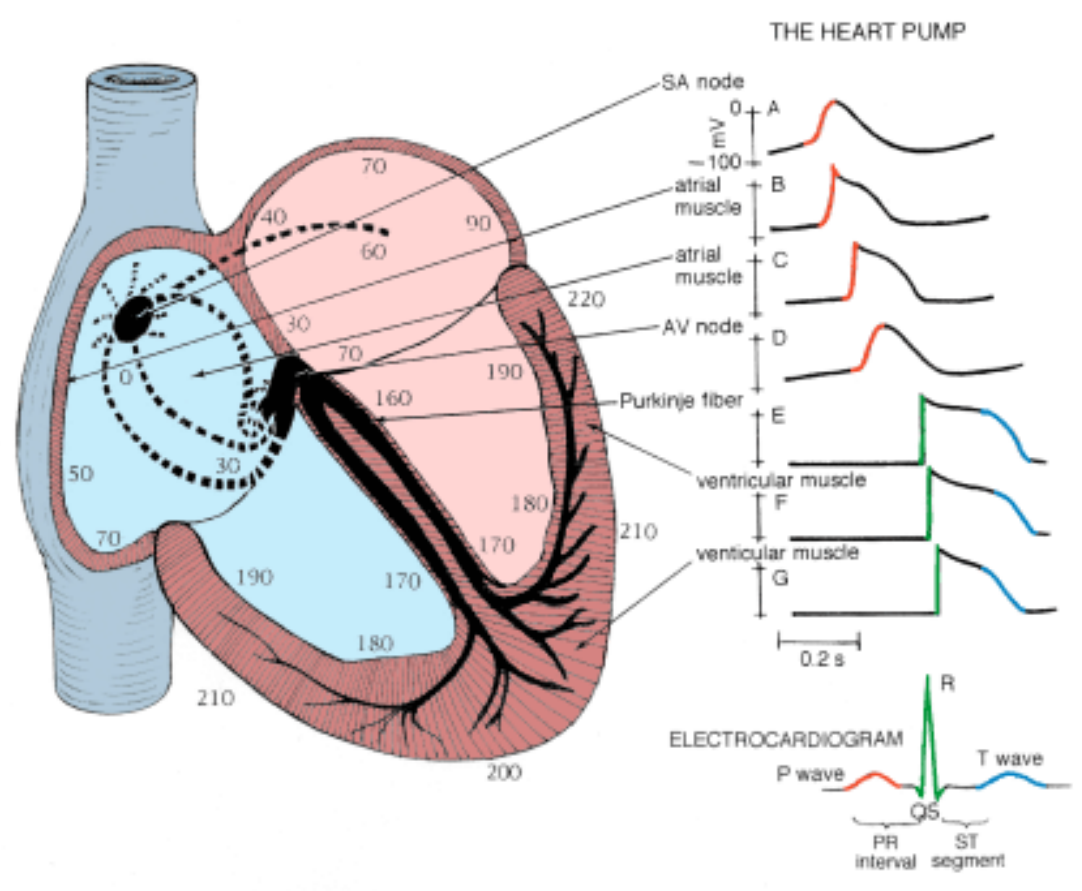

Figure 1.1. Cardiac conduction system, activation times (in $\mathrm{ms}$ ), action potential waveforms from different heart regions and the resulting electrocardiogram. Image adapted from [3].

Alterations in an ECG are a sign of heart-related diseases. The arrhythmogenic phenomena and contractile dysfunction observed in patients with cardiac disorders occur because of pathological changes in tissue, cell, and proteins, but the origin cannot be identified only with an ECG. The complexity of the multiscale system requires the examination at smaller scale levels: from molecules and cells to tissue and organ preparations. 
Experimental observations at the different scales have revealed the underlying mechanisms of cardiac electrophysiology. These have been used to develop comprehensive mathematical models of the heart. Together with computational methods, cardiac models have facilitated the study of both the normal and pathological functioning of the heart because can analyze different components of the system simultaneously and obtain outputs at the different scales. Therefore, computational simulations have become a powerful tool to understand cardiac disorders and help in the optimization of clinical treatments.

The basis in cardiac electrophysiology modeling is the single-cell action potential model. For this reason, much effort has been focused on the development and validation of accurate cardiac cell models. Decades of research have contributed to formulate from subcellular nanodomains to the whole organ. Larger scale simulations, incorporating the geometry and structure of the heart, are the most complex and advanced techniques that show the progress in cardiac modelling to address clinical problems.

\subsubsection{Cellular electrophysiology}

\section{Cell membrane and ion fluxes}

Cardiomyocytes, the main components of the heart, are excitable cells that contract after an electrical impulse. The electrical activity is a biophysical process determined by the transmembrane potential that results from the voltage difference between the intracellular and extracellular milieu due to their relative ionic composition. The cell membrane, a lipid bilayer, act as the barrier between both compartments because is impermeable to ions. However, several transmembrane proteins form pores and can selectively allow the transport of cations $\left(\mathrm{Na}^{+}, \mathrm{Ca}^{2+}, \mathrm{K}^{+}\right)$and anions $\left(\mathrm{Cl}^{-}\right)$across the cell membrane, altering the intracellular ionic concentration. The movement of ions is caused by both electric and concentration gradients and results in currents that depolarize and repolarize the cell membrane, which changes the transmembrane potential and originates an action potential. Therefore, the mechanism of cardiac excitation and contraction is regulated by the action of proteins embedded in the cell membrane that exert passive or active ionic transport, mainly ion channels, ion pumps and ion exchangers.

\section{Action Potential}

At rest, when there is no net movement of ions across the cell membrane, it exists a negative transmembrane potential known as resting potential, which is about $-90 \mathrm{mV}$. The flux of ions is initiated when an excitatory stimulus causes the membrane potential to become less negative and, if a threshold level is achieved, depolarization occurs. The membrane potential reverses transiently but other currents that are activated a posteriori contribute to repolarize the cell membrane to the resting potential. There are different ion currents because of the existence of diverse families of channels that differ in ion selectivity and permeability. The permeability is a property of the protein influenced by changes in voltage or ligand binding and is controlled by gates. The open or close state of these gates depends on protein conformation. Among the different types of ion channels, voltage-gated channels are the main regulators of the action potential.

The initial phase of the cardiac action potential is very fast (within milliseconds) and is caused by the rapid activation and inactivation of sodium channels. During the depolarization, an inward sodium current $\left(\mathrm{I}_{\mathrm{Na}}\right)$ causes the upstroke of the action potential. Then, a first repolarization is initiated 
by a particular potassium channel that generates a transient outward current $\left(\mathrm{I}_{\mathrm{to}}\right)$. A balance between depolarizing (inward) and repolarizing (outward) currents maintain the membrane potential elevated during the plateau phase. Calcium channels are opened during the depolarization initiating an inward current $\left(\mathrm{I}_{\mathrm{Ca}}\right)$, while potassium currents $\left(\mathrm{I}_{\mathrm{K}}\right)$ cause the repolarization of the action potential.

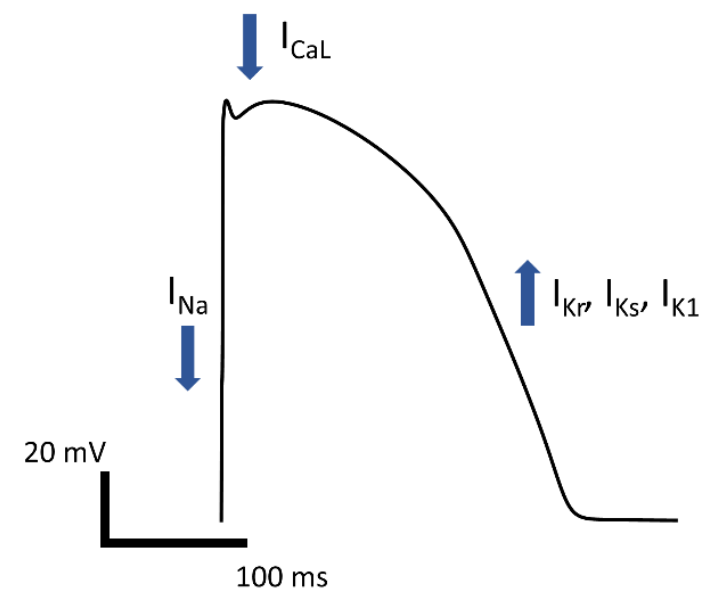

Figure 1.2. Action potential and main ionic currents in an endocardial cell. Upward arrows and downward arrows represent outward and inward currents respectively.

\section{Excitation-Contraction Coupling}

Calcium $\left(\mathrm{Ca}^{2+}\right)$ is the major signaling molecule in excitation-contraction coupling. Elevated intracellular $\mathrm{Ca}^{2+}$ concentration is required for myofilament contraction. At rest, cytosolic $\mathrm{Ca}^{2+}$ is small compared to the extracellular concentration, but the sarcoplasmic reticulum (SR) is an intracellular store of $\mathrm{Ca}^{2+}$ and can release it when needed. During the cardiac AP, extracellular $\mathrm{Ca}^{2+}$ ions enter through the activated L-type $\mathrm{Ca}^{2+}$ channels (LTCC) but due to $\mathrm{Ca}^{2+}$ buffering, this influx is not enough to increase $\left[\mathrm{Ca}^{2+}\right]_{\mathrm{i}}$ to the levels required for myofilament contraction $(\sim 1 \mu \mathrm{M})$. The $\mathrm{Na}^{+}-\mathrm{Ca}^{2+}$ exchanger (NCX) is another transport mechanism that contributes, to a lesser extent, to increase intracellular $\mathrm{Ca}^{2+}$ during membrane depolarization. Sarcolemmal $\mathrm{Ca}^{2+}$ influx activates ryanodine receptors (RyR) and leads to a larger $\mathrm{Ca}^{2+}$ release from the SR. This $\mathrm{Ca}^{2+}$-induced $\mathrm{Ca}^{2+}$ release (CICR) process raises cytosolic $\mathrm{Ca}^{2+}$ enough to activate myofilaments and initiate cellular contraction. CICR occurs in microdomains called dyads, where membrane invaginations called transverse tubules $(\mathrm{T}$ tubules) are close associated with the SR network. This way, sarcolemmal LTCCs and sarcoplasmic RyRs are co-localized facilitating $\mathrm{SR} \mathrm{Ca}^{2+}$ release.

But the elevated $\left[\mathrm{Ca}^{2+}\right]_{\mathrm{i}}$ only lasts a few milliseconds (systolic peak). For relaxation, $\mathrm{Ca}^{2+}$ must be removed from the cytosol and achieve a reduced level (diastolic concentration). There are four transport mechanisms that contribute to decrease intracellular $\mathrm{Ca}^{2+}$ level: SR $\mathrm{Ca}^{2+}$ ATPase (SERCA), sarcolemmal NCX, sarcolemmal $\mathrm{Ca}^{2+}$-ATPase $\left(\mathrm{I}_{\mathrm{Cap}}\right)$ and mitochondrial $\mathrm{Ca}^{2+}$ uniporter. As most of the $\mathrm{Ca}^{2+}$ was released from the SR, SERCA is the predominant mechanism that reduces cytosolic $\mathrm{Ca}^{2+}$ by reintroducing it into the SR. Among $\mathrm{Ca}^{2+}$ extrusion mechanisms, the NCX activity is higher than $\mathrm{I}_{\text {Cap. }}$. Indeed, $\mathrm{I}_{\mathrm{Cap}}$ and mitochondrial $\mathrm{Ca}^{2+}$ uniporter are referred collectively as slow systems contributing to only $1 \%$ of $\mathrm{Ca}^{2+}$ removal.

Although $\mathrm{Ca}^{2+}$ dynamics depends on membrane excitation, $\mathrm{Ca}^{2+}$ cycling involves ion currents that can modulate the action potential. This means that cellular electrical instabilities that can induce arrhythmias can be originated by an altered $\mathrm{Ca}^{2+}$ regulation. Among the pro-arrhythmic mechanisms 
related to $\mathrm{Ca}^{2+}$ are beat-to-beat alternans and afterdepolarizations. In fact, many cardiac pathologies have identified an abnormal $\mathrm{Ca}^{2+}$ homeostasis because of defects in the excitation-contraction coupling (ECC). What are not clear are the underlying mechanisms that lead to the different disorders.

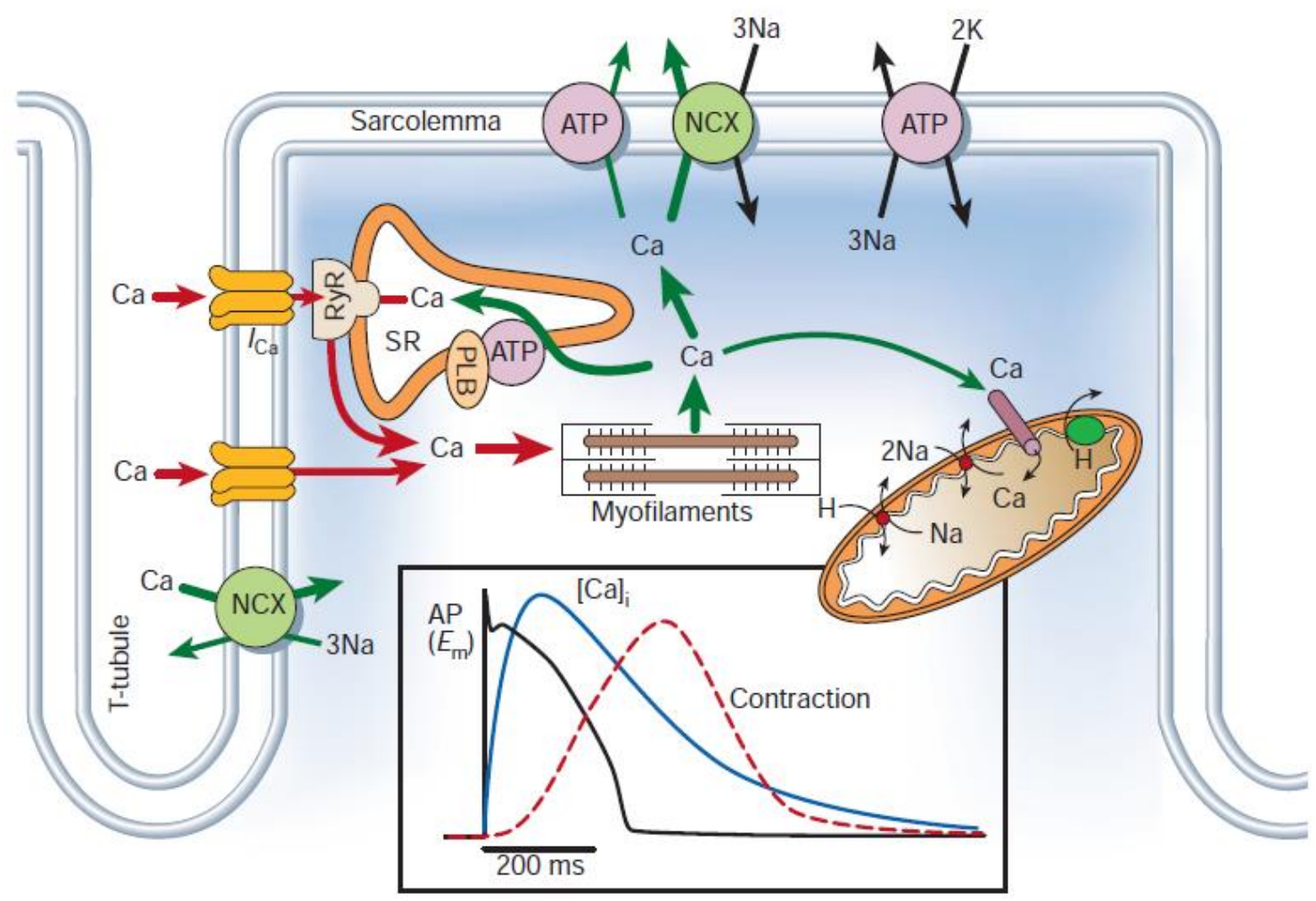

Figure 1.3. $\mathrm{Ca}^{2+}$ cycling in a ventricular myocyte. Image adapted from [4].

\section{Electrical propagation}

The cardiac muscle is made up of fibers, which are individual myocytes connected in series and in parallel with one another by means of sarcolemmal structures known as intercalated disks. Adjacent to these, gap junction proteins allow the rapid diffusion of intracellular ions between neighboring cells, providing an electrical cell-to-cell coupling and mediating in the propagation of the action potential. The protein connexin form the gap junctions, and the $\mathrm{Cx} 43$ isoform is the predominant subtype in the ventricles, located at the long end of the myocytes and to a lesser extent on the sides. Therefore, current flow in the fiber direction is higher in comparison to transversal propagation. Remodeling of connexins in cardiac diseases may affect the number and distribution of connexins expressed. Indeed, a reduced expression of these proteins is one of the main causes of impaired conduction.

\subsection{Electrophysiological modeling}

\subsubsection{Action potential model}

Mathematical models of cardiac cellular electrophysiology have evolved over the last years and have increased in detail and complexity by including more aspects of cellular physiology. The initial models only included a small number of differential equations and now, models present multiple equations and hundreds of parameters. Although an increase in complexity results in significant 
computational cost, which is a limiting factor in the use of models at larger scales, technology development helps to remove these barriers and facilitates the use of simulations.

The first to develop an electrophysiological model of a single cell were Hodgkin and Huxley in 1952. Their work became the basis for much of the present electrical modeling, including that for cardiac cells. They performed experiments in squid nerve fibers using the voltage clamp technique and suggested that the cell membrane may be represented by an equivalent electrical circuit similar to that shown in Figure 1.4. The lipidic bilayer of the membrane act as a capacitor $\left(\mathrm{C}_{\mathrm{m}}\right)$ and is connected in parallel with the membrane transport mechanisms. Each ion channel, which allow the movement of ions $\left(\mathrm{I}_{\mathrm{x}}\right)$, is represented by a variable resistance in series with a voltage source. The voltage difference between inside and outside the cell is the transmembrane voltage $\left(\mathrm{V}_{\mathrm{m}}\right)$ and the net sum of currents in an isolated cell is equal to zero:

$$
C_{m} \frac{d V_{m}}{d t}+\sum I_{x}=0
$$

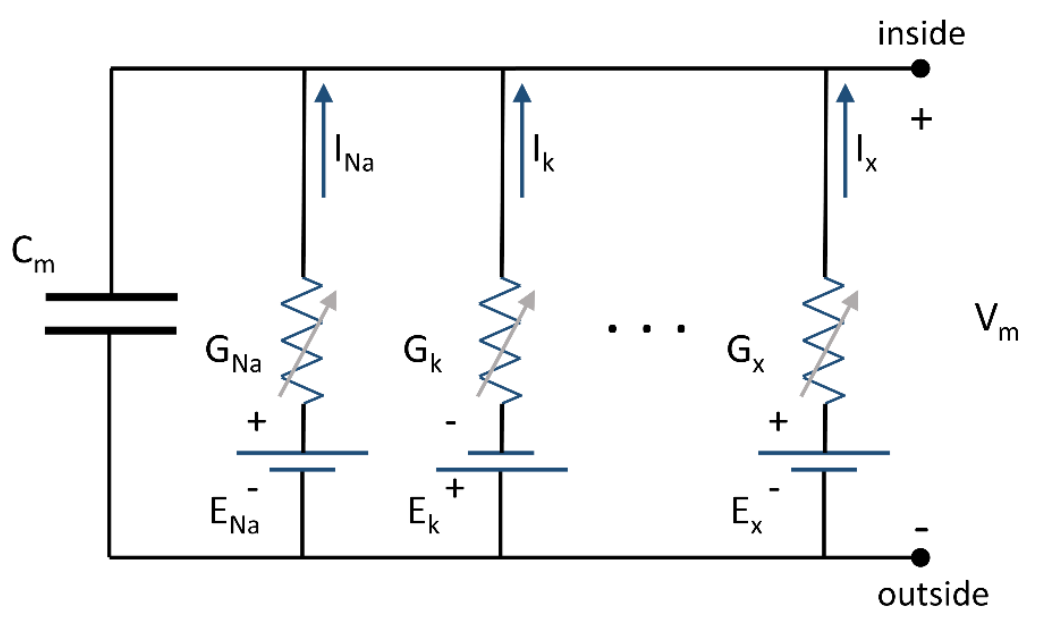

Figure 1.4. Equivalent electrical circuit of an excitable cell.

Each current $\left(I_{x}\right)$ represents the total current generated by a family of ion channels (e.g. $\mathrm{Na}^{+}$ channels) and is determined by a driving force measured as an electrical potential difference $\left(\mathrm{V}_{\mathrm{m}}-\mathrm{E}_{\mathrm{x}}\right)$ and a variable conductance $\left(\mathrm{G}_{\mathrm{x}}\right)$, which varies with time and voltage:

$$
I_{x}=G_{x}\left(V_{m}, t\right) \cdot\left(V_{m}-E_{x}\right)
$$

$\mathrm{E}_{\mathrm{x}}$ is the equilibrium potential of an ion determined by the concentration difference between the intracellular and extracellular medium and is calculated using the Nernst equation:

$$
E_{x}=\frac{R T}{z_{x} F} \ln \frac{[X]_{o}}{[X]_{i}}
$$

The conductance is maximal $\left(\bar{G}_{\mathrm{x}}\right)$ when all the channels are completely open but voltagedependent gates (activation or inactivation), and to a lesser extent ligand-dependent gates, regulate the state of the channel. Gates are formulated by a first order differential equation as follows: 


$$
\frac{d f}{d t}=\frac{f_{\infty}-f}{\tau_{f}}
$$

where $\mathrm{f}_{\infty}$ is the steady state value and $\tau_{\mathrm{f}}$ the time constant of the gate $\mathrm{f}$. Therefore, the conductance is determined by the maximum value and the product of gates:

$$
G_{x}=\overline{G_{x}} \cdot \prod_{i} f_{i}
$$

This is the basic mathematical formulation of cellular electrophysiology, but the higher the number of ion currents and differential equations present in the model the more complex its resolution becomes. For this reason, computational methods are a powerful tool to obtain a numerical solution to the problem. Most of the present cardiac cellular models still use Hodgkin and Huxley equations, although have incorporated variations and implemented more details in the formulation. For instance, the human action potential model (ORd) of ventricular myocytes used in this thesis has 14 ionic current, a complete formulation of ionic concentrations in different cell compartments including buffers, and the phosphorylation of channels by CaMK [5]. The ORd model also distinguish between endocardial, midmiocardial and epicardial cells. Figure 1.5 illustrates a diagram with the ion transport mechanisms present in the ORd model.

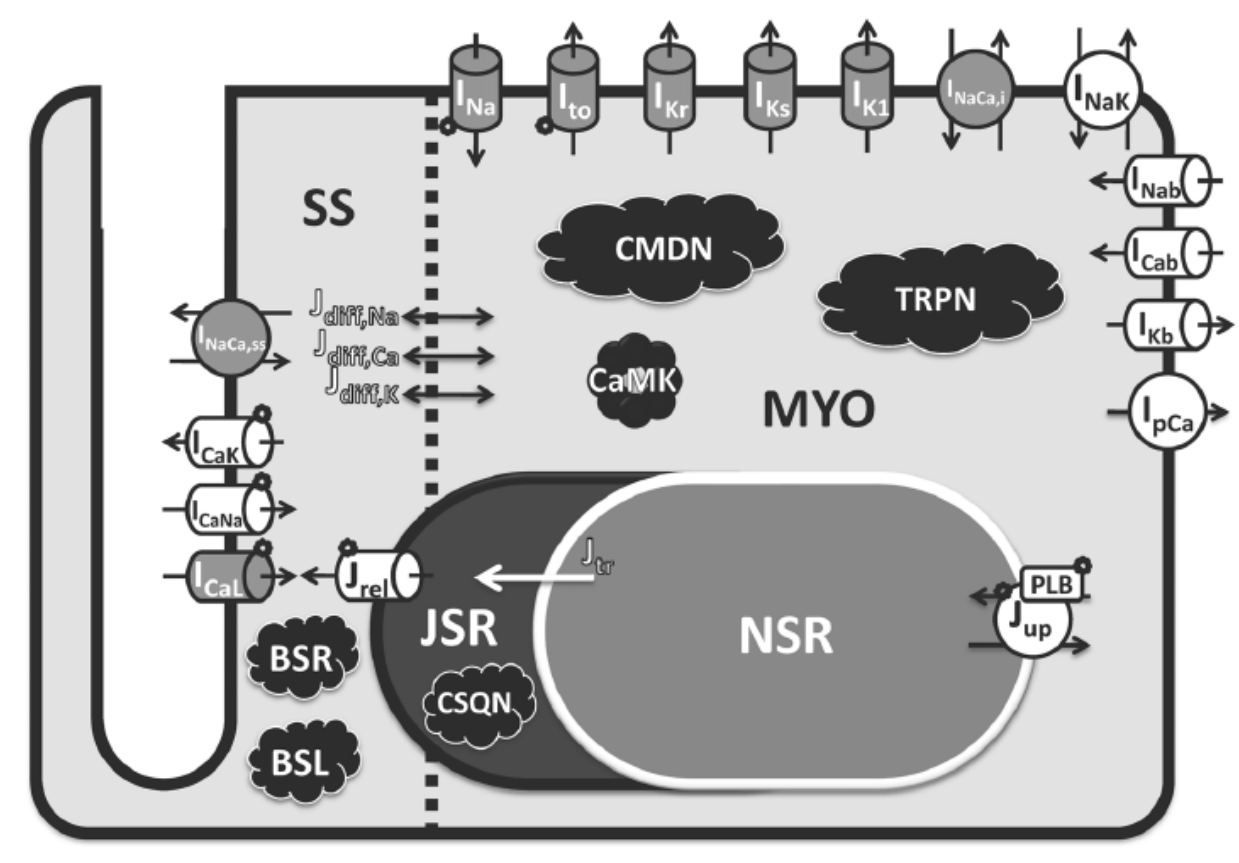

Figure 1.5. Diagram of a human ventricular cell model. Image adapted from [5]

\subsubsection{Fiber and tissue modeling}

Cellular models can be incorporated into larger-scale models to simulate electrical propagation. Electrical coupling between myocytes is assumed that occurs in a continuous excitable medium. The bidomain formulation considers cardiac tissue electrically anisotropic and that current flows in both the extracellular and intracellular spaces. A simplification of the bidomain model is commonly used 
for the advantages in mathematical resolution and computation. It is the monodomain model, which assumes that intracellular and extracellular domains are equally anisotropic. The reaction-diffusion equation for electrical propagation is as follows:

$$
\nabla \cdot\left(D \nabla V_{m}\right)=C_{m} \frac{\partial V_{m}}{\partial t}+\sum I_{x}
$$

The left part of the equation is the diffusive term, where D represents a conductivity tensor. The monodomain equation is solved with finite element algorithms [6].

\subsection{Heart failure}

Congestive heart failure (HF) is a chronic condition resulting from the end stage of many cardiac diseases, such as ischemic or hypertrophic cardiomyopathy. It is characterized by the heart's inability to provide sufficient blood flow to meet the metabolic demands of the body. Heart damage and the subsequent myocardial remodeling commonly affect the left ventricle and this causes cardiac dysfunction. The consequences are an impaired mechanical contraction and electrophysiological changes, which can also aggravate this pathology by inducing, for instance, lethal arrhythmias.

Different types of HF have been categorized according to differences in left ventricular ejection fraction $(\mathrm{EF})$, which is a measure of pump function. This distinction is usually made because apart from phenotype differences, the response to therapies may differ. If EF is less than $40 \%$, patients present HF with reduced EF (HFrEF), also known as systolic HF because contraction becomes deficient. In diastolic HF or HF with preserved EF (HFpEF), patients present normal EF ( $\geq 50 \%$ ) but heart does not relax properly.

HFrEF (hereinafter referred only as HF) has been widely investigated and medical therapies have progressed but their effectiveness are still limited by the complexity of the disease. The development of new treatments that better target the underlying mechanisms causing human HF is the main aim to reduce mortality rate and improve clinical outputs.

Heart disease is associated with cardiac remodeling or changes in the electrical and mechanical properties of the myocardium. These changes involve alterations in ion channels, ion homeostasis, cellular coupling, and structural modifications. In HF, the characteristic phenotype in ventricular myocytes (prolonged action potential and an altered intracellular $\mathrm{Ca}^{2+}$ transient with elevated diastolic level, reduced systolic level and slow $\left[\mathrm{Ca}^{2+}\right]_{\mathrm{i}}$ decay) can be modeled with modifications in ion channels and $\mathrm{Ca}^{2+}$-handling proteins. The cellular model representing failing conditions has advanced over the years but can still be improved by implementing additional alterations observed in experiments.

Detubulation, i.e. disruption of T-tubules, has been reported in failing ventricular myocytes and related to the existence of orphaned RyRs and decrease of the CICR process, contributing to the abnormal cellular phenotype.

$\beta$-adrenergic stimulation, known for the inotropic and chronotopic effects to maintain the demands of the body under specific conditions, modulates the electrophysiology by means of the PKA phosphorylation cascade. The overstimulation of the sympathetic system that occurs under HF conditions causes a defective $\beta$-adrenergic regulation which has been linked to cardiac dysfunction.

Apart from cellular remodeling, structural remodeling in failing cardiac tissues has been identified as a proarrhythmic factor in HF. The redistribution of the gap junctional protein $\mathrm{Cx} 43$ from 
longitudinal to transversal myocyte borders causes a reduction in cellular coupling that decreases electrical propagation in failing tissues. Another structural change described in experiments is the development of fibrotic tissue, which includes the proliferation of fibroblasts and the electrotonic interactions with myocytes through gap junctions.

Understanding the underlying ionic mechanisms that contribute to the pathology of HF is crucial to improve clinical therapies. A comprehensive and accurate analysis of the model, including detailed electrophysiology, signaling and structural factors can pave the way for the treatment of HF. 


\subsection{Motivation and objectives}

\subsubsection{Background}

Cardiovascular diseases are a major health problem and are the leading cause of mortality. In particular, there is an increasing number of patients with heart failure (HF) and despite the number of well-established clinical treatments, the complexity of the pathology can ultimately lead to fatal arrhythmias and death [7]. Therefore, the understanding of the underlying mechanisms is essential to develop more effective therapies.

Investigations on the molecular and cellular basis of electrophysiology have contributed to gain insight into the different mechanisms that control cardiac function [8]. However, multiple studies involving human failing hearts are required to study alterations during cardiac disease. Animal models usually replace the scarcity of human heart preparations, but differences between animals and human models are a major limitation. An approach based on the development and use of mathematical models has been extended due its power to systematically explore electrophysiological phenomena from the molecular to the entire organ level with computational techniques [9,10]. Moreover, computer simulations are a strong alternative to experiments because of the capacity to perform multiple variations and measurements simultaneously.

Since model formulation depends on experimental data, the predictive potential of simulations depends on previous existing experimental information to create and validate the results. In case of unavailable data, simulation results can suggest experimental conditions that should be explored.

In the literature, we find studies that have identified ion channel, signaling and structural remodeling during heart failure and myocytes manifesting abnormalities in action potentials and $\mathrm{Ca}^{2+}$ transients [11]. We made use of this information to model and computationally investigate the causes of heart failure on a recent and detailed human action potential model [5]. We noticed that unlike electrical instabilities, $\mathrm{Ca}^{2+}$ handling alterations have been less studied despite the major role of $\mathrm{Ca}^{2+}$ in excitation-contraction coupling [4]. Hence, we found that the study of heart failure from a $\mathrm{Ca}^{2+}$ point of view could contribute to progress in the management of this cardiac pathology.

\subsubsection{Objectives}

The main aim of the present thesis was to gain mechanistic insights into cardiac electrophysiology, focusing on $\mathrm{Ca}^{2+}$ dynamics and $\mathrm{HF}$ alterations, by means of computer simulations in human models to identify therapeutic targets for HF. To achieve this, several specific objectives were proposed:

Objective 1. Selection and analysis of biomarkers determining $\mathrm{Ca}^{2+}$ dynamics.

$\mathrm{Ca}^{2+}$ plays a crucial role in excitation-contraction coupling. To find the underlying causes of contractile dysfunction and pro-arrhythmic conditions in $\mathrm{HF}$, changes in $\mathrm{Ca}^{2+}$ cycling, involving $\mathrm{Ca}^{2+}$ concentrations in the different subcellular compartments, need to be investigated together with electrical alterations.

Objective 2. Quantification and analysis of the modulation of action potentials and $\mathrm{Ca}^{2+}$ transients with variations in model parameters. 
The electrophysiological phenotype results from the contribution of multiple components and their interactions. However, different phenotypes can be observed due to biological variability, the effect of drugs or the remodeling of proteins after cardiac damage. Therefore, it is crucial to evaluate the impact of parameters on the modulation of electrophysiological biomarkers to determine causeeffect relationships and to establish limits for physiological inter-individual variability.

Objective 3. Implementation and study of the main changes in cardiac myocytes and tissues observed in failing hearts to reproduce the HF phenotype: abnormal action potentials and $\mathrm{Ca}^{2+}$ transients, and defective electrical conduction.

One consequence of $\mathrm{HF}$ is protein remodeling, altering their expression and function. Application of specific changes in ion channels and $\mathrm{Ca}^{2+}$-handling proteins lead to the characteristic failing action potential and $\mathrm{Ca}^{2+}$ transient, different from healthy myocytes. This approach is useful to investigate the mechanisms and potential targets in HF.

In addition to ion channel remodeling, loss of T-tubular structure is observed in failing myocytes. It is essential to consider this remodeling due to its role in $\mathrm{Ca}^{2+}$ dynamics and signaling.

Cellular signaling processes, such as the $\beta$-adrenergic system, modulate the electrophysiology. In HF, a sustained and defective $\beta$-adrenergic signaling might be related with contractile and electrical alterations. The study of the mechanisms governing this system may suggest additional targets to treat HF.

The structural remodeling consists of reduced cell-to-cell coupling and fibroblast proliferation that interact with myocytes. How these conditions contribute to exacerbate the pathology is another subject of study at the tissue level.

Objective 4. Comparison of normal and failing myocytes in response to different conditions.

Electrophysiological differences between normal and failing hearts contribute to alter the electrophysiological response of myocytes to factors such as the effect of drugs, heart rate variation, the interaction with fibroblasts or sympathetic stimulation. The investigation of these different responses could help explain the increased arrhythmogenesis in HF and the failure of some treatments.

Objective 5. Study of the influence of altered $\mathrm{Ca}^{2+}$ cycling on electrical instabilities.

It has been observed that some pro-arrhythmic events can have an origin in $\mathrm{Ca}^{2+}$ handling. Specifically, alternans and afterdepolarizations have been related to altered $\mathrm{Ca}^{2+}$ dynamics. Since similar abnormalities are common in $\mathrm{HF}$, it would be interesting to find out if the causes of arrhythmogenesis are due to the altered $\mathrm{Ca}^{2+}$ handling. 


\subsection{Overview}

This thesis is a comprehensive study of $\mathrm{Ca}^{2+}$ handling in simulated human failing hearts and is presented as a compendium of articles. The document has been structured in 7 chapters. Chapter $\mathbf{1}$ provides an overview of the topic and the problem, with basic theoretical concepts of cardiac electrophysiology to contextualize the present work. The following four chapters correspond to articles published (Chapters 2 to 4 ) or submitted (Chapter 5) to scientific journals. The study started with the analysis of the AP model by assessing the impact of ionic parameter modulation when including HF electrophysiological remodeling and it was progressively extended to additional HF-induced modifications such as fibroblast-myocytes interactions, detubulation and altered $\beta$-adrenergic stimulation. Almost all the objectives are partially or totally covered in each chapter:

Chapter 2 is focused on the AP model of a ventricular human cardiomyocyte, in which ion channel remodeling was introduced a parameter variation to reproduce the failing phenotype at the cellular level. A univariate parameter sensitivity analysis was performed to quantitatively analyze the relative impact of ion channels and $\mathrm{Ca}^{2+}$-handling proteins variability on cellular electrophysiology. Comparison of the effects between normal and failing myocytes highlighted differences arisen because of ion channel remodeling and suggested the need to consider failing conditions when testing drug effects. This chapter corresponds to the publication:

"Mora MT, Ferrero JM, Romero L, Trenor B. Sensitivity analysis revealing the effect of modulating ionic mechanisms on calcium dynamics in simulated human heart failure. PLoS One. 2017;12(11).”

In Chapter 3, fibrosis effect is considered by coupling an active fibroblast AP model to the myocyte. It was studied how fibroblast-myocyte interactions affected electrical and $\mathrm{Ca}^{2+}$ properties. Univariate and multivariate sensitivity analysis results were compared while analyzing parameter modulation. Then, a mechanistic investigation of parameters restoring normal electrophysiological activity was performed to identify target proteins. This chapter corresponds to the publication:

"Mora MT, Ferrero JM, Gomez JF, Sobie EA, Trenor B. $\mathrm{Ca}^{2+}$ cycling impairment in heart failure is exacerbated by fibrosis: insights gained from mechanistic simulations. Front Physiol. 2018;9."

In Chapter 4, cell-to-cell interactions, mainly fibroblast-myocyte coupling, are examined to evaluate their contribution in promoting repolarization alternans. The cause of beat-to-beat alternation of $\mathrm{Ca}^{2+}$ transient in myocytes at high heart rate was investigated as a precursor of APD alternans. Apart from cellular simulations, electrical propagation on cardiac tissue was evaluated and compared between normal and failing strands with or without fibroblasts to identify the most arrhythmogenic conditions. This chapter corresponds to the publication:

"Mora MT, Gomez JF, Morley G, Ferrero JM, Trenor B. Mechanistic investigation of $\mathrm{Ca}^{2+}$ alternans in human heart failure and its modulation by fibroblasts. PLoS One. 2019;14(6)."

Chapter 5 presents an improvement in the myocyte AP model by considering the regulation effects of the $\beta$-adrenergic system. To reproduce HF phenotype, additional modifications were applied in the signaling pathway, and electrophysiological remodeling included detubulation. Selective $\beta$ - 
adrenergic receptor stimulation effects were analyzed and compared in normal and failing myocytes, and transmural electrical propagation was simulated to evaluate arrhythmogenesis vulnerability. This chapter corresponds to the following manuscript, which is currently under the final review phase in the Journal of Molecular and Cellular Cardiology:

"Mora MT, Gong JQX, Sobie EA, Trenor B. The role of $\beta$-adrenergic system remodeling in human heart failure: A mechanistic investigation. Journal of Molecular and Cellular Cardiology."

Finally, Chapter 6 summarizes and briefly discusses the main findings and contributions of this thesis, and Chapter 7 links the conclusions with the initial proposed objectives and suggests future directions for this work. 


\section{REFERENCES}

1. J.E. Hall, Guyton and Hall. Textbook of Medical Physiology, 12th editi, Elsevier, Philadelphia, PA, 2011.

2. D.C. Sigg, P.A. Iaizzo, Y.-F. Xiao, B. He, eds., Cardiac Electrophysiology Methods and Models, Springer US, Boston, MA, 2010. https://doi.org/10.1007/978-1-4419-6658-2.

3. http://www.vhlab.umn.edu/atlas/conduction-system-tutorial/graphics/Fig06.gif

4. D.M. Bers, Cardiac excitation-contraction coupling, Nature. 415 (2002) 198-205. https://doi.org/10.1038/415198a

5. T. O'Hara, L. Virág, A. Varró, Y. Rudy, Simulation of the undiseased human cardiac ventricular action potential: model formulation and experimental validation., PLoS Comput. Biol. 7 (2011) e1002061. https://doi.org/10.1371/journal.pcbi.1002061.

6. E.A. Heidenreich, J.M. Ferrero, M. Doblaré, J.F. Rodríguez, Adaptive Macro Finite Elements for the Numerical Solution of Monodomain Equations in Cardiac Electrophysiology, Ann. Biomed. Eng. 38 (2010) 2331-2345. https://doi.org/10.1007/s10439-010-9997-2.

7. Ponikowski P, Voors AA, Anker SD, Bueno H, Cleland JGF, Coats AJS, et al. 2016 ESC Guidelines for the diagnosis and treatment of acute and chronic heart failure. Eur Heart J. 2016;37: 2129-2200. doi:10.1093/eurheartj/ehw128

8. Yeo JM, Tse V, Kung J, Lin HY, Lee YT, Kwan J, et al. Isolated heart models for studying cardiac electrophysiology: A historical perspective and recent advances [Internet]. Journal of Basic and Clinical Physiology and Pharmacology. Walter de Gruyter GmbH; 2017. pp. 191-200. doi:10.1515/jbcpp-2016-0110

9. Holzem KM, Madden EJ, Efimov IR. Human cardiac systems electrophysiology and arrhythmogenesis: Iteration of experiment and computation. Europace. 2014;16: iv77-iv85. doi:10.1093/europace/euu264

10. Trayanova NA, Rice JJ. Cardiac electromechanical models: From cell to organ. Front Physiol. 2011;2 AUG. doi:10.3389/fphys.2011.00043

11. Gloschat CR, Koppel AC, Aras KK, Brennan JA, Holzem KM, Efimov IR. Arrhythmogenic and metabolic remodelling of failing human heart. J Physiol. 2016;594: 3963-3980. doi:10.1113/JP271992 



\section{COMPENDIUM OF ARTICLES}





\title{
Chapter 2
}

\section{Sensitivity analysis revealing the effect of modulating ionic mechanisms on calcium dynamics in simulated human heart failure}

\author{
Maria T. Mora ${ }^{\mathrm{a}}$, Jose M. Ferrero ${ }^{\mathrm{a}}$, Lucia Romero ${ }^{\mathrm{a}}$, Beatriz Trenor ${ }^{\mathrm{a}}$
}

\begin{abstract}
Abnormal intracellular $\mathrm{Ca}^{2+}$ handling is the major contributor to the depressed cardiac contractility observed in heart failure. The electrophysiological remodeling associated with this pathology alters both the action potential and the $\mathrm{Ca}^{2+}$ dynamics, leading to a defective excitationcontraction coupling that ends in mechanical dysfunction. The importance of maintaining a correct intracellular $\mathrm{Ca}^{2+}$ concentration requires a better understanding of its regulation by ionic mechanisms. To study the electrical activity and ionic homeostasis of failing myocytes, a modified version of the O'Hara et al. human action potential model was used, including electrophysiological remodeling. The impact of the main ionic transport mechanisms was analyzed using single-parameter sensitivity analyses, the first of which explored the modulation of electrophysiological characteristics related to $\mathrm{Ca}^{2+}$ exerted by the remodeled parameters. The second sensitivity analysis compared the potential consequences of modulating individual channel conductivities, as one of the main effects of potential drugs, on $\mathrm{Ca}^{2+}$ dynamic properties under both normal conditions and in heart failure. The first analysis revealed the important contribution of the sarcoplasmic reticulum $\mathrm{Ca}^{2+}$-ATPase (SERCA) dysfunction to the altered $\mathrm{Ca}^{2+}$ homeostasis, with the $\mathrm{Na}^{+} / \mathrm{Ca}^{2+}$ exchanger (NCX) and other $\mathrm{Ca}^{2+}$ cycling proteins also playing a significant role. Our results highlight the importance of improving the SR uptake function to increase $\mathrm{Ca}^{2+}$ content and restore $\mathrm{Ca}^{2+}$ homeostasis and contractility. The second sensitivity analysis highlights the different response of the failing myocyte versus the healthy myocyte to potential pharmacological actions on single channels. The result of modifying the conductances of the remodeled proteins such as SERCA and NCX in heart failure has less impact on $\mathrm{Ca}^{2+}$ modulation. These differences should be taken into account when designing drug therapies.
\end{abstract}

\footnotetext{
Mora MT, Ferrero JM, Romero L, Trenor B. Sensitivity analysis revealing the effect of modulating ionic mechanisms on calcium dynamics in simulated human heart failure. PLoS ONE 2017; 12(11): e0187739. https://doi.org/10.1371/journal.pone.0187739
}

${ }^{\text {a}}$ Centro de Investigación e Innovación en Bioingeniería, Universitat Politècnica de València, Valencia, Spain 


\subsection{Introduction}

Heart failure (HF), characterized by contractile dysfunction and arrhythmogenesis, is the final stage of many cardiovascular diseases. To understand the mechanisms that lead to these pathological conditions, a large body of research has focused on the electrophysiological changes in failing myocytes. At the cellular level, the hallmarks of $\mathrm{HF}$ are a prolongation of the action potential and alterations in ionic concentrations, such as intracellular $\mathrm{Na}^{+}\left(\left[\mathrm{Na}^{+}\right]_{i}\right)$ and $\mathrm{Ca}^{2+}\left(\left[\mathrm{Ca}^{2+}\right]_{i}\right)$, as a consequence of ion channel remodeling [1-4].

As intracellular $\mathrm{Ca}^{2+}$ is the main regulator of the cardiac excitation-contraction coupling, mishandling of $\mathrm{Ca}^{2+}$ is directly related to the mechanical dysfunction and certain arrhythmias associated with HF. Specifically, the alterations in $\mathrm{Ca}^{2+}$ dynamics are a decrease of the systolic peak, an increase of the diastolic level, a prolongation of the $\mathrm{Ca}^{2+}$ transient $(\mathrm{CaT})$, and a reduced sarcoplasmic reticulum (SR) $\mathrm{Ca}^{2+}$ load [5-7], so that it is clear that restoring normal $\mathrm{Ca}^{2+}$ cycling in HF could have beneficial therapeutic effects.

The study of the reduced mechanical performance in failing human myocytes has shown a strong correlation with depressed intracellular $\mathrm{Ca}^{2+}$ transients and it has also been related to altered mRNA levels of $\mathrm{Ca}^{2+}$-handling proteins [8]. Changes in the expression or activity of $\mathrm{Ca}^{2+}$ transport proteins in failing human ventricular myocytes, reviewed elsewhere [9-13], highlight the significant alteration in proteins involved in $\mathrm{Ca}^{2+}$ removal from the cytosol, such as the sarcoplasmic reticulum $\mathrm{Ca}^{2+}$-ATPase (SERCA) and the $\mathrm{Na}^{+} / \mathrm{Ca}^{2+}$ exchanger (NCX), and the existence of an important impaired diastolic $\mathrm{Ca}^{2+}$ release from the SR. On this basis, therapies are now being designed to restore $\mathrm{Ca}^{2+}$ homeostasis by targeting $\mathrm{Ca}^{2+}$-handling proteins $[14,15]$. Most of these consist of improving SR function by increasing SR $\mathrm{Ca}^{2+}$ uptake or preventing SR $\mathrm{Ca}^{2+}$ leak, although they have not been systematically explored. There are also other ionic transporters involved in the electrophysiology of the heart that have not been analyzed from this point of view.

Pharmacological agents interacting with specific ionic channels can improve the electrical and mechanical properties of the heart. In fact, many studies have focused on the pharmacological effects on the action potential, but less attention has been paid to the effects on $\mathrm{Ca}^{2+}$ dynamics. The need for a better understanding of the mechanisms in this complex electrophysiological system requires a systematic methodology. Mathematical models and computational simulations can help identify and explain interactions and effects that cannot be easily understood experimentally. In cardiac electrophysiology, studies using this approach have provided new findings on the ionic basis of arrhythmogenic processes [16,17], while electromechanical models have highlighted the need for a balanced $\mathrm{Ca}^{2+}$ handling mechanism to prevent cardiac dysfunction, since treatments targeting increased contractility alone are not sufficient [18].

The aim of this study is thus to analyze in silico the alterations of $\mathrm{Ca}^{2+}$ handling in failing human myocytes and to identify possible pharmacological targets that could restore them. The first sensitivity analysis, performed in a HF model, elucidates the main mechanisms responsible for the alterations of $\mathrm{Ca}^{2+}$ homeostasis in such pathological conditions. Secondly, the comparison of two sensitivity analyses, in normal and failing conditions, reveals differences between both models in the effect of ionic parameters on $\mathrm{Ca}^{2+}$ handling. These findings suggest that pharmacological treatments might not produce the same results in HF as in healthy myocytes, meaning that it may be necessary to adapt the treatment to the specific pathological situation. 


\subsection{Methods}

\subsubsection{Human action potential model}

The most recent and complete human ventricular action potential (AP) model is that of O'Hara et al. (ORd) [19], which provides a detailed description of $\mathrm{Ca}^{2+}$ handling, allowing the analysis of electrophysiological characteristics related to $\mathrm{Ca}^{2+}$. A modified version of this model was used to simulate the electrophysiological activity at the cellular level. The reason for not using the original ORd formulation is that in a 1D multicellular fiber, conduction velocity is low, especially under pathological situations when sodium current is reduced. Thus, the original fast sodium current $\left(\mathrm{I}_{\mathrm{Na}}\right)$ formulation was modified by shifting its steady state activation $\left(m_{s s}\right)$ and inactivation gates $\left(h_{s s}\right.$ and $\left.j_{s s}\right)$, as depicted in Figure 2.1. Passini et al. [20] had already proposed an optimized formulation for the sodium steadystate inactivation response, which consisted basically of matching ten Tusscher et al. [21] curves by shifting the half potential and changing the slope. The $\mathrm{m}_{\mathrm{ss}}$ was left-shifted, as suggested by Passini et al. [20], but we also modified the slope of the curve. The conductance $\left(\mathrm{G}_{\mathrm{Na}}\right)$ was reduced by $60 \%$ to maintain $(\mathrm{dV} / \mathrm{dt})_{\max }$ in the range of $260 \mathrm{~V} / \mathrm{s}$.

Since it has been reported in voltage-clamp experiments [22] that the late sodium current $\left(\mathrm{I}_{\mathrm{NaL}}\right)$ is $0.07 \%$ of the value of $\mathrm{I}_{\mathrm{Na}}$ peak at $-30 \mathrm{mV}$ after $200 \mathrm{~ms}$, its conductance value $\left(\mathrm{G}_{\mathrm{NaL}}\right)$ was doubled to satisfy this condition. From now on, we will refer to the ORd modified model as the ORdmm.
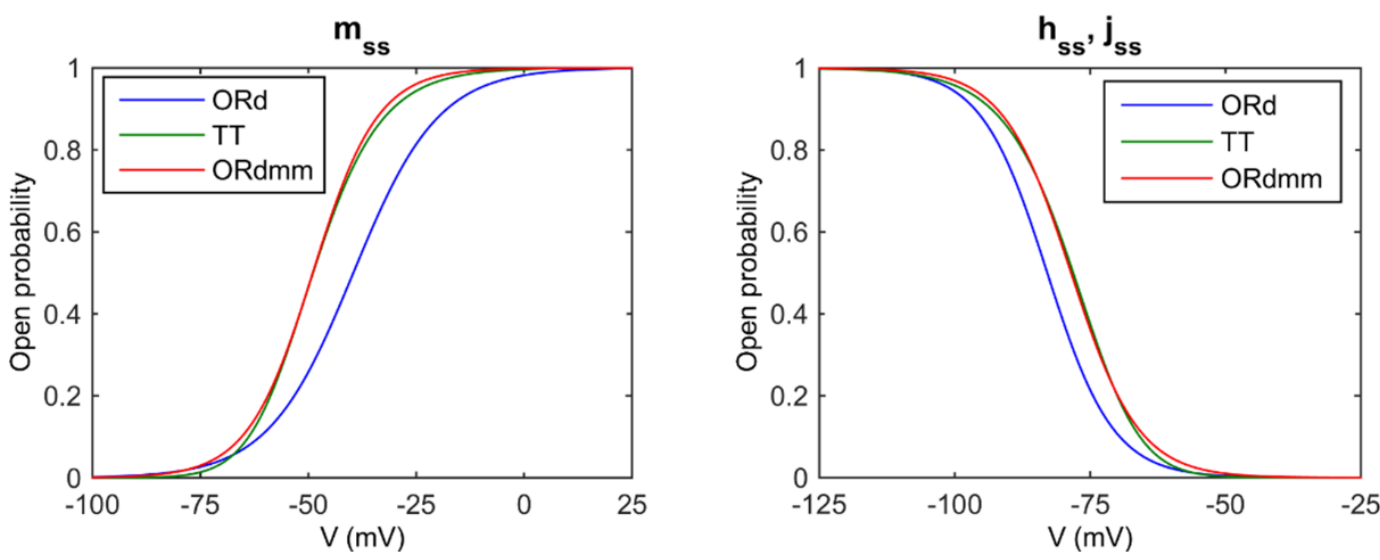

Figure 2.1. Steady state activation (left) and inactivation (right) gates of the fast $\mathrm{Na}^{+}$current in the different models. Original O'Hara et al. model (ORd), ten Tusscher et al. model (TT), and the modified ORd model (ORdmm).

\subsubsection{Simulation protocol}

All the simulations in this study were carried out in endocardial cells paced at $1 \mathrm{~Hz}$. Quantitative indicators characterizing $\mathrm{Ca}^{2+}$ dynamics were measured for the last of 1000 beats, after steady-state was reached (Figures 2.9 and 2.10 of the Supplemental Material show the last traces of AP and CaT in different simulations). The measured electrophysiological (EP) indicators were: systolic peak and diastolic value of $\left[\mathrm{Ca}^{2+}\right]_{\mathrm{i}}, \mathrm{Ca}^{2+}$ transient $(\mathrm{CaT})$ duration measured as the time from upstroke to $30 \%$ and $80 \%$ recovery $\left(\mathrm{CaTD}_{30}\right.$ and $\left.\mathrm{CaTD}_{80}\right)$, rise time of $\mathrm{CaT}\left(\mathrm{t}_{10-90}\right)$ defined as the time from $10 \% \mathrm{CaT}$ (close to the baseline) to $90 \% \mathrm{CaT}$ (close to peak) (see Figure 2.2 for details). Other important concentrations are systolic and diastolic values of $\mathrm{Ca}^{2+}$ reached in the subspace $\left(\left[\mathrm{Ca}^{2+}\right]_{\mathrm{ss}}\right)$, representing the space near the T-tubules, and in the sarcoplasmic reticulum (SR), which is divided into the 
junctional (JSR) and network SR (NSR). AP duration (APD) was measured as the time from the upstroke to $30 \%$ and $90 \%$ repolarization $\left(\mathrm{APD}_{30}\right.$ and $\left.\mathrm{APD} 90\right)$, as well as the $\left[\mathrm{Na}^{+}\right]_{\mathrm{i}}$ peak.

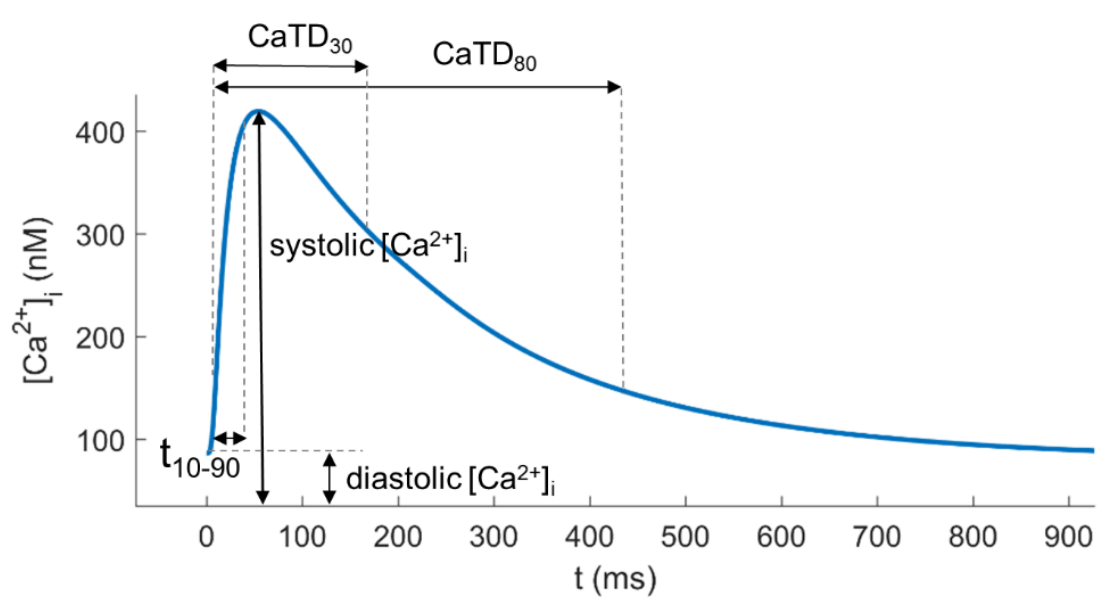

Figure 2.2. Time course of a steady state $\mathrm{Ca}^{2+}$ transient $(\mathrm{CaT})$ and its electrophysiological characteristics. Systolic $\left[\mathrm{Ca}^{2+}\right]_{\mathrm{i}}$ and diastolic $\left[\mathrm{Ca}^{2+}\right]_{\mathrm{i}}$, CaT duration measured as the time from upstroke to $30 \%$ and $80 \%$ recovery $\left(\mathrm{CaTD}_{30}\right.$ and $\left.\mathrm{CaTD}_{80}\right)$ and $10 \%$ to $90 \% \mathrm{CaT}$ rise time $\left(\mathrm{t}_{10-90}\right)$.

\subsubsection{Sensitivity analysis of the HF model}

An AP model for the failing myocyte was formulated on the basis of experimental observations to reproduce the main EP characteristics under these conditions in failing human ventricular myocytes. Table 2.1 shows the changes performed in the ORdmm model, following Gomez et al. changes performed in the original ORd model [23]. This electrical remodeling consists of applying a scale factor to maximal conductances of the $\mathrm{I}_{\mathrm{NaL}}$, the transient outward $\mathrm{K}^{+}$current $\left(\mathrm{I}_{\mathrm{to}}\right)$, and the inward rectifier $\mathrm{K}^{+}$current $\left(\mathrm{I}_{\mathrm{K} 1}\right)$, to the time constant of inactivation of the $\mathrm{I}_{\mathrm{NaL}}\left(\tau_{\mathrm{hL}}\right)$, to the maximal fluxes of the $\mathrm{Na}^{+} / \mathrm{K}^{+}$ATPase current $\left(\mathrm{I}_{\mathrm{NaK}}\right)$, the $\mathrm{Na}^{+} / \mathrm{Ca}^{2+}$ exchange current $\left(\mathrm{I}_{\mathrm{NCX}}\right)$, the $\mathrm{Ca}^{2+}$ uptake via SERCA pump ( $\left.\mathrm{J}_{\text {SERCA }}\right)$, and the $\mathrm{SR} \mathrm{Ca}^{2+}$ leak $\left(\mathrm{J}_{\text {leak }}\right)$, to the fraction of active binding sites of the $\mathrm{Ca}^{+2}$ calmodulin-dependent protein kinase II (CaMKa), and to the $\mathrm{SR} \mathrm{Ca}^{2+}$-dependence of the steady-state activation of ryanodine receptor $(\mathrm{RyR})$ release $\left(\mathrm{K}_{\mathrm{rel}, \mathrm{Ca}}\right)$. Further details of these variables can be found in the Supplementary Material (Section 2.5).

A sensitivity analysis was performed to study the variability of HF remodeling. The ionic parameters altered in HF were varied one at a time with a new scale factor to assess the impact of their variability on $\mathrm{Ca}^{2+}$ dynamics. The baseline model was the ORdmm model with the EP remodeling described in Table 2.1 ("HF basic"). Different degrees of HF were evaluated: without HF ("no change"), intermediate HF (" $50 \%$ HF") and severe HF (" $150 \%$ HF"), and applied to one parameter at a time in each simulation, as detailed below. First, each remodeled variable was individually modified to its normal value as in the ORdmm model, i.e. without HF, while the others were fixed to the values of the basic HF model. This gave rise to 10 different "no change" models, each one for a specific parameter. The same parameters were similarly varied one at a time to a value representing $\pm 50 \%$ of that observed in the HF basic remodeling. In this way we obtained 10 different basic HF models in which only one parameter was at $50 \%$ of its HF condition (" $50 \%$ HF") and another 10 in which one parameter was increased by $50 \%$ of the basic HF remodeling (" $150 \%$ HF") (the exact percentages of change are specified in Table 2.2 in the Supplemental Material). 
Table 2.1. HF remodeling in ORdmm model.

\begin{tabular}{ll}
\hline Ionic parameter & $\begin{array}{l}\% \text { in the HF model } \\
\text { compared to the } \\
\text { ORdmm }\end{array}$ \\
\hline $\mathrm{I}_{\mathrm{NaL}}$ & $180 \%$ \\
\hline$\tau_{\mathrm{hL}}$ & $180 \%$ \\
\hline $\mathrm{I}_{\mathrm{to}}$ & $40 \%$ \\
\hline $\mathrm{I}_{\mathrm{K} 1}$ & $68 \%$ \\
\hline $\mathrm{I}_{\mathrm{NaK}}$ & $70 \%$ \\
\hline $\mathrm{I}_{\mathrm{NCX}}$ & $175 \%$ \\
\hline $\mathrm{CaMKa}$ & $150 \%$ \\
\hline $\mathrm{J}_{\mathrm{SERCA}}$ & $50 \%$ \\
\hline $\mathrm{J}_{\text {leak }}$ & $130 \%$ \\
\hline $\mathrm{K}_{\mathrm{rel}, \mathrm{Ca}}$ & $80 \%$ \\
\hline
\end{tabular}

The modified parameters are: the late $\mathrm{Na}^{+}$current $\left(\mathrm{I}_{\mathrm{NaL}}\right)$, the time constant of inactivation of the $\mathrm{I}_{\mathrm{NaL}}\left(\tau_{\mathrm{hL}}\right)$, the transient outward current $\left(\mathrm{I}_{\mathrm{to}}\right)$, the inward rectifier $\mathrm{K}^{+}$current $\left(\mathrm{I}_{\mathrm{K} 1}\right)$, the $\mathrm{Na}^{+} / \mathrm{K}^{+}$pump current $\left(\mathrm{I}_{\mathrm{NaK}}\right)$, the $\mathrm{Na}^{+} / \mathrm{Ca}^{2+}$ exchanger $\left(\mathrm{I}_{\mathrm{NCX}}\right)$, the fraction of active binding sites of the $\mathrm{Ca}^{+2}$ calmodulin-dependent protein kinase II (CaMKa), the sarcoplasmic reticulum (SR) $\mathrm{Ca}^{2+}$ pump $\left(\mathrm{J}_{\mathrm{SERCA}}\right)$, the $\mathrm{SR} \mathrm{Ca}^{2+}$ leak $\left(\mathrm{J}_{\text {leak }}\right)$ and the sensitivity to $\left[\mathrm{Ca}^{2+}\right]_{\mathrm{JSR}}$ of the ryanodine receptors $\left(\mathrm{Ca}^{2+}\right.$ sensitivity of $\mathrm{J}_{\mathrm{rel}, \infty}$, called $\left.\mathrm{K}_{\mathrm{rel}, \mathrm{Ca}}\right)$.

The different sensitivities of the most severe HF condition ("150\% HF") and the "no change" condition were then calculated, as described in Trenor et al. [17], where the indexes' percentage of change $\left(D_{c, p, x}\right)$ and sensitivities $\left(S_{c, p}\right)$ were calculated as follows:

$$
\begin{gathered}
D_{c, p, x}=\frac{c_{p, x}-c_{\text {basic }}}{c_{\text {basic }}} \cdot 100 \\
S_{c, p}=\frac{D_{c, p, 2}-D_{c, p, 1}}{\Delta a}
\end{gathered}
$$

with $c_{p, x}$ being the magnitude of the characteristic "c" when parameter " $p$ " undergoes a change with respect to the basic HF model ( $\mathrm{x}=1$ : without $\mathrm{HF}$ and $\mathrm{x}=2: 150 \% \mathrm{HF}$ ), and $\mathrm{c}_{\text {basic }}$ the value of the same property in the basic HF model; $\Delta \mathrm{a}$ is the total interval of change of parameter $\mathrm{p}$. The evaluated EP characteristics are the indicators specified in the simulation protocol section and were obtained from the steady-state APs and CaTs (see Figure 2.9 in the Supplemental Material). Finally, the calculated sensitivities were normalized to the maximum absolute sensitivity for each particular characteristic to facilitate the detection of the strongest effects.

\subsubsection{Sensitivity analysis of the effects of potential drugs}

One of the aims of the present work is to study how potential drug-induced alterations in the main ionic currents could modulate important electrophysiological characteristics related to $\mathrm{Ca}^{2+}$ handling in normal and failing hearts. The methodology employed consisted of modulating individual ionic conductances or maximal fluxes by applying a scale factor of $\pm 60 \%$. These variations were considered as a surrogate for enhancement or inhibition of one ionic transport mechanism due to the possible effect of a drug. The targeted currents or fluxes were the main parameters of the model, well known in the EP activity of myocytes: $\mathrm{I}_{\mathrm{Na}}, \mathrm{I}_{\mathrm{NaL}}, \mathrm{I}_{\mathrm{to}}$, the L-type $\mathrm{Ca}^{2+}$ current $\left(\mathrm{I}_{\mathrm{CaL}}\right)$, the rapid delayed rectifier $\mathrm{K}^{+}$current $\left(\mathrm{I}_{\mathrm{Kr}}\right)$, the slow delayed rectifier $\mathrm{K}^{+}$current $\left(\mathrm{I}_{\mathrm{Ks}}\right), \mathrm{I}_{\mathrm{K} 1}, \mathrm{I}_{\mathrm{NCX}}, \mathrm{I}_{\mathrm{NaK}}, \mathrm{J}_{\mathrm{SERCA}}$, the SR Ca ${ }^{2+}$ 
release flux via RyR $\left(J_{\text {rel }}\right), J_{\text {leak }}$, and the $\mathrm{Na}^{+}$background current $\left(\mathrm{I}_{\mathrm{Nab}}\right)$. Since we wanted to study and compare the modulation in normal and failing conditions, these changes were applied to both models separately, obtaining two sensitivity analyses. When the HF model was used, modifications were done by maintaining the electrical remodeling affecting ionic parameters. Once the simulations had been performed, the EP characteristics were measured from the steady-state APs and CaTs (see Figure 2.10 in Supplemental Material). For each EP characteristic and parameter, the indexes' percentage of change $\left(D_{c, p, x}\right)$ and sensitivities $\left(S_{c, p}\right)$ were calculated similarly to those of the first sensitivity analysis (equations. 2.1 and 2.2). In this case, there were two basic models, the ORdmm model with and without $\mathrm{HF}$, and sensitivities were calculated from the variation $-60 \%(\mathrm{x}=1)$ to $+60 \%(\mathrm{x}=2)$; $\Delta$ a remains constant and has a value of 1.2.

In the last step, to identify the parameters with the strongest influence on each EP indicator, the relative sensitivity was calculated as the ratio between each sensitivity and the maximum absolute sensitivity for that particular characteristic.

\subsection{Results}

\subsubsection{Impact of $\mathrm{HF}$ remodeling variability on $\mathrm{Ca}^{2+}$ dynamics}

Firstly, we analyzed the individual effects of the variability on the different ionic parameters remodeled in $\mathrm{HF}$ on $\mathrm{Ca}^{2+}$ indicators (see Figure 2.3), to find the relative sensitivities of all the combinations of EP characteristics (vertical) to parameter variations (horizontal). A color scale, from dark blue to dark red highlights the strongest effects of each indicator (rows). The maximum absolute sensitivity $\left(S_{c, p}\right)$ is shown in each row to indicate the total impact of the parameters on a particular characteristic. In addition to sensitivity values, it is also important to find the dependency directions between the variables. For this, positive and negative signs indicate whether the change of the ionic current and the HF characteristic follow the same tendency or an inverse tendency, respectively.

From this sensitivity analysis, it can be deduced that $\mathrm{I}_{\mathrm{NaL}}$ and $\mathrm{I}_{\mathrm{NaK}}$ are the most important contributors to APD variations. The enhancement of both currents prolongs APD, but the former has a greater effect on $\mathrm{APD}_{90}$ and the latter on $\mathrm{APD}_{30}$. $\tau_{\mathrm{hL}}$ and $\mathrm{I}_{\mathrm{NCX}}$ also have a mild effect. Figure 2.4 shows the values of selected EP indicators with the variations of the parameters and the currents that exert a relevant influence. Panel A shows how APD 90 is modulated by these parameters.

Interestingly, $\mathrm{J}_{\mathrm{SERCA}}$ is the major contributor to most of the EP properties related to $\mathrm{Ca}^{2+}$ dynamics (Figure 2.3). It can be seen in Figure 2.4 that the SERCA "no change" condition is able to restore these indicators to their normal values, despite EP remodeling in other parameters due to HF. Figure 2.5 shows the changes in CaT morphology due to SERCA remodeling in HF; a considerable recovery can be obtained by simply restoring the $\mathrm{SR} \mathrm{Ca}^{2+}$ uptake function. CaTD shows a negative sensitivity to SERCA and the duration is increased with the inhibition of the pump during HF (Figure 2.4B, dashed green line). The other ionic parameters with an effect on CaTD are far from the influence of $\mathrm{J}_{\mathrm{SERCA}}$. For instance, although the reduction of $\mathrm{I}_{\mathrm{NaK}}$ (dashed red line) has a positive dependence and could help to reduce the duration, the sensitivity value is small. Thus, restoring $\mathbf{J}_{\text {SERCA }}$ to its normal value would restore the CaTD value of non-failing myocytes (around $400 \mathrm{~ms}$ ). The $\mathrm{CaTD}_{30}$ sensitivities show a similar tendency to the $\mathrm{CaTD}_{80}$ sensitivities in all the parameters but the values are higher. 


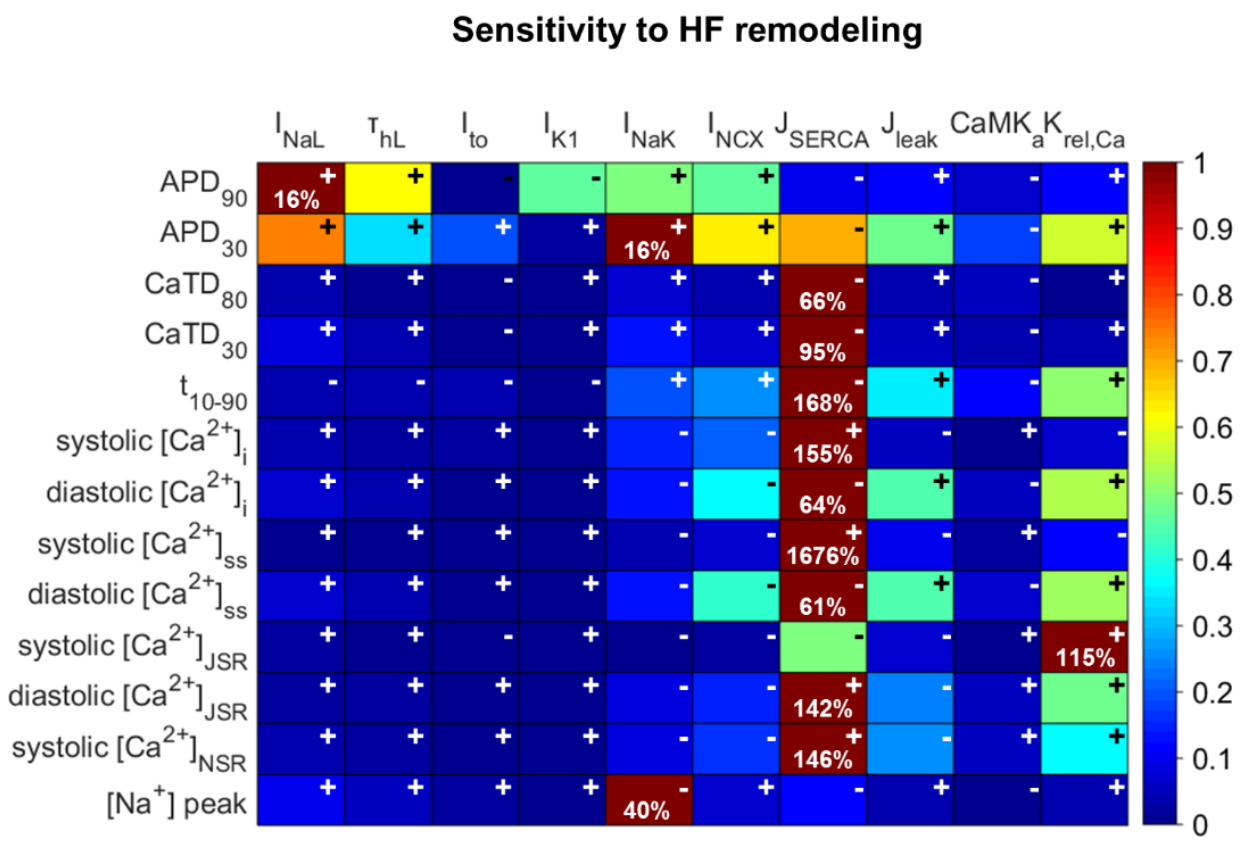

Figure 2.3. Relative sensitivities of the electrophysiological properties to changes in electrophysiological remodeling in the HF model. In the color scale, dark red indicates maximum relative sensitivity of a particular electrophysiological property to one ionic parameter, whereas dark blue indicates lack of dependency. Signs indicate whether the dependency is direct $(+)$ or inverse (-). Percentages in each box indicate the maximum absolute sensitivity of the EP property in that row to one of the ionic parameters. The modulated parameters are: the late $\mathrm{Na}^{+}$current $\left(\mathrm{I}_{\mathrm{NaL}}\right)$, the time constant of inactivation of the $\mathrm{I}_{\mathrm{NaL}}\left(\tau_{\mathrm{hL}}\right)$, the transient outward current $\left(\mathrm{I}_{\mathrm{to}}\right)$, the inward rectifier $\mathrm{K}^{+}$current $\left(\mathrm{I}_{\mathrm{K} 1}\right)$, the Na $\mathrm{Na}^{+}$pump current $\left(\mathrm{I}_{\mathrm{NaK}}\right)$, the $\mathrm{Na}^{+} / \mathrm{Ca}^{2+}$ exchanger $\left(\mathrm{I}_{\mathrm{NCX}}\right)$, the fraction of active binding sites of the $\mathrm{Ca}^{+2}$ calmodulin-dependent protein kinase II (CaMKa), the sarcoplasmic reticulum (SR) $\mathrm{Ca}^{2+}$ pump $\left(\mathrm{J}_{\mathrm{SERCA}}\right)$, the $\mathrm{SR} \mathrm{Ca}^{2+}$ leak $\left(\mathrm{J}_{\text {leak }}\right)$ and the sensitivity to $\left[\mathrm{Ca}^{2+}\right]_{\text {JSR }}$ of the RyR $\left(\mathrm{Ca}^{2+}\right.$ sensitivity of $\mathrm{J}_{\mathrm{rel}, \infty}$, called $\left.\mathrm{K}_{\mathrm{rel}, \mathrm{Ca}}\right)$. The electrophysiological properties are: action potential duration $\left(\mathrm{APD}_{90}\right.$ and $\left.\mathrm{APD}_{30}\right), \mathrm{Ca}^{2+}$ transient duration $\left(\mathrm{CaTD}_{80}\right.$ and $\left.\mathrm{CaTD}_{30}\right)$, rise time of $\mathrm{CaT}\left(\mathrm{t}_{10-90}\right)$, systolic and diastolic $\mathrm{Ca}^{2+}$ levels in the cytosol $\left(\left[\mathrm{Ca}^{2+}\right]_{\mathrm{i}}\right)$, the subsarcolemmal space $\left(\left[\mathrm{Ca}^{2+}\right]_{\mathrm{ss}}\right)$, the junctional SR $\left(\left[\mathrm{Ca}^{2+}\right]_{\mathrm{JSR}}\right)$ and the network SR $\left(\left[\mathrm{Ca}^{2+}\right]_{\mathrm{NSR}}\right)$, and intracellular $\mathrm{Na}^{+}$peak $\left(\left[\mathrm{Na}^{+}\right]_{\mathrm{i}}\right)$

Another important characteristic of $\mathrm{Ca}^{2+}$ dynamics is the rise time $\left(\mathrm{t}_{10-90}\right)$. The SERCA pump is the strongest modulator of $\mathrm{t}_{10-90}$. As shown in Figure 2.3, $\mathrm{J}_{\text {leak }}$ and $\mathrm{K}_{\mathrm{rel}, \mathrm{Ca}}$ also affect $\mathrm{t}_{10-90}$, although to a lesser extent than SERCA. Both parameters are related with $\mathrm{Ca}^{2+}$ extrusion from the $\mathrm{SR}$, in the cytosol and the subspace, respectively. Indeed $\mathrm{K}_{\mathrm{rel}, \mathrm{Ca}}$ is the sensitivity of $\mathrm{J}_{\mathrm{rel}}$ to $\left[\mathrm{Ca}^{2+}\right]_{\text {JSR }}$, meaning that a reduction of $\mathrm{K}_{\mathrm{rel}, \mathrm{Ca}}$ leads to a higher release through RyRs. In general, HF conditions slow down the $\mathrm{CaT}$ rise, but reduced $\mathrm{K}_{\mathrm{rel}, \mathrm{Ca}}$ helps to accelerate it (Figure 2.4E, solid red line). The high impact of the abnormal SERCA function, increasing $\mathrm{t}_{10-90}$, is one of the major problems in $\mathrm{HF}$, and the enhancement of $\mathrm{I}_{\mathrm{NCX}}$ (dotted blue line) contributes to a slow rise in CaT, although to a lesser extent.

$\left[\mathrm{Ca}^{2+}\right]$ in all cell compartments is strongly modulated by the reduced $\mathrm{J}_{\mathrm{SERCA}}$ in HF. Specifically, systolic $\left[\mathrm{Ca}^{2+}\right]_{\mathrm{i}}$ values decrease when SERCA activity is reduced (Figure 2.4C), while diastolic concentrations increase (Figure 2.4D). The influence of $\mathrm{I}_{\mathrm{NCX}}$ (dotted blue line) enhancement is also important and contributes to a general reduction of $\left[\mathrm{Ca}^{2+}\right]_{\mathrm{i}}$. Reduced $\mathrm{I}_{\mathrm{NaK}}$ (dashed red line) also leads to higher systolic $\mathrm{Ca}^{2+}$. Diastolic values are also sensitive to changes in $\mathrm{J}_{\text {leak }}$ and $\mathrm{K}_{\text {rel,Ca }}$ (dashed blue and solid red lines, respectively). In the subspace, the sensitivity of $\left[\mathrm{Ca}^{2+}\right]$ to ionic parameters is similar to the sensitivity in the cytoplasm, but with higher sensitivity values of the systolic $\mathrm{Ca}^{2+}$ peak (see rows 8 and 9 in Figure 2.3). 


\section{HF remodeling effects}

A

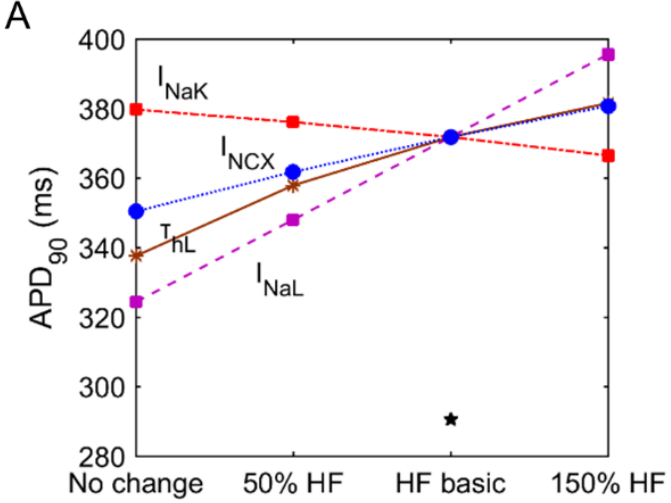

C

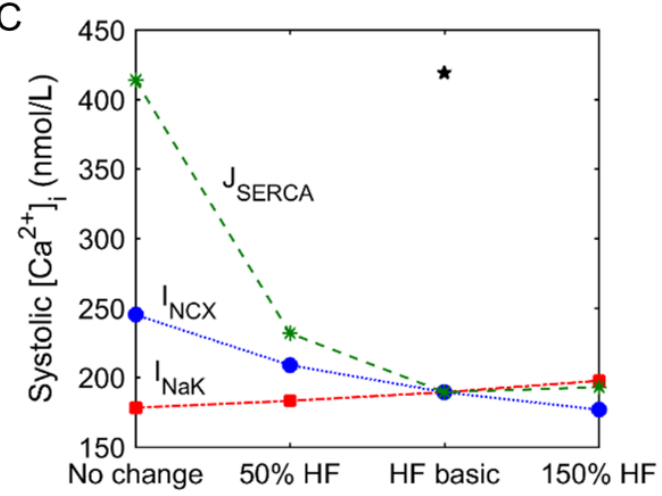

E

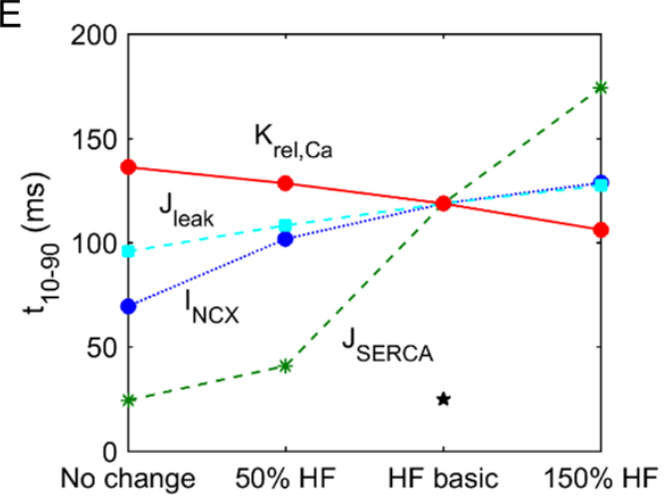

B
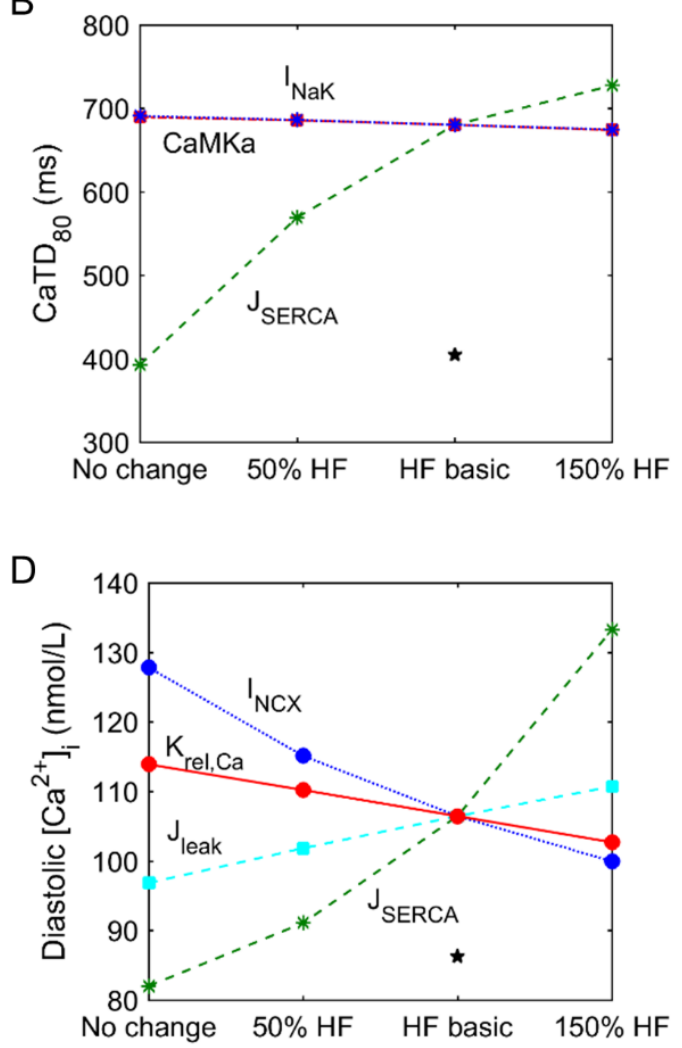

$\mathrm{F}$

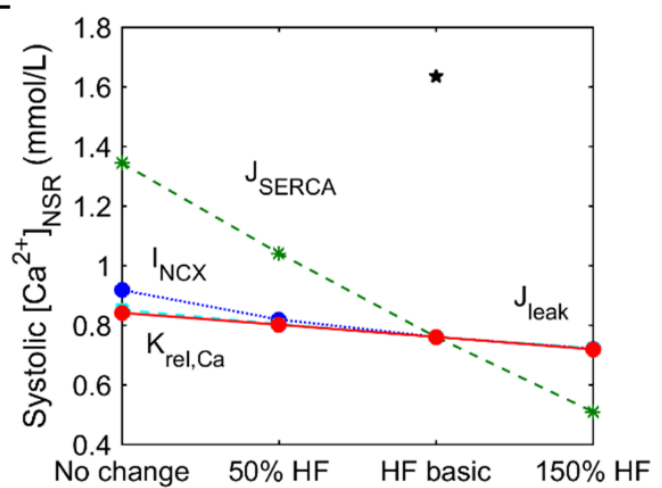

Figure 2.4. Sensitivity of electrophysiological properties to changes in ionic current parameters in the HF model. Changes in $\mathrm{APD}_{90}$ (panel A), CaTD 80 (panel B), systolic and diastolic $\left[\mathrm{Ca}^{2+}\right]_{\mathrm{i}}($ panels C and D), rise time of CaT (panel E) and $\mathrm{SR} \mathrm{Ca}^{2+}$ systolic load (panel F) with the ionic parameters labeled. Axis x represents the simulation conditions; for " $\mathrm{HF}$ basic" the remodeling of the basic HF model is considered, for "No change" the labeled parameter is unchanged as it is in the ORdmm model, for " $50 \% \mathrm{HF}$ " the HF condition is reduced by $50 \%$ in the labeled parameter and for " $150 \% \mathrm{HF}$ " the HF condition is increased by $50 \%$. The star represents the value of the indicator under simulated normal conditions.

As the $\mathrm{SR} \mathrm{Ca}^{2+}$ load is altered in $\mathrm{HF}$ and contributes to $\mathrm{CaT}$ changes, $\mathrm{Ca}^{2+}$ concentrations during an AP in this compartment were also analyzed. Both the junction and the network compartments have similar sensitivities to EP remodeling changes. In fact, $\mathrm{J}_{\mathrm{SERCA}}$ (dashed green line) remains the most important factor in modulating $\mathrm{SR} \mathrm{Ca}{ }^{2+}$ load, followed by $\mathrm{J}_{\text {leak }}, \mathrm{K}_{\text {rel,Ca, and }} \mathrm{I}_{\mathrm{NCX}}$ (Figure 2.4F). Exceptionally, it can be seen that in the JSR, $\mathrm{K}_{\mathrm{rel}, \mathrm{Ca}}$ is the main parameter that affects systolic 
concentration, closely followed by $\mathrm{J}_{\mathrm{SERCA}}$ (see row 10 in Figure 2.3). The negative effect of $\mathrm{J}_{\mathrm{SERCA}}$ on systolic $\left[\mathrm{Ca}^{2+}\right]_{\mathrm{JSR}}$ is because of the smaller gradient between intracellular and $\mathrm{SR}\left[\mathrm{Ca}^{2+}\right]$, leading to lower $\mathrm{J}_{\text {rel }}$. Consequently, the systolic $\left[\mathrm{Ca}^{2+}\right]_{\text {JSR }}$ minimum peak is less marked and the value becomes more positive as SERCA activity decreases.

The $\left[\mathrm{Na}^{+}\right]_{\mathrm{i}}$ analysis shows high dependence on $\mathrm{I}_{\mathrm{NaK}}$ in an inverse mode, as expected (Figure 2.3, last row), while the sensitivity of the rest of the parameters is less than $10 \%$.

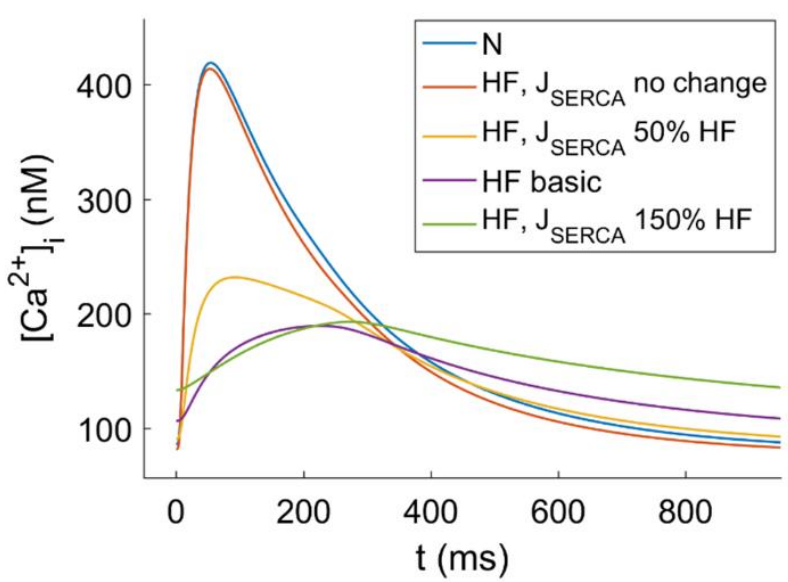

Figure 2.5. Effect of JSERCA remodeling in HF on CaTs. Normal (N) vs failing (HF) conditions varying $\mathrm{J}_{\mathrm{SERCA}}$ from the original value in the ORdmm model (no change) to $150 \%$ of its value in $\mathrm{HF}$.

\subsubsection{Sensitivity of the normal and the HF model to potential effects of drugs}

Figure 2.6 summarizes the results of the sensitivity analyses of AP and $\mathrm{Ca}^{2+}$ indicators to the same ionic modulation, simulating potential effects of pharmacological treatments in normal and failing conditions, showing the relative sensitivities on a color scale. The differences between the two models are indicated by the colors as well as by the different maximal sensitivities.

The response of normal and failing EP properties to the same changes in the main ionic currents can be seen in this sensitivity analysis. In general, the effects on EP characteristics follow the same tendency in both models, but with different sensitivities in some cases, showing a different response to the same change. Figures 2.7 and 2.8 show the most important ionic factors leading to important changes in the different indicators (APD $90, \mathrm{APD}_{30}$ and $\mathrm{CaTD}_{80}$ in Figure 2.7, and $\mathrm{t}_{10-90}$ and systolic and diastolic $\left[\mathrm{Ca}^{2+}\right]_{i}$ in Figure 2.8) in normal and failing myocytes.

First, APD is highly sensitive to $\mathrm{I}_{\mathrm{Kr}}$, which shortens APD when the current is enhanced (Figure 2.6, rows 1 and 2 of both panels). $\mathrm{I}_{\mathrm{NaL}}$ and $\mathrm{I}_{\mathrm{CaL}}$ are also important contributors to APD changes. However, in comparison with normal conditions, in $\mathrm{HF} \mathrm{APD}_{90}$ is more sensitive to changes in $\mathrm{I}_{\mathrm{NaL}}$ (compare panels $\mathrm{A}$ and $\mathrm{B}$ of Figure 2.7, dashed magenta line). Furthermore, $\mathrm{APD}_{30}$ shows a negative dependency on $\mathrm{I}_{\mathrm{CaL}}$ (dashed brown line) and $\mathrm{J}_{\text {SERCA }}$ (dashed green line) when these are reduced, which is not seen in normal conditions (Figure 2.7, panels $\mathrm{C}$ and $\mathrm{D}$ ). Thus, under HF conditions, the $\mathrm{I}_{\mathrm{NaL}}$ block should be more effective in reducing $\mathrm{APD}_{90}$ than in normal conditions, and unexpectedly, an $\mathrm{I}_{\mathrm{CaL}}$ block or a reduction in $\mathrm{J}_{\mathrm{SERCA}}$ could have negative effects and increase $\mathrm{APD}_{30}$. 


\section{Comparison of $\mathrm{N}$ and HF sensitivities}

\section{A. $\mathrm{N}$ conditions}

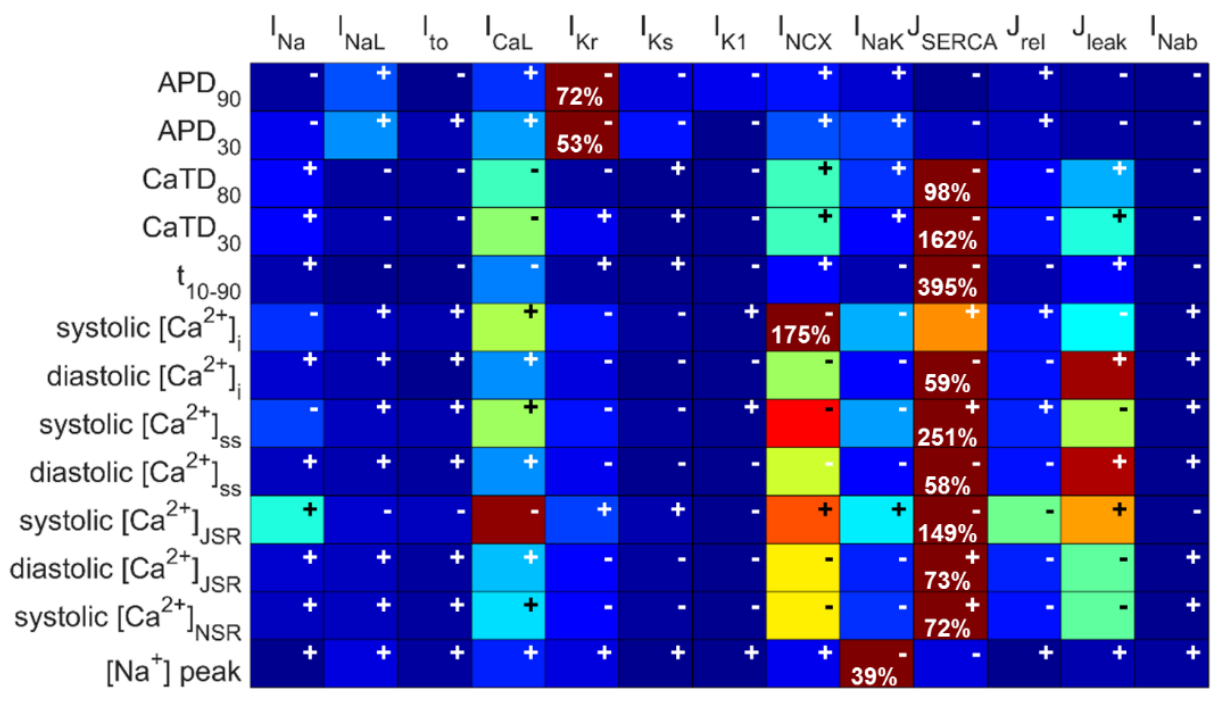

\section{B. HF conditions}

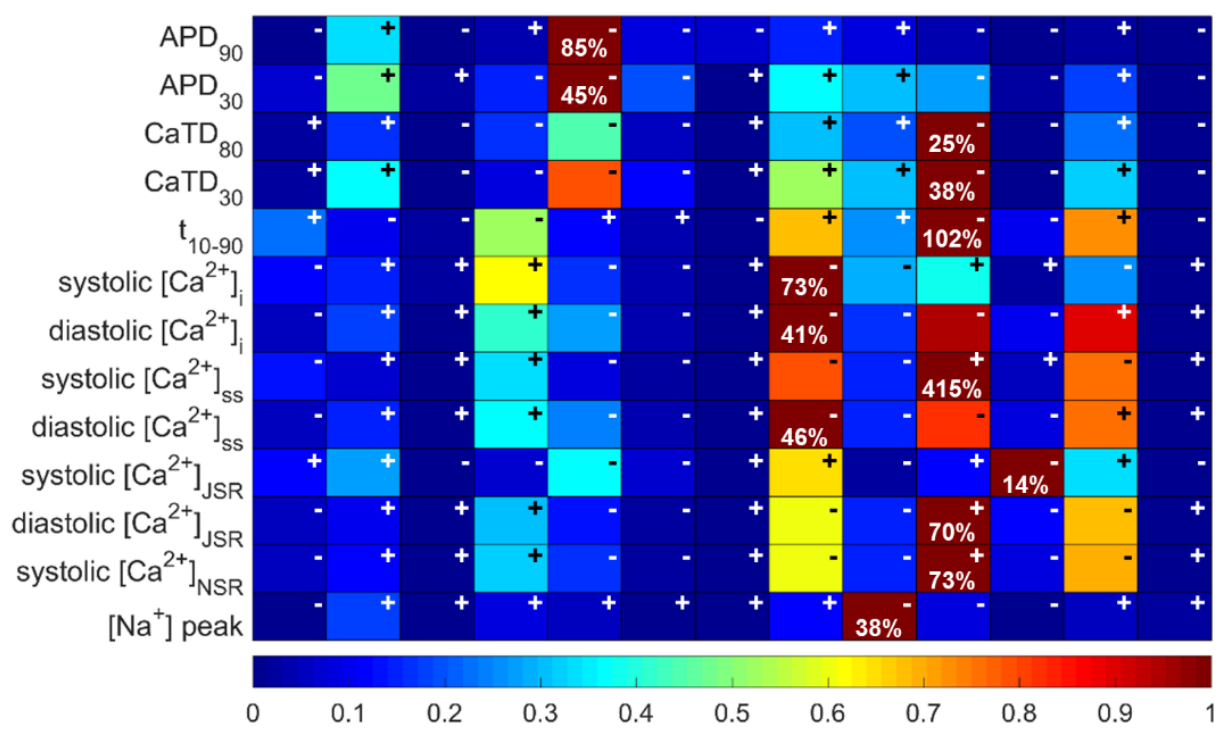

Figure 2.6. Relative sensitivities of the electrophysiological properties to modulating effects of potential drugs. Sensitivities in normal (panel A) and failing conditions (panel B). In the color scale, dark red indicates maximum relative sensitivity of a particular electrophysiological property to one ionic parameter, whereas dark blue indicates lack of dependency. Signs indicate whether the dependency is direct (+) or inverse (-). Percentages in each box indicate the maximum absolute sensitivity of the EP property in that row for all ionic parameters. The modulated parameters are: the fast $\mathrm{Na}^{+}$current $\left(\mathrm{I}_{\mathrm{Na}}\right)$, the late $\mathrm{Na}^{+}$current $\left(\mathrm{I}_{\mathrm{NaL}}\right)$, the transient outward $\mathrm{K}^{+}$current $\left(\mathrm{I}_{\mathrm{to}}\right)$, the L-type $\mathrm{Ca}^{2+}$ current $\left(\mathrm{I}_{\mathrm{CaL}}\right)$, the rapid delayed rectifier $\mathrm{K}^{+}$current $\left(\mathrm{I}_{\mathrm{Kr}}\right)$, the slow delayed rectifier $\mathrm{K}^{+}$current $\left(\mathrm{I}_{\mathrm{Ks}}\right)$, the inward rectifier $\mathrm{K}^{+}$current $\left(\mathrm{I}_{\mathrm{K} 1}\right)$, the $\mathrm{Na}^{+} / \mathrm{Ca}^{2+}$ exchange current $\left(\mathrm{I}_{\mathrm{NCX}}\right)$, the $\mathrm{Na}^{+} / \mathrm{K}^{+}$pump current $\left(\mathrm{I}_{\mathrm{NaK}}\right)$, the $\mathrm{Ca}^{2+}$ uptake via SERCA pump $\left(\mathrm{J}_{\mathrm{SERCA}}\right)$, the $\mathrm{SR} \mathrm{Ca}{ }^{2+}$ release flux via $\mathrm{RyR}\left(\mathrm{J}_{\mathrm{rel}}\right)$, the $\mathrm{SR} \mathrm{Ca}{ }^{2+}$ leak $\left(\mathrm{J}_{\text {leak }}\right)$ and the $\mathrm{Na}^{+}$background current $\left(\mathrm{I}_{\mathrm{Nab}}\right)$. The electrophysiological properties are: action potential duration $\left(\mathrm{APD}_{90}\right.$ and $\left.\mathrm{APD}_{30}\right), \mathrm{Ca}^{2+}$ transient duration $\left(\mathrm{CaTD}_{80}\right.$ and $\left.\mathrm{CaTD}_{30}\right)$, rise time of $\mathrm{CaT}\left(\mathrm{t}_{10-90}\right)$, systolic and diastolic $\mathrm{Ca}^{2+}$ levels in the cytosol $\left(\left[\mathrm{Ca}^{2+}\right]_{\mathrm{i}}\right)$, the subsarcolemmal space $\left(\left[\mathrm{Ca}^{2+}\right]_{\mathrm{ss}}\right)$, the junctional SR $\left(\left[\mathrm{Ca}^{2+}\right]_{\mathrm{SR}}\right)$ and the network SR $\left(\left[\mathrm{Ca}^{2+}\right]_{\mathrm{NSR}}\right)$, and intracellular $\mathrm{Na}^{+}$peak $\left(\left[\mathrm{Na}^{+}\right]_{\mathrm{i}}\right)$. 


\section{Ionic modulation effects}

A

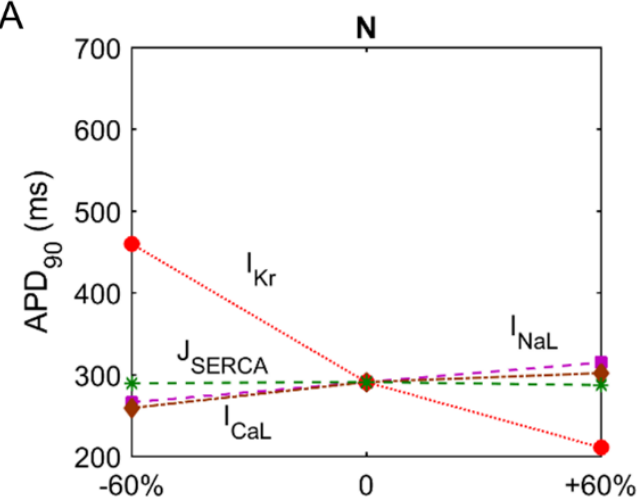

C

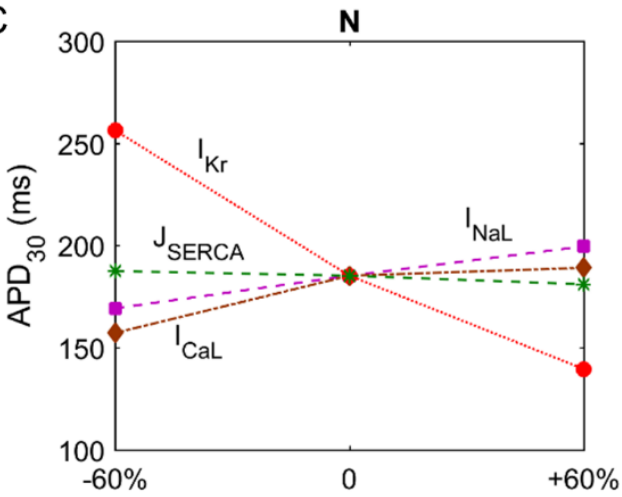

$\mathrm{E}$

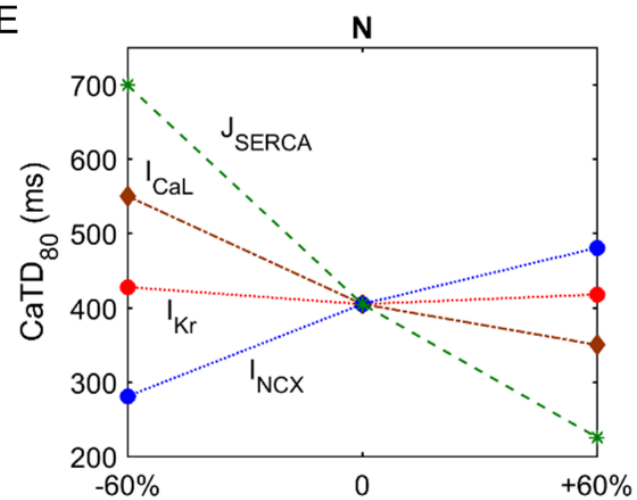

B

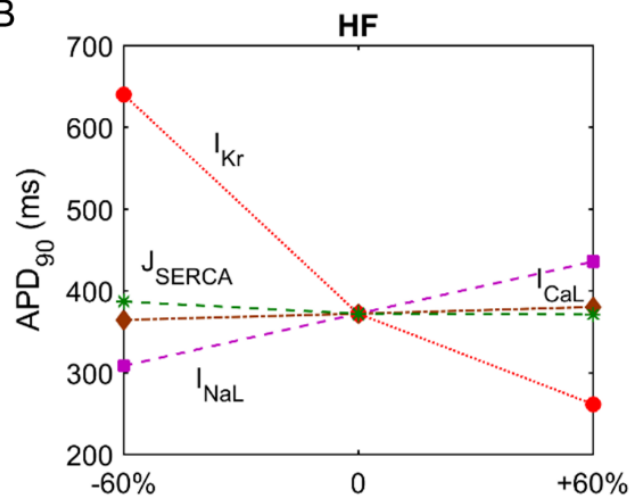

D

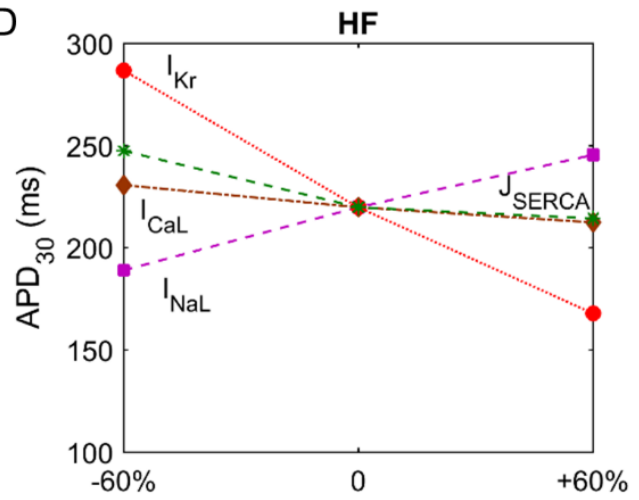

$\mathrm{F}$

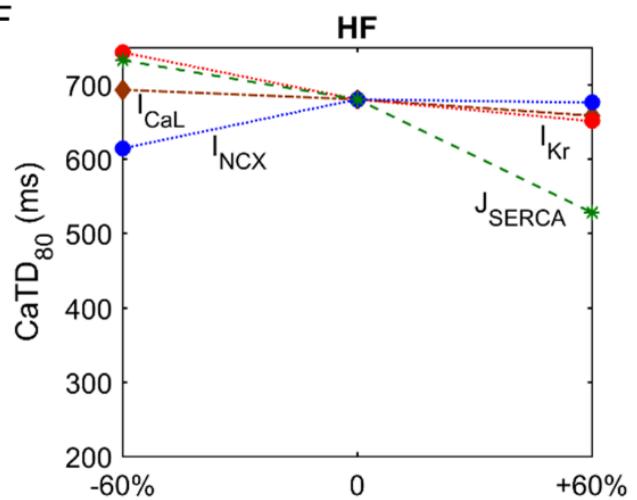

Figure 2.7. Sensitivity of $A P D_{90}, \mathrm{APD}_{30}$ and $\mathrm{CaTD}_{80}$ to the effects of drugs in normal $(\mathrm{N})$ and failing $(\mathrm{HF})$ conditions. Changes in $\mathrm{APD}_{90}$ (panels $\mathrm{A}$ and $\mathrm{B}$ ), $\mathrm{APD}_{30}$ (panels $\mathrm{C}$ and $\mathrm{D}$ ) and $\mathrm{CaTD}_{80}$ (panels $\mathrm{E}$ and $\mathrm{F}$ ). Axis $\mathrm{x}$ represents simulation conditions; for " 0 " the basic model is considered, for " $\pm 60 \%$ " the labeled parameter has been changed by this percentage.

With respect to $\mathrm{CaT}$ characteristics in normal conditions, again $\mathrm{J}_{\mathrm{SERCA}}$ seems to be the major contributor (Figure 2.6, rows 3-7 of both panels). CaTD has a negative sensitivity to SERCA, and although in HF this ionic transport also has a strong effect, it is less marked than in normal conditions. It can be observed that increasing the $\mathrm{J}_{\text {SERCA }}$ block in the HF model barely increases CaTD, compared to the lengthening produced in normal conditions (Figure 2.7, panels $\mathrm{E}$ and $\mathrm{F}$, dashed green line). However, the enhancement of $\mathrm{Ca}^{2+}$ uptake reduces CaTD similarly in both conditions. Blocking NCX (dotted blue line) shortens CaTD, but the influence of $\mathrm{I}_{\mathrm{CaL}}$ (dashed brown line) is reduced in HF in 
such a way that an enhancement of this current does not improve CaTD. On the other hand, it is to be noted that the effect of changes in $\mathrm{I}_{\mathrm{Kr}}$ on CaTD in the HF model becomes important (Figure 2.6, row 4, panel B). $\mathrm{I}_{\mathrm{Kr}}$ (dotted red line) block in HF prolongs CaTD, whereas this effect is non-existent in normal conditions. Thus, $\mathrm{I}_{\mathrm{Kr}}$ block in HF could have negative effects on $\mathrm{CaTD}$, in addition to the prolongation of APD.

\section{Ionic modulation effects}

A

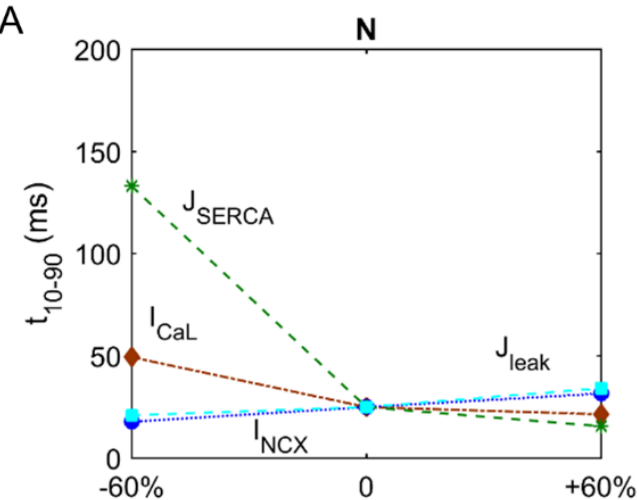

C

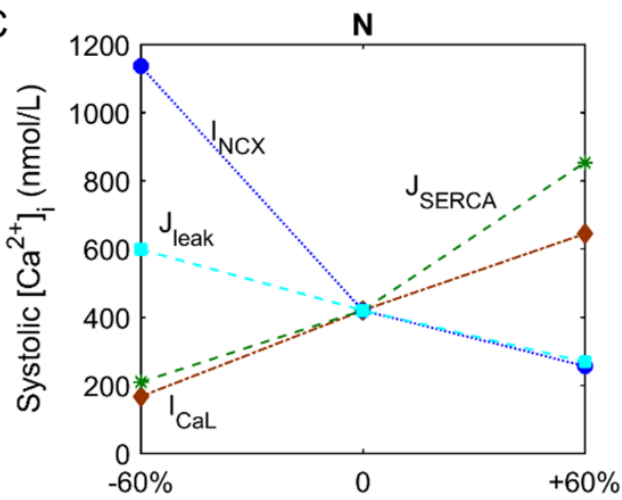

$\mathrm{E}$

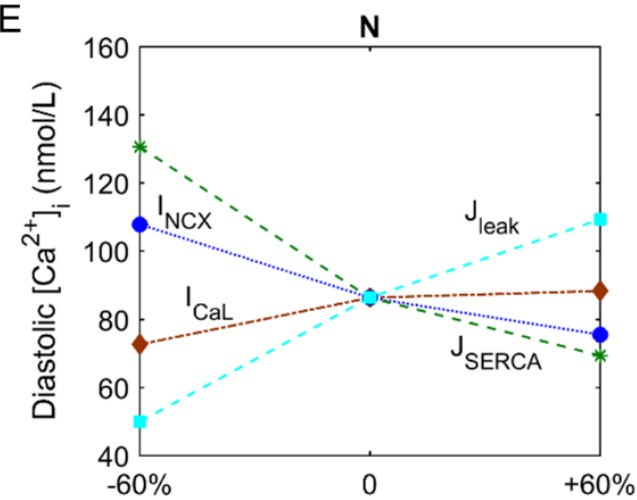

B

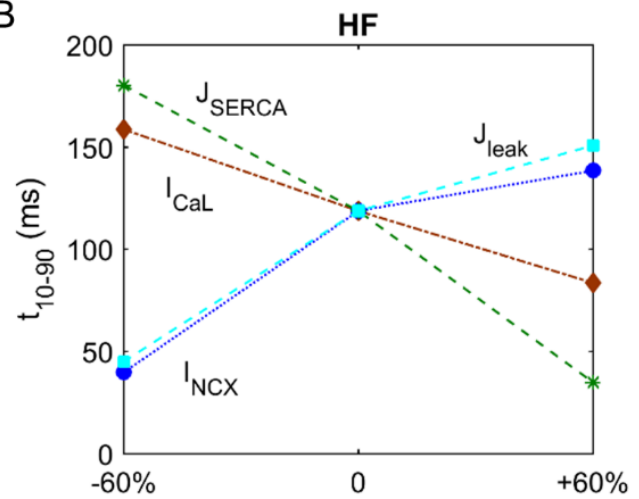

D

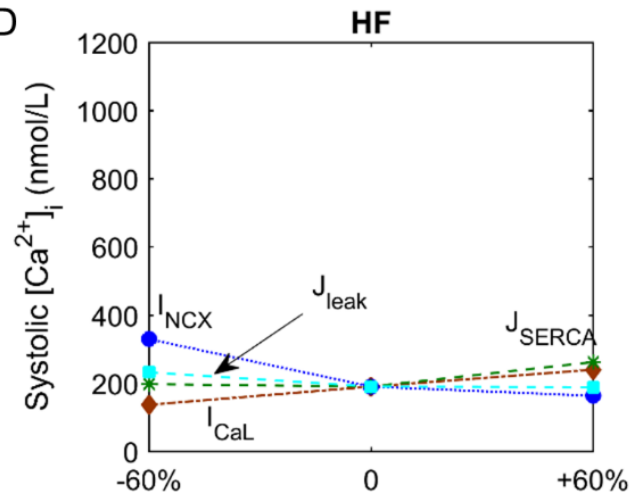

$\mathrm{F}$

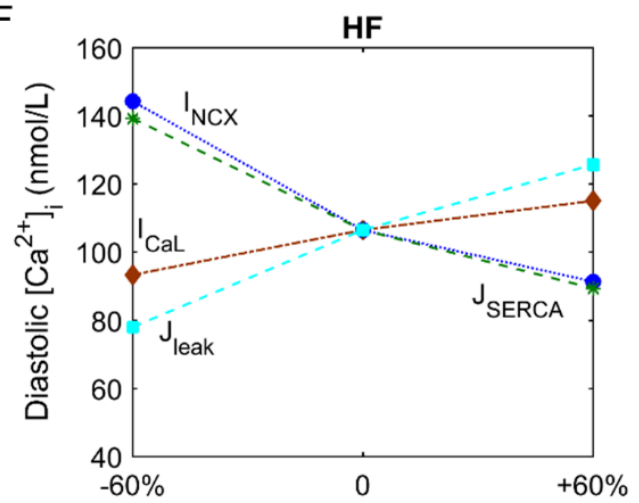

Figure 2.8. Sensitivity of $\mathrm{t}_{10-90}$, systolic and diastolic $\left[\mathrm{Ca}^{2+}\right]_{i}$ to the effects of drugs in normal $(\mathrm{N})$ and failing $(\mathrm{HF})$ conditions. Changes in the rise time of $\mathrm{CaT}$ (panels A and B), in systolic and diastolic $\left[\mathrm{Ca}^{2+}\right]_{i}$ (panels $\mathrm{C}, \mathrm{D}$ and E, F). Axis $\mathrm{x}$ represents simulation conditions; for " 0 " the basic model is considered, for " $\pm 60 \%$ " the labeled parameter has been changed by this percentage. 
Regarding CaT rise time ( $\left.\mathrm{t}_{10-90}\right)$, a $\mathrm{J}_{\text {SERCA }}$ block in normal conditions significantly increases this property, acting as the most influential parameter. On the other hand, when it is enhanced, a very slight reduction of $\mathrm{t}_{10-90}$ is observed (Figure 2.8A, dashed green line). However, in HF, SERCA enhancement significantly contributes to the reduction of $\mathrm{t}_{10-90}$, reaching a value close to the normal rise time (Figure 2.8B). Similar reductions can be obtained with the $\mathrm{I}_{\mathrm{NCX}}$ block (dotted blue line). $\mathrm{I}_{\mathrm{CaL}}$ and $\mathrm{J}_{\text {leak }}$ also modulate the rise time, especially in HF.

$\left[\mathrm{Ca}^{2+}\right]$ in all cell compartments is highly regulated by $\mathrm{J}_{\mathrm{SERCA}}$, followed by $\mathrm{I}_{\mathrm{NCX}}, \mathrm{J}_{\text {leak }}$, and $\mathrm{I}_{\mathrm{CaL}}$

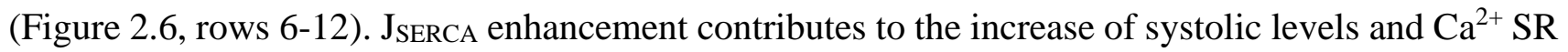
load and to the reduction of diastolic levels. However, $\mathrm{I}_{\mathrm{NCX}}$ inhibition increases $\mathrm{Ca}^{2+}$ concentration and has a greater effect than SERCA during systole (Figure 2.6, row 6). In HF, these parameters have less impact on the $\mathrm{Ca}^{2+}$ peak and the modification of $\mathrm{I}_{\mathrm{NCX}}$ (dotted blue line) and $\mathrm{J}_{\text {SERCA }}$ (dashed green line) produce smaller variations than those in normal conditions (Figure 2.8, panels $\mathrm{C}$ and D). Diastolic $\left[\mathrm{Ca}^{2+}\right]_{i}$ presents a similar sensitivity to $\mathrm{I}_{\mathrm{NCX}}$ and $\mathrm{J}_{\text {SERCA }}$ in $\mathrm{HF}$ and normal conditions. However, the $\mathrm{I}_{\mathrm{NCX}}$ block (dotted blue line) has a relevant effect, enhancing diastolic levels and worsening HF changes (Figure 2.8, panels $\mathrm{E}$ and F). In the subspace, responses to variations in ionic currents are similar to those of the cytosol but with higher sensitivity values during the systole (Figure 2.6, rows 8 and 9). $\mathrm{Ca}^{2+}$ concentrations in the SR are also regulated by $\mathrm{J}_{\text {SERCA }}$, followed by $\mathrm{J}_{\text {leak }}$ and $\mathrm{I}_{\mathrm{NCX}}$. $\mathrm{J}_{\text {rel }}$ seems to affect only systolic $\left[\mathrm{Ca}^{2+}\right]_{\text {JSR }}$ in $\mathrm{HF}$, whereas in normal conditions it is a secondary influence (Figure 2.6, rows 10-12).

Finally, the $\left[\mathrm{Na}^{+}\right]_{i}$ analysis shows high sensitivity to $\mathrm{I}_{\mathrm{NaK}}$ in an inverse mode. There are no important differences between normal and HF sensitivities, but $\mathrm{I}_{\mathrm{NaL}}$ has a higher impact in HF (Figure 2.6, last row).

\subsection{Discussion}

\subsubsection{Major findings}

In this study $\mathrm{Ca}^{2+}$ dynamics and APs were simulated in a human ventricular model (ORdmm) to shed light on the role of some ionic current characteristics and reveal other mechanisms that may take part in $\mathrm{Ca}^{2+}$ cycling during HF. The first sensitivity analysis highlights the strong effect of $\mathrm{J}_{\mathrm{SERCA}}$, among other parameters remodeled in $\mathrm{HF}$, on the modulation of $\mathrm{Ca}^{2+}$ indicators. Under $\mathrm{HF}$ conditions, depressed SERCA activity worsens all the EP characteristics related to $\mathrm{Ca}^{2+}$, which are the hallmark of HF: CaT rise time, systolic and diastolic $\left[\mathrm{Ca}^{2+}\right], \mathrm{CaT}$ duration and $\mathrm{SR} \mathrm{Ca}^{2+}$ content. Enhancing the SERCA uptake function to its normal activity improves all these $\mathrm{Ca}^{2+}$ characteristics and could restore contraction.

The comparison of $\mathrm{Ca}^{2+}$ sensitivities to drug-induced alterations in the main ionic currents in normal and HF conditions reveals some parameters that modulate $\mathrm{Ca}^{2+}$ dynamics in a different way. As blocking $\mathrm{I}_{\mathrm{Kr}}$ has a marked influence in prolonging CaTD in HF in comparison to its effect in normal conditions, IKr blocking drugs should be avoided in HF for their impact not only on APD but also on contractility. Blocking $\mathrm{I}_{\mathrm{NCX}}$ could be beneficial in $\mathrm{HF}$, as it improves CaT rise time, however it could also increase diastolic $\left[\mathrm{Ca}^{2+}\right]$, which worsens contraction. These opposing effects should be taken into account when considering blocking NCX. SERCA enhancement in HF is highly effective in reducing $\mathrm{t}_{10-90}$, but its depressed activity requires extreme enhancement to restore systolic $\left[\mathrm{Ca}^{2+}\right]_{\mathrm{i}}$. 


\subsubsection{Comparison with experimental results}

In this work the electrophysiological activity of human ventricular myocytes was simulated using the latest human AP model with a detailed formulation of $\mathrm{Ca}^{2+}$ dynamics [19], using $\mathrm{Ca}^{2+}$ cycling formulated from human experimental data. However, the simulated $\mathrm{Ca}^{2+}$ transients and concentrations are generally smaller than those found in the literature, possibly because of the high electrophysiological variability of the experimental data, due in part to the fluorescence-based technique used to measure intracellular $\mathrm{Ca}^{2+}[5,7,24]$. Despite these drawbacks, simulations are able to mimic $\mathrm{Ca}^{2+}$ transients and reproduce the abnormalities in $\mathrm{Ca}^{2+}$ dynamics observed in failing human hearts. The main alterations are long $\mathrm{Ca}^{2+}$ transients of reduced amplitude and SR with less $\mathrm{Ca}^{2+}$ content $[3,25,26]$.

Some experimental studies have focused on the main ionic transporters taking part in $\mathrm{Ca}^{2+}$ cycling (L-type $\mathrm{Ca}^{2+}$ channels, RyR channels, SERCA, and NCX) to improve contraction $[14,15,27,28]$, and many mechanistic details of $\mathrm{Ca}^{2+}$ dynamics have been discovered to date. The present work was designed to analyze these mechanisms under different conditions (normal and heart failure) to complement the experimental results and increase our understanding of how they work. From our sensitivity analysis, it can be seen that SERCA plays an important role in modulating $\mathrm{Ca}^{2+}$. SERCA's main function is to remove cytosolic $\mathrm{Ca}^{2+}$ and reintroduce it into the SR during diastole for myocardial relaxation. It is therefore reasonable to assume that reducing SERCA activity would increase diastolic $\left[\mathrm{Ca}^{2+}\right]_{i}$, slow the rate of $\mathrm{CaT}$ decay, and reduce the $\mathrm{SR} \mathrm{Ca}^{2+}$ load. SR $\mathrm{Ca}^{2+}$ store depletion indirectly reduces $\mathrm{Ca}^{2+}$ release and systolic function. In fact, after $\mathrm{Ca}^{2+}$ uptake function inhibition, healthy myocytes showed changes in $\mathrm{CaT}$ and $\mathrm{SR} \mathrm{Ca}^{2+}$ content, for example using the use of thapsigargin or TBQ in rats [29-31]. Under failing conditions, we obtained the same alterations in $\mathrm{Ca}^{2+}$ indicators, which presented a high sensitivity to SERCA, which highlights the strong effect of SERCA on the rest of the ionic mechanisms affected by HF remodeling. Increased inhibition of the SERCA function resulted in higher alteration in $\mathrm{Ca}^{2+}$ dynamics, while the restoration of a normal SR $\mathrm{Ca}^{2+}$ uptake showed a significant improvement of all these EP characteristics. Specific pharmacological agents to enhance SERCA activity have not been developed so far, but our results can be compared with those obtained using gene therapy methods. In agreement with our simulations of SERCA variability in normal conditions, transgenic rabbit cardiomyocytes overexpressing SERCA led to an increased magnitude of $\mathrm{CaT}$ and SR content compared to the control [32]. However, Morimoto et al. [33] did not find significant changes in $\mathrm{SR} \mathrm{Ca}^{2+}$ content nor in time to peak in transgenic mice, although SERCA overexpression did increase the CaT peak, which could be related with the insignificant effect on $\mathrm{t}_{10-90}$ in normal conditions that we observed in our analysis with enhanced SERCA.

Enhancing SERCA in HF improves cellular $\mathrm{Ca}^{2+}$ homeostasis. SERCA overexpression in failing cells restored $\mathrm{Ca}^{2+}$ handling in rats [34], as well as in humans [35]. In our simulations, a $60 \%$ increase in SERCA activity led to the lower recovery of $\mathrm{Ca}^{2+}$ indicators in $\mathrm{HF}$ than in normal conditions. Indeed, the depressed activity of the pump in HF is responsible for these discrepancies, and studies should be performed taking into account that different results may be obtained applying the same therapy under normal and failing conditions. Rocchetti et al. [36] observed that istaroxime stimulated SERCA uptake function in failing myocytes, restoring $\mathrm{Ca}^{2+}$ levels and, in contrast to our results, the effect on failing myocytes was higher than on the non-failing ones. However, differences between experiments and simulations should be taken with caution. Our 60\% SERCA enhancement represents an increase of the 
downregulated protein in $\mathrm{HF}$ whereas istaroxime seems to restore the abnormal $\mathrm{SR} \mathrm{Ca}^{+2}$ uptake function by targeting secondary molecules interacting with the pump, such as PLB. There might be other sources for discrepancies between our simulation results and Rocchetti et al. experiments, such as species differences (guinea pig vs human myocytes), HF stage, and EP remodeling.

The altered NCX activity in HF also has an impact on $\mathrm{Ca}^{2+}$ handling. An increased reverse mode occurs due to $\left[\mathrm{Na}^{+}\right]_{i}$ accumulation, increasing $\mathrm{Ca}^{2+}$ influx. At the same time, the upregulated forward mode increases $\mathrm{Ca}^{2+}$ efflux, resulting in cellular $\mathrm{Ca}^{2+}$ loss and a reduced $\mathrm{SR} \mathrm{Ca}^{2+}$ load. Therefore, most of the consequences of remodeled NCX worsen $\mathrm{Ca}^{2+}$ dynamics and the possible beneficial effect of NCX inhibition has been analyzed in several studies. SEA0400, a NCX inhibitor, did not produce significant changes either in the shape or in the magnitude of the CaT in normal guinea pig or canine myocytes [37-39], although Ozdemir et al. [40] observed an increased CaT peak and SR Ca ${ }^{2+}$ content in pigs. However, positive effects were also observed on $\mathrm{Ca}^{2+}$ homeostasis in transgenic animals with NCX overexpression [41,42], as observed in the present simulations. These results suggest a dependency on the animal model and highlight the need for human experimental data, as well as the careful selection of the pharmacological agent. SN-6, another NCX inhibitor, was found to have a negative inotropic action in normal and failing cardiomyocytes, with a greater reduction of $\mathrm{SR} \mathrm{Ca}^{2+}$ content in HF [43]. In this case, the non-specificity of the blocker and the effect on other currents, such as $\mathrm{I}_{\mathrm{CaL}}$ can affect the results, so that further experimental studies are required to clarify the effects of NCX inhibition, especially in the failing human myocardium.

The third pathway related to sarcoplasmic $\mathrm{Ca}^{2+}$ is its release through RyR channels. In HF, these $\mathrm{Ca}^{2+}$ proteins undergo a slightly increased $\mathrm{Ca}^{2+}$ sensitivity, which favors the $\mathrm{Ca}^{2+}$-induced $\mathrm{Ca}^{2+}$ release process. The main problem in $\mathrm{HF}$ is that RyRs become leaky and $\mathrm{Ca}^{2+}$ is released spontaneously during diastole, typically in the form of $\mathrm{Ca}^{2+}$ sparks [44]. As our HF model reproduces the effect of $\mathrm{J}_{\text {leak, }}$, contributing to abnormal $\mathrm{Ca}^{2+}$ cycling, its inhibition would thus be beneficial for myocardial contraction. However, in the ORd model, $\mathrm{J}_{\text {leak }}$ was formulated independently of the RyR channel, representing a continuous $\mathrm{Ca}^{2+}$ leakage from the SR through the SERCA pump. In this case, it is not possible to compare our results with the effects of any drug able to alleviate this leak. In our simulation study, sensitivity to RyR channels $\left(\mathrm{J}_{\text {rel }}\right)$ was analyzed independently of $\mathrm{J}_{\text {leak }}$. This ionic mechanism did not have strong effects on $\mathrm{Ca}^{2+}$ dynamics in our simulations, unlike most of the published experimental results. Inducing $\mathrm{Ca}^{2+}$-leak with caffeine or ryanodine in rats reduced $\mathrm{CaT}$ amplitude and changed systolic and diastolic concentrations [30]. Tetracaine, an RyR inhibitor, could reverse these variations and restore normal $\mathrm{Ca}^{2+}$ dynamics. Since caffeine decreases $\mathrm{SR} \mathrm{Ca}^{2+}$ content, increasing the activity of the RyR does not have a positive inotropic effect [45], but the negative effects are not clear.

\subsubsection{Benefits and predictions from systematic sensitivity analyses}

Unlike experimental studies, sensitivity analyses are a systematic methodology that allows many parameters to be varied either independently (one at a time) or at the same time, which avoids the difficulty of replicating conditions and allows the control of all the sources of variability that affect experimental results. The selection of the animal species when analyzing cellular electrophysiology is one of the most influential factors. Due to the need for human data and the scarcity of human hearts for experimental purposes, the use of a detailed human model such as the ORd model is extremely useful. Modeling and simulation also allow the assessment of EP characteristics, which cannot be measured experimentally, such as $\left[\mathrm{Ca}^{2+}\right]$ in different cellular compartments. With this approach, the 
modification of each parameter is quantified, while this cannot always be done accurately in experiments.

The use of sensitivity analyses has been widely extended to study physiological processes providing valuable predictions [16,17]. Other commonly used methods are multivariate analyses, which can provide additional information to that obtained with single parameter analyses [46,47]. However, we chose the simplicity and intuitive interpretation of the results by changing parameters individually, as this is also an accepted method used in this type of study [16,17]. Once the consistency of the sensitivity analyses results have been verified and compared against available experimental data, predictions can be made of how specific EP indicators are modulated by changes in ionic parameters for which data are not available. In agreement with previous studies, $\mathrm{I}_{\mathrm{Kr}}$ block and $\mathrm{I}_{\mathrm{NaL}}$ enhancement prolong APD, a situation aggravated under failing conditions [48-50]. The high sensitivity of $\left[\mathrm{Na}^{+}\right]_{\mathrm{i}}$ to $\mathrm{I}_{\mathrm{NaK}}$ and the increase in $\left[\mathrm{Na}^{+}\right]_{\mathrm{i}}$ due to the dysfunction of this pump in HF extruding less $\mathrm{Na}^{+}$out of the cell were also as expected $[51,52]$. This $\left[\mathrm{Na}^{+}\right]_{\mathrm{i}}$ accumulation is related to APD shortening when the electrogenic $\mathrm{Na}^{+} / \mathrm{K}^{+}$pump is inhibited because it increases the NCX reverse mode (outward current) and contributes to cell repolarization [16,17,51,53]. Other modulations of EP characteristics by ionic parameters in HF are less obvious. For instance, blocking $\mathrm{I}_{\mathrm{CaL}}$ and $\mathrm{J}_{\mathrm{SERCA}}$ may have negative prolonging effects on $\mathrm{APD}_{30}$ which does not occur under normal conditions. In terms of $\mathrm{Ca}^{2+}$ characteristics, blocking I $\mathrm{Kr}$ prolongs CaTD. The present simulation results predict that several $\mathrm{Ca}^{2+}$ indicators are unexpectedly more influenced by changes in $\mathrm{I}_{\mathrm{NCX}}$ than changes in SERCA in the failing myocyte. Unfortunately, the supposed beneficial blocking of NCX has negative consequences on diastolic $\left[\mathrm{Ca}^{2+}\right]_{\mathrm{i}}$ (raising its value), while enhancing SERCA always contributes to improving $\mathrm{Ca}^{2+}$ dynamics. These predictions would of course need to be validated using experimental results. The strength of systematic sensitivity analyses is their predictive power and the indications they provide for the design of the required experiments thus contributing to reducing the time and costs involved in drug design.

\subsubsection{Limitations of the study}

The limitations of the present study are linked, on the one hand, to the use of a mathematical model for the action potential. Despite its validation using human data, there are still some quantitative differences in intracellular $\mathrm{Ca}^{2+}$ levels. Additionally, in some situations, the model does not represent all the ionic mechanisms that are commonly described in the literature as is the case of $\mathrm{J}_{\text {leak }}$ which, in the ORd model, was formulated only as a backflux of the SERCA pump. However, in other models $[21,54,55], \mathrm{J}_{\text {leak }}$ is considered as a secondary efflux through the RyR channels, sometimes coexisting with a reverse SERCA flux [44]. For this reason, the analysis of the effects of $J_{\text {leak }}$ and $J_{\text {rel }}$ should be taken with caution, i.e. accordingly to the model formulation. Also, in our study, JSERCA was considered separately from the $\mathrm{J}_{\text {leak }}$ term, both of them included in the original ORd $\mathrm{J}_{\text {up }}$ formulation. Finally, the electrical remodeling associated with HF is not unique [23,56-58], as there are discrepancies and variations regarding some ionic currents due to the data generated in different experimental studies.

The scarcity of available human data has hampered the validation of our results, thus affecting their predictive value, and the wide variations in the existing experimental studies on different species and treatments, also make the validation of the simulations difficult. 


\subsection{Supplemental Material}

\subsubsection{Extended Methods}

The baseline model considered in this investigation is the O'Hara et al. action potential (ORd) [19] with the minor modifications indicated in the main text (ORdmm). All the parameters modulated in the sensitivity analyses are defined and formulated in [19]; some of the equations are detailed in the present section to help the interpretation of the results.

The parameter $\mathrm{K}_{\mathrm{rel}, \mathrm{Ca}}$ appears in the steady-state formulation of $\mathbf{J}_{\mathrm{rel}}$, i.e. sarcoplasmic reticulum

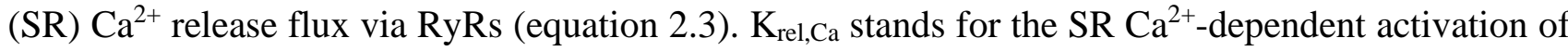
$J_{\text {rel }}$. As the activation constant of a Hill equation, higher values of $\mathrm{K}_{\mathrm{rel}, \mathrm{Ca}}$ lead to a smaller $\mathrm{Ca}^{+2}$ release through RyR. The value of $\mathrm{K}_{\mathrm{rel}, \mathrm{Ca}}$ is reduced in $\mathrm{HF}$, increasing $\mathrm{SR} \mathrm{Ca}^{2+}$ release [59].

$$
J_{r e l, \infty}=\frac{\alpha_{r e l} \cdot\left(-I_{C a L}\right)}{1+\left(\frac{K_{r e l, C a}}{\left[\mathrm{Ca}^{2+}\right]_{j s r}}\right)^{8}}
$$

$\mathrm{Ca}^{2+}$ leakage refers to a flux of $\mathrm{Ca}^{+2}$ leaking from the SR through the SERCA pump, in a reverse passive mode. The driving force only depends on $\left[\mathrm{Ca}^{2+}\right]_{\mathrm{nrs}}$ according to:

$$
J_{\text {leak }}=\frac{0.0039375 \cdot\left[\mathrm{Ca}^{2+}\right]_{n s r}}{15.0}
$$

In O'Hara et al's model [19], the net SERCA pump flux ( $\left.\mathrm{J}_{\mathrm{up}}\right)$ includes the inward active $\mathrm{Ca}^{2+}$ uptake $\left(\mathrm{J}_{\mathrm{SERCA}}\right)$ and the outward passive leak $\left(\mathrm{J}_{\text {leak }}\right)$, as detailed in equation 2.5 .

$$
J_{u p}=\left(1-\emptyset_{u p, C a M K}\right) \cdot J_{u p, N P}+\emptyset_{u p, C a M K} \cdot J_{u p, C a M K}-J_{l e a k}=J_{S E R C A}-J_{l e a k}
$$

In the present study, as we were interested in all $\mathrm{Ca}^{2+}$ transport mechanisms, we considered $\mathrm{J}_{\text {leak }}$ and $\mathrm{J}_{\text {SERCA }}$ independently, to distinguish the passive leak form the active uptake, respectively.

Table 2.2. Individual modulation of heart failure (HF) electrophysiological remodeling. Percentages are indicated with respect to baseline ORdmm model.

\begin{tabular}{l|lccc}
\hline Ionic parameter & No change & $\mathbf{5 0 \%} \mathbf{H F}$ & HF basic & $\mathbf{1 5 0 \%} \mathbf{H F}$ \\
\hline $\mathrm{I}_{\mathrm{NaL}}$ & $100 \%$ & $140 \%$ & $180 \%$ & $220 \%$ \\
\hline$\tau_{\mathrm{hL}}$ & $100 \%$ & $140 \%$ & $180 \%$ & $220 \%$ \\
\hline $\mathrm{I}_{\mathrm{to}}$ & $100 \%$ & $70 \%$ & $40 \%$ & $10 \%$ \\
\hline $\mathrm{I}_{\mathrm{K} 1}$ & $100 \%$ & $84 \%$ & $68 \%$ & $52 \%$ \\
\hline $\mathrm{I}_{\mathrm{NaK}}$ & $100 \%$ & $85 \%$ & $70 \%$ & $55 \%$ \\
\hline $\mathrm{I}_{\mathrm{NCX}}$ & $100 \%$ & $137.5 \%$ & $175 \%$ & $212.5 \%$ \\
\hline $\mathrm{CaMKa}$ & $100 \%$ & $125 \%$ & $150 \%$ & $175 \%$ \\
\hline $\mathrm{J}_{\mathrm{SERCA}}$ & $100 \%$ & $75 \%$ & $50 \%$ & $25 \%$ \\
\hline $\mathrm{J}_{\text {leak }}$ & $100 \%$ & $115 \%$ & $130 \%$ & $145 \%$ \\
\hline $\mathrm{K}_{\mathrm{rel}, \mathrm{Ca}}$ & $100 \%$ & $90 \%$ & $80 \%$ & $70 \%$ \\
\hline
\end{tabular}


As explained in the Methods section, the sensitivity analysis on HF variability was performed by modifying individually every parameter altered in HF to different degrees of decreased or enhanced activity. These modifications are summed up in Table 2.2.

\subsubsection{Steady-state conditions}

All the simulations carried out in the sensitivity analyses led to action potential (AP) and $\mathrm{Ca}^{2+}$ transient $(\mathrm{CaT})$ curves from which the different quantitative indicators were calculated. Figures 2.9 and 2.10 show consecutive traces after $1000 \mathrm{~s}$ of simulation, the achievement of the steady state, and the most important differences after specific ionic modulation.

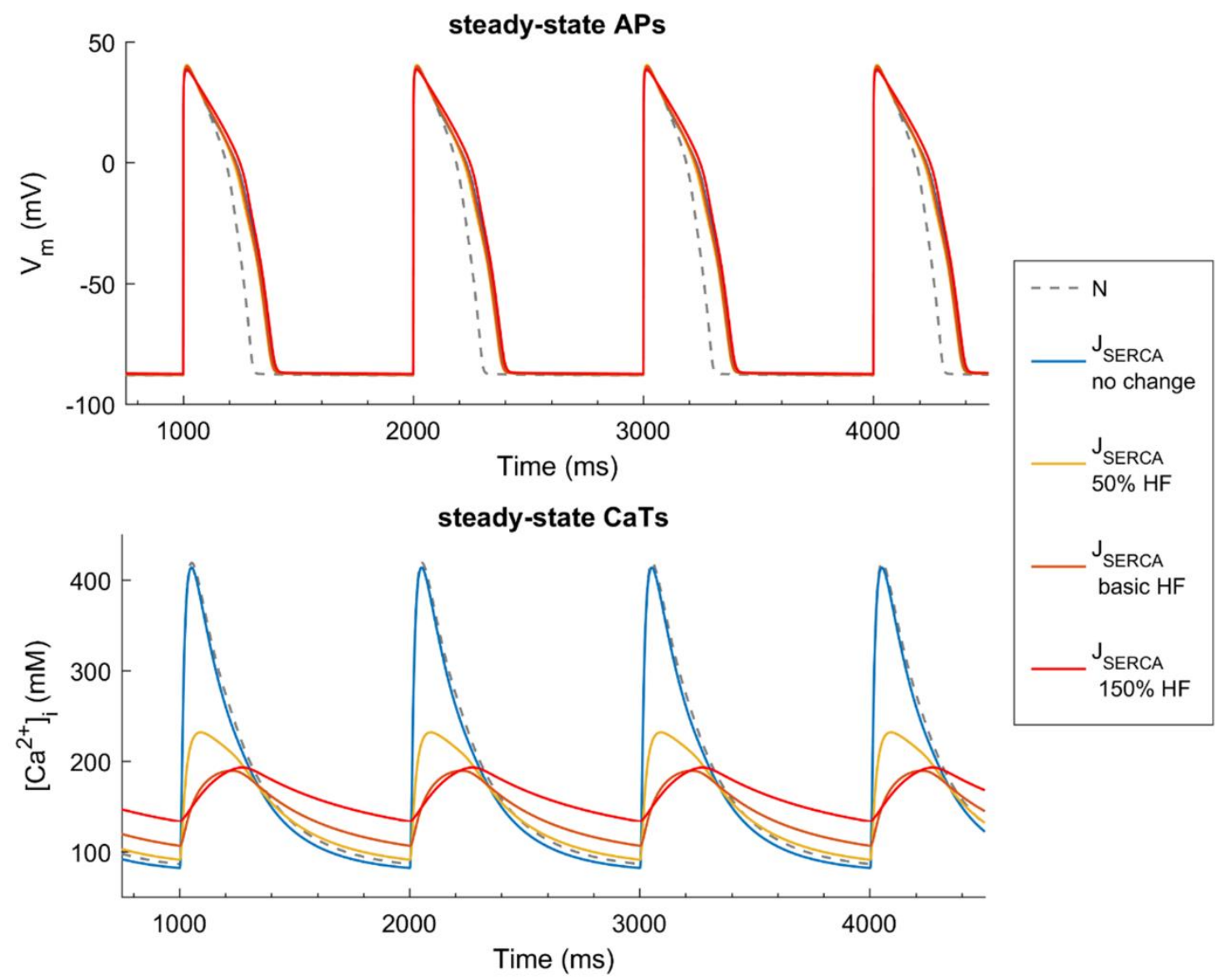

Figure 2.9. Steady - state time course of the last APs and CaTs after $1000 \mathrm{~s}$ of simulation in the heart failure (HF) sensitivity analysis. Modification of $\mathrm{J}_{\mathrm{SERCA}}$ parameter. 


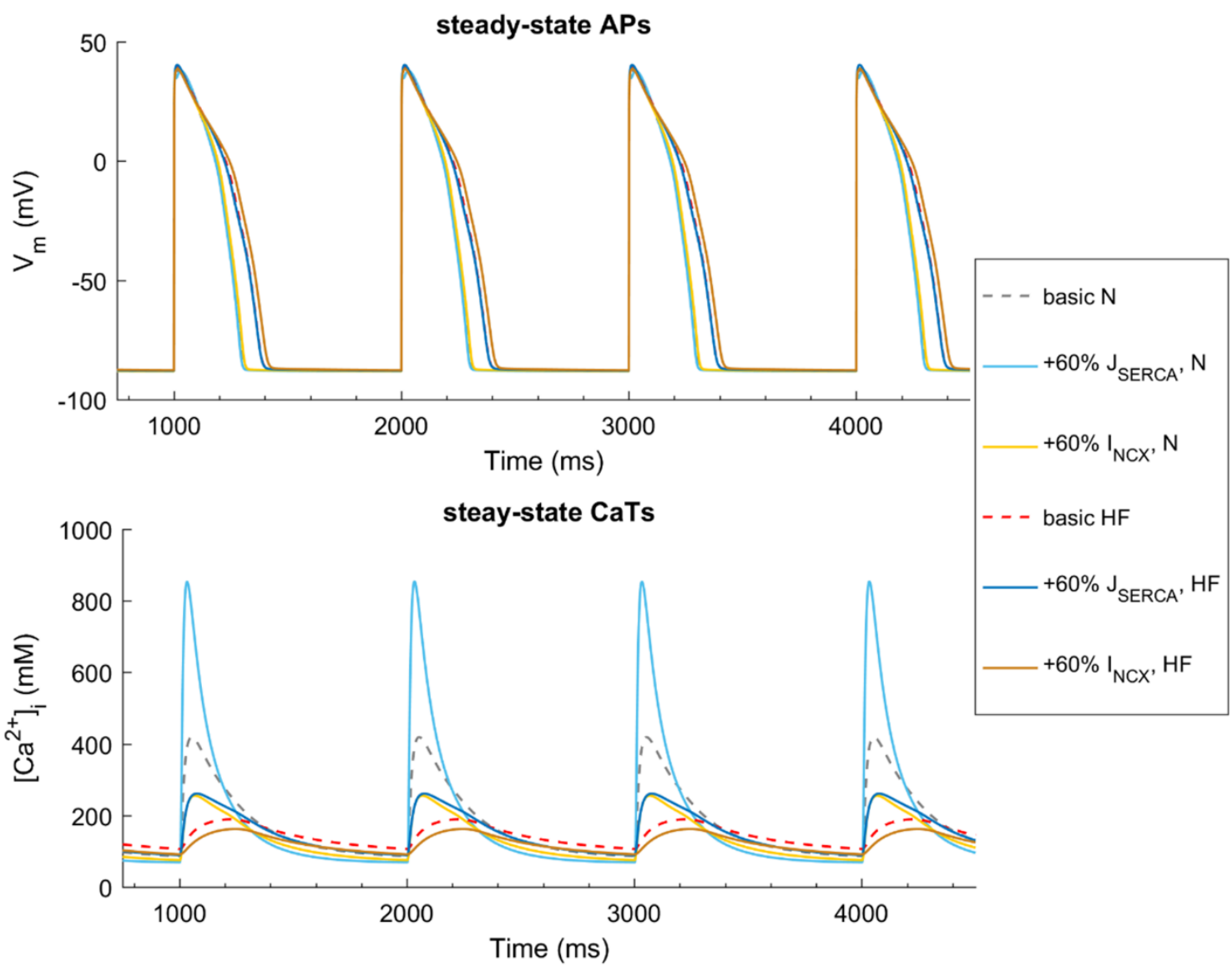

Figure 2.10. Steady - state time course of the last APs and CaTs after $1000 \mathrm{~s}$ of simulation in the sensitivity analysis of 'drug' effects. Modulation of $\mathrm{J}_{\mathrm{SERCA}}$ and $\mathrm{I}_{\mathrm{NCX}}$ parameters in normal $(\mathrm{N})$ and heart failure (HF). 


\section{REFERENCES}

1. Drouin E, Lande G, Charpentier F. Amiodarone reduces transmural heterogeneity of repolarization in the human heart. J Am Coll Cardiol. 1998;32: 1063-1067. doi:10.1016/S0735-1097(98)00330-1

2. Li G-R, Lau C-P, Leung T-K, Nattel S. Ionic current abnormalities associated with prolonged action potentials in cardiomyocytes from diseased human right ventricles. Heart Rhythm. 2004;1: 460-468. doi:10.1016/j.hrthm.2004.06.003

3. Piacentino V, Weber CR, Chen X, Weisser-Thomas J, Margulies KB, Bers DM, et al. Cellular basis of abnormal calcium transients of failing human ventricular myocytes. Circ Res. 2003;92: 651-658. doi:10.1161/01.RES.0000062469.83985.9B

4. Gomez JF, Cardona K, Trenor B. Lessons learned from multi-scale modeling of the failing heart. J Mol Cell Cardiol. 2015;89: 146-159. doi:10.1016/j.yjmcc.2015.10.016

5. Beuckelmann DJ, Näbauer M, Krüger C, Erdmann E. Altered diastolic $[\mathrm{Ca} 2+]$ i handling in human ventricular myocytes from patients with terminal heart failure. Am Heart J. 1995;129: 684-689. doi:10.1016/00028703(95)90316-X

6. Bers DM. Altered cardiac myocyte Ca regulation in heart failure. Physiology. 2006;21: 380-387. doi:10.1152/physiol.00019.2006

7. Lou Q, Fedorov V V., Glukhov A V., Moazami N, Fast VG, Efimov IR. Transmural heterogeneity and remodeling of ventricular excitation- contraction coupling in human heart failure. Circulation. 2011;123: 1881-1890. doi:10.1161/CIRCULATIONAHA.110.989707

8. Alpert NR, Hasenfuss G, Leavitt BJ, Ittleman FP, Pieske B, Mulieri LA. A mechanistic analysis of reduced mechanical performance in human heart failure. Jpn Hear J. 2000;41: 103-115.

9. Hasenfuss G, Meyer M, Schillinger W, Preuss M, Pieske B, Just H. Calcium handling proteins in the failing human heart. Basic Res Cardiol. 1997;92 Suppl 1: 87-93. doi:10.1007/BF00794072

10. Houser SR, Piacentino V, Mattiello J, Weisser J, Gaughan JP. Functional properties of failing human ventricular myocytes. Trends Cardiovasc Med. 2000;10: 101-7. doi:10.1016/S1050-1738(00)00057-8

11. Lou Q, Janardhan A, Efimov IR. Remodeling of calcium handling in human heart failure. Adv Exp Med Biol. 2012;740: 1145-74. doi:10.1007/978-94-007-2888-2_52

12. Zima A V., Bovo E, Mazurek SR, Rochira JA, Li W, Terentyev D. Ca handling during excitation-contraction coupling in heart failure. Pflugers Arch Eur J Physiol. 2014;466: 1129-1137. doi:10.1007/s00424-014-1469-3

13. Gorski PA, Ceholski DK, Hajjar RJ. Altered myocardial calcium cycling and energetics in heart failure - A rational approach for disease treatment. Cell Metab. 2015;21: 183-194. doi:10.1016/j.cmet.2015.01.005

14. Acsai K, Ördög B, Varró A, Nánási PP. Role of the dysfunctional ryanodine receptor - Na+-Ca2+exchanger axis in progression of cardiovascular diseases: What we can learn from pharmacological studies? Eur J Pharmacol. 2016;779: 91-101. doi:10.1016/j.ejphar.2016.03.016

15. Roe AT, Frisk M, Louch WE. Targeting cardiomyocyte Ca2+ homeostasis in heart failure. Curr Pharm Des. 2015;21: 431-48. doi:10.2174/138161282104141204124129

16. Romero L, Pueyo E, Fink M, Rodríguez B. Impact of ionic current variability on human ventricular cellular electrophysiology. Am J Physiol Heart Circ Physiol. 2009;297: H1436-H1445. doi:10.1152/ajpheart.00263.2009

17. Trenor B, Cardona K, Gomez JF, Rajamani S, Ferrero JM, Belardinelli L, et al. Simulation and mechanistic investigation of the arrhythmogenic role of the late sodium current in human heart failure. PLoS One. 2012;7: e32659. doi:10.1371/journal.pone.0032659

18. Cai L, Wang Y, Gao H, Li Y, Luo X. A mathematical model for active contraction in healthy and failing myocytes and left ventricles. PLoS One. 2017;12: e0174834. doi:10.1371/journal.pone.0174834

19. O'Hara T, Virág L, Varró A, Rudy Y. Simulation of the undiseased human cardiac ventricular action potential: model formulation and experimental validation. PLoS Comput Biol. 2011;7: e1002061. doi:10.1371/journal.pcbi.1002061

20. Passini E, Mincholé A, Coppini R, Cerbai E, Rodriguez B, Severi S, et al. Mechanisms of pro-arrhythmic abnormalities in ventricular repolarisation and anti-arrhythmic therapies in human hypertrophic cardiomyopathy. $\mathrm{J}$ Mol Cell Cardiol. 2016;96: 72-81. doi:10.1016/j.yjmcc.2015.09.003

21. ten Tusscher KHWJ, Noble D, Noble PJ, Panfilov A V. A model for human ventricular tissue. Am J Physiol Heart Circ Physiol. 2004;286: H1573-89. doi:10.1152/ajpheart.00794.2003

22. Maltsev VA, Undrovinas AI. A multi-modal composition of the late $\mathrm{Na}+$ current in human ventricular 
cardiomyocytes. Cardiovasc Res. 2006;69: 116-127. doi:10.1016/j.cardiores.2005.08.015

23. Gomez JF, Cardona K, Romero L, Ferrero JM, Trenor B. Electrophysiological and structural remodeling in heart failure modulate arrhythmogenesis. 1D simulation study. PLoS One. 2014;9: e106602. doi:10.1371/journal.pone.0106602

24. Schmidt U, Hajjar RJ, Helm PA, Kim CS, Doye AA, Gwathmey JK. Contribution of Abnormal Sarcoplasmic Reticulum ATPase Activity to Systolic and Diastolic Dysfunction in Human Heart Failure. J Mol Cell Cardiol. 1998;30: 1929-1937. doi:10.1006/jmcc.1998.0748

25. Lindner M, Erdmann E, Beuckelmann DJ. Calcium Content of the Sarcoplasmic Reticulum in Isolated Ventricular Myocytes from Patients with Terminal Heart Failure. J Mol Cell Cardiol. 1998;30: 743-749. doi:10.1006/jmcc.1997.0626

26. Kubo H, Margulies KB, Piacentino V, Gaughan JP, Houser SR. Patients With End-Stage Congestive Heart Failure Treated With B-Adrenergic Receptor Antagonists Have Improved Ventricular Myocyte Calcium Regulatory Protein Abundance. Circulation. 2001;104: 1012-1018. doi:10.1161/hc3401.095073

27. Njeim MT, Hajjar RJ. Gene therapy for heart failure. Arch Cardiovasc Dis. 2010;103: 477-85. doi:10.1016/j.acvd.2010.04.004

28. Kho C, Lee A, Hajjar RJ. Altered sarcoplasmic reticulum calcium cycling--targets for heart failure therapy. Nat Rev Cardiol. 2012;9: 717-33. doi:10.1038/nrcardio.2012.145

29. Bode EF, Briston SJ, Overend CL, O’Neill SC, Trafford AW, Eisner DA. Changes of SERCA activity have only modest effects on sarcoplasmic reticulum Ca2+ content in rat ventricular myocytes. J Physiol. 2011;589: 4723-9. doi:10.1113/jphysiol.2011.211052

30. Sankaranarayanan R, Li Y, Greensmith DJ, Eisner DA, Venetucci L. Biphasic decay of the Ca transient results from increased sarcoplasmic reticulum Ca leak. J Physiol. 2016;594: 611-623. doi:10.1113/JP271473

31. Miller L, Greensmith DJ, Sankaranarayanan R, O’Neill SC, Eisner DA. The effect of 2,5-di-(tert-butyl)-1,4benzohydroquinone (TBQ) on intracellular $\mathrm{Ca} 2+$ handling in rat ventricular myocytes. Cell Calcium. 2015;58: 208214. doi:10.1016/j.ceca.2015.05.002

32. Teucher N, Prestle J, Seidler T, Currie S, Elliott EB, Reynolds DF, et al. Excessive sarcoplasmic/endoplasmic reticulum $\mathrm{Ca} 2+-\mathrm{ATPase}$ expression causes increased sarcoplasmic reticulum $\mathrm{Ca} 2+$ uptake but decreases myocyte shortening. Circulation. 2004;110: 3553-3559. doi:10.1161/01.CIR.0000145161.48545.B3

33. Morimoto S, Hongo K, Kusakari Y, Komukai K, Kawai M, O-Uchi J, et al. Genetic modulation of the SERCA activity does not affect the $\mathrm{Ca} 2+$ leak from the cardiac sarcoplasmic reticulum. Cell Calcium. 2014;55: 17-23. doi:10.1016/j.ceca.2013.10.005

34. Lyon AR, Bannister ML, Collins T, Pearce E, Sepehripour AH, Dubb SS, et al. SERCA2a gene transfer decreases sarcoplasmic reticulum calcium leak and reduces ventricular arrhythmias in a model of chronic heart failure. Circ Arrhythmia Electrophysiol. 2011;4: 362-372. doi:10.1161/CIRCEP.110.961615

35. del Monte F, Harding SE, Schmidt U, Matsui T, Kang ZB, Dec GW, et al. Restoration of contractile function in isolated cardiomyocytes from failing human hearts by gene transfer of SERCA2a. Circulation. 1999;100: $2308-11$. doi:10.1161/01.CIR.100.23.2308

36. Rocchetti M, Alemanni M, Mostacciuolo G, Barassi P, Altomare C, Chisci R, et al. Modulation of sarcoplasmic reticulum function by PST2744 [istaroxime; (E,Z)-3-((2-aminoethoxy)imino) androstane-6,17-dione hydrochloride)] in a pressure-overload heart failure model. J Pharmacol Exp Ther. 2008;326: 957-965. doi:10.1124/jpet.108.138701

37. Szentandrássy N, Birinyi P, Szigeti G, Farkas A, Magyar J, Tóth A, et al. SEA0400 fails to alter the magnitude of intracellular $\mathrm{Ca} 2+$ transients and contractions in Langendorff-perfused guinea pig heart. Naunyn Schmiedebergs Arch Pharmacol. 2008;378: 65-71. doi:10.1007/s00210-008-0296-5

38. Nagy ZA, Virág L, Tóth A, Biliczki P, Acsai K, Bányász T, et al. Selective inhibition of sodium-calcium exchanger by SEA-0400 decreases early and delayed after depolarization in canine heart. Br J Pharmacol. 2004;143: 827-31. doi:10.1038/sj.bjp.0706026

39. Birinyi P, Tóth A, Jóna I, Acsai K, Almássy J, Nagy N, et al. The Na+/Ca2+ exchange blocker SEA0400 fails to enhance cytosolic $\mathrm{Ca} 2+$ transient and contractility in canine ventricular cardiomyocytes. Cardiovasc Res. 2008;78: 476-484. doi:10.1093/cvr/cvn031

40. Ozdemir S, Bito V, Holemans P, Vinet L, Mercadier JJ, Varro A, et al. Pharmacological inhibition of Na/Ca exchange results in increased cellular Ca2+ load attributable to the predominance of forward mode block. Circ Res. 2008;102: 1398-1405. doi:10.1161/CIRCRESAHA.108.173922 
41. Terracciano CMN, Philipson KD, MacLeod KT. Overexpression of the Na+/Ca2+ exchanger and inhibition of the sarcoplasmic reticulum Ca2+-ATPase in ventricular myocytes from transgenic mice. Cardiovasc Res. 2001;49: 3847. doi:10.1016/S0008-6363(00)00205-4

42. Wang J, Chan TO, Zhang X-Q, Gao E, Song J, Koch WJ, et al. Induced overexpression of Na+/Ca2+ exchanger transgene: altered myocyte contractility, $[\mathrm{Ca} 2+] \mathrm{i}$ transients, SR Ca2+ contents, and action potential duration. Am J Physiol Hear Circ Physiol. 2009;297: H590-H601. doi:10.1152/ajpheart.00190.2009

43. Gandhi A, Siedlecka U, Shah AP, Navaratnarajah M, Yacoub MH, Terracciano CM. The effect of SN-6, a novel sodium-calcium exchange inhibitor, on contractility and calcium handling in isolated failing rat ventricular myocytes. Cardiovasc Ther. 2013;31: 115-124. doi:10.1111/1755-5922.12045

44. Shannon TR, Ginsburg KS, Bers DM. Quantitative assessment of the SR Ca 2+ leak-load relationship. Circ Res. 2002;91: 594-600. doi:10.1161/01.RES.0000036914.12686.28

45. Greensmith DJ, Galli GLJ, Trafford AW, Eisner DA. Direct measurements of SR free Ca reveal the mechanism underlying the transient effects of RyR potentiation under physiological conditions. Cardiovasc Res. 2014;103: 554563. doi:10.1093/cvr/cvu158

46. Sobie EA. Parameter sensitivity analysis in electrophysiological models using multivariable regression. Biophys J. 2009;96: 1264-1274. doi:10.1016/j.bpj.2008.10.056

47. Walmsley J, Rodriguez JF, Mirams GR, Burrage K, Efimov IR, Rodriguez B. mRNA expression levels in failing human hearts predict cellular electrophysiological remodeling: A population-based simulation study. PLoS One. 2013;8: e56359. doi:10.1371/journal.pone.0056359

48. Jost N, Virág L, Comtois P, Ordög B, Szuts V, Seprényi G, et al. Ionic mechanisms limiting cardiac repolarization reserve in humans compared to dogs. J Physiol. 2013;591: 4189-206. doi:10.1113/jphysiol.2013.261198

49. Valdivia CR, Chu WW, Pu J, Foell JD, Haworth RA, Wolff MR, et al. Increased late sodium current in myocytes from a canine heart failure model and from failing human heart. J Mol Cell Cardiol. 2005;38: 475-483. doi:10.1016/j.yjmcc.2004.12.012

50. Undrovinas AI, Belardinelli L, Undrovinas NA, Sabbah HN. Ranolazine improves abnormal repolarization and contraction in left ventricular myocytes of dogs with heart failure by inhibiting late sodium current. J Cardiovasc Electrophysiol. 2006;17: S169-S177. doi:10.1038/jid.2014.371

51. Levi AJ, Dalton GR, Hancox JC, Mitcheson JS, Issberner J, Bates JA, et al. Role of intracellular sodium overload in the genesis of cardiac arrhythmias. J Cardiovasc Electrophysiol. 1997;8: 700-721.

52. Pieske B, Maier LS, Piacentino V, Weisser J, Hasenfuss G, Houser S. Rate dependence of [Na+]i and contractility in nonfailing and failing human myocardium. Circulation. 2002;106: 447-453. doi:10.1161/01.CIR.0000023042.50192.F4

53. Bueno-orovio A, Sánchez C, Pueyo E. Na/K pump regulation of cardiac repolarization: insights from a systems biology approach. Pflugers Arch Eur J Physiol. 2014;466: 183-193. doi:10.1007/s00424-013-1293-1

54. Shannon TR, Wang F, Puglisi J, Weber C, Bers DM. A Mathematical Treatment of Integrated Ca Dynamics within the Ventricular Myocyte. Biophys J. 2004;87: 3351-3371. doi:10.1529/biophysj.104.047449

55. Grandi E, Pasqualini FS, Bers DM. A novel computational model of the human ventricular action potential and Ca transient. J Mol Cell Cardiol. 2010;48: 112-121. doi:10.1016/j.yjmcc.2009.09.019

56. Priebe L, Beuckelmann DJ. Simulation study of cellular electric properties in heart failure. Circ Res. 1998;82: 12061223. doi:10.1161/01.RES.82.11.1206

57. Yu Zhang, Guofa Shou, Ling Xia. Simulation Study of Transmural Cellular Electrical Properties in Failed Human Heart. Conf Proc IEEE Eng Med Biol. 2005. pp. 337-340. doi:10.1109/IEMBS.2005.1616413

58. Elshrif MM, Shi P, Cherry EM. Representing Variability and Transmural Differences in a Model of Human Heart Failure. IEEE J Biomed Heal Informatics. 2015;19: 1308-1320. doi:10.1109/JBHI.2015.2442833

59. George $\mathrm{CH}$. Sarcoplasmic reticulum $\mathrm{Ca} 2+$ leak in heart failure: Mere observation or functional relevance? Cardiovasc Res. 2008;77: 302-314. doi:10.1093/cvr/cvm006 


\title{
Chapter 3
}

\section{$\mathrm{Ca}^{2+}$ cycling impairment in heart failure is exacerbated by fibrosis: Insights gained from mechanistic simulations}

\author{
Maria T Mora $^{\mathrm{a}}$, Jose M Ferrero ${ }^{\mathrm{a}}$, Juan F Gomez ${ }^{\mathrm{a}}$, Eric A Sobie ${ }^{\mathrm{b}}$, Beatriz Trenor ${ }^{\mathrm{a}}$
}

\begin{abstract}
Heart failure $(\mathrm{HF})$ is characterized by altered $\mathrm{Ca}^{2+}$ cycling, resulting in cardiac contractile dysfunction. Failing myocytes undergo electrophysiological remodeling, which is known to be the main cause of abnormal $\mathrm{Ca}^{2+}$ homeostasis. However, structural remodeling, specifically proliferating fibroblasts coupled to myocytes in the failing heart, could also contribute to $\mathrm{Ca}^{2+}$ cycling impairment.

The goal of the present study was to systematically analyze the mechanisms by which myocytefibroblast coupling could affect $\mathrm{Ca}^{2+}$ dynamics in normal conditions and in HF. Simulations of healthy and failing human myocytes were performed using established mathematical models, and cells were either isolated or coupled to fibroblasts. Univariate and multivariate sensitivity analyses were performed to quantify effects of ion transport pathways on biomarkers computed from intracellular $\left[\mathrm{Ca}^{2+}\right]$ waveforms. Variability in ion channels and pumps was imposed and populations of models were analyzed to determine effects on $\mathrm{Ca}^{2+}$ dynamics.

Our results suggest that both univariate and multivariate sensitivity analyses are valuable methodologies to shed light into the ionic mechanisms underlying $\mathrm{Ca}^{2+}$ impairment in $\mathrm{HF}$, although differences between the two methodologies are observed at high parameter variability. These can result from either the fact that multivariate analyses take into account ion channels or non-linear effects of ion transport pathways on $\mathrm{Ca}^{2+}$ dynamics. Coupling either healthy or failing myocytes to fibroblasts decreased $\mathrm{Ca}^{2+}$ transients due to an indirect sink effect on action potential and thus on $\mathrm{Ca}^{2+}$ related currents. Simulations that investigated restoration of normal physiology in failing myocytes showed that $\mathrm{Ca}^{2+}$ cycling can be normalized by increasing SERCA and L-type Ca ${ }^{2+}$ current activity while decreasing $\mathrm{Na}^{+}-\mathrm{Ca}^{2+}$ exchange and $\mathrm{SR} \mathrm{Ca}^{2+}$ leak. Changes required to normalize action potentials in failing myocytes depended on whether myocytes were coupled to fibroblasts.

In conclusion, univariate and multivariate sensitivity analyses are helpful tools to understand how $\mathrm{Ca}^{2+}$ cycling is impaired in heart failure and how this can be exacerbated by coupling of myocytes
\end{abstract}

\footnotetext{
Mora MT, Ferrero JM, Gomez JF, Sobie EA, Trenor B. Ca ${ }^{2+}$ cycling impairment in heart failure is exacerbated by fibrosis: insights gained from mechanistic simulations. Front Physiol. 2018;9: 1-15. doi:10.3389/fphys.2018.01194

${ }^{a}$ Centro de Investigación e Innovación en Bioingeniería (Ci2B), Universitat Politècnica de València, Valencia, Spain ${ }^{b}$ Department of Pharmacological Sciences, Icahn School of Medicine at Mount Sinai, New York, NY, USA
} 
to fibroblasts. The design of pharmacological actions to restore normal activity should take into account the degree of fibrosis in the failing heart.

\subsection{Introduction}

Heart failure (HF) is a major public health problem worldwide [1] and the development of appropriate therapies to manage HF requires an in-depth knowledge of this syndrome. HF is classified as $\mathrm{HF}$ with reduced ejection fraction (HFrEF) or HF with preserved ejection fraction (HFpEF) according to left ventricular systolic function and the type of remodeling [2]. In HFrEF, the heart is unable to pump blood efficiently due to a reduction in cardiac contractility after diverse cardiovascular diseases. The complexity of the excitation-contraction sequence and the multiscale problem can be approached through mathematical models, which significantly help to gain insight into the underlying mechanisms of cardiac dysfunction and guide future research lines [3,4].

Contractile dysfunction in $\mathrm{HF}$ has been associated with an altered $\mathrm{Ca}^{2+}$ handling in myocytes, since $\mathrm{Ca}^{2+}$ homeostasis is crucial for cell contraction and relaxation [5,6]. Failing myocytes present a diminished intracellular $\mathrm{Ca}^{2+}$ transient $(\mathrm{CaT})$ with a slow rise time and a reduced rate of $\left[\mathrm{Ca}^{2+}\right]_{\mathrm{i}}$ removal that prolong $\mathrm{CaT}$ duration and elevate the diastolic intracellular $\mathrm{Ca}^{2+}$ level [7,8]. Prolonged action potential duration (APD) and $\left[\mathrm{Na}^{+}\right]_{i}$ increase are other of the hallmark electrophysiological abnormalities in HF and all of them result from ion channel remodeling in myocytes, i.e. changes in the expression and function of proteins involved in the electrical activity of cells [9].

A tissue-level hallmark of heart failure is increased fibrosis and proliferation of cardiac fibroblasts. Several in vitro studies and mathematical modeling studies have documented that electrical coupling between myocytes and fibroblasts will lead to changes in APD and intracellular $\mathrm{Ca}^{2+}[10,11]$. Experimental evidence suggesting the formation of gap junctions between myocytes and fibroblasts in vitro [12] has focused researchers attention on the altered electrophysiological properties of myocytes due to this intercellular coupling to explain conduction abnormalities and reentries [13-15]. We have already addressed, in a previous work, the consequences on electrical propagation in cardiac tissue under conditions of HF and fibrosis confirming the vulnerability to reentrant activity $[9,16]$. While electrical changes, with a cellular origin in action potential (AP) properties, have been widely investigated in the heterocellular coupling [17,18], changes in $\mathrm{Ca}^{2+}$ dynamics have not been explored in depth. It is important, therefore, to understand the role of fibroblasts in the modulation of $\mathrm{Ca}^{2+}$ cycling and to progress in the management of HFrEF, improving mechanical contraction.

Therefore, the goal of the present study was to investigate with computational models the effects

of fibroblasts on ion transport mechanisms that regulate $\mathrm{Ca}^{2+}$ handling in human failing cardiomyocytes. To understand the complex processes taking place in these cells, we made use of sensitivity analyses. Sensitivity calculation has been commonly used for its predictive value in determining electrophysiological properties with parameter variability [19-23]. As univariate and multivariate sensitivity analyses are widely used [24,25], a comparison of both approaches was an initial objective of this work. Inter-subject variability in electrophysiological properties was considered and reproduced by populations of models. Failing populations, with drug-induced alterations in addition to the natural variability, were useful to identify specific combinations of model parameters that could counteract the effects of HF remodeling and fibroblasts. Our results identify the main targets 
to improve $\mathrm{Ca}^{2+}$ dynamics under the pathological conditions explored, improving cardiac contraction recovery.

\subsection{Material and Methods}

\subsubsection{Cellular Models}

All simulations were performed at the cellular level. To study the electrophysiological behavior of cardiac myocytes, we used the most complete undiseased human ventricular action potential model, developed by O'Hara et al. [3] (ORd model), which comprises 15 sarcolemmal currents, as shown in equation (1), known as fast $\mathrm{Na}^{+}$current $\left(\mathrm{I}_{\mathrm{Na}}\right)$, late $\mathrm{Na}^{+}$current $\left(\mathrm{I}_{\mathrm{NaL}}\right)$, transient outward $\mathrm{K}^{+}$current $\left(\mathrm{I}_{\mathrm{to}}\right)$, L-type $\mathrm{Ca}^{2+}$ current $\left(\mathrm{I}_{\mathrm{CaL}}\right), \mathrm{Na}^{+}$current through the L-type channel $\left(\mathrm{I}_{\mathrm{CaNa}}\right), \mathrm{K}^{+}$current through the Ltype channel $\left(\mathrm{I}_{\mathrm{CaK}}\right)$, rapid delayed rectifier $\mathrm{K}^{+}$current $\left(\mathrm{I}_{\mathrm{Kr}}\right)$, slow delayed rectifier $\mathrm{K}^{+}$current $\left(\mathrm{I}_{\mathrm{Ks}}\right)$, inward rectifier $\mathrm{K}^{+}$current $\left(\mathrm{I}_{\mathrm{K} 1}\right), \mathrm{Na}^{+} / \mathrm{Ca}^{2+}$ exchange current $\left(\mathrm{I}_{\mathrm{NCX}}\right), \mathrm{Na}^{+} / \mathrm{K}^{+}$ATPase current $\left(\mathrm{I}_{\mathrm{NaK}}\right)$, background currents $\left(\mathrm{I}_{\mathrm{Nab}}, \mathrm{I}_{\mathrm{Cab}}, \mathrm{I}_{\mathrm{Kb}}\right)$, and sarcolemmal $\mathrm{Ca}^{2+}$ pump current $\left(\mathrm{I}_{\mathrm{pCa}}\right)$. A detailed $\mathrm{Ca}^{2+}$ dynamics is also formulated in the model. Properties such as conductances determining ionic densities and membrane kinetics can be found in the original work [3]. We introduced slight modifications in sodium current formulation, as reported in our previous work [26] and leading to ORdmm model, which can also be found in Table 3.3. To reproduce HFrEF phenotype, specific parameters of the model were modified to represent the downregulation or upregulation of cellular proteins experimentally observed in failing cells. This electrophysiological remodeling involved different ion currents and $\mathrm{Ca}^{2+}$ fluxes and has already been described in previous studies of our group $[9,26]$. Specifically, the time constant of inactivation of $\mathrm{I}_{\mathrm{NaL}}\left(\tau_{\mathrm{hL}}\right), \mathrm{I}_{\mathrm{NaL}}$ conductance, the maximal flux of $\mathrm{I}_{\mathrm{NCX}}$ and SR $\mathrm{Ca}^{2+}$ leak $\left(\mathrm{J}_{\text {leak }}\right)$, and the fraction of active binding sites of the $\mathrm{Ca}^{+2}$ calmodulin-dependent protein kinase II (CaMKa) were upregulated, while conductances of $\mathrm{I}_{\mathrm{to}}$ and $\mathrm{I}_{\mathrm{K} 1}$, the maximal flux of $\mathrm{I}_{\mathrm{NaK}}$, and $\mathrm{Ca}^{2+}$ uptake via SERCA pump $\left(\mathrm{J}_{\mathrm{SERCA}}\right)$, and $\mathrm{SR} \mathrm{Ca}^{2+}$-dependence of the steady-state activation of ryanodine receptor release $\left(\mathrm{K}_{\mathrm{rel}, \mathrm{Ca}}\right)$ were downregulated. Further details about values and experimental references can be found in Table 3.4.

$$
\begin{gathered}
I_{i o n}=I_{N a}+I_{N a L}+I_{t o}+I_{C a L}+I_{C a N a}+I_{C a K}+I_{K r}+I_{K s}+I_{K 1}+I_{N a C a}+I_{N a K}+I_{N a b} \\
+I_{C a b}+I_{K b}+I_{p C a}
\end{gathered}
$$

The increase in fibroblasts density due to aging and/or HF, and their interaction with myocytes were modeled using established cell-cell coupling equations. Fibroblasts were resistively coupled to one myocyte (Equation 3.2), and a current ( $\left.I_{g a p}\right)$ flows from one cell to the other through gap junctions, driven by the potential gradient between the myocyte $\left(V_{M}\right)$ and the fibroblast $\left(V_{F}\right)$ membrane potential and regulated by a junctional conductance $\left(\mathrm{G}_{\mathrm{gap}}\right)$.

$$
I_{\text {gap }}=G_{\text {gap }} \cdot\left(V_{M}-V_{F}\right)
$$

The electrical activity of fibroblasts was formulated using an active fibroblast model [27]. The fibroblast action potential model incorporates four transmembrane currents: a time- and voltagedependent delayed-rectifier $\mathrm{K}^{+}$current $\left(\mathrm{I}_{\mathrm{Kr}}\right)$, an inward-rectifying $\mathrm{K}^{+}$current $\left(\mathrm{I}_{\mathrm{K} 1}\right)$, a Na $\mathrm{Na}^{+}$ATPase 
current $\left(\mathrm{I}_{\mathrm{NaK}}\right)$, and a background $\mathrm{Na}^{+}$current $\left(\mathrm{I}_{\mathrm{b}, \mathrm{Na}}\right)$. The membrane potential is governed by the following ordinary differential equation:

$$
\frac{d V_{F}}{d t}=-\frac{1}{C_{F}}\left(I_{K r}+I_{K 1}+I_{N a K}+I_{b, N a}-I_{g a p}\right)
$$

The electrotonic interaction with the myocyte is included in the term $\mathrm{I}_{\mathrm{gap}}$. Regarding fibroblast properties, the membrane capacitance $\left(\mathrm{C}_{\mathrm{F}}\right)$ was set to $6.3 \mathrm{pF}$ and the resting membrane potential $\left(\mathrm{E}_{\mathrm{F}}\right)$ had a value of $-49.6 \mathrm{mV}$ as in MacCannell et al. [27]. Similarly, the differential equation for the membrane potential of the myocyte, taking into account myocyte-fibroblast coupling, is as follows:

$$
\frac{d V_{M}}{d t}=-\frac{1}{C_{M}}\left(I_{\text {ion }}+I_{\text {stim }}+I_{\text {gap }}\right)
$$

Myocyte dimensions are bigger than fibroblasts, which is considered in membrane capacitance differences $\left(\mathrm{C}_{\mathrm{M}}=153.4 \mathrm{pF}\right.$ vs $\left.\mathrm{C}_{\mathrm{F}}=6.3 \mathrm{pF}\right)$. The value of $\mathrm{G}_{\text {gap }}$ was set to $3 \mathrm{nS}$ for a single fibroblast, considered the nominal value in MacCannell et al. [27] model. This value is within the range of 0.3 $8 \mathrm{nS}$ measured in cultured myocyte-fibroblast pairs [28]. In our simulations, an elevated degree of fibrosis was considered by setting a myocyte-fibroblast ratio of 1:5, obtained by increasing $G_{\text {gap }}$ fivefold $[21,29]$. In the absence of fibrosis, $\mathrm{G}_{\text {gap }}$ is 0 , and the myocyte is not coupled to fibroblasts.

Both types of myocytes, with and without electrophysiological HF remodeling, were coupled to the same number of fibroblasts with identical properties to simulate the effect of fibrosis on a single myocyte under different conditions. Four basic models were then considered: ORdmm model, ORdmm model with HF remodeling, ORdmm model with 5 coupled fibroblasts, and HF ORdmm model coupled to 5 fibroblasts.

\subsubsection{Measurement of Biomarkers}

To evaluate the electrophysiological activity of myocytes, and particularly $\mathrm{Ca}^{2+}$ dynamics, the electrophysiological indicators chosen were action potential duration from maximal upstroke to $90 \%$ of repolarization (APD90), calcium transient (CaT) duration from maximal upstroke to $80 \%$ of recovery $\left(\mathrm{CaTD}_{80}\right)$, CaT rise time from $10 \%$ to $90 \%$ of upstroke $\left(\mathrm{t}_{10-90}\right)$, and systolic and diastolic $\left[\mathrm{Ca}^{2+}\right]_{\mathrm{i}}$ values. All biomarkers were calculated under steady state conditions after application of 1000 stimuli at $1 \mathrm{~Hz}$.

\subsubsection{Population of Models}

The aforementioned models were used as the baseline to generate four populations of 300 different individuals. Inter-subject electrophysiological variability was represented by variating maximal ion current conductances with a scale factor, assuming that there are variations in the number of ion channels in the cell membrane between individuals [30]. The variation in these scale factors is also a way to simulate the effects of drugs on ion channels, as a simplified action of pharmacological compounds inhibiting or enhancing ion currents. We selected and modified 13 key variables of the model, accounting for maximal ionic conductances and fluxes of $\mathrm{I}_{\mathrm{Na}}, \mathrm{I}_{\mathrm{NaL}}, \mathrm{I}_{\mathrm{to}}, \mathrm{I}_{\mathrm{CaL}}, \mathrm{I}_{\mathrm{Kr}}, \mathrm{I}_{\mathrm{Ks}}, \mathrm{I}_{\mathrm{K} 1}, \mathrm{I}_{\mathrm{NaK}}$, $\mathrm{I}_{\mathrm{NCX}}$, the SR $\mathrm{Ca}^{2+}$ uptake via SERCA pump (J $\left.\mathrm{J}_{\mathrm{SERCA}}\right)$, the $\mathrm{SR} \mathrm{Ca}^{2+}$ release flux via RyR $\left(\mathrm{J}_{\text {rel }}\right)$, the $\mathrm{SR}$ $\mathrm{Ca}^{2+}$ leak $\left(\mathrm{J}_{\text {leak }}\right)$, and $\mathrm{I}_{\mathrm{Nab}}$. These parameters were varied with a scaling factor obtained from a $\log$ - 
normal distribution of standard deviation $(\sigma)$ equal to 0.3 . This led to a $95 \%( \pm 2 \sigma)$ of parameters varying between $55 \%$ and $182 \%$ of its control value, representing inter-individual variability and druginduced effects. A standard deviation of 0.1 was also considered in different sets of populations.

In order to analyze how failing APs and CaTs could be restored to normal physiological ranges, larger populations of models were generated. Latin Hypercube Sampling (LHS) of parameters in the range of $\pm 60 \%$ variation was used for this purpose. In this case, only the basic HF model (with and without coupled fibroblasts) was considered. We set limits for $\mathrm{APD}_{90}$ and systolic and diastolic $\left[\mathrm{Ca}^{2+}\right]_{\mathrm{i}}$ values, in which electrical myocyte activity was considered normal. These limits were obtained from the baseline models as $\mathrm{APD}_{90 \text { normal }} \pm\left(\mathrm{APD}_{90 \mathrm{HF}}-\mathrm{APD}_{90 \text { normal }}\right) / 2$ and after being compared to experimental studies [31-33]. Table 3.1 shows the considered ranges.

Table 3.1. Biomarkers ranges for normal electrophysiological activity.

\begin{tabular}{lc|cc|c}
\hline & \multirow{2}{*}{ Basic ORdmm } & \multicolumn{2}{|c|}{ Normal range } & Basic ORdmm HF \\
& & Min & Max & \\
\hline APD90 $(\mathrm{ms})$ & 290.6 & 240 & 341 & 371.8 \\
systolic $\left[\mathrm{Ca}^{2+}\right]_{\mathrm{i}}(\mathrm{nM})$ & 420 & 300 & 1000 & 190 \\
diastolic $\left[\mathrm{Ca}^{2+}\right]_{\mathrm{i}}(\mathrm{nM})$ & 80 & 50 & 200 & 100 \\
\hline
\end{tabular}

\subsubsection{Sensitivity Analysis}

Linear regression was employed to analyze biomarker sensitivities to electrophysiological variables. First, a univariate sensitivity analysis was conducted varying each parameter individually by a scaling factor of equal magnitude from the baseline models. The individual variation was set to $\pm 60 \%$ or $\pm 15 \%$ in different sensitivity analyses. This approach was based on our previous work [26].

Multivariate regression analyses were then performed using the generated populations of models. We related all the conductance scaling factors configurations (x) to each biomarker (y) with regression coefficients (b) that attempted to predict the indicators (Equation 3.5). These coefficients were obtained by applying PLS (partial least squares) method to data as shown in Equation 3.6 and after several transformations, such as log-transformations and z-score calculations [25,34]. The obtained coefficients indicate the relative contribution of parameters variation in biomarker changes and can be considered as sensitivities. This methodology takes into account inter-variable effects that cannot be differentiated in the univariate analyses. Coefficients of determination $\left(\mathrm{R}^{2}\right)$ indicated the predictive power of the simplified linear model, being $\mathrm{R}^{2}=1$ a good fit.

$$
\begin{gathered}
y_{\text {predicted }}=\sum b \cdot x \\
B_{P L S}=\left(X^{T} X\right)^{-1} \times X^{T} \times Y
\end{gathered}
$$

Both types of sensitivity analyses were compared with normalized sensitivities to study the similarities and differences in parameter identification as the most important contributors to each 
electrophysiological characteristic. Normalized sensitivities were calculated as the ratio between each sensitivity and the maximum absolute value obtained for a particular biomarker.

The comparison between isolated and coupled myocytes was performed after adjusting the bar graphs to the standard deviation of the log-transformed biomarkers in $\mathrm{N}$ and HF conditions, to ensure equivalent percentages of change.

\subsection{Results}

\subsubsection{Comparison of univariate and multivariate sensitivity analyses in normal and failing conditions}

Figure 3.1 illustrates two populations of models $(n=300)$ for endocardial human cells paced at 1 $\mathrm{Hz}$, under normal (blue traces) and HF (red traces) conditions, with baseline models for the two respective populations indicated with solid and dashed black lines. The model population calibration process, meant to reproduce natural variability, generates a wide range of physiological AP waveforms and CaTs in both groups. This variability allows us to understand predicted drug effects by considering the HF cells with behavior most similar to normal cells, or vice-versa. The electrophysiological remodeling applied to the basic ORdmm model to generate a baseline HF model reproduced the characteristic HF phenotype of prolonged APD and a slower $\mathrm{Ca}^{2+}$ dynamics with depressed systolic $\left[\mathrm{Ca}^{2+}\right]_{\mathrm{i}}$ and elevated diastolic levels. In the generated normal and failing populations, significant differences between both conditions are observed in APs and CaTs, although some traces overlap. To understand the variability within the populations and predict what alterations might cause HF cells to behave more like normal cells, we performed a sensitivity analysis.
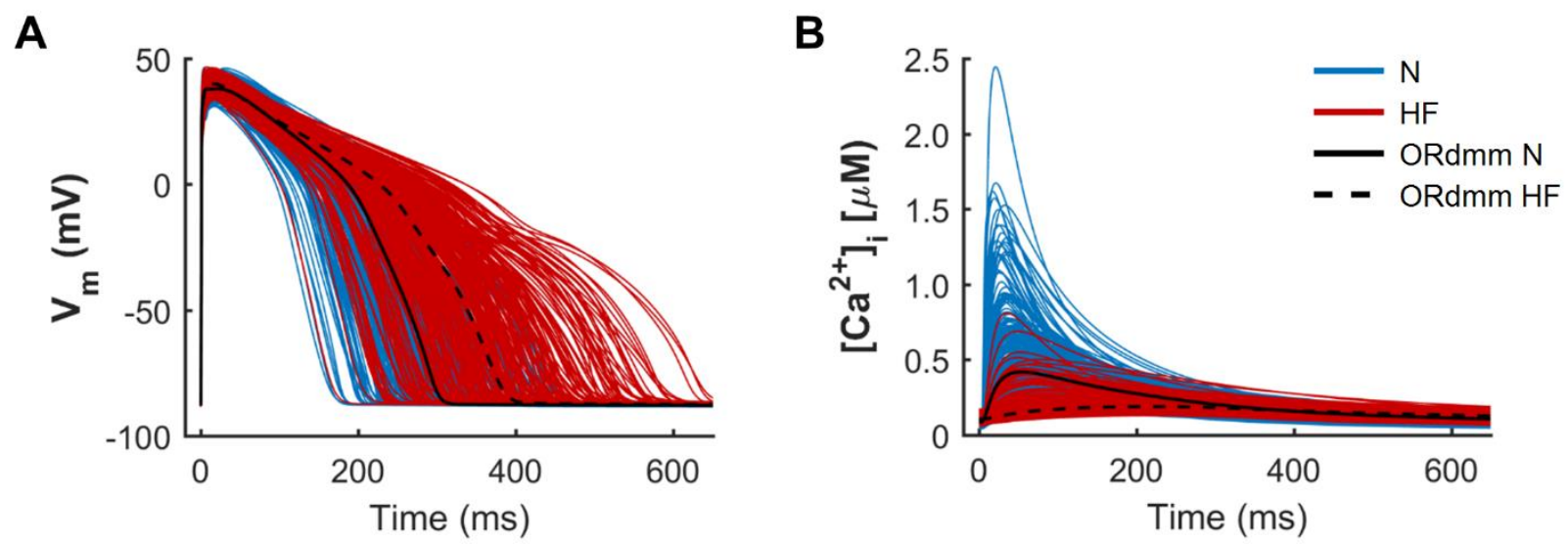

Figure 3.1. Population of normal (N, blue) and heart failure (HF, red) human ventricular cell models. Simulated action potentials (A) and intracellular $\mathrm{Ca}^{2+}$ transients (B) obtained from a multivariate set of ionic conductances ( $\mathrm{n}=300$ ), using the baseline ORdmm model in $\mathrm{N}$ conditions (solid black line) and with HF ionic remodeling (dashed black line).

Figure 3.2 represents the sensitivity of quantitative indicators of AP and CaT characteristics to changes in ion channels obtained in the univariate and multivariate sensitivity analyses. Sensitivities helped reveal the most important modulators of a determined electrophysiological property. High regression coefficients highlighted an important effect of a particular transport mechanism on $\mathrm{Ca}^{2+}$ indicators, taking into account the synergy between variables in the case of multivariate analysis. Our 
results showed that $\mathrm{I}_{\mathrm{Kr}}$ was the parameter with the major impact on APD $_{90}$ (Figure 3.2A), while SERCA had the leading role in $\mathrm{Ca}^{2+}$ biomarkers (Figure 3.2 panels $\mathrm{B}, \mathrm{C}$, and $\mathrm{D}$ ).

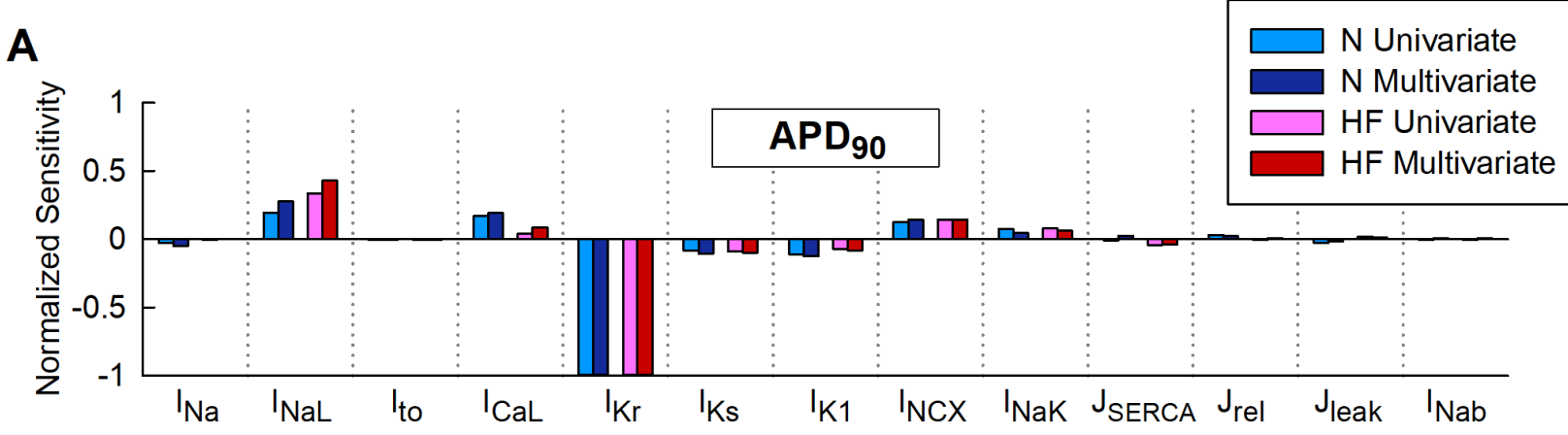

B

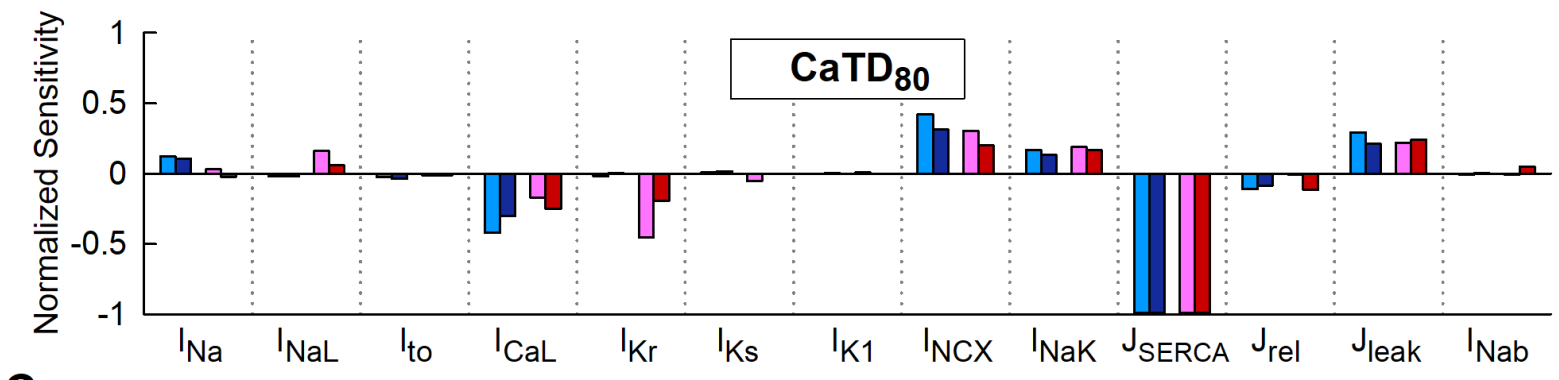

C

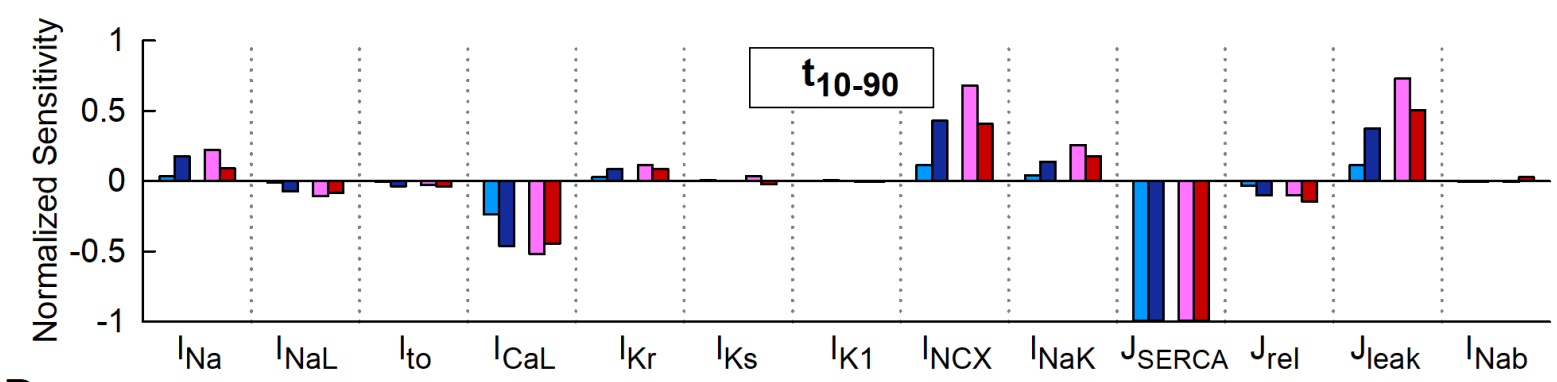

D

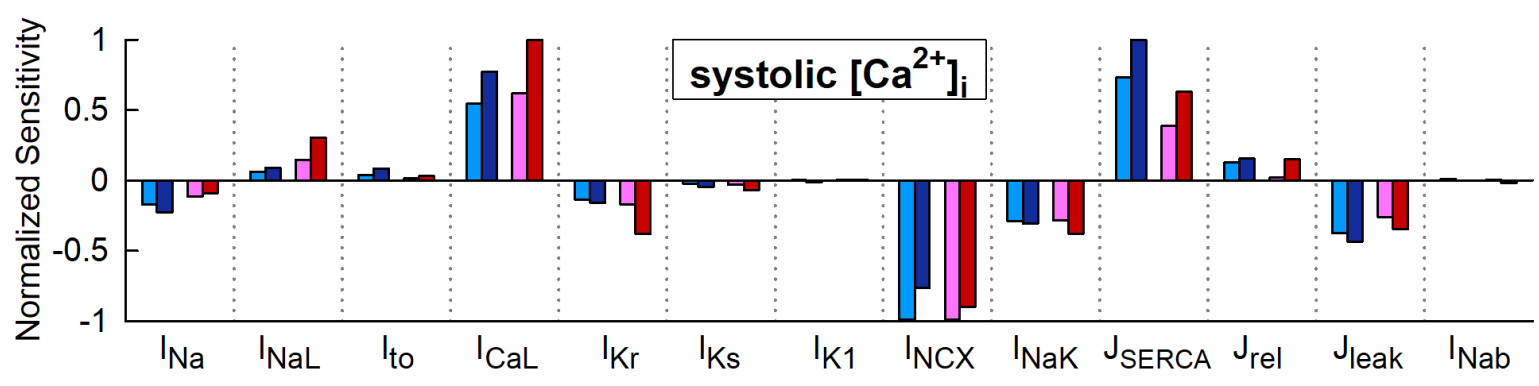

Figure 3.2. Comparison of univariate and multivariate relative sensitivities in normal $(\mathbf{N})$ and heart failure $(\mathrm{HF})$ conditions. Modulators of A) action potential duration to $90 \%$ of repolarization ( $\mathrm{APD}_{90}$ ), B) $\mathrm{Ca}^{2+}$ transient $(\mathrm{CaT})$ duration to $80 \%$ of recovery $\left.\left(\mathrm{CaTD}_{80}\right), \mathrm{C}\right) \mathrm{CaT}$ rise time $\left(\mathrm{t}_{10-90}\right)$ and, D) Systolic peak of CaT. Parameter variability of $60 \%$.

Sensitivities were normalized to allow comparison between the sensitivities obtained through a $\pm 60 \%$ univariate sensitivity analysis (light blue for $\mathrm{N}$ conditions and pink bars for HF conditions) with multivariate sensitivity analysis (dark blue for $\mathrm{N}$ conditions and red bars for HF conditions). In this comparison, results from both methodologies were consistent for APD sensitivities (Figure 3.2A). Small differences were though observed in the case of $\mathrm{Ca}^{2+}$ biomarkers (Figures 3.2B, 3.2C, and 3.2D). For instance, Figure 3.2B shows that in $\mathrm{HF}$, $\mathrm{I}_{\mathrm{Kr}}$ seems to have a moderate impact on $\mathrm{CaTD}_{80}$ according to the univariate results (pink bars), whilst multivariate sensitivity indicates that the effect is lower (red 
bars). In other cases, with the univariate analysis, the relative importance of parameters can be altered between the $\mathrm{N}$ and HF conditions. This was the case for $\mathrm{I}_{\mathrm{CaL}}, \mathrm{I}_{\mathrm{NCX}}$, and $\mathrm{J}_{\text {leak }}$ on $\mathrm{t}_{10-90}$ (Figure 3.2C light blue and pink bars). Figure 3.2D shows how NCX has the main role in modulating systolic $\mathrm{Ca}^{2+}$ according to the univariate sensitivity analysis (light blue in $\mathrm{N}$ and pink bars in HF), while the multivariate sensitivity highlights SERCA and $\mathrm{I}_{\mathrm{CaL}}$ as the main modulators in $\mathrm{N}$ (dark blue bars) and $\mathrm{HF}$ (red bar) conditions, respectively, and the exchanger has a secondary role.

Multivariate and univariate analyses also identified similar changes in parameter sensitivities from $\mathrm{N}$ to HF (Figure 3.2, light and dark blue vs pink and red), such as an increased impact of $\mathrm{I}_{\mathrm{NaL}}$ on $\mathrm{APD}_{90}$ in $\mathrm{HF}$ with respect to normal conditions (Figure 3.2A), a higher $\mathrm{I}_{\mathrm{Kr}}$ influence on CaTD 80 (Figure 3.2B) and a decrease of SERCA modulation effect on systolic $\left[\mathrm{Ca}^{2+}\right]_{i}$ (Figure 3.2D).

We further investigated the aforementioned discrepancies by performing additional sensitivity analyses with a lower conductance variability. Parameter variability was reduced to $15 \%$ in the univariate study and the standard deviation was decreased to 0.1 in the multivariate regression, resulting in sensitivities slightly different from those described above with higher variability (60\% and $\sigma=0.3$, respectively). After reducing parameter variability, negligible differences were found when comparing both methods (see Figures 3.9 and 3.10 in the Supplemental material, light-colored bars). For example, considering low variability in HF (Figure 3.10 panel D, light bars), both analyses (univariate and multivariate) highlighted $\mathrm{I}_{\mathrm{CaL}}$ as the most important parameter regulating systolic $\left[\mathrm{Ca}^{2+}\right]_{i}$, whilst univariate sensitivities obtained with $60 \%$ variability (darker pink bar) highlighted $\mathrm{I}_{\mathrm{NCX}}$ as the main regulator and underestimated the impact of $\mathrm{I}_{\mathrm{CaL}}$.

Coefficients of determination of the multivariable regression are shown in Table 3.2 for the different sensitivity analyses. Values were closer to 1 as variability decreased. CaTD 80 and systolic $\left[\mathrm{Ca}^{2+}\right]_{\mathrm{i}}$ linear fit significantly improved with lower variability, especially in HF ( 0.938 vs 0.677 and 0.970 vs 0.792 , respectively). This indicates that, with large parameter variability, and in the HF condition, significant non-linear relationships between parameter values and $\mathrm{Ca}^{2+}$ handling processes make the multivariable regression model less accurate.

Table 3.2. Coefficients of determination $\left(\mathbf{R}^{2}\right)$ of the multivariable regression analyses in normal (N) and heart failure (HF).

\begin{tabular}{l|cccc}
\hline $\mathbf{R}^{2}$ & APD90 & CaTD $_{\mathbf{8 0}}$ & $\mathbf{t}_{\mathbf{1 0 - 9 0}}$ & {$\left[\mathbf{C a}^{\mathbf{2 +}}\right]_{\mathbf{i}}$ Syst } \\
\hline $\mathrm{N}(\sigma=0.3)$ & 0.987 & 0.940 & 0.908 & 0.954 \\
$\mathrm{~N}(\sigma=0.1)$ & 0.994 & 0.997 & 0.975 & 0.994 \\
$\mathrm{HF}(\sigma=0.3)$ & 0.987 & 0.677 & 0.871 & 0.792 \\
$\mathrm{HF}(\sigma=0.1)$ & 0.999 & 0.938 & 0.910 & 0.970 \\
\hline
\end{tabular}

In summary, univariate and multivariate sensitivity analyses yield very similar results for low variability of parameters, which would correspond to natural inter-subject electrophysiological differences. Univariate analysis is less computational expensive and is thus a valid methodology under these conditions. However, when large variability is applied, which would respond to effects of drugs, significant discrepancies arise between both methodologies. Multivariate analysis should be more reliable, at least for biomarkers with coefficients of determination close to one. Indeed, multivariate analysis considers interaction between the different parameters of the ion channels altered. 


\subsubsection{Effects of fibroblast-myocyte coupling in normal and failing conditions}

When simulations were performed to electrically coupled fibroblasts to a myocyte, the myocyte's AP and CaT were significantly changed. Figure 3.3 shows APD and systolic $\left[\mathrm{Ca}^{2+}\right]_{\mathrm{i}}$ reduction in the normal baseline human endocardial model when fibroblasts were coupled (solid vs discontinuous blue trace), as well as in the failing baseline endocardial model (solid vs discontinuous red trace).
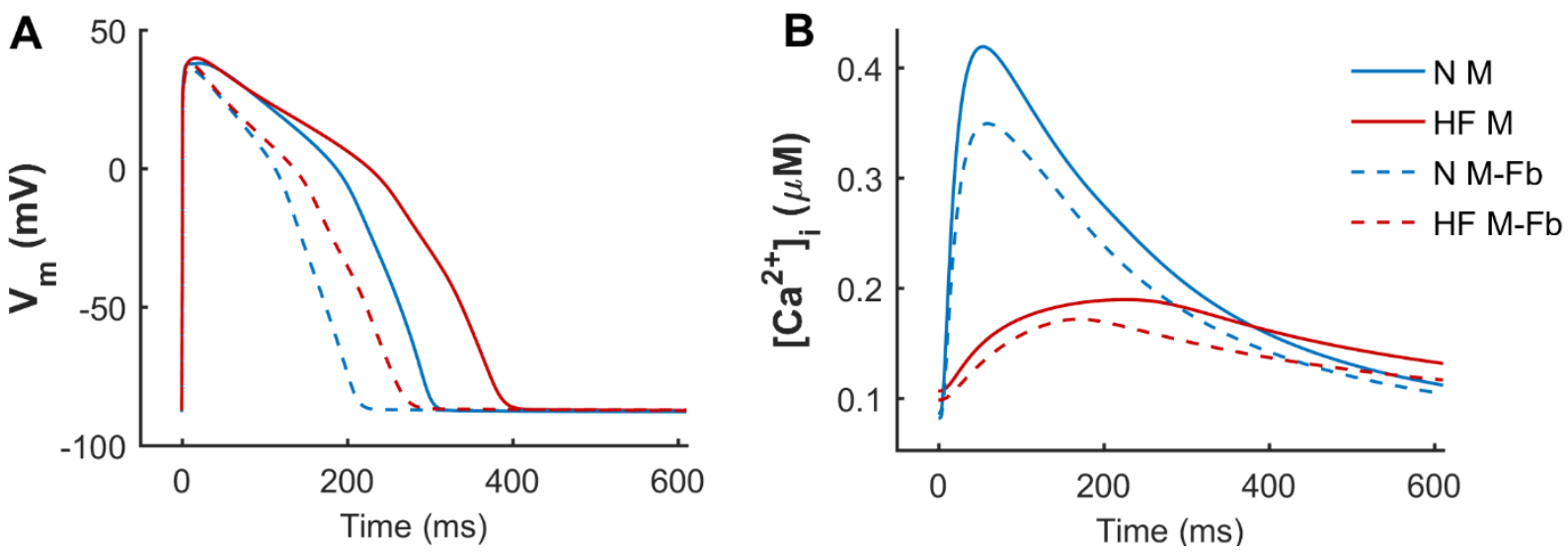

Figure 3.3. Effect of fibrosis on action potential (A) and $\mathbf{C a}^{2+}$ transient (B).Normal (N) and failing (HF) baseline myocyte models in an uncoupled myocyte $(\mathrm{M})$ and a myocyte coupled to 5 fibroblasts $(\mathrm{M}-\mathrm{Fb})$.

A
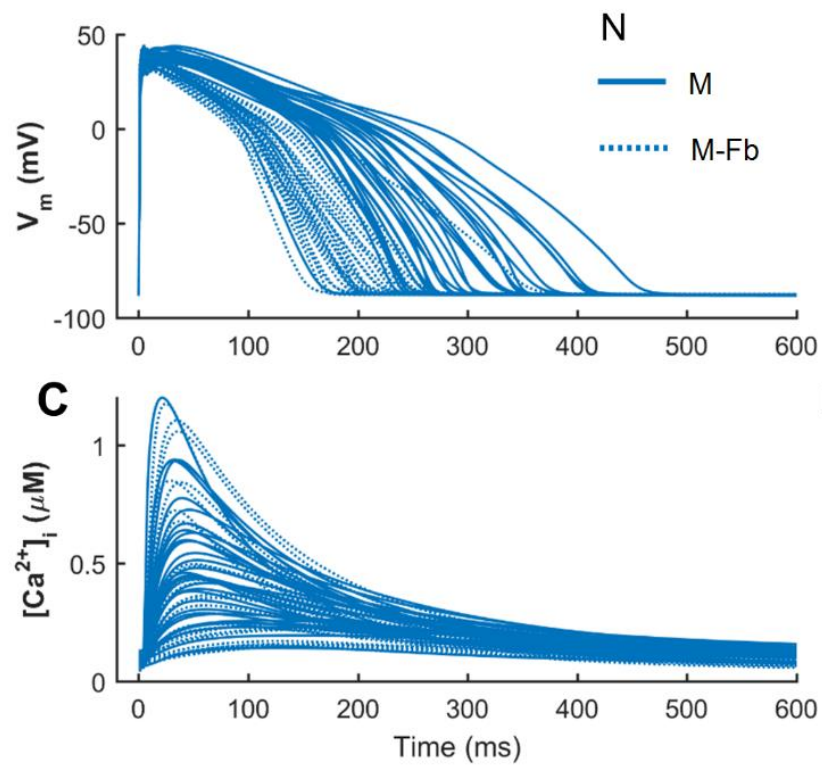

B
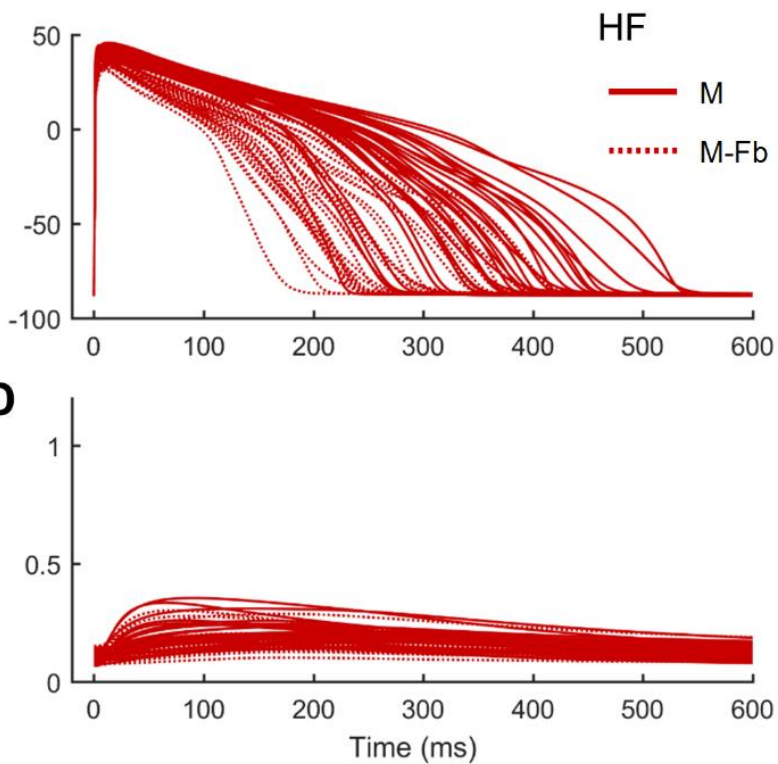

Figure 3.4. Action potential and $\mathbf{C a}^{2+}$ transient samples $(\mathbf{n}=\mathbf{3 0})$. Uncoupled myocytes (solid traces) and myocytes coupled to 5 fibroblasts (discontinuous traces) from 2 population of models, obtained from a multivariate set of ionic conductances ( $\mathrm{n}=300)$, using the basic ORdmm in normal conditions (A and C) and the basic HF remodeling model (B and D).

When fibroblasts were coupled to myocytes from 2 populations of models $(n=300)$ generated for both $\mathrm{N}$ and HF conditions, the above mentioned effects on APD and CaT were maintained, as shown 
in Figure 3.4. CaT traces in normal conditions (panel B, left) with coupled fibroblasts (discontinuous blue traces) overlapped with CaT traces in the absence of fibroblasts (solid blue traces).

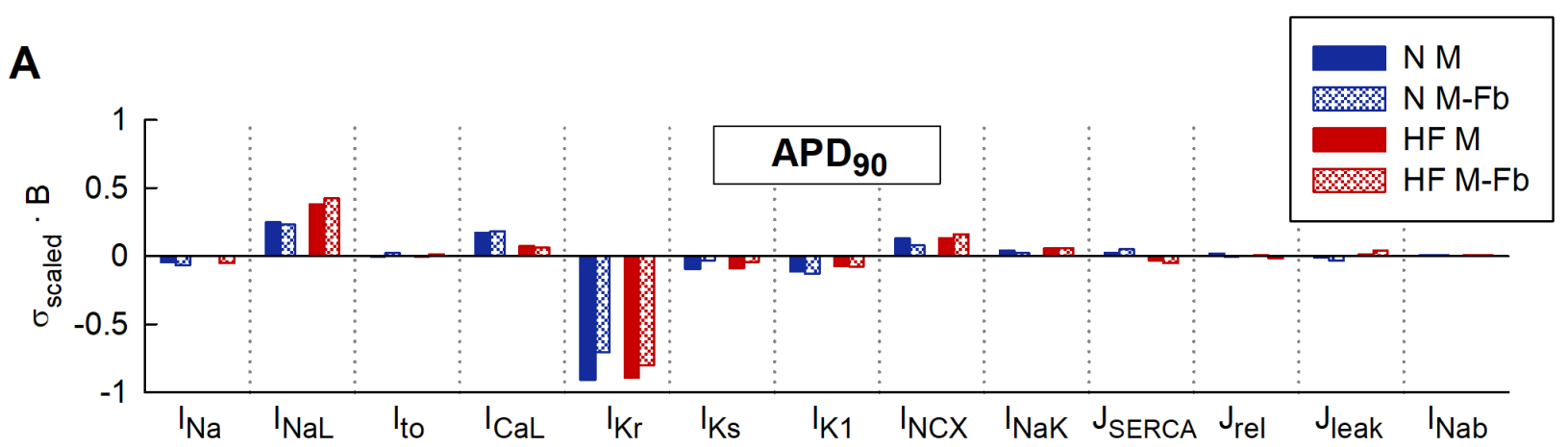

B

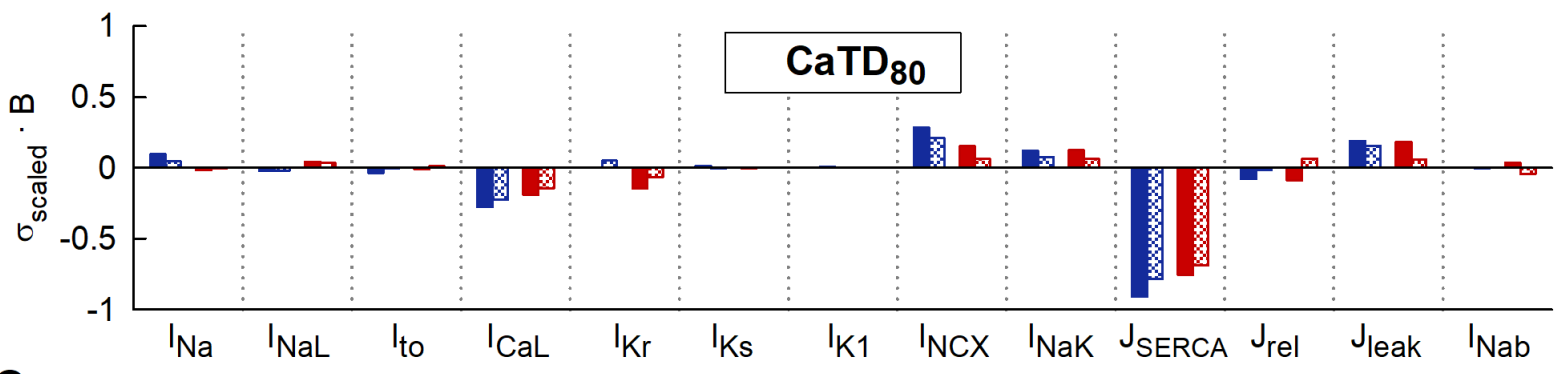

C

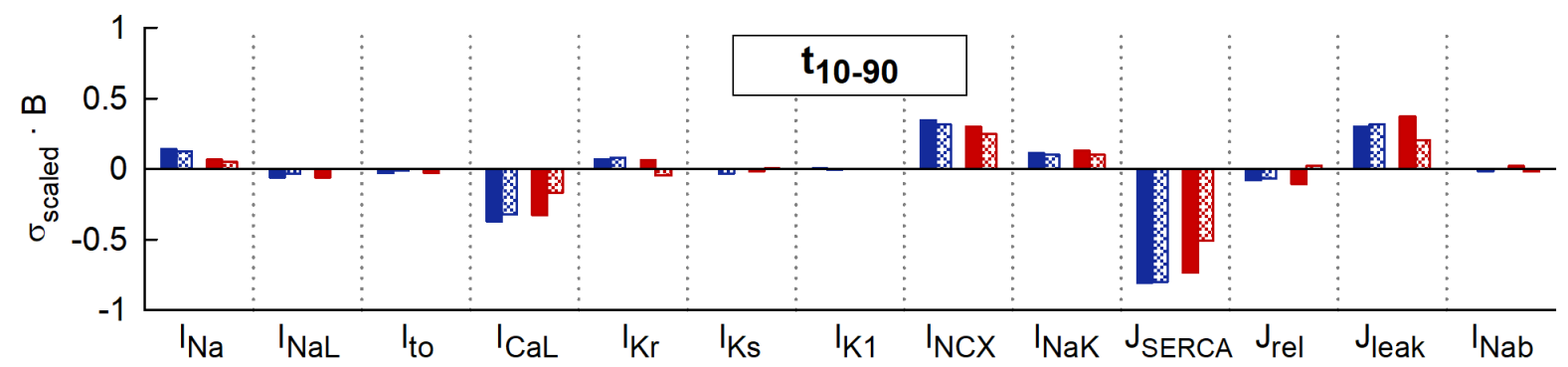

D

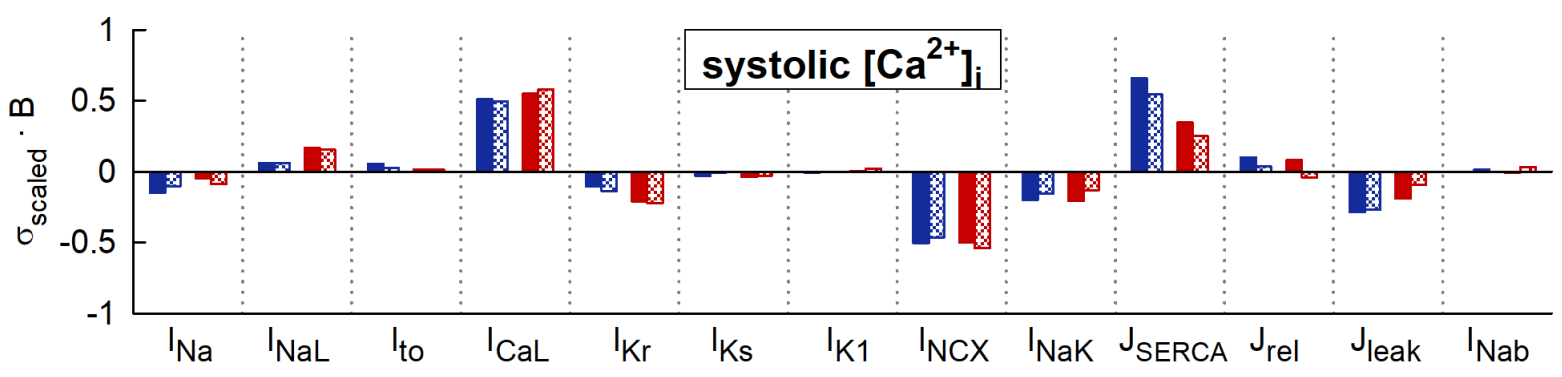

Figure 3.5. Comparison of sensitivities obtained from 4 multivariable regression analyses. Normal $(\mathrm{N})$ and heart failure (HF) conditions with or without coupled fibroblasts $(\mathrm{Fb})$. Modulators of A) action potential duration to $90 \%$ of repolarization $\left.\left(\mathrm{APD}_{90}\right), \mathrm{B}\right) \mathrm{Ca}^{2+}$ transient $(\mathrm{CaT})$ duration to $80 \%$ of recovery $\left.\left(\mathrm{CaTD}_{80}\right), \mathrm{C}\right) \mathrm{CaT}$ rise time $\left(\mathrm{t}_{10-90}\right)$ and, D) Systolic peak of CaT. High parameter variability. Regression coefficients (B) are scaled to the standard deviation $(\sigma)$ of log-normal distributed biomarkers in uncoupled myocytes (M).

To evaluate whether fibroblasts coupling would significantly change sensitivities of electrophysiological biomarkers to parameters variability, multivariate analyses were conducted on these new populations. When a high variability of parameters was considered $(\sigma=0.3)$, our results showed that in the presence of fibroblasts, biomarkers sensitivities to ionic variables slightly changed 
with respect to uncoupled myocytes. As displayed in Figure 3.5, most of these differences were quantitative, as fibroblasts reduced sensitivities to parameters, but the qualitative role of each parameter was maintained. For instance, SERCA contribution to $\mathrm{Ca}^{2+}$ indicators (panels $5 \mathrm{~B}, 5 \mathrm{C}$, and 5D) decreased both in normal and failing conditions when fibroblasts were considered (discontinuous bars).

A

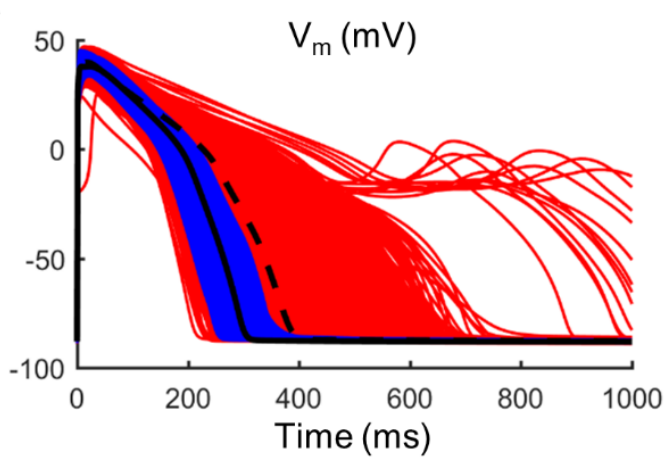

HF

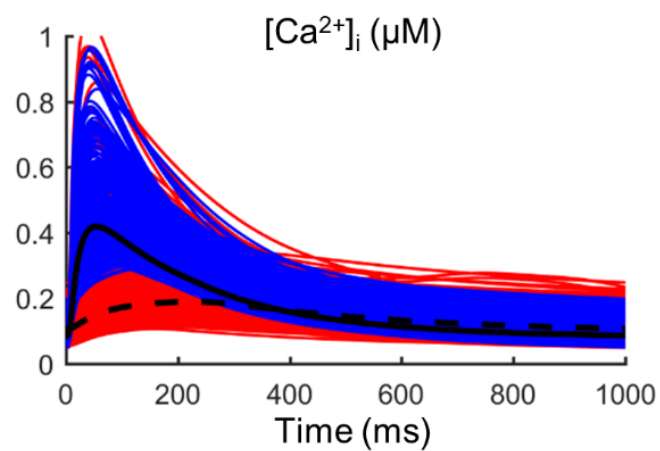

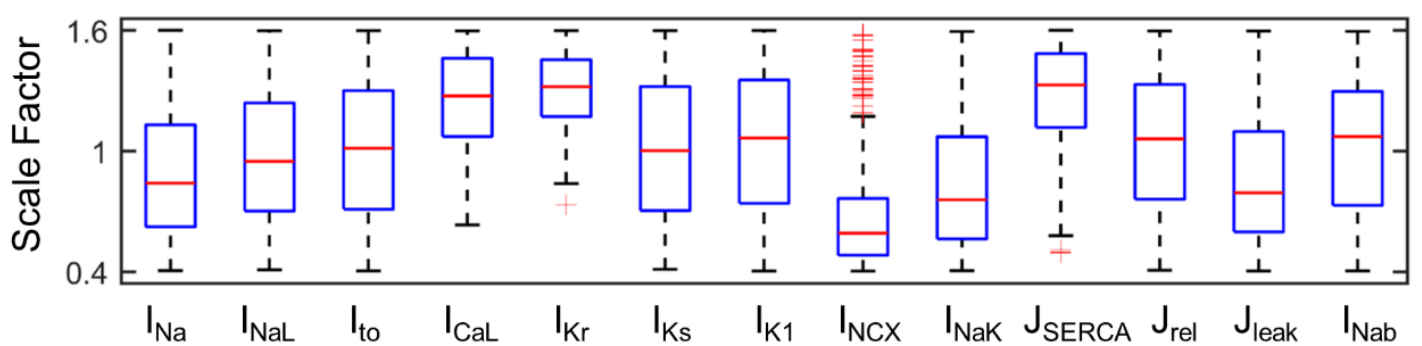

B

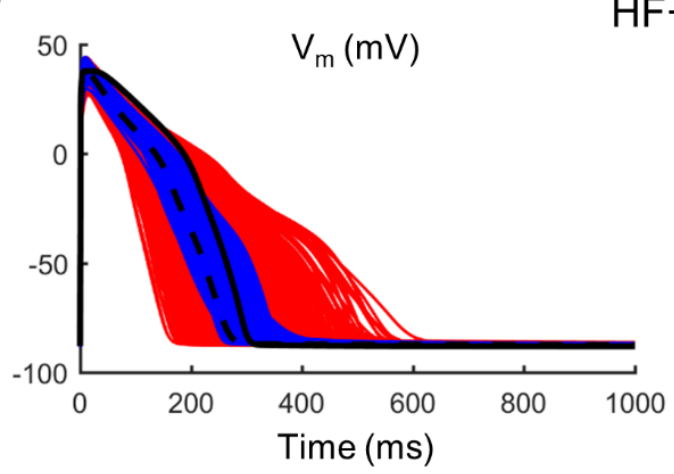

$\mathrm{HF}+\mathrm{Fb}$
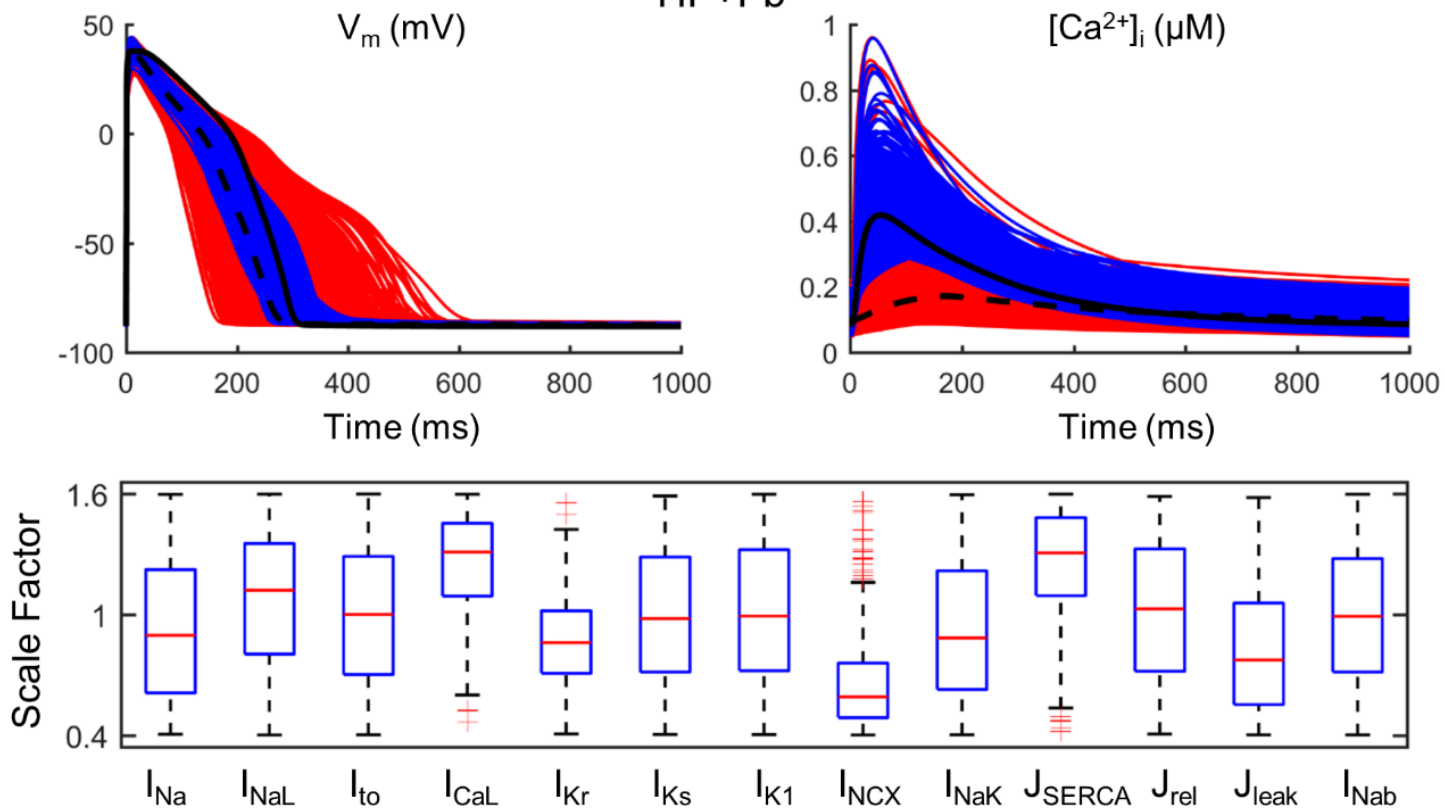

Figure 3.6. Restoration of normal action potential (AP) and calcium transient $(\mathrm{CaT})$ in a population of failing models $(\mathbf{n = 1 0 , 0 0 0 )}$. All simulated models (red traces) are obtained from a HF basic model (dashed black line) in which parameters have been varied $\pm 60 \%$. Calibrated models (blue traces) are within the limits of normal biomarkers (basic ORdmm in solid black line). Distributions of parameter scaling factors for the restored models. A) Population of an uncoupled myocyte. B) Population of a myocyte coupled to 5 fibroblasts. 
To confirm these results, we decreased parameter variability to $\sigma=0.1$ and obtained more accurate regression coefficients. In the new range of parameter variability (see Figure 3.11 in the Supplemental material), sensitivities hardly changed with respect to higher variability.

\subsubsection{AP and CaT restoration in $\mathrm{HF}$}

To analyze how failing APs and CaTs could be restored and brought to normal ranges, a larger population of failing models was generated $(n=10,000)$. The population of models approach generates cells exhibiting a wide variety of physiological behaviors, including cells within the HF population that have APs and CaTs similar to those observed in healthy cells. Selecting this subpopulation and examining the distributions of parameters provides guidance for therapeutic targets. We identified parameter combinations restoring APs and CaTs to waveforms within a healthy range shown in Table 3.1 in the Methods section. In Figure 3.6A, red traces represent all models generated from the baseline ORdmm HF model (dashed black line) and blue lines are models satisfying healthy ranges of both AP and CaT biomarkers. Electrophysiological HF phenotype was restored in around 500 models when $\mathrm{I}_{\mathrm{Kr}}$, SERCA and $\mathrm{I}_{\mathrm{CaL}}$ activities were enhanced, and NCX function decreased. Interestingly, NCX distribution presented several outliers at high scaling factors. When myocytes were coupled to fibroblasts (Figure 3.6B), the role of SERCA, $\mathrm{I}_{\mathrm{CaL}}$, and NCX was similar, whereas $\mathrm{I}_{\mathrm{Kr}}$ modulation was not important.

\subsubsection{Mechanistic analysis of calcium dynamics impairment in fibrosis}

Fibroblast coupling decreased systolic $\mathrm{Ca}^{2+}$ in normal myocytes and exacerbated calcium dynamics impairment in failing myocytes, although parameter sensitivities were hardly affected. To understand the underlying mechanisms, ion currents were carefully analyzed in our simulations. Figure 3.7 shows the traces of selected electrophysiological variables of the model in the time course of an AP at steady state for a failing myocyte with (solid line) and without (dashed line) fibroblast coupling. To understand how these steady-state conditions were reached, we analyzed transient changes in myocyte $\left[\mathrm{Ca}^{2+}\right]$ after fibroblast coupling, as shown in Figure 3.8. In these panels, isolated myocytes are initially at steady state, then fibroblasts are coupled beginning on the second beat. As shown in Figure 3.7C, $I_{g a p}$ is an outward current flowing from the myocyte to fibroblasts, non-existing in the uncoupled myocyte. This outward current decreases membrane potential and has an indirect effect on voltage dependent currents such as $\mathrm{I}_{\mathrm{CaL}}$. Indeed, we can observe that when fibroblasts are coupled (dashed traces) all currents and fluxes present a shorter duration, as well as AP, and a reduced peak (see for instance $\mathrm{CaT}$ in panel B), except $\mathrm{I}_{\mathrm{CaL}}$. Despite the reduced duration of this current, the initial $\mathrm{I}_{\mathrm{CaL}}$ peak contributed to a larger $\mathrm{Ca}^{2+}$ influx through these channels (increase from 140 to $146 \mathrm{pC} / \mu \mathrm{F}$ ). The integral of NCX was also computed and indicated an increase in inward NCX extruding more $\mathrm{Ca}^{2+}$ when fibroblasts were coupled (from 77 to $81 \mathrm{pC} / \mu \mathrm{F}$ ). In the transient evolution shown in Figure $3.8 \mathrm{~F}$, the peak of $\mathrm{I}_{\mathrm{CaL}}$ exhibited a maintained increase compared with the uncoupled myocyte (shown in solid red). Due to the increased $\mathrm{Ca}^{2+}$ extrusion through $\mathrm{NCX}$, however, $\left[\mathrm{Ca}^{2+}\right]_{\text {JSR }}$ progressively declined, leading to the decrease in $\left[\mathrm{Ca}^{2+}\right]_{i}$ peak observed in steady state. 

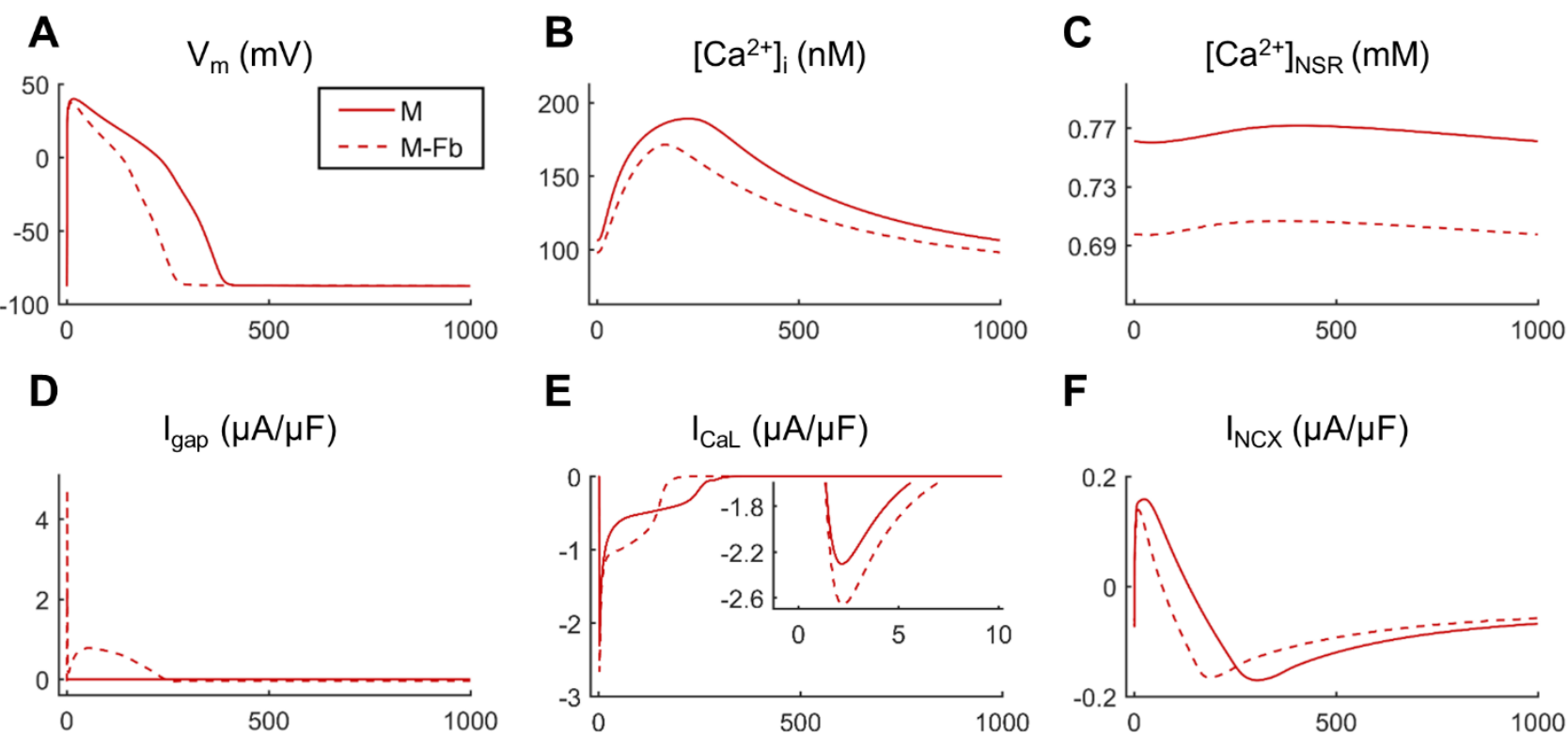

E

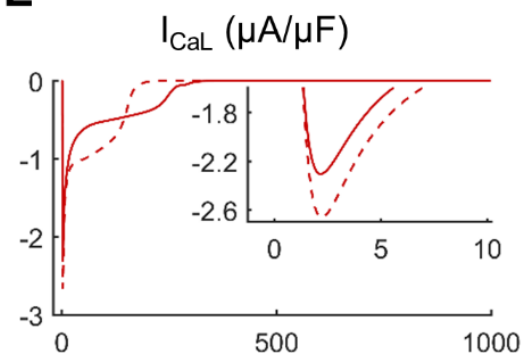

$\mathbf{F}$
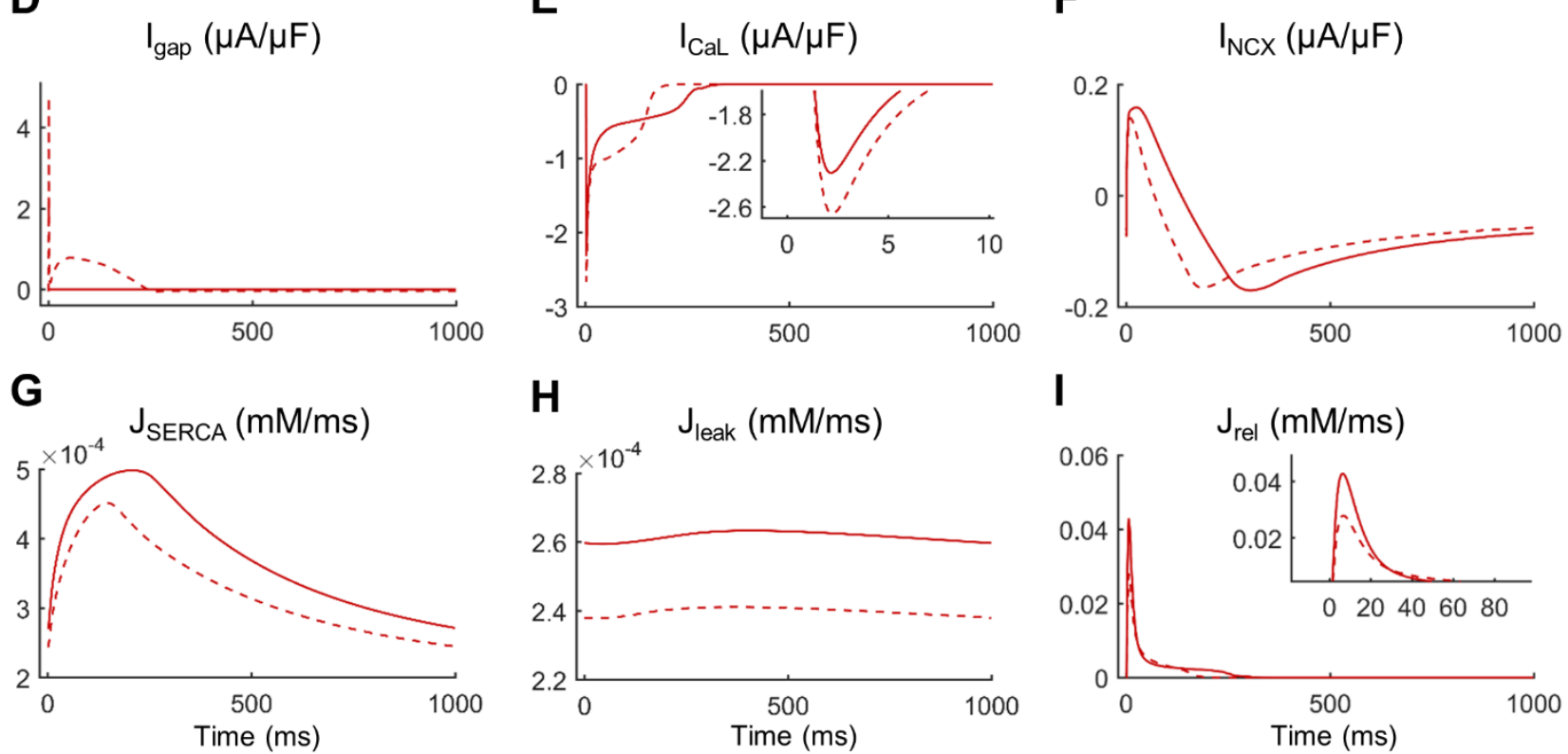

Figure 3.7. Main ionic properties and mechanisms in steady state of a failing myocyte interacting (M-Fb) or not (M) with fibroblasts.A) Membrane potential $\left(\mathrm{V}_{\mathrm{m}}\right)$, B) Intracellular $\mathrm{Ca}^{2+}$ concentration $\left(\left[\mathrm{Ca}^{2+}\right]_{\mathrm{i}}\right)$, C) Sarcoplasmic reticulum (SR) $\mathrm{Ca}^{2+}$ concentration $\left.\left(\left[\mathrm{Ca}^{2+}\right]_{\mathrm{SR}}\right), \mathrm{D}\right)$ Outward positive current circulating from the myocyte to the fibroblast (I $\left.\mathrm{I}_{\text {gap }}\right)$, E) Ltype $\mathrm{Ca}^{2+}$ current $\left(\mathrm{I}_{\mathrm{CaL}}\right) \mathrm{F}$ ) $\mathrm{Na}^{+} / \mathrm{Ca}^{2+}$ exchange current $\left(\mathrm{I}_{\mathrm{NCX}}\right)$, G) SR $\mathrm{Ca}^{2+}$ uptake via SERCA pump (J $\left.\left.\mathrm{J}_{\mathrm{SERCA}}\right) \mathrm{H}\right) \mathrm{SR}$ Ca ${ }^{2+}$ leak $\left(\mathrm{J}_{\text {leak }}\right)$, and I) $\mathrm{SR} \mathrm{Ca}^{2+}$ release flux via ryanodine receptors $\left(\mathrm{J}_{\text {rel }}\right)$.

\subsection{Discussion}

\subsubsection{Main Findings}

In this study, two methodologies were used to perform sensitivity analyses evaluating the effects of fibroblast-myocyte coupling under normal and HF conditions. Our main findings are that i) univariate and multivariate analyses yield very similar results and low variability of parameters yields more reliable multivariate sensitivity analyses, ii) despite exacerbating $\mathrm{Ca}^{2+}$ impairment in heart failure, fibroblast to myocyte coupling does not alter the role of the main mechanisms regulating $\mathrm{Ca}^{2+}$ dynamics in myocytes, iii) drug action on $\mathrm{I}_{\mathrm{CaL}}$ and SERCA enhancement and NCX block would help $\mathrm{CaT}$ restoration in $\mathrm{HF}$ regardless of fibrosis presence. 
A
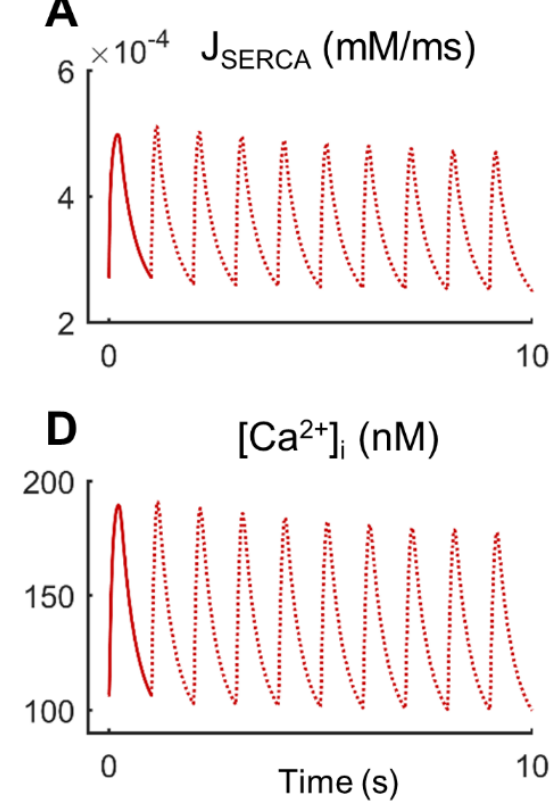

B
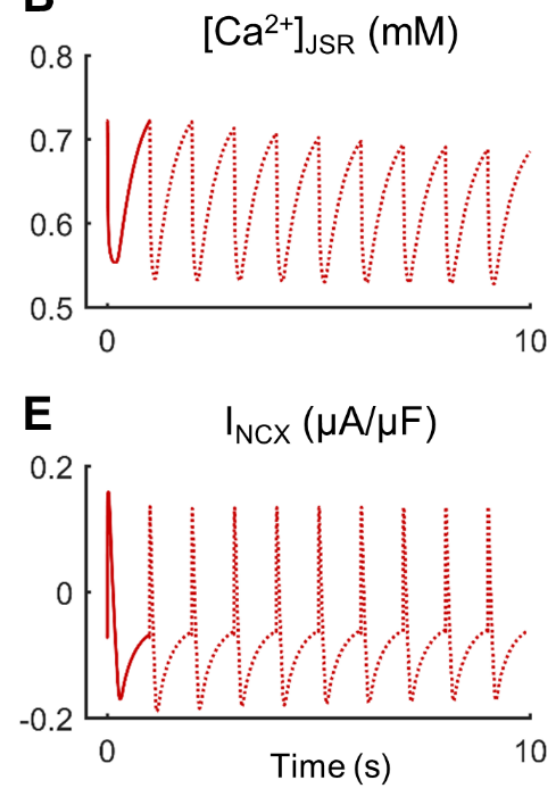

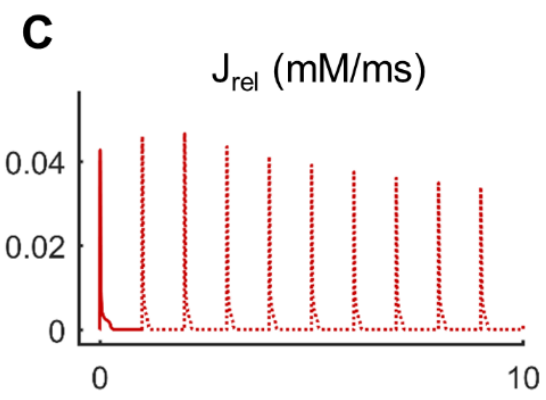

$\mathbf{F}$

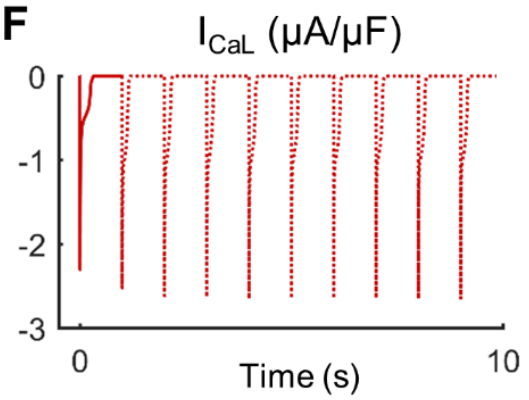

Figure 3.8. Transient state of ionic mechanisms and $\mathrm{Ca}^{2+}$ concentration in cellular compartments of a failing myocyte coupled to 5 fibroblasts (dashed lines). Initial steady state of an uncoupled myocyte (solid line). A) SR $\mathrm{Ca}^{2+}$ uptake via SERCA pump (J $\left.\mathrm{J}_{\mathrm{SERCA}}\right)$, B) Junctional SR $\mathrm{Ca}^{2+}$ concentration $\left.\left(\left[\mathrm{Ca}^{2+}\right]_{\mathrm{ISR}}\right), \mathrm{C}\right) \mathrm{SR} \mathrm{Ca}^{2+}$ release flux via ryanodine receptors $\left.\left(\mathrm{J}_{\mathrm{rel}}\right), \mathrm{D}\right)$ Intracellular $\mathrm{Ca}^{2+}$ concentration $\left.\left(\left[\mathrm{Ca}^{2+}\right]_{\mathrm{i}}\right), \mathrm{E}\right) \mathrm{Na}^{+} / \mathrm{Ca}^{2+}$ exchange current $\left(\mathrm{I}_{\mathrm{NCX}}\right)$, and F) L-type $\mathrm{Ca}^{2+}$ current ( $\left.\mathrm{I}_{\mathrm{CaL}}\right)$.

\subsubsection{Suitable Sensitivity Analyses}

Univariate and multivariate sensitivity analyses were performed using an initial large variability $( \pm 60 \%)$ and then smaller $( \pm 15 \%)$. At lower variability, changes in electrophysiological properties behaved linearly, making results from univariate and multivariate analysis more similar. Indeed, ionic currents and fluxes work synergistically to generate AP and CaT. Variables such as membrane potential and ionic concentrations link all ionic mechanisms in a way that a change in one parameter (conductivity in this case) has an effect on other parameters, and final differences in electrophysiological properties are the result of an interaction of all these variations. In addition, within the range of variation of a specific parameter, the effects on biomarkers can be different, and assuming linearity can become less accurate when a wide interval is considered. In fact, as electrophysiological remodeling in HF is simulated by changing parameters, the same scale factor applied in N and HF implies a different range of variation of such parameters, accounting for different sensitivities to biomarkers. This explains the increase in APD sensitivity to $\mathrm{I}_{\mathrm{NaL}}$, or the decrease of systolic $\left[\mathrm{Ca}^{2+}\right]_{\mathrm{i}}$ sensitivity to SERCA in $\mathrm{HF}$ with respect to $\mathrm{N}$ conditions.

Multivariate parameter sets, unlike varying one parameter at a time, can provide information about electrophysiological properties in a wide combination of parameters, which could be useful to evaluate the response of a drug in different individuals, instead of on a fixed baseline model. The high physiological or pathological variability of ionic parameters requires the analysis of the behavior in the whole range.

Despite accuracy loss with high parameter variability, sensitivity analyses are a useful systematic tool to determine the most important mechanisms involved in $\mathrm{Ca}^{2+}$ dynamics. We observed that univariate and multivariate sensitivities agreed in the most important parameters contributing to each biomarker. For instance, it was observed the strong impact of $\mathrm{I}_{\mathrm{Kr}}$ on $\mathrm{APD}_{90}$, as O'Hara et al [3] 
described in their model. For CaT indicators, the main role of parameters such as SERCA, NCX, and $\mathrm{I}_{\mathrm{CaL}}$ was highlighted with both methodologies, agreeing with experimental observations [35-37], and with a previous study comparing populations of normal and failing myocytes [23].

In electrophysiological models, biomarker sensitivities are usually calculated within a wide range of variation in ionic conductances, which has been reported experimentally. In their work, Romero et al. [24] simulated univariate variations up to $\pm 30 \%$ to evaluate the arrhythmogenic risk of ionic change, with AP properties falling within the experimental range. In the multivariable regression conducted by Sobie [25], it was assessed how variability ( $\sigma$ ranging from 0.1 to 0.5 ) affected the regression model and observed a $\mathrm{R}^{2}$ reduction with the increase of $\sigma$, although many regression coefficients remained constant, being small the decrease in accuracy obtained for APD. This is consistent with our results, highlighting the robustness of sensitivity analysis for AP biomarkers. However, $\mathrm{Ca}^{2+}$-biomarkers sensitivities were more affected by variability. Comparing low and high parameter variability, sensitivities differed more in the univariate case due to changes in parameterbiomarker relation along the variation range, including non-linearities. Sensitivities derived from the multivariate study for HF showed the lowest coefficients of determination, suggesting that HF remodeling enhances non-linearities between variables.

In other modeling studies, experimentally-calibrated populations are first generated with conductances scaled up to $\pm 100 \%$. Constrained biomarkers according to experimental values determine the range of parameters in the subsequent regression analysis [38,39]. This way, linear fit problem could be solved but natural variability dominates the results and high effects of drugs are not evaluated in this range.

It can be concluded that the roles of the different parameters on electrophysiological biomarkers can be qualitatively estimated using linear methods, including different variability and parameter distributions. Furthermore, our findings highlight that both types of sensitivity studies, univariate and multivariate, provide similar results. However, when large variability is considered, discrepancies arising between these methodologies can become notable, affecting $\mathrm{Ca}^{2+}$ properties and patholological conditions to a greater extent. Univariate analysis is less computational expensive and is thus a valid methodology within a moderate variability range and for a reasonable number of parameters. Quantitative results from the multivariate analysis should be more reliable, as parameter interaction is considered, but caution should be taken if coefficients of determination are not close to one, which can happen under HF conditions.

\subsubsection{Fibrosis exacerbates $\mathrm{Ca}^{2+}$ transient impairment in heart failure}

This computational study shows that the electrical activity of myocytes, including calcium dynamics, is affected by fibroblast coupling. Specifically, $\mathrm{Ca}^{2+}$ transient peaks are smaller and SR $\left[\mathrm{Ca}^{2+}\right]$ is reduced when fibroblasts are coupled to myocytes. Despite these alterations, the ionic mechanisms regulating $\mathrm{Ca}^{2+}$ cycling are barely affected by the intercellular interaction, indicating that fibroblast coupling does not influence which pathways represent the best drug targets. HF remodeling seems to have a greater impact on the relative role of the different ionic mechanisms that regulate $\mathrm{Ca}^{2+}$ cycling. However, our results show that fibroblast coupling could be contributing to the excitationcontraction coupling impairment seen in HF.

An important effect observed when simulating fibroblast-myocyte coupling is the marked APD shortening. Experimental studies showing the existence of gap junctions (connexin43) between 
fibroblasts and myocytes also revealed changes in AP waveform and conduction velocity due to a modulation of myocyte electrophysiology [12,15,40]. Previous computational studies exploring fibroblast-myocyte electrophysiological interactions also showed reductions in APD. When MacCannell et al. [27] developed the mathematical model for the active fibroblast, they coupled it to a human myocyte model and reported an APD shortening, as fibroblasts acted as current sinks. The theoretical work of Jacquemet and Henriquez [41] also showed that the effect of coupling caused a faster myocyte repolarization, but changing fibroblast properties, such as a less negative fibroblast resting potential, reversed the effect. It is known that fibroblasts differentiate into myofibroblasts in response to inflammation, an activated form which presents contractile proteins, implying the existence of $\mathrm{Ca}^{2+}$ cycling [42]. To date, no specific models for myofibroblasts have been developed but simulations have been performed increasing the membrane capacitance and depolarizing the resting membrane potential of the fibroblast model $[17,18]$. In the present study, we used the fibroblast model by MacCannell [27] with a resting potential of $-49.4 \mathrm{mV}$, thus the effect in normal and failing myocytes was a reduction in APD. We also conducted some additional simulations (see Supplementary Figure 3.4) changing to myofibroblast phenotype $\left(\mathrm{C}_{\mathrm{F}}=50 \mathrm{pF}, \mathrm{E}_{\mathrm{F}}=-24.5 \mathrm{mV}\right)$, and we observed similar effects, i.e. APD shortening and $\mathrm{Ca}^{2+}$-handling impairment. The improvement of myofibroblast models, incorporating $\mathrm{Ca}^{2+}$ dynamics, would certainly shed light into the understanding of $\mathrm{Ca}^{2+}$ dynamics alterations in the failing tissue.

The number of coupled fibroblasts considered could also alter the results. The uncertainty about the in vivo coupling, different degrees of fibrosis and the difficult to quantify coupled fibroblasts in tissue has led to the exploration of different values of $\mathrm{G}_{\text {gap }}$ or a range of myocyte-fibroblast ratios $[13,41,43]$. We compared the effects of coupling 1 fibroblast to 5 (results not shown) and we found that the impact on APD and CaT was lower with one fibroblast and increasing the number of fibroblasts to 5 did not increase the effects fivefold. This finding suggested that the sensitivity of the myocyte to $\mathrm{G}_{\text {gap }}$ is not linear, saturating for higher values, as observed in other analyses of $\mathrm{G}_{\text {gap }}$ effects when strong coupling was considered [41]. We finally used 5 fibroblasts in order to represent fibroblast proliferation observed in pathological conditions.

In our simulations, the baseline ORdmm model showed a notable $\mathrm{Ca}^{2+}$ impairment when fibroblast interaction was considered in both $\mathrm{N}$ and $\mathrm{HF}$ conditions, but the population of models revealed that not every individual might have an impaired $\mathrm{Ca}^{2+}$ handling in a fibrotic heart. However, in $\mathrm{HF}$, even a minor $\mathrm{Ca}^{2+}$-handling alteration should be considered important because it worsens contractility dysfunction. Only a few studies have measured intracellular $\mathrm{Ca}^{2+}$ in myocytes interacting with fibroblasts. In co-culture experiments used to investigate the crosstalk between both cell types, it was found that fibroblasts from normal hearts increased CaT amplitude, while fibroblasts and myofibroblasts from pressure-overloaded hearts led to a smaller amplitude associated with a reduction in SR $\mathrm{Ca}^{2+}$ content [44]. A more recent in vitro study to explore the influence of heterocellular interactions on cardiomyocyte function showed that only adult fibroblasts had significant consequences on the electrical and mechanical function, by prolonging action potential duration and reducing CaT amplitude [10]. In computational studies, only the work by Zhan et al. [11] has considered the role of fibroblast proliferation in a mathematical model with $\mathrm{Ca}^{2+}$, and reported a longer APD and CaT width, modulating cardiac electromechanical behavior. This discrepancy with our results, a prediction of APD prolongation rather than shortening, might be due to the use of a passive fibroblast model with a resting membrane potential set to $-20 \mathrm{mV}$. Indeed, when modeling fibroblast electrophysiological behavior, the value of several parameters are crucial in the outcome, including 
the number of fibroblasts coupled to each myocyte, the resting potential and the capacitance of each fibroblast [45], and whether myofibroblast properties are considered [17].

Our sensitivity analysis showed minimal differences in the mechanisms determining APD and CaT waveform between myocytes coupled or not to fibroblasts. This could simplify therapies, as presence or absence of fibrotic tissue would not alter the treatment. The slightly reduced sensitivities in the presence of fibrosis indicate that targeted ion transport pathways require a higher variation to produce the same percentage of change to improve the considered electrophysiological property. $\mathrm{I}_{\mathrm{Kr}}$ is the main modulator of APD, as O'Hara et al. (2011) reported in their sensitivity analysis, and its enhancement in HF would restore the prolonged APD. However, in myocytes coupled to fibroblasts there is no need to reduce APD via $\mathrm{I}_{\mathrm{Kr}}$ modulation as fibroblasts act as a current sink and lead to an earlier repolarization. Regarding CaT indicators, $\mathrm{HF}$ remodeling seems to be the main cause of $\mathrm{Ca}^{2+}$ alteration, which explains why coupled and uncoupled myocytes require the same measures to restore $\mathrm{Ca}^{2+}$ cycling: increase of SERCA and $\mathrm{I}_{\mathrm{CaL}}$, and NCX reduction.

Finally, the mechanistic analysis of $\mathrm{Ca}^{2+}$ cycling with fibroblasts reveals that, despite an increase in $\mathrm{I}_{\mathrm{CaL}}$ peak with fibroblast coupling, increased $\mathrm{NCX} \mathrm{Ca}^{2+}$ extrusion leads lower SR content and smaller $\mathrm{Ca}^{2+}$ transient peaks. In the steady state, there is a balance between fluxes, maintaining constant $\mathrm{Ca}^{2+}$ levels, which does not happen in the transient state. In fact, the progressive reduction in intracellular $\mathrm{Ca}^{2+}$ is a sign of negative balance between $\mathrm{Ca}^{2+}$ influx and efflux in the myocyte, which occurs after a perturbation in the system, i.e. fibroblast coupling. The modulation of all ionic mechanisms including $\mathrm{Ca}^{2+}$ cycling is caused by the active role of fibroblasts, becoming a current sink. The new outward current in myocytes, $I_{\text {gap }}$, accelerated AP repolarization and consequently, all voltage-dependent currents were affected, including $\mathrm{I}_{\mathrm{CaL}}$. The model used for human endocardial AP does not present a notch with a marked early repolarization phase as in other species. For this reason, $I_{g a p}$ does not affect the excitation-contraction coupling by changing the rate of the initial repolarization as in Xie et al. [46]. In the present study, the implicated mechanism becomes more important in later phases of the AP. We also conducted simulations using the epicardial model of ventricular AP formulated by O'Hara et al. [3] to see the effect on the early repolarization phase which is indeed present in the epicardial model. As shown in Supplementary Figure 3.5, no important changes are observed in this phase under the effect of coupled fibroblasts.

The static formulation of myocyte-fibroblast coupling differed from the dynamic gap junctions channels modeled by Brown et al. [47]. They observed a reduction in the junctional current during the upstroke of the AP when considering time- and voltage-sensitive gating channels in homotypic and heterotypic channels, i.e. with different connexins combinations ( $\mathrm{Cx} 43$ and $\mathrm{Cx} 45)$. Although it did not significantly alter conduction velocity compared to static gap junctions, fibroblasts with a smaller sink impact could have a different effect on $\mathrm{Ca}^{2+}$ dynamics.

Our findings showed that a higher $\mathrm{I}_{\mathrm{CaL}}$ peak introduced more $\mathrm{Ca}^{2+}$ in the myocyte but did not trigger a higher $\mathrm{SR} \mathrm{Ca}^{2+}$ release as expected. According to Shannon et al. [48], there cannot be a release from the SR with a $\mathrm{Ca}^{2+}$ load of less than $50 \%$ of its maximal content, explaining that the reduced SR $\mathrm{Ca}^{2+}$ content characteristic of failing myocytes contributes to reduce force development. Similarly, changes in $\mathrm{SR} \mathrm{Ca}^{2+}$ load of $58 \%$ have been measured in failing isolated myocytes, and related to a smaller CaT [7]. Therefore, a reduction in $\mathrm{SR} \mathrm{Ca}^{2+}$ content due to fibroblasts could be the cause of an exacerbated $\mathrm{Ca}^{2+}$ impairment. The transient evolution shown in Figure 3.8 helps understand the mechanisms leading to cellular $\mathrm{Ca}^{2+}$ loss. One of the advantages of mathematical models is the power to analyze hypothetical situations that cannot be measured experimentally, such as myocyte response 
to a sudden electrical connection with fibroblasts. In the transient state (Figure 3.8), we observed that $I_{C a L}$ peak increased since the first beat, due to the immediate effects of $I_{\text {gap }}$ on AP. Initially, there was also an intracellular $\mathrm{Ca}^{2+}$ rise, as $\mathrm{SR} \mathrm{Ca}^{2+}$ content was still elevated. The mechanisms to remove $\mathrm{Ca}^{2+}$ from the cytosol were then activated: SERCA and inward current through $\mathrm{NCX}$ (extruding $\mathrm{Ca}^{2+}$ ). $\mathrm{NCX}$ role, extruding $\mathrm{Ca}^{2+}$ out of the cell, becomes relevant in the transient state because if there is an imbalance with $\mathrm{Ca}^{2+}$ influx through $\mathrm{I}_{\mathrm{CaL}}$ channels, $\mathrm{Ca}^{2+}$ loss occurs. This mechanism might explain the reduced $\mathrm{SR} \mathrm{Ca}^{2+}$ load in myocytes interacting with fibroblasts.

Our findings suggest that fibroblasts increase $\mathrm{Ca}^{2+}$ impairment in $\mathrm{HF}$ by further reducing SR $\mathrm{Ca}^{2+}$ content in myocytes.

\subsubsection{Limitations}

Several limitations need to be considered when drawing conclusions from the present study. Although simulations of cellular electrophysiological behavior and systematic analyses of biomarkers complement and enrich experimental research, uncertainties in the development of the mathematical models employed might affect the outcome of the simulations. The limited availability of electrophysiology data from human fibroblasts has led to the use of a fibroblast model developed on the basis of adult rat ventricular tissue data, without taking into consideration potential changes in HF. Fibroblasts with the same characteristics were considered in normal and failing conditions, but electrophysiological remodeling in fibroblast currents could have an additional effect on myocytes [49]. Another limitation is the use of a fibroblast model, instead of using a myofibroblast model (not available to date), which is the characteristic form in pathological conditions, which would take into account $\mathrm{Ca}^{2+}$ dynamics in these cells. $\mathrm{Ca}^{2+}$ signaling has been observed in human cardiac fibroblasts although with different pathways to those in contractile myocytes [50], and myofibroblasts show intracellular CaTs, modulated by intercellular coupling with myocytes [42], but neither of them have been modeled. Specific data for fibroblasts features are still lacking and one of the major concerns in studies focusing myocyte-fibroblast interactions is the use of data from co-cultures and the need of data describing the real electrophysiological behavior in vivo.

Gap junctional coupling between a myocyte and a fibroblast has been modeled by a simple conductance as in previous simulation studies of fibroblast-myocyte coupling. However, recent findings suggesting the interaction of connexin45 with $\mathrm{CaM}$ [51] highlight that some ions such as $\mathrm{Ca}^{2+}$ can modulate the coupling current. If the modulation of the intercellular coupling by $\mathrm{Ca}^{2+}$ ions was taken into account, larger alterations in $\mathrm{Ca}^{2+}$ dynamics mechanisms could be observed. Any mechanism related to $\mathrm{Ca}^{2+}$ included into our model, such as realistic $\mathrm{Ca}^{2+}$ dynamics in fibroblasts, may affect the regulation of $\mathrm{Ca}^{2+}$ cycling in myocytes, and enhance the influence of fibroblasts.

Other structural modifications in HF, concerning myocytes, involve the loss of transverse tubules and reorganization of the cell membrane [52]. We have assumed that with the electrophysiological remodeling applied to ionic mechanisms we qualitatively reproduce the delayed $\mathrm{SR} \mathrm{Ca}^{2+}$ release resulting from detubulation. However, a detailed model including local changes in membrane structure related to the spatial organization of ion channels in $\mathrm{HF}$ could provide more accurate results about $\mathrm{Ca}^{2+}$ impairment [53,54].

Although $\mathrm{Ca}^{2+}$ homeostasis is related to contraction and relaxation force, other mechanical factors, such as myofibroblast contractility when fibroblasts are differentiated into the activated form or extracellular stiffness due to the excessive accumulation of collagen in HF, can contribute to cardiac 
dysfunction. Our model only considers intracellular $\mathrm{Ca}^{2+}$ in myocytes at a cellular level to evaluate the contraction of the heart. The behavior in tissue or even in the whole organ could also be different. A defined architecture of the myocyte when considering spatial distribution would allow to take into consideration the distribution of gap junctions as well as the extracellular space which could modulate $\mathrm{Ca}^{2+}$ homeostasis as it does in electrical propagation [43,55-57]. We consider a natural continuation of the present work the analysis of fibrosis effects on calcium waves in 2D and 3D tissues, in which altered impulse propagation and generation of arrhythmias should develop because of the heterogeneities in tissue, according to other studies [16,18,29,40,43,55].

Regarding sensitivity analyses, the non-linearities are the main issue in quantifying the impact of parameters on biomarkers. To restore the electrical activity and contraction of myocytes, the effect of some drugs can imply a high change in an ionic mechanism, and the predictive value of this methodology decreases with increased variability.

Nonetheless, despite these limitations, cellular simulations can shed light in the causes of $\mathrm{Ca}^{2+}$ impairment observed in HF, which together with the arrhythmogenic activity of fibrotic tissue, can compromise the function of the myocardium. In the present study, the measures suggested to restore $\mathrm{Ca}^{2+}$ dynamics and contractility at cellular level are reliable because they are supported by experiments and according to our findings, tackling the electrophysiology remodeling in failing myocytes can also improve the effects of fibroblasts interactions.

\subsection{Supplemental Material}

In the following tables we provide the required information to replicate our simulations:

Table 3.3. Changes in ORd model leading to ORdmm.

\begin{tabular}{ccc}
\hline Ion current & New formulation & References \\
\hline $\mathrm{G}_{\mathrm{Na}}=31 \mathrm{mS} / \mu \mathrm{F}$ & \\
$h_{s s}=j_{s s}=\frac{1}{1+e^{\frac{V+78.5}{6.22}}}$ & {$[26,58,59]$} \\
$\mathrm{I}_{\mathrm{Na} p}$ & $=\frac{1}{1+e^{\frac{V+84.7}{6.22}}}$ \\
& $m_{s S}=\frac{1}{1+e^{-\frac{V+48.97}{7.5}}}$ & \\
\hline $\mathrm{I}_{\mathrm{NaL}}$ & $\mathrm{G}_{\mathrm{NaL}}=0.0144 \mathrm{mS} / \mu \mathrm{F}$ & {$[26,60]$} \\
\hline
\end{tabular}

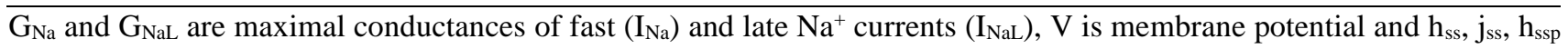
and $\mathrm{m}_{\mathrm{ss}}$ are steady-state inactivation and activation gates of $\mathrm{I}_{\mathrm{Na}}$. 
Chapter 3 Fibrosis exacerbates $\mathrm{Ca}^{2+}$ cycling impairment

Table 3.4. Heart failure (HF) remodeling in ORdmm model.

\begin{tabular}{lcl}
\hline Ionic parameter & $\begin{array}{c}\text { \% of change compared to } \\
\text { the ORdmm }\end{array}$ & Experimental references \\
\hline $\mathbf{I}_{\mathbf{N a L}}$ & $180 \%$ & {$[61]$} \\
\hline $\boldsymbol{\tau}_{\mathbf{h L}}$ & $180 \%$ & {$[61]$} \\
\hline $\mathbf{I}_{\mathbf{t o}}$ & $40 \%$ & {$[62]$} \\
\hline $\mathbf{I}_{\mathbf{K} 1}$ & $68 \%$ & {$[63]$} \\
\hline $\mathbf{I}_{\mathbf{N a K}}$ & $70 \%$ & {$[63-65]$} \\
\hline $\mathbf{I}_{\mathbf{N C X}}$ & $175 \%$ & {$[66]$} \\
\hline $\mathbf{C a M K a}$ & $150 \%$ & {$[67,68]$} \\
\hline $\mathbf{J}_{\text {SERCA }}$ & $50 \%$ & {$[7]$} \\
\hline $\mathbf{J}_{\text {leak }}$ & $130 \%$ & {$[69]$} \\
\hline $\mathbf{K}_{\text {rel,Ca }}$ & $80 \%$ & {$[70]$} \\
\hline
\end{tabular}

The modified parameters are the maximum values of the late $\mathrm{Na}^{+}$current $\left(\mathrm{I}_{\mathrm{NaL}}\right)$, the time constant of inactivation of the $\mathrm{I}_{\mathrm{NaL}}$ $\left(\tau_{\mathrm{hL}}\right)$, the transient outward current $\left(\mathrm{I}_{\mathrm{t}}\right)$, the inward rectifier $\mathrm{K}^{+}$current $\left(\mathrm{I}_{\mathrm{K} 1}\right)$, the $\mathrm{Na}^{+} / \mathrm{K}^{+}$pump current $\left(\mathrm{I}_{\mathrm{NaK}}\right)$, the $\mathrm{Na}^{+} / \mathrm{Ca}^{2+}$ exchanger ( $\mathrm{I}_{\mathrm{NCX}}$ ), the fraction of active binding sites of the $\mathrm{Ca}^{+2}$ calmodulin-dependent protein kinase II (CaMKa), the sarcoplasmic reticulum (SR) $\mathrm{Ca}^{2+}$ pump (J $\mathrm{J}_{\mathrm{SERCA}}$ ), the SR $\mathrm{Ca}^{2+}$ leak $\left(\mathrm{J}_{\text {leak }}\right)$ and the sensitivity to $\left[\mathrm{Ca}^{2+}\right]_{\text {JSR }}$ of the ryanodine receptors $\left(\mathrm{Ca}^{2+}\right.$ sensitivity of $\mathrm{J}_{\mathrm{rel}, \infty}$, called $\left.\mathrm{K}_{\mathrm{rel}, \mathrm{Ca}}\right)$. 


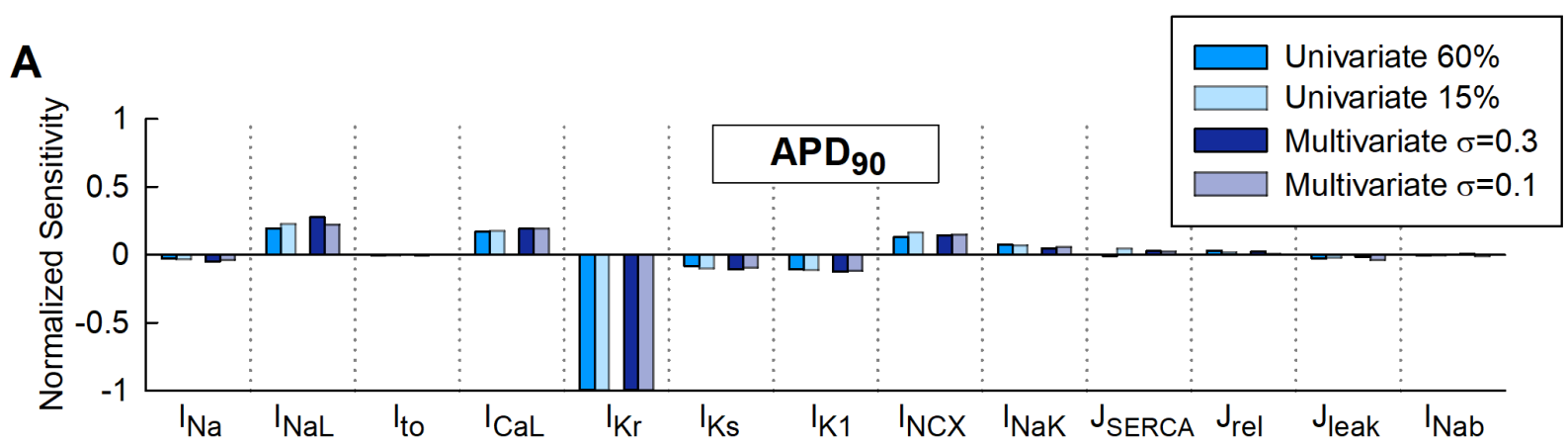

B

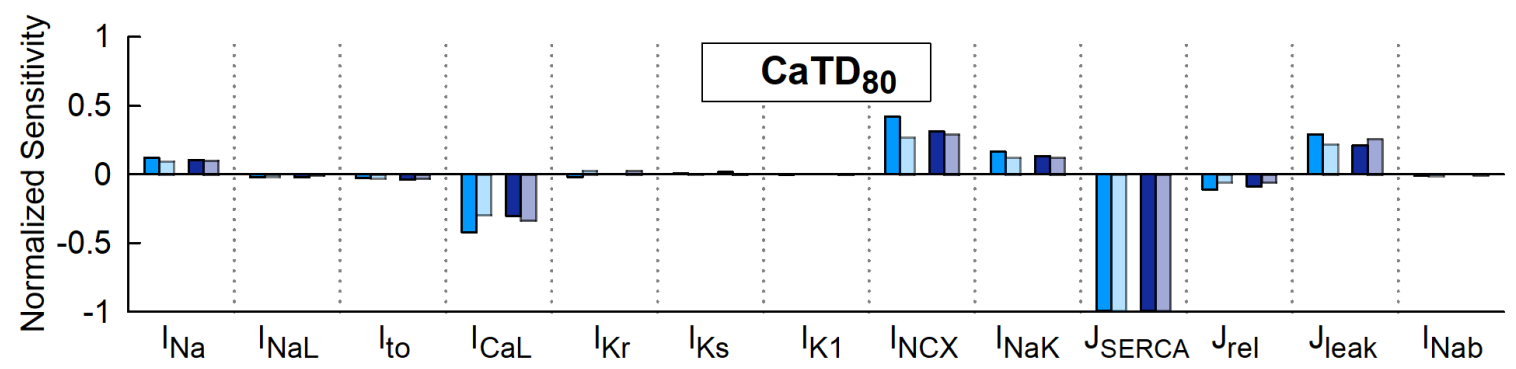

C

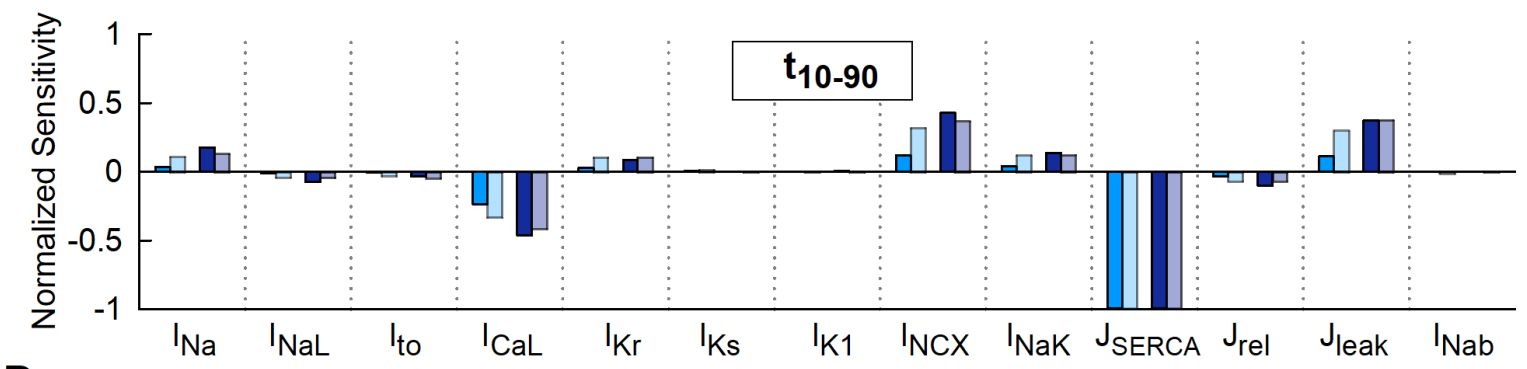

D

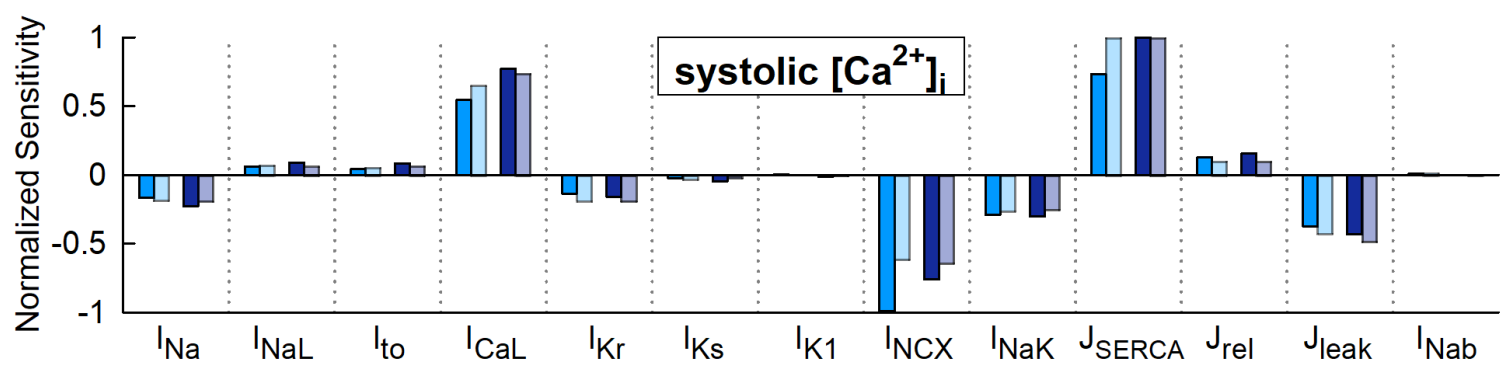

Figure 3.9. Univariate and multivariate sensitivities in normal conditions with high and low parameter variability. Modulators of A) action potential duration to $90 \%$ of repolarization ( $\mathrm{APD}_{90}$ ), B) $\mathrm{Ca}^{2+}$ transient (CaT) duration to $80 \%$ of recovery $\left(\mathrm{CaTD}_{80}\right)$, C) CaT rise time $\left(\mathrm{t}_{10-90}\right)$ and, D) Systolic peak of CaT. 


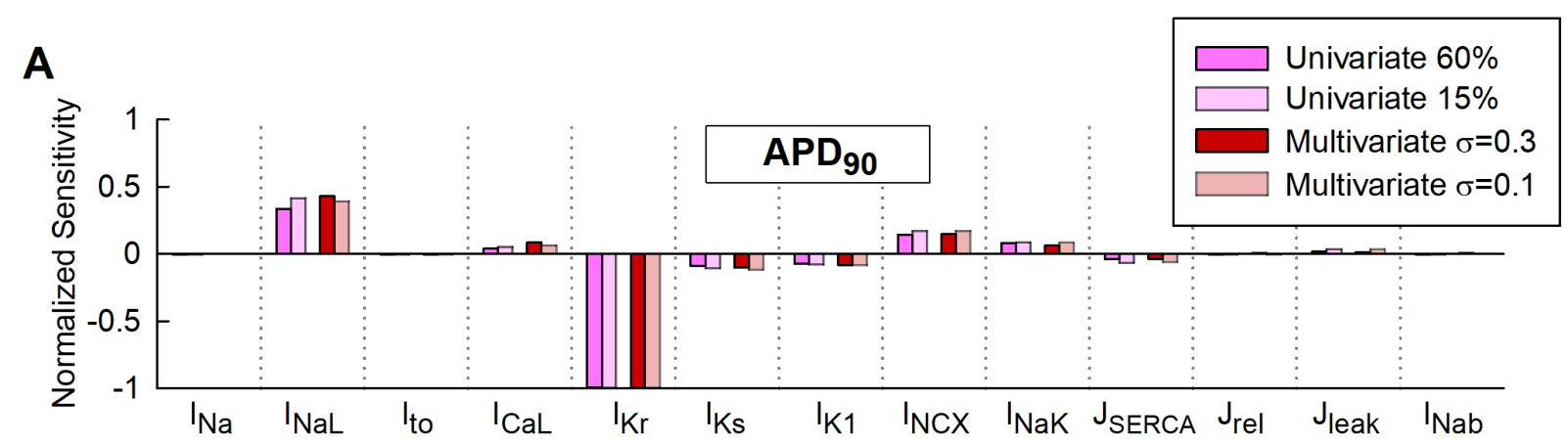

B

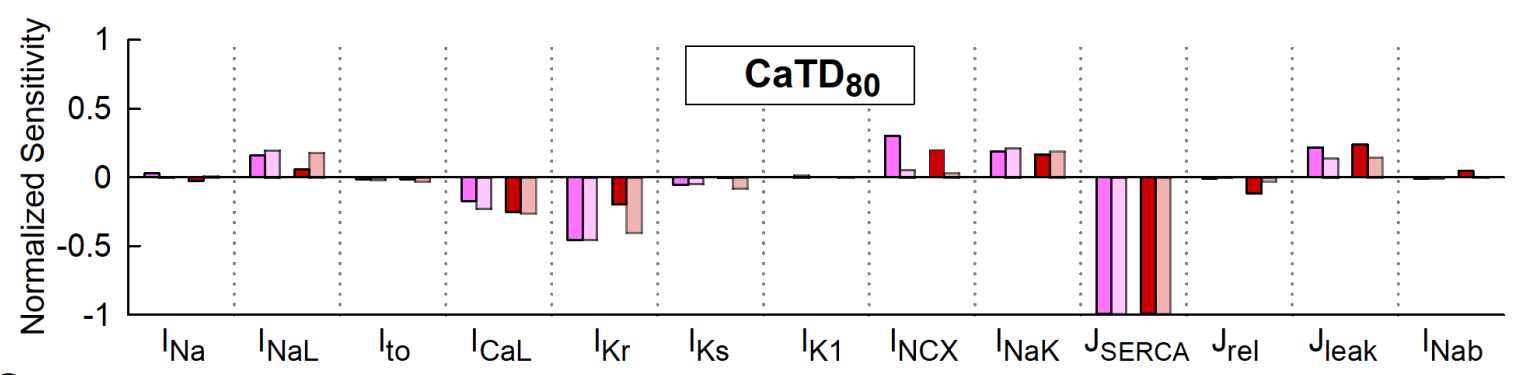

C

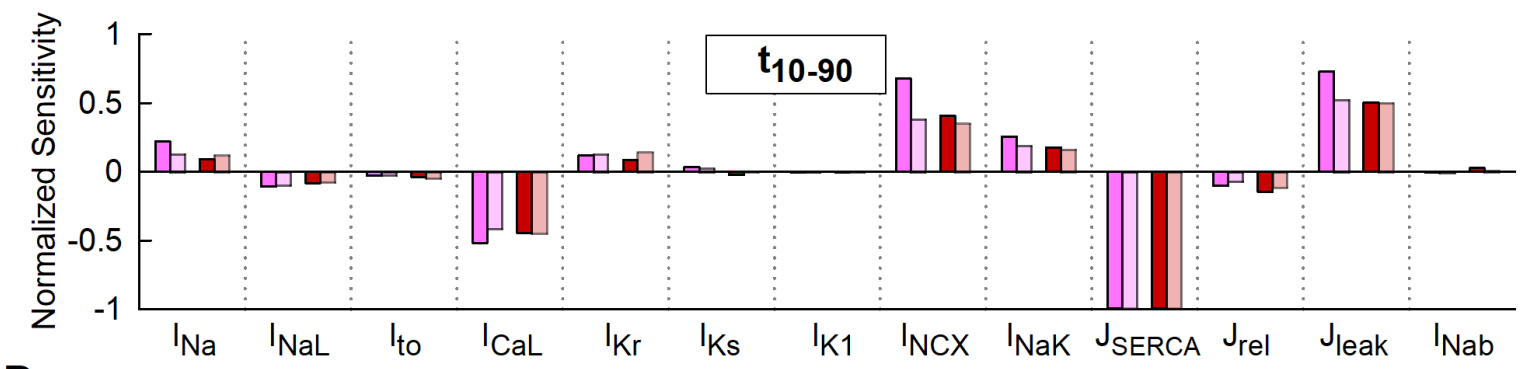

D

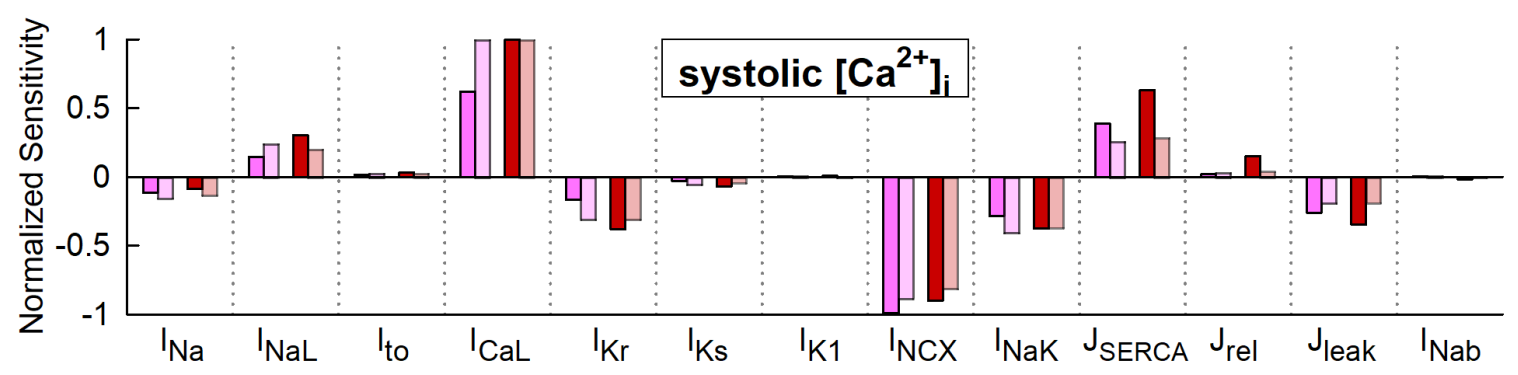

Figure 3.10. Univariate and multivariate sensitivities in heart failure with high and low parameter variability. Modulators of $\mathrm{A}$ ) action potential duration to $90 \%$ of repolarization $\left.\left(\mathrm{APD}_{90}\right), \mathrm{B}\right) \mathrm{Ca}^{2+}$ transient $(\mathrm{CaT})$ duration to $80 \%$ of recovery $\left.\left(\mathrm{CaTD}_{80}\right), \mathrm{C}\right) \mathrm{CaT}$ rise time $\left(\mathrm{t}_{10-90}\right)$ and, D) Systolic peak of CaT. 


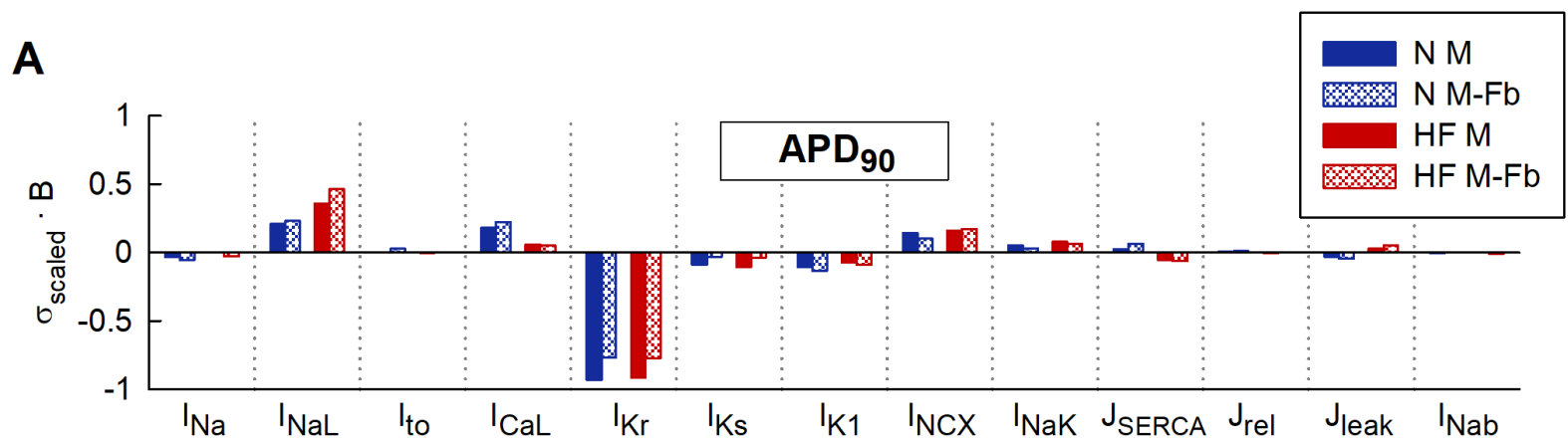

B

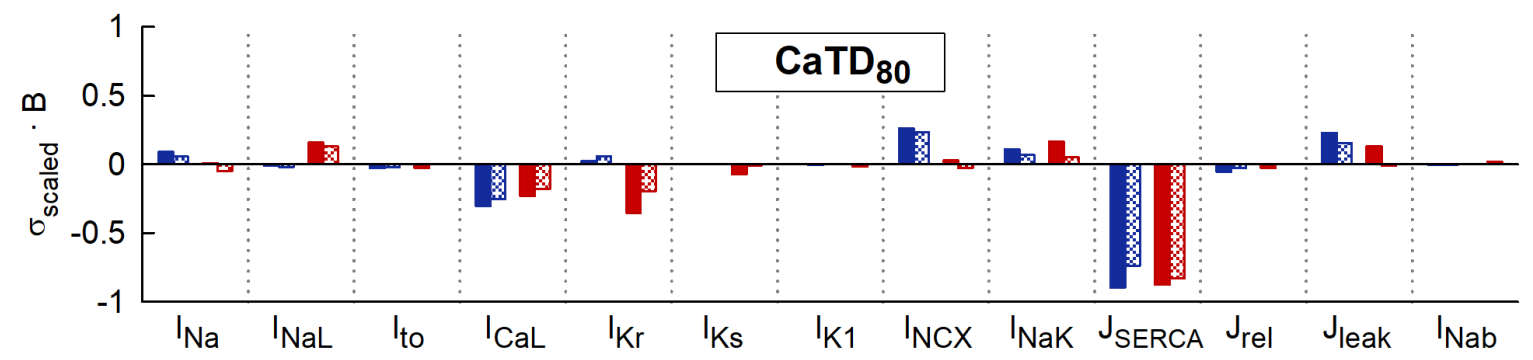

C

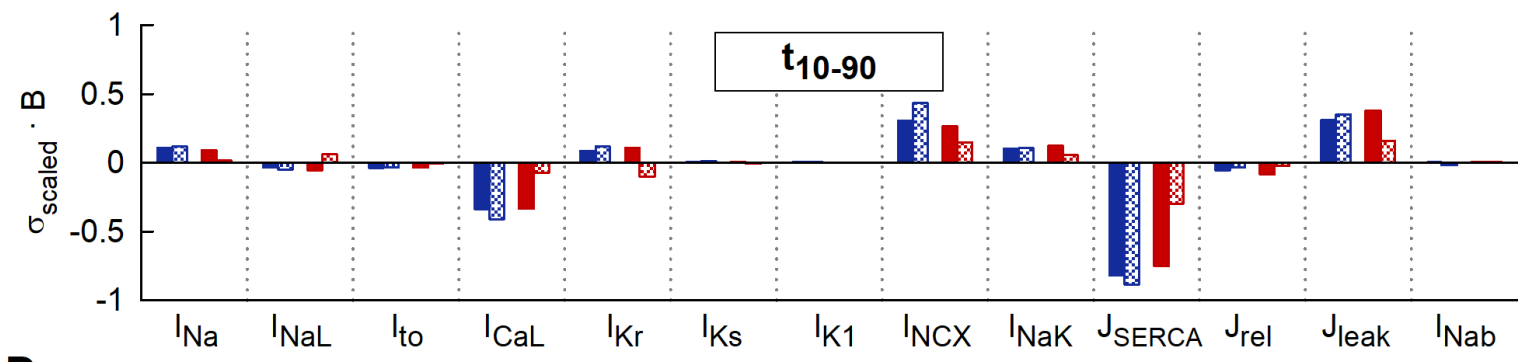

D

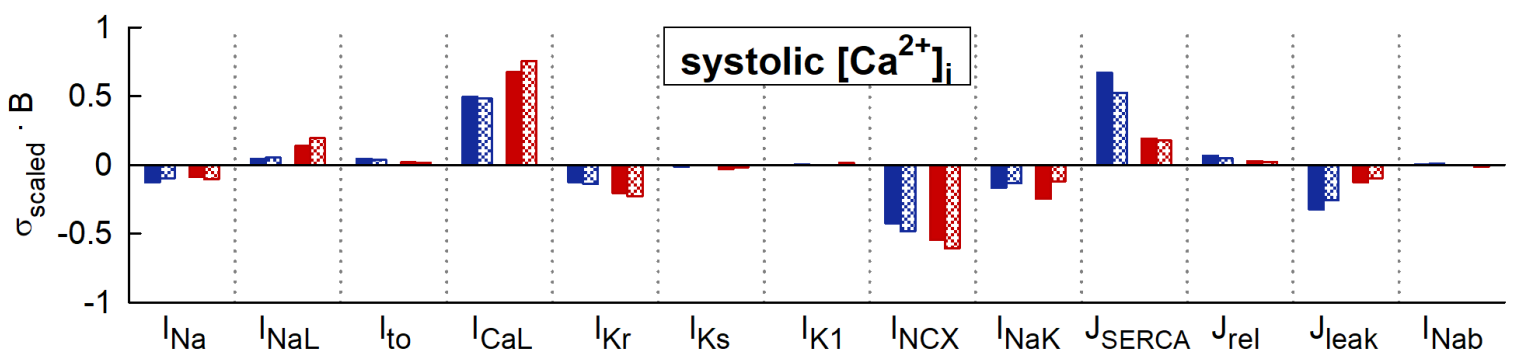

Figure 3.11. Comparison of sensitivities obtained from 4 multivariable regression analyses: normal $(\mathrm{N})$ and heart failure (HF) conditions with or without coupled fibroblasts (Fb). Modulators of A) action potential duration to $90 \%$ of repolarization $\left.\left(\mathrm{APD}_{90}\right), \mathrm{B}\right) \mathrm{Ca}^{2+}$ transient $(\mathrm{CaT})$ duration to $80 \%$ of recovery $\left(\mathrm{CaTD}_{80}\right)$, C) CaT rise time $\left(\mathrm{t}_{10-90}\right)$ and, D) Systolic peak of CaT. Low parameter variability $(\sigma=0.1)$. Regression coefficients $(\mathrm{B})$ are scaled to the standard deviation $(\sigma)$ of log-normal distributed biomarkers in uncoupled myocytes $(M)$. 

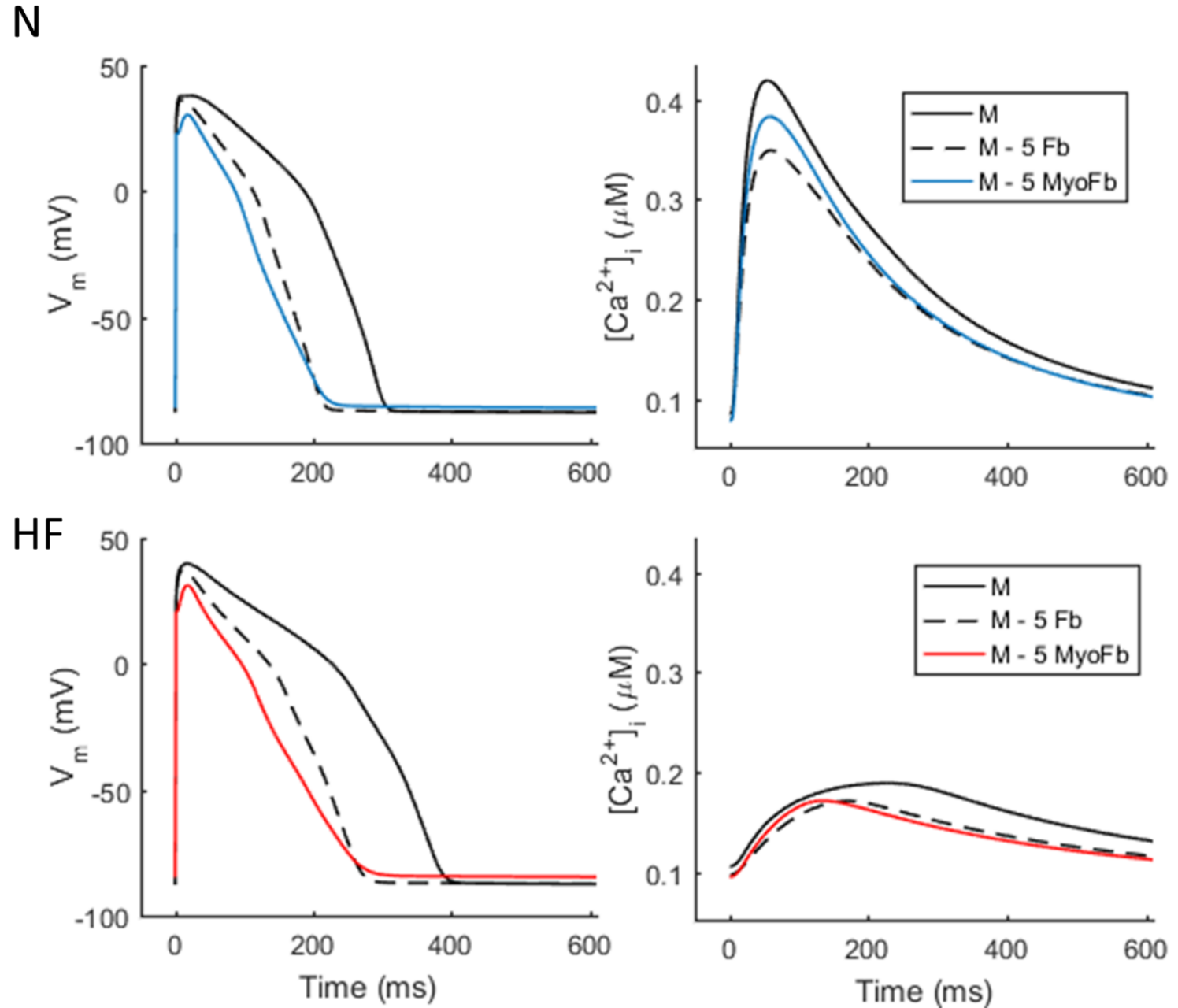

Figure 3.12. Comparison of the effects of coupling fibroblasts $(\mathrm{Fb})$ and myofibroblasts (MyoFb) on action potential and $\mathrm{Ca}^{2+}$ transient of a myocyte $(\mathrm{M})$ in normal $(\mathrm{N})$ and heart failure $(\mathrm{HF})$ conditions. For myofibroblast simulations, MacCannell et al. [27] active model was modified, increasing $\mathrm{C}_{\mathrm{m}}$ to $50 \mathrm{pF}$ and depolarizing the resting membrane potential of the fibroblast to $-24.5 \mathrm{mV}$.
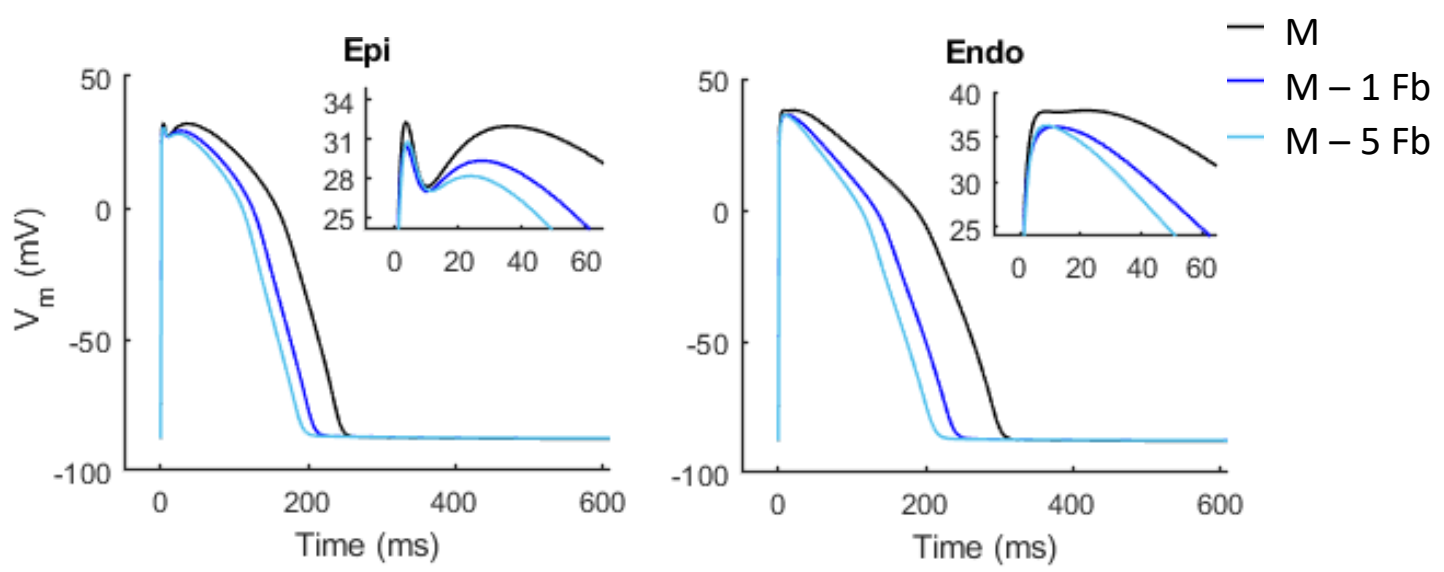

Figure 3.13. Comparison of the effects of coupling fibroblasts (Fb) to epicardial and endocardial cells (M) on action potential waveform. Insets show phase 1 with higher resolution. The number of coupled fibroblasts is 0 (M), 1 and 5 . 


\section{REFERENCES}

1. Savarese G, Lund LH. Global public health burden of heart failure. Card Fail Rev. Radcliffe Cardiology; 2017;3: 711. doi:10.15420/cfr.2016:25:2

2. Fukuta H, Little WC. Contribution of systolic and diastolic abnormalities to heart failure with a normal and a reduced ejection fraction. Prog Cardiovasc Dis. Elsevier; 2007;49: 229-240. doi:10.1016/j.pcad.2006.08.009

3. O’Hara T, Virág L, Varró A, Rudy Y. Simulation of the undiseased human cardiac ventricular action potential: model formulation and experimental validation. PLoS Comput Biol. 2011;7: e1002061. doi:10.1371/journal.pcbi.1002061

4. Trayanova NA, Chang KC. How computer simulations of the human heart can improve anti-arrhythmia therapy. J Physiol. 2016;594: 2483-2502. doi:10.1113/JP270532

5. Bers DM. Calcium fluxes involved in control of cardiac myocyte contraction. Circ Res. 2000;87: 275-281. doi:10.1161/01.RES.87.4.275

6. Alpert NR, Hasenfuss G, Leavitt BJ, Ittleman FP, Pieske B, Mulieri LA. A mechanistic analysis of reduced mechanical performance in human heart failure. Jpn Hear J. 2000;41: 103-115.

7. Piacentino V, Weber CR, Chen X, Weisser-Thomas J, Margulies KB, Bers DM, et al. Cellular basis of abnormal calcium transients of failing human ventricular myocytes. Circ Res. 2003;92: 651-658. doi:10.1161/01.RES.0000062469.83985.9B

8. Lou Q, Janks DL, Holzem KM, Lang D, Onal B, Ambrosi CM, et al. Right ventricular arrhythmogenesis in failing human heart: the role of conduction and repolarization remodeling. Am J Physiol Hear Circ Physiol. 2012;303: H1426-1434. doi:10.1152/ajpheart.00457.2012

9. Gomez JF, Cardona K, Romero L, Ferrero JM, Trenor B. Electrophysiological and structural remodeling in heart failure modulate arrhythmogenesis. 1D simulation study. PLoS One. 2014;9: e106602. doi:10.1371/journal.pone.0106602

10. Li Y, Asfour H, Bursac N. Age-dependent functional crosstalk between cardiac fibroblasts and cardiomyocytes in a 3D engineered cardiac tissue. Acta Biomater. Elsevier; 2017;55: 120-130. doi:10.1016/j.actbio.2017.04.027

11. Zhan H, Xia L, Shou G, Zang Y, Liu F, Crozier S. Fibroblast proliferation alters cardiac excitation conduction and contraction: a computational study. J Zhejiang Univ Sci B. 2014;15: 225-242. doi:10.1631/jzus.B1300156

12. Gaudesius G, Miragoli M, Thomas SP, Rohr S. Coupling of cardiac electrical activity over extended distances by fibroblasts of cardiac origin. Circ Res. American Heart Association, Inc.; 2003;93: 421-428. doi:10.1161/01.RES.0000089258.40661.0C

13. Xie Y, Garfinkel A, Camelliti P, Kohl P, Weiss JN, Qu Z. Effects of fibroblast-myocyte coupling on cardiac conduction and vulnerability to reentry: A computational study. Hear Rhythm. Elsevier Inc.; 2009;6: 1641-1649. doi:10.1016/j.hrthm.2009.08.003

14. Majumder R, Nayak AR, Pandit R. Nonequilibrium arrhythmic states and transitions in a mathematical model for diffuse fibrosis in human cardiac tissue. Chen X, editor. PLoS One. 2012;7: e45040. doi:10.1371/journal.pone.0045040

15. Miragoli M, Gaudesius G, Rohr S. Electrotonic modulation of cardiac impulse conduction by myofibroblasts. Circ Res. American Heart Association, Inc.; 2006;98: 801-810. doi:10.1161/01.RES.0000214537.44195.a3

16. Gomez JF, Cardona K, Martinez L, Saiz J, Trenor B. Electrophysiological and Structural Remodeling in Heart Failure Modulate Arrhythmogenesis. 2D Simulation Study. Panfilov A V., editor. PLoS One. 2014;9: e103273. doi:10.1371/journal.pone.0103273

17. Sridhar S, Vandersickel N, Panfilov A V. Effect of myocyte-fibroblast coupling on the onset of pathological dynamics in a model of ventricular tissue. Sci Rep. Nature Publishing Group; 2017;7: 40985. doi:10.1038/srep40985

18. Nguyen TP, Xie Y, Garfinkel A, Qu Z, Weiss JN. Arrhythmogenic consequences of myofibroblast-myocyte coupling. Cardiovasc Res. Oxford University Press; 2012;93: 242-251. doi:10.1093/cvr/cvr292

19. Romero L, Carbonell B, Trenor B, Rodríguez B, Saiz J, Ferrero JM. Systematic characterization of the ionic basis of rabbit cellular electrophysiology using two ventricular models. Prog Biophys Mol Biol. Pergamon; 2011;107: 6073. doi:10.1016/J.PBIOMOLBIO.2011.06.012

20. Trenor B, Cardona K, Gomez JF, Rajamani S, Ferrero JM, Belardinelli L, et al. Simulation and mechanistic investigation of the arrhythmogenic role of the late sodium current in human heart failure. PLoS One. 2012;7: e32659. doi:10.1371/journal.pone.0032659

21. Mayourian J, Savizky RM, Sobie EA, Costa KD. Modeling electrophysiological coupling and fusion between human 
mesenchymal stem cells and cardiomyocytes. PLoS Comput Biol. 2016;12: 1-29. doi:10.1371/journal.pcbi.1005014

22. Cummins MA, Dalal PJ, Bugana M, Severi S, Sobie EA. Comprehensive analyses of ventricular myocyte models identify targets exhibiting favorable rate dependence. PLoS Comput Biol. Public Library of Science; 2014;10: e1003543. doi:10.1371/journal.pcbi.1003543

23. Walmsley J, Rodriguez JF, Mirams GR, Burrage K, Efimov IR, Rodriguez B. mRNA expression levels in failing human hearts predict cellular electrophysiological remodeling: A population-based simulation study. PLoS One. 2013;8: e56359. doi:10.1371/journal.pone.0056359

24. Romero L, Pueyo E, Fink M, Rodríguez B. Impact of ionic current variability on human ventricular cellular electrophysiology. Am J Physiol Heart Circ Physiol. 2009;297: H1436-H1445. doi:10.1152/ajpheart.00263.2009

25. Sobie EA. Parameter sensitivity analysis in electrophysiological models using multivariable regression. Biophys J. 2009;96: 1264-1274. doi:10.1016/j.bpj.2008.10.056

26. Mora MT, Ferrero JM, Romero L, Trenor B. Sensitivity analysis revealing the effect of modulating ionic mechanisms on calcium dynamics in simulated human heart failure. Csernoch L, editor. PLoS One. 2017;12: e0187739. doi:10.1371/journal.pone.0187739

27. MacCannell KA, Bazzazi H, Chilton L, Shibukawa Y, Clark RB, Giles WR. A mathematical model of electrotonic interactions between ventricular myocytes and fibroblasts. Biophys J. 2007;92: 4121-4132. doi:10.1529/biophysj.106.101410

28. Rook MB, van Ginneken AC, de Jonge B, el Aoumari A, Gros D, Jongsma HJ. Differences in gap junction channels between cardiac myocytes, fibroblasts, and heterologous pairs. Am J Physiol Physiol. 1992;263: C959-C977. doi:10.1152/ajpcell.1992.263.5.C959

29. Zimik S, Pandit R. Instability of spiral and scroll waves in the presence of a gradient in the fibroblast density: the effects of fibroblast-myocyte coupling. New J Phys. IOP Publishing; 2016;18: 1-13. doi:10.1088/13672630/18/12/123014

30. Muszkiewicz A, Britton OJ, Gemmell P, Passini E, Sánchez C, Zhou X, et al. Variability in cardiac electrophysiology: Using experimentally-calibrated populations of models to move beyond the single virtual physiological human paradigm. Prog Biophys Mol Biol. 2016;120: 115-127. doi:10.1016/j.pbiomolbio.2015.12.002

31. Drouin E, Lande G, Charpentier F. Amiodarone reduces transmural heterogeneity of repolarization in the human heart. J Am Coll Cardiol. 1998;32: 1063-1067. doi:10.1016/S0735-1097(98)00330-1

32. Li GR, Feng J, Yue L, Carrier M. Transmural heterogeneity of action potentials and Ito1 in myocytes isolated from the human right ventricle. Am J Physiol. 1998;275: H369-H377.

33. Pereon Y, Demolombe S, Baro I, Drouin E, Charpentier F, Escande D. Differential expression of KvLQT1 isoforms across the human ventricular wall. Am J Physiol Hear Circ Physiol. 2000;278: H1908-H1915.

34. Morotti S, Nieves-Cintrón M, Nystoriak MA, Navedo MF, Grandi E. Predominant contribution of L-type Cav1.2 channel stimulation to impaired intracellular calcium and cerebral artery vasoconstriction in diabetic hyperglycemia. Channels. 2017;11: 340-346. doi:10.1080/19336950.2017.1293220

35. Rocchetti M, Alemanni M, Mostacciuolo G, Barassi P, Altomare C, Chisci R, et al. Modulation of sarcoplasmic reticulum function by PST2744 [istaroxime; (E,Z)-3-((2-aminoethoxy)imino) androstane-6,17-dione hydrochloride)] in a pressure-overload heart failure model. J Pharmacol Exp Ther. 2008;326: 957-965. doi:10.1124/jpet.108.138701

36. Ozdemir S, Bito V, Holemans P, Vinet L, Mercadier JJ, Varro A, et al. Pharmacological inhibition of Na/Ca exchange results in increased cellular Ca2+ load attributable to the predominance of forward mode block. Circ Res. 2008;102: 1398-1405. doi:10.1161/CIRCRESAHA.108.173922

37. Tamayo M, Manzanares E, Bas M, Martín-Nunes L, Val-Blasco A, Jesús Larriba M, et al. Calcitriol (1,25dihydroxyvitamin D3) increases L-type calcium current via protein kinase A signaling and modulates calcium cycling and contractility in isolated mouse ventricular myocytes. Hear Rhythm. Elsevier Inc.; 2017;14: 432-439. doi:10.1016/j.hrthm.2016.12.013

38. Zhou X, Bueno-Orovio A, Orini M, Hanson B, Hayward M, Taggart P, et al. In vivo and in silico investigation into mechanisms of frequency dependence of repolarization alternans in human ventricular cardiomyocytes. Circ Res. 2016;118: 266-278. doi:10.1161/CIRCRESAHA.115.307836

39. Britton OJ, Bueno-Orovio A, Virág L, Varró A, Rodriguez B. The electrogenic Na+/K+ pump is a key determinant of repolarization abnormality susceptibility in human ventricular cardiomyocytes: A population-based simulation study. Front Physiol. 2017;8: 1-13. doi:10.3389/fphys.2017.00278

40. Zlochiver S, Muñoz V, Vikstrom KL, Taffet SM, Berenfeld O, Jalife J. Electrotonic myofibroblast-to-myocyte 
coupling increases propensity to reentrant arrhythmias in two-dimensional cardiac monolayers. Biophys J. Elsevier; 2008;95: 4469-80. doi:10.1529/biophysj.108.136473

41. Jacquemet V, Henriquez CS. Loading effect of fibroblast-myocyte coupling on resting potential, impulse propagation, and repolarization: insights from a microstructure model. Am J Physiol Circ Physiol. 2008;294: H2040 H2052. doi:10.1152/ajpheart.01298.2007

42. Chilton L, Giles WR, Smith GL. Evidence of intercellular coupling between co-cultured adult rabbit ventricular myocytes and myofibroblasts. J Physiol. 2007;583: 225-236. doi:10.1113/jphysiol.2007.135038

43. Sachse FB, Moreno AP, Seemann G, Abildskov JA. A model of electrical conduction in cardiac tissue including fibroblasts. Ann Biomed Eng. 2009;37: 874-889. doi:10.1007/s10439-009-9667-4

44. Cartledge JE, Kane C, Dias P, Tesfom M, Clarke L, Mckee B, et al. Functional crosstalk between cardiac fibroblasts and adult cardiomyocytes by soluble mediators. Cardiovasc Res. 2015;105: 260-270. doi:10.1093/cvr/cvu264

45. Chilton L, Ohya S, Freed D, George E, Drobic V, Shibukawa Y, et al. K+ currents regulate the resting membrane potential, proliferation, and contractile responses in ventricular fibroblasts and myofibroblasts. Am J Physiol Circ Physiol. 2005;288: H2931-H2939. doi:10.1152/ajpheart.01220.2004

46. Xie Y, Garfinkel A, Weiss JN, Qu Z. Cardiac alternans induced by fibroblast-myocyte coupling: mechanistic insights from computational models. Am J Physiol Circ Physiol. American Physiological Society; 2009;297: H775-H784. doi:10.1152/ajpheart.00341.2009

47. Brown TR, Krogh-Madsen T, Christini DJ. Illuminating Myocyte-Fibroblast Homotypic and Heterotypic Gap Junction Dynamics Using Dynamic Clamp. Biophys J. Elsevier; 2016;111: 785-797. doi:10.1016/j.bpj.2016.06.042

48. Shannon TR, Ginsburg KS, Bers DM. Potentiation of fractional sarcoplasmic reticulum calcium release by total and free intra-sarcoplasmic reticulum calcium concentration. Biophys J. 2000;78: 334-343. doi:10.1016/S00063495(00)76596-9

49. Aguilar M, Qi XY, Huang H, Comtois P, Nattel S. Fibroblast electrical remodeling in heart failure and potential effects on atrial fibrillation. Biophys J. Elsevier; 2014;107: 2444-2455. doi:10.1016/j.bpj.2014.10.014

50. Chen J-B, Tao R, Sun H-Y, Tse H-F, Lau C-P, Li G-R. Multiple Ca2+ signaling pathways regulate intracellular Ca2+ activity in human cardiac fibroblasts. J Cell Physiol. 2010;223: 68-75. doi:10.1002/jcp.22010

51. Zou J, Salarian M, Chen Y, Zhuo Y, Brown NE, Hepler JR, et al. Direct visualization of interaction between calmodulin and connexin45. Biochem J. 2017;474: 4035-4051. doi:10.1042/BCJ20170426

52. Lyon AR, MacLeod KT, Zhang Y, Garcia E, Kanda GK, Lab MJ, et al. Loss of T-tubules and other changes to surface topography in ventricular myocytes from failing human and rat heart. Proc Natl Acad Sci U S A. National Academy of Sciences; 2009;106: 6854-9. doi:10.1073/pnas.0809777106

53. Sanchez-Alonso JL, Bhargava A, O’Hara T, Glukhov A V, Schobesberger S, Bhogal N, et al. Microdomain-Specific Modulation of L-Type Calcium Channels Leads to Triggered Ventricular Arrhythmia in Heart Failure. Circ Res. 2016;119: 944-945. doi:10.1161/CIRCRESAHA.116.308698

54. Nivala M, Song Z, Weiss JN, Qu Z. T-tubule disruption promotes calcium alternans in failing ventricular myocytes: Mechanistic insights from computational modeling. J Mol Cell Cardiol. Elsevier Ltd; 2015;79: 32-41. doi:10.1016/j.yjmcc.2014.10.018

55. Greisas A, Zlochiver S. The Multi-Domain Fibroblast/Myocyte Coupling in the Cardiac Tissue: A Theoretical Study. Cardiovasc Eng Technol. 2016;7: 290-304. doi:10.1007/s13239-016-0266-X

56. Cabo C, Boyden PA. Extracellular space attenuates the effect of gap junctional remodeling on wave propagation: a computational study. Biophys J. Elsevier; 2009;96: 3092-101. doi:10.1016/j.bpj.2009.01.014

57. Seidel T, Salameh A, Dhein S. A simulation study of cellular hypertrophy and connexin lateralization in cardiac tissue. Biophys J. Elsevier; 2010;99: 2821-30. doi:10.1016/j.bpj.2010.09.010

58. ten Tusscher KHWJ, Noble D, Noble PJ, Panfilov A V. A model for human ventricular tissue. Am J Physiol Heart Circ Physiol. 2004;286: H1573-89. doi:10.1152/ajpheart.00794.2003

59. Passini E, Mincholé A, Coppini R, Cerbai E, Rodriguez B, Severi S, et al. Mechanisms of pro-arrhythmic abnormalities in ventricular repolarisation and anti-arrhythmic therapies in human hypertrophic cardiomyopathy. $\mathrm{J}$ Mol Cell Cardiol. 2016;96: 72-81. doi:10.1016/j.yjmcc.2015.09.003

60. Maltsev VA, Undrovinas AI. A multi-modal composition of the late $\mathrm{Na}+$ current in human ventricular cardiomyocytes. Cardiovasc Res. 2006;69: 116-127. doi:10.1016/j.cardiores.2005.08.015

61. Maltsev VA, Silverman N, Sabbah HN, Undrovinas AI. Chronic heart failure slows late sodium current in human and canine ventricular myocytes: Implications for repolarization variability. Eur J Heart Fail. Wiley-Blackwell; 
2007;9: 219-227. doi:10.1016/j.ejheart.2006.08.007

62. Beuckelmann DJ, Nabauer M, Erdmann E. Alterations of K+ currents in isolated human ventricular myocytes from patients with terminal heart failure. Circ Res. 1993;73: 379-385. doi:10.1161/01.RES.73.2.379

63. Tomaselli G, Marbán E. Electrophysiological remodeling in hypertrophy and heart failure. Cardiovasc Res. Oxford University Press; 1999;42: 270-283. doi:10.1016/S0008-6363(99)00017-6

64. Tomaselli GF. What Causes Sudden Death in Heart Failure? Circ Res. American Heart Association, Inc.; 2004;95: 754-763. doi:10.1161/01.RES.0000145047.14691.db

65. Bundgaard H, Kjeldsen K. Human myocardial Na,K-ATPase concentration in heart failure. Mol Cell Biochem. Kluwer Academic Publishers; 1996;163-164: 277-283. doi:10.1007/BF00408668

66. Winslow RL, Rice J, Jafri S, Marban E, O’Rourke B. Mechanisms of Altered Excitation-Contraction Coupling in Canine Tachycardia-Induced Heart Failure, II: Model Studies. Circ Res. 1999;84: 571-586. doi:10.1161/01.RES.84.5.571

67. Antoons G, Oros A, Bito V, Sipido KR, Vos MA. Cellular basis for triggered ventricular arrhythmias that occur in the setting of compensated hypertrophy and heart failure: considerations for diagnosis and treatment. J Electrocardiol. Elsevier; 2007;40: S8-S14. doi:10.1016/j.jelectrocard.2007.05.022

68. Sossalla S, Maurer U, Schotola H, Hartmann N, Didié M, Zimmermann W-H, et al. Diastolic dysfunction and arrhythmias caused by overexpression of CaMKII $\delta \mathrm{C}$ can be reversed by inhibition of late Na+ current. Basic Res Cardiol. Springer-Verlag; 2011;106: 263-272. doi:10.1007/s00395-010-0136-x

69. Bers DM, Despa S, Bossuyt J. Regulation of Ca2+ and Na+ in Normal and Failing Cardiac Myocytes. Ann N Y Acad Sci. Wiley/Blackwell (10.1111); 2006;1080: 165-177. doi:10.1196/annals.1380.015

70. George CH. Sarcoplasmic reticulum $\mathrm{Ca} 2+$ leak in heart failure: observation or functional relevance? Cardiovasc Res. Oxford University Press; 2007;77: 302-314. doi:10.1093/cvr/cvm006 


\title{
Chapter 4
}

\section{Mechanistic investigation of $\mathrm{Ca}^{2+}$ alternans in human heart failure and its modulation by fibroblasts}

Maria T. Mora ${ }^{\mathrm{a}}$, Juan F. Gomez ${ }^{\mathrm{a}}$, Gregory Morley ${ }^{\mathrm{b}}$, Jose M. Ferrero ${ }^{\mathrm{a} \text { III }}$, Beatriz Trenor ${ }^{\mathrm{a} I I}$

\begin{abstract}
Background

Heart failure $(H F)$ is characterized, among other factors, by a progressive loss of contractile function and by the formation of an arrhythmogenic substrate, both aspects partially related to intracellular $\mathrm{Ca}^{2+}$ cycling disorders. In failing hearts both electrophysiological and structural remodeling, including fibroblast proliferation, contribute to changes in $\mathrm{Ca}^{2+}$ handling which promote the appearance of $\mathrm{Ca}^{2+}$ alternans (Ca-alt). Ca-alt in turn give rise to repolarization alternans, which promote dispersion of repolarization and contribute to reentrant activity. The computational analysis of the incidence of $\mathrm{Ca}^{2+}$ and/or repolarization alternans under HF conditions in the presence of fibroblasts could provide a better understanding of the mechanisms leading to HF arrhythmias and contractile function disorders.
\end{abstract}

\section{Methods and findings}

The goal of the present study was to investigate in silico the mechanisms leading to the formation of Ca-alt in failing human ventricular myocytes and tissues with disperse fibroblast distributions. The contribution of ionic currents variability to alternans formation at the cellular level was analyzed and the results show that in normal ventricular tissue, altered $\mathrm{Ca}^{2+}$ dynamics lead to Ca-alt, which precede APD alternans and can be aggravated by the presence of fibroblasts. Electrophysiological remodeling of failing tissue alone is sufficient to develop alternans. The incidence of alternans is reduced when fibroblasts are present in failing tissue due to significantly depressed $\mathrm{Ca}^{2+}$ transients. The analysis of the underlying ionic mechanisms suggests that Ca-alt are driven by $\mathrm{Ca}^{2+}$-handling protein and $\mathrm{Ca}^{2+}$ cycling dysfunctions in the junctional sarcoplasmic reticulum and that their contribution to alternans occurrence depends on the cardiac remodeling conditions and on myocyte-fibroblast interactions.

\footnotetext{
Mora MT, Gomez JF, Morley G, Ferrero JM, Trenor B. Mechanistic investigation of $\mathrm{Ca}^{2+}$ alternans in human heart failure and its modulation by fibroblasts. PLoS One. 2019;14: 1-19. doi:10.1371/journal.pone.0217993
}

aCentro de Insvestigación e Innovación en Bioingeniería, Universitat Politècnica de València, Valencia, Spain
${ }^{b}$ Leon H. Charney Division of Cardiology, New York University School of Medicine, New York, New York, USA

IThese authors contributed equally to this work. 


\section{Conclusion}

It can thus be concluded that fibroblasts modulate the formation of Ca-alt in human ventricular tissue subjected to heart failure-related electrophysiological remodeling. Pharmacological therapies should thus consider the extent of both the electrophysiological and structural remodeling present in the failing heart.

\subsection{Introduction}

Heart failure (HF) with reduced left ventricular ejection fraction is characterized by a progressive loss of contractile function and the genesis of malignant arrhythmias, leading to cardiac dysfunction and sudden cardiac death. Altered action potentials (APs), $\mathrm{Ca}^{2+}$ transients (CaTs) in myocytes and abnormal electrical conduction in cardiac tissue may result from the electrophysiological and structural remodeling of the failing heart, in which fibroblast proliferation has been observed [1-3].

Despite the extensive research on heterocellular connections between cardiac myocytes and nonexcitable cells, the existence of this heterocellular coupling in vivo is still controversial [4]. The first experimental evidence was found in isolated cells and cultures in animal models and showed functional gap junctions between fibroblasts and myocytes, allowing electrical propagation [5-8]. More recent studies have demonstrated electrical coupling between scar tissue and the surrounding myocardium in live injured hearts [9-11]. These electrotonic interactions affect myocyte impulse conduction and electrophysiological activity [12-15] and increase the arrhythmogenic consequences [16,17]. Although numerous studies have used computer simulations of cardiac tissue with fibroblast coupling to investigate the origin of reentrant activity $[18,19]$, including our previous work on failing tissue [20], the role of beat-to-beat alternans has not yet been considered.

Mechanoelectrical alternans, i.e. T-wave and contractile beat-to-beat oscillations, have been observed in HF patients [21]. Electrical alternans are linked to arrhythmogenesis because of dispersion of refractoriness and have become a risk indicator of sudden cardiac death [22], in addition to the ventricular dysfunction resulting from mechanical alternans. Cardiac alternans manifest as AP and $\mathrm{Ca}^{2+}$ cycling fluctuations in myocytes due to the fact that the membrane voltage and $\mathrm{Ca}^{2+}$ processes are coupled. However, the underlying mechanisms leading to alternans have not yet been fully identified and the feedback nature of coupling between voltage and $\mathrm{Ca}^{2+}$ dynamics complicates the task. Among the proposed mechanisms, voltage-driven $\mathrm{Ca}^{2+}$-mediated alternans and the contribution of both systems [23-27] have been suggested.

The most extensively developed theory is that alternans are induced by $\mathrm{Ca}^{2+}$ cycling instabilities, by which an altered sarcoplasmic reticulum $(\mathrm{SR}) \mathrm{Ca}^{2+}$ release process through the ryanodine receptor (RyR) impairs $\mathrm{Ca}^{2+}$ dynamics and initiates alternans [28,29]. Fluctuations in the $\mathrm{SR} \mathrm{Ca}^{2+}$ content [30] have suggested an impairment between $\mathrm{Ca}^{2+}$ uptake and release mechanisms. Computational studies have analyzed the role of the different $\mathrm{Ca}^{2+}$-handling proteins and their interactions that contribute to $\mathrm{Ca}^{2+}$ alternans [31,32]. In agreement with computational results, SERCA overexpression has been shown to supress cellular alternans [33].

Since the normal heart can develop alternans at rapid heart rates, the vast majority of experimental and computational studies on cellular alternans $[28,31,34]$ have been performed on non- 
failing myocytes or without considering all the main HF features, such as electrophysiological remodeling, intercellular decoupling and fibroblast coupling. These changes in the cardiac tissue modify myocyte electrophysiology and could alter the susceptibility to alternans. We consider that the passive characteristics of the tissue also play a role in generating alternans. Discordant alternans can produce spatial repolarization gradients that may generate electrical reentries leading to ventricular fibrillation [35], so that it is crucial to determine the causes and susceptibility to spatially discordant versus concordant alternans.

The aim of this study was thus to characterize the onset of alternans in HF under the influence of disperse fibroblasts using a virtual two-dimensional human model. In the first part of the study, we used a mathematical model of a single human ventricular myocyte to study its bioelectrical activity, including $\mathrm{Ca}^{2+}$ dynamics in health and during $\mathrm{HF}$, coupled or uncoupled to fibroblasts. Simulations were performed to determine the influence of pacing frequency on the alternans occurrence threshold. In the second part we simulated the activity of a virtual ventricular tissue with normal and failing myocyte populations, with or without inserted fibroblasts. We built populations of models by imposing variability to ion channels and pumps. The biological variability represented in the different models can reveal the most favorable conditions that induce $\mathrm{Ca}^{2+}$ beat-to-beat alternans and, by means of the $\mathrm{Ca}^{2+}$-driven theory, the important role of $\mathrm{Ca}^{2+}$-handling proteins in modifying $\mathrm{Ca}^{2+}$ dynamics.

\subsection{Methods}

\subsubsection{Cellular simulations}

Cardiac tissue consists of interconnected cardiomyocytes and other non-muscular cells, such as fibroblasts, which might establish electrical connections with myocytes through gap junctions. The role of fibroblast-myocyte interactions at the onset of alternans was first studied in single-cell simulations and compared to two coupled myocytes to identify the key parameters responsible for beat-to-beat oscillations, as well as the impact of HF. The reduction of the variables at the cellular level made it possible to reduce the computational time in the 2D study. The second study was essential in order to understand the origin, features and effects of alternans, such as arrhythmogenic spatial discordance.

The O'Hara et al. [36] human AP model (ORd) was used to simulate the electrophysiological activity of endocardial myocytes. As in our previous work [37], small changes were made to the sodium current $\left(\mathrm{I}_{\mathrm{Na}}\right)$ in the model to improve electrical conduction and update the late component to the most recent experimental evidence. The active fibroblast model developed by MacCannell et al. [38] was coupled to myocytes to analyze fibroblast-myocyte interactions. Myocyte-fibroblast coupling was performed taking into account an individual gap junction conductance $\left(\mathrm{G}_{\mathrm{gap}}\right)$ of $3 \mathrm{nS}$, within the experimental range [8], which was increased five-fold to establish a 1:5 ratio between cells, accounting for an increased degree of disperse fibroblasts. Although cell-to-cell coupling between myocytes is stronger, the experimental measurements in myocyte pairs span a wide range $[39,40]$, so that the $\mathrm{G}_{\text {gap }}$ was set to an intermediate value of $1.3 \mu \mathrm{S}$. HF conditions, i.e. electrophysiological myocyte remodeling, were also simulated. In HF, myocyte-myocyte coupling was reduced by $50 \%$.

Electrophysiological remodeling in HF was simulated by applying a scale factor to the maximal conductances of the selected ionic channels (Table 4.1), which represents an upregulation or 
downregulation of protein expression and/or function obtained from experimental human myocytes when possible, as detailed in Gomez et al. [41].

Table 4.1. Electrophysiological remodeling in HF applied to the basic ORd model.

\begin{tabular}{lc}
\hline $\begin{array}{l}\text { ORd model } \\
\text { parameter }\end{array}$ & $\begin{array}{l}\text { Upregulation/ } \\
\text { Downregulation in } \\
\text { HF remodeling }\end{array}$ \\
\hline $\mathbf{I}_{\mathbf{N a L}}$ & $+80 \%$ \\
$\tau_{\mathrm{hL}}$ & $+80 \%$ \\
$\mathbf{I}_{\mathbf{t}}$ & $-60 \%$ \\
$\mathbf{I}_{\mathbf{K} 1}$ & $-32 \%$ \\
$\mathbf{I}_{\mathbf{N a K}}$ & $-30 \%$ \\
$\mathbf{I}_{\mathbf{N C X}}$ & $+75 \%$ \\
$\mathbf{C a M K a}_{\mathbf{J}}$ & $+50 \%$ \\
$\mathbf{J}_{\text {SERCA }}$ & $-50 \%$ \\
$\mathbf{J}_{\text {leak }}$ & $+30 \%$ \\
$\mathbf{K}_{\text {rel, Ca }}$ & $-20 \%$ \\
\hline
\end{tabular}

The modified parameters in heart failure (HF) are: the late $\mathrm{Na}^{+}$current $\left(\mathrm{I}_{\mathrm{NaL}}\right)$, the inactivation time constant of $\mathrm{I}_{\mathrm{NaL}}\left(\tau_{\mathrm{hL}}\right)$, the transient outward current $\left(I_{t o}\right)$, the inward rectifier $\mathrm{K}^{+}$current $\left(\mathrm{I}_{\mathrm{K} 1}\right)$, the $\mathrm{Na}^{+} / \mathrm{K}^{+}$pump current $\left(\mathrm{I}_{\mathrm{NaK}}\right), \mathrm{the} \mathrm{Na}^{+} / \mathrm{Ca}^{2+}$ exchanger $\left(\mathrm{I}_{\mathrm{NCX}}\right)$, the active fraction of the $\mathrm{Ca}^{+2}$ calmodulin-dependent protein kinase II (CaMKa), the sarcoplasmic reticulum (SR) $\mathrm{Ca}^{2+}$ pump $\left(\mathrm{J}_{\mathrm{SERCA}}\right)$, the $\mathrm{SR} \mathrm{Ca}{ }^{2+}$ leak $\left(\mathrm{J}_{\text {leak }}\right)$, and the sensitivity to $\left[\mathrm{Ca}^{2+}\right]_{\mathrm{JSR}}$ of the ryanodine receptors $\left(\mathrm{Ca}^{2+}\right.$ sensitivity of $\mathrm{J}_{\mathrm{rel}, \infty}$, called $\mathrm{K}_{\mathrm{rel}, \mathrm{Ca}}$ ).

Alternans typically occur at fast pacing rates. The pacing cycle length (PCL) threshold was determined by computing a restitution curve starting at a PCL of $1000 \mathrm{~ms}$ and reducing the cycle length until loss of capture was observed. Each simulation was run until steady-state was reached. The last two APs and CaTs were used to measure AP duration from maximal upstroke to $90 \%$ of repolarization $\left(\mathrm{APD}_{90}\right)$ and the maximum intracellular $\left[\mathrm{Ca}^{2+}\right]$, respectively.

After determining pacing threshold in the baseline models, populations of models were built and simulations were carried out at a fixed low PCL in which alternans tend to occur. Populations of models consisted of different cellular models built after varying the selected parameters related to ionic currents of the baseline model, mimicking biological inter-individual variability. We modified 13 maximal ion channel conductances and fluxes simultaneously using random scale factors obtained from a normal distribution of mean equal to 1 and standard deviation $(\sigma)$ equal to 0.15 , so that $95 \%$ $( \pm 2 \sigma)$ of the parameters varied in the range $\pm 30 \%$ of their baseline values. The selected variables affect the conductances of the fast $\mathrm{Na}^{+}$current $\left(\mathrm{I}_{\mathrm{Na}}\right)$, late $\mathrm{Na}^{+}$current $\left(\mathrm{I}_{\mathrm{NaL}}\right)$, transient outward $\mathrm{K}^{+}$current $\left(\mathrm{I}_{\mathrm{to}}\right)$, L-type $\mathrm{Ca}^{2+}$ current $\left(\mathrm{I}_{\mathrm{CaL}}\right)$, rapid delayed rectifier $\mathrm{K}^{+}$current $\left(\mathrm{I}_{\mathrm{Kr}}\right)$, slow delayed rectifier $\mathrm{K}^{+}$current $\left(\mathrm{I}_{\mathrm{KS}}\right)$, inward rectifier $\mathrm{K}^{+}$current $\left(\mathrm{I}_{\mathrm{K} 1}\right), \mathrm{Na}^{+} / \mathrm{K}^{+}$ATPase current $\left(\mathrm{I}_{\mathrm{NaK}}\right), \mathrm{Na}^{+} / \mathrm{Ca}^{2+}$ exchange current ( $\left.\mathrm{I}_{\mathrm{NCX}}\right)$, SR $\mathrm{Ca}^{2+}$ uptake via SERCA pump $\left(\mathrm{J}_{\mathrm{SERCA}}\right)$, SR Ca ${ }^{2+}$ release flux via RyR $\left(\mathrm{J}_{\text {rel }}\right)$, SR Ca ${ }^{2+}$ leak $\left(\mathrm{J}_{\text {leak }}\right)$, and $\mathrm{Na}^{+}$background current $\left(\mathrm{I}_{\mathrm{Nab}}\right)$. Four basic cellular models were considered with different baseline conditions and/or coupling to build the populations: normal myocyte coupled to normal myocyte $(\mathrm{N}-\mathrm{N})$, normal myocyte coupled to fibroblast $(\mathrm{N}-\mathrm{Fb})$, failing myocyte coupled to failing myocyte (HF-HF), and failing myocyte coupled to fibroblast (HF-Fb). Populations of 300 different human AP models were analyzed and compared to study the role of ion channel variation in alternans generation. 
Alternans were measured in AP and CaT waveforms, as shown in Eqs (4.1) and (4.2), but the final model classification criterion was the $\mathrm{Ca}^{2+}$ alternans ratio [34], i.e. the relative differences between the small and large CaT amplitude (CaTA), since these were more evident than APD variations. While 0 indicated no alternation, models with $\mathrm{Ca}$-alt $>0.1$ were considered as having alternans.

$$
\text { Ca-alt }=1-\frac{\text { CaTA } A_{\text {small }}}{\text { CaTA } A_{\text {large }}}
$$

APD alternans (APD-alt) were also calculated as the APD 90 difference between two consecutive beats.

$$
A P D \text {-alt }=A P D_{90 \text { Long }}-A P D_{90 \text { short }}
$$

The models were classified into two groups according to whether or not the CaTs presented alternation. The analysis of the differences in parameter scaling factors between both groups determined the mechanistic contribution of ionic parameters to alternans generation. Statistical differences between groups were determined by the Wilcoxon rank-sum test $(\mathrm{p}<0.05)$. Simulations and data analysis were performed on MATLAB (R2017b, Mathworks).
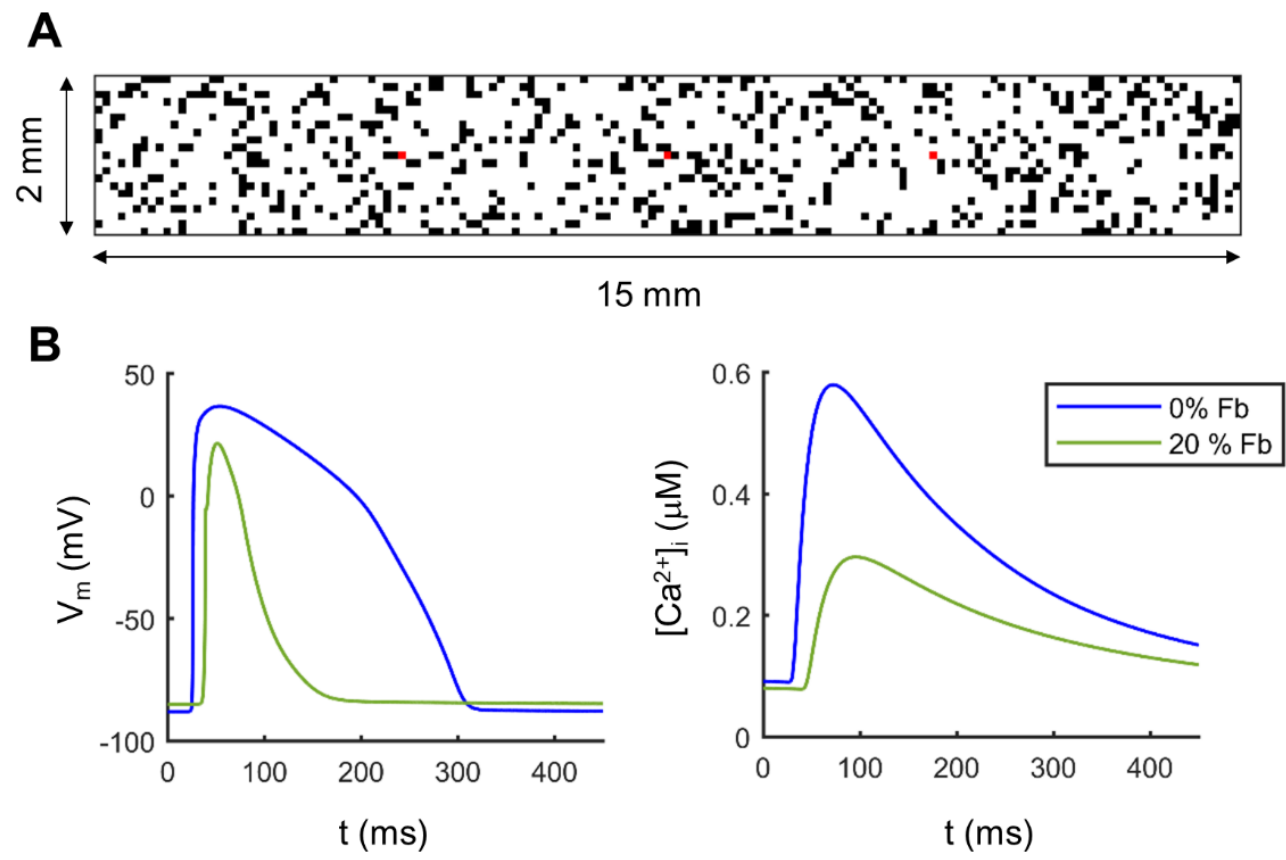

Figure 4.1. Electrophysiology in cardiac tissue simulations. A) Distribution of fibroblasts (20 \%; black squares) in a tissue of myocytes. Each square represents a node of the mesh and measurement nodes are marked in red. B) Action potential (AP) and calcium transient (CaT) waveforms obtained in the central node of the tissue without fibroblasts by stimulating at $1.25 \mathrm{~Hz}$ (blue traces) and with $20 \%$ of fibroblasts (green traces).

\subsubsection{Tissue simulations}

Electrical propagation was simulated in a set of two-dimensional strands (15 $\mathrm{mm}$ along the $\mathrm{x}$ axis and $2 \mathrm{~mm}$ along the y-axis) formed by myocytes and fibroblasts. Longitudinal fiber orientation was assigned along the $\mathrm{x}$-axis. The tissue was isotropic, i.e. longitudinal and transversal conductivities 
were identical. The domain was discretized at a spatial resolution of $0.1 \mathrm{~mm}$, which provided 3000 squared elements and 3171 nodes within the tissue, where the cellular model was computed. The timestep for the numerical method was set to $0.01 \mathrm{~ms}$ to ensure numerical convergence.

$20 \%$ of disperse fibroblasts were considered in half of the cases and were randomly intercalated among the myocytes, as shown in Figure 4.1A, i.e. $20 \%$ of the mesh nodes were solved with the fibroblast model. Electrotonic coupling between myocytes and fibroblasts was weaker than myocytemyocyte coupling. A myocyte-myocyte diffusion coefficient (D) of $0.0024 \mathrm{~cm}^{2} / \mathrm{ms}$ was used, which yielded a conduction velocity $(\mathrm{CV})$ of $0.7 \mathrm{~m} / \mathrm{s}$ along the fibers in normal conditions [42]. To simulate intercellular uncoupling, diffusion between myocytes was reduced by $50 \%$ in $\mathrm{HF}\left(\mathrm{D}=0.0012 \mathrm{~cm}^{2} / \mathrm{ms}\right)$ and 3-fold for the fibroblast-myocyte and fibroblast-fibroblast coupling ( $D=0.0008 \mathrm{~cm}^{2} / \mathrm{ms}$ ). The assignment of the diffusion coefficient to each element was chosen as in Gomez et al. [20].

Stimulation was applied to the left (short) side of the tissue and APs and CaTs were recorded in three different myocytes after 400 beats to ensure steady-state waveforms and alternans. We used the critical PCL obtained in the first part of the study (couple single-cells simulations) at which alternans appeared. Initial simulations at a basal PCL of $800 \mathrm{~ms}$ were conducted in tissues with different configurations to ensure that the results were independent of variations in fibroblast distribution (Figure 4.1B).

To reduce the computational cost of these tissue simulations, instead of considering a large population, as in the coupled single cells, we considered a subpopulation of models by varying the four most crucial factors that led to cellular alternans in the coupled single-cell simulations in the first part of the study, assuming that this subpopulation could be used to elucidate the onset of arrhythmogenic events and also the different behavior of failing and fibrotic tissue.

The most important parameters that contributed to alternans were selected from the coupled single-cell populations of models. The cardiac tissue subpopulation involved varying parameters by $\pm 30 \%$ of their maximum value and accounted for all the possible combinations $\left(3^{4}=81\right)$. As in the coupled single-cell populations, we classified models into two groups: alternans (Ca-alt $>0.1)$ and no alternans, and calculated APD-alt. The magnitude of alternans and the spatial distribution of alternans along the tissue were also taken into account.

The simulations were performed on ELVIRA software [43], which is based on the finite element method to solve the monodomain equation by the operator splitting technique $[20,44]$.

\subsection{Results}

\subsubsection{Coupled single-cell simulations}

\section{Restitution curve}

The initial simulations in coupled single cells provided a preliminary overview of the electrophysiological behavior in myocytes under pathological conditions and fast pacing rates to force beat-to-beat alternation. The following models were compared: $\mathrm{N}-\mathrm{N}, \mathrm{N}-\mathrm{Fb}, \mathrm{HF}-\mathrm{HF}$, and HF-Fb.

Figure 4.2 shows the restitution curves of $\mathrm{APD}_{90}$ and systolic $\mathrm{Ca}^{2+}$ of the four baseline models. These data indicate that an increase in heart rate leads to fluctuations in APD 90 in consecutive beats in $\mathrm{N}-\mathrm{N}$, which are concomitant with Ca-alt. The large magnitude of Ca-alt is more evident than APD-alt. Figure 4.2 also shows the different alternans thresholds, according to the simulated conditions of the 
baseline models. While the CaT of N-N begins to alternate at a PCL of $300 \mathrm{~ms}$, the electrical interactions between myocytes and fibroblasts in $\mathrm{N}-\mathrm{Fb}$ increase this value to $360 \mathrm{~ms}$. Myocytemyocyte interactions seemed to slightly affect the bidirectional coupling between APD $_{90}$ and $\mathrm{Ca}^{2+}$ alternans, as there were small Ca-alt not translated into APD-alt.

HF-HF myocytes, with changes in $\mathrm{APD}_{90}$ and $\mathrm{CaT}$ amplitude, do not show alternans at fast pacing rates and end up in loss of capture at an early PCL equal to $250 \mathrm{~ms}$. The HF-Fb model presents a lower $\mathrm{APD}_{90}$ and loss of capture is delayed. Although it is difficult to compare the slope of the restitution curves for the four models at high frequencies, when the PCL is longer, HF-HF shows a steeper slope than N-N and fibroblast coupling contributes to reducing the slope.
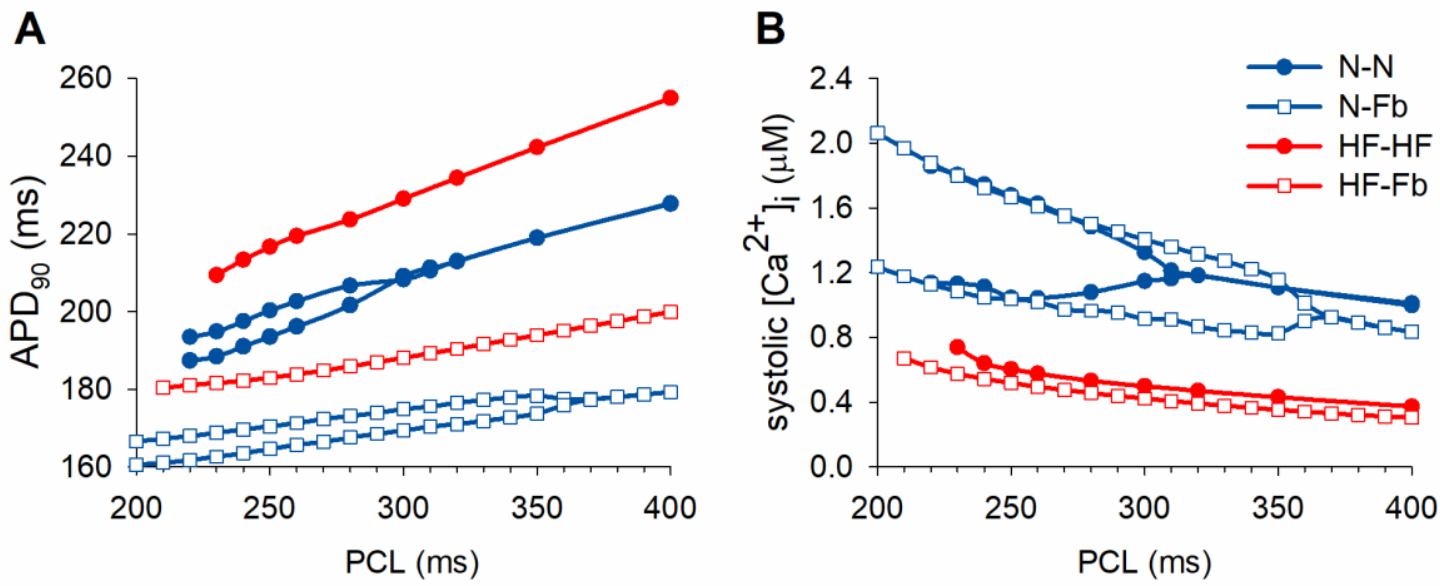

Figure 4.2. Restitution curves of baseline coupled single-cell models. A) Action potential duration ( $\left.A P D_{90}\right)$ and B) Systolic $\left[\mathrm{Ca}^{2+}\right]_{\mathrm{i}}$. Comparison of electrophysiological indicators and alternans onset in myocyte-myocyte (solid circles) and myocyte-fibroblast (1:5 ratio) aggregations (empty squares) under normal (blue) and failing (red) conditions.The four traces are: normal myocyte coupled to normal myocyte $(\mathrm{N}-\mathrm{N})$, normal myocyte coupled to fibroblasts $(\mathrm{N}-\mathrm{Fb})$, failing myocyte coupled to failing myocyte (HF-HF), and failing myocyte coupled to fibroblasts (HF-Fb).

To clarify the origin of alternans, an AP clamp test was simulated (results not shown). When forcing fixed APs, $\mathrm{Ca}^{2+}$ dynamics alternans were not eliminated, while when fixing $\left[\mathrm{Ca}^{2+}\right]_{\mathrm{i}},\left[\mathrm{Ca}^{2+}\right]_{\mathrm{JSR}}$ or $\mathrm{J}_{\mathrm{rel}}$, all the alternans types disappeared, revealing a $\mathrm{Ca}^{2+}$-driven mechanism. Positive coupling between $\mathrm{Ca}^{2+}$ and APD alternans was also observed, as the large (small) CaT was always in phase with the long (short) APD. NCX was the mechanism coupling between Ca-alt and APD-alt, by generating a higher inward current during the large $\mathrm{CaT}$ to remove $\mathrm{Ca}^{2+}$, which prolonged APD and suppressed the small reducing effects of an inward $\mathrm{Ca}^{2+}$-inactivated $\mathrm{I}_{\mathrm{CaL}}$.

\section{Populations of models}

The four baseline models described above were used to build populations of cells by introducing natural variability into the electrophysiological variables. Small inter-individual differences can have remarkable effects on alternans development and may help to understand their origin. The boxplots in Figure 4.3 show the distribution of ionic conductances after classifying the models into the nonalternans or alternans groups. With scale factors in the range of 0.3-1.3, significant differences were found in $\mathrm{I}_{\mathrm{Na}}, \mathrm{I}_{\mathrm{NaL}}, \mathrm{I}_{\mathrm{Kr}}, \mathrm{NCX}, \mathrm{I}_{\mathrm{NaK}}$, SERCA, $\mathrm{J}_{\text {rel }}$ and $\mathrm{J}_{\text {leak }}$ for the N-N population. In N-Fb models, the effect of $\mathrm{I}_{\mathrm{CaL}}$ as also significant, as well as that of NCX, $\mathrm{I}_{\mathrm{NaK}}$, SERCA and $\mathrm{J}_{\text {rel. }}$. In the HF setting (HF- 
$\mathrm{HF}$ and $\mathrm{HF}-\mathrm{Fb}$ ), although there was agreement between the main mechanisms that contribute to alternans, unlike healthy myocytes, the failing myocytes in the alternans group presented the inverse modulation of $\mathrm{Ca}^{+2}$-related parameters, regardless of fibroblast content. While high $\mathrm{I}_{\mathrm{CaL}}$ and SERCA values and small NCX and $\mathrm{J}_{\text {leak }}$ values facilitated alternans in the failing populations, normal populations showed the opposite behaviour. As an exception, the impact of $J_{\text {rel }}$ was consistent in all the populations because the higher $\mathrm{Ca}^{+2}$ release induced alternans.

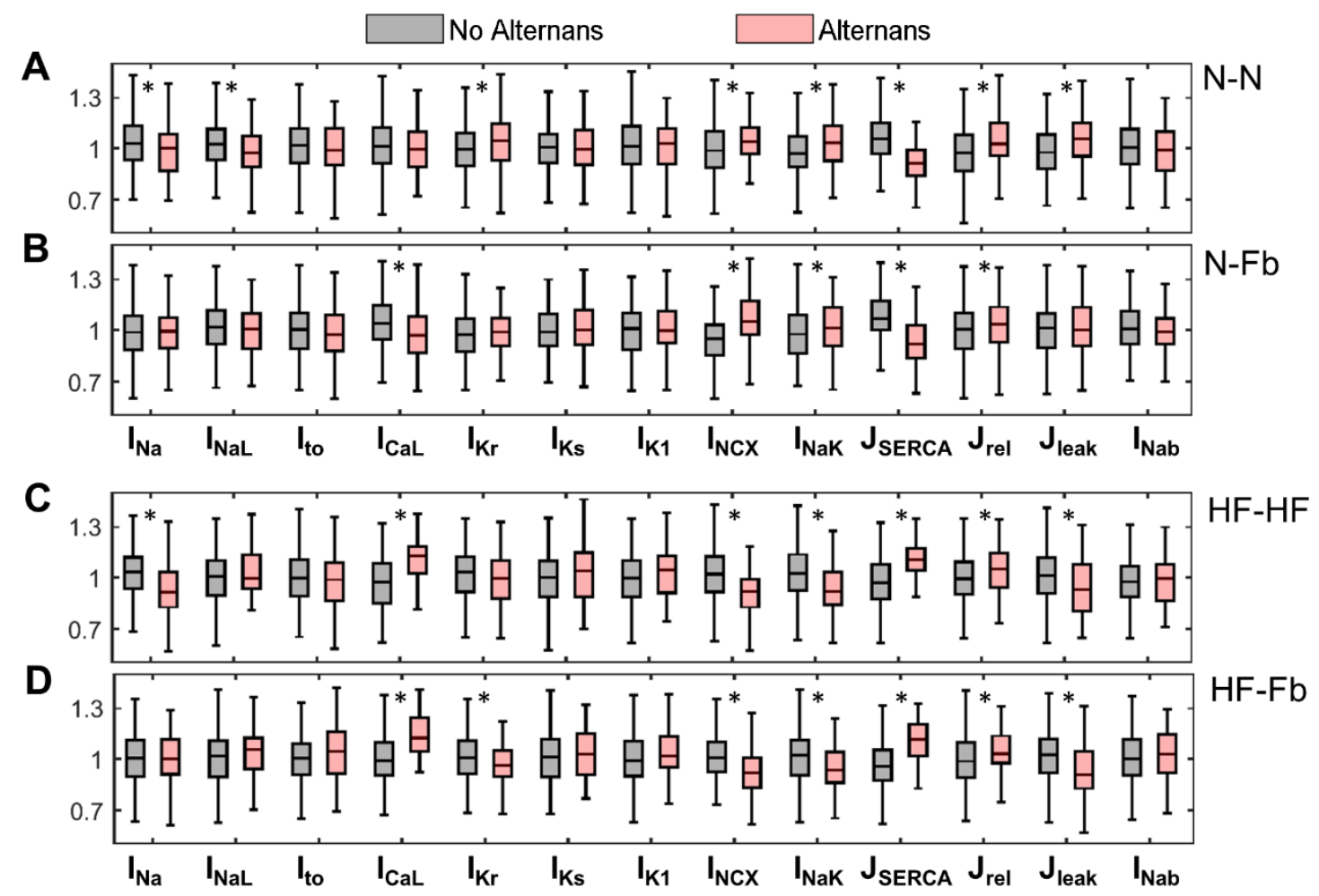

Figure 4.3. Parameter distribution according to alternans occurrence in coupled single-cell populations. The four populations are: A) normal myocyte coupled to normal myocyte (N-N), B) normal myocyte coupled to fibroblasts (N-Fb), C) failing myocyte coupled to failing myocyte (HF-HF), and D) failing myocyte coupled to fibroblasts (HF-Fb). Parameter values are represented by the scaling factors applied to the baseline models. A value of $p<0.05\left(^{*}\right)$ in the medians was considered statistically significant.

\subsubsection{Cardiac tissue simulations}

\section{Two-dimensional populations of models}

Cardiac tissue myocyte simulations provide more reliable information than coupled single-cell simulations, due to electrical propagation. Four tissue configurations were considered: normal myocytes (N-tissue), failing myocytes (HF-tissue), normal myocytes and fibroblasts (N-Fb-tissue), and failing myocytes and fibroblasts (HF-Fb-tissue). Ionic parameters in myocytes (SERCA, I $\mathrm{CaL}_{\text {, }}$ $\mathrm{NCX}$ and $\mathrm{I}_{\mathrm{NaK}}$ ) were varied to generate sets of tissue prone to alternans, on the basis of the mechanisms observed in the coupled single-cell populations. The variation of the four most important parameters related to alternans generation yielded 81 tissue models for each configuration (see Methods). The numbers of alternans cases in the different tissues are given in Table 4.2. 
Although the magnitude of alternans can be different, accounting for the central myocytes exhibiting Ca-alt > 0.1, the results obtained highlight the major incidence of alternans in HF-tissue (including loss of AP capture). The effect of disperse fibroblasts in cardiac tissue increases alternans events in $\mathrm{N}$-Fb-tissue, while it reduces the occurrence in HF-Fb-tissue. In HF-tissue, many simulations end up in one AP for every two consecutive stimulations (loss of capture), which were considered as a special case of alternans, although the origin could be different. This 2:1 block activity was not observed in any of the other cases.

Table 4.2. Alternans occurrence in four subpopulations of cardiac tissue.

\begin{tabular}{lll}
\hline & $\mathbf{N}$ & $\mathbf{H F}$ \\
\hline $\begin{array}{l}\text { without } \\
\text { fibroblasts }\end{array}$ & $37 \%$ & $43(65) \%$ \\
$\mathbf{2 0} \%$ & $52 \%$ & $30 \%$ \\
fibroblasts & 5 & \\
\hline
\end{tabular}

There were four tissue configurations: healthy myocytes $(\mathrm{N})$ or myocytes with heart failure remodeling (HF), combined with or without disperse fibroblasts (20\% of nodes). The pacing cycle length was set to 300 ms. Four electrophysiological parameters were modified ( $\mathrm{I}_{\mathrm{CaL}}$, SERCA, NCX and $\mathrm{I}_{\mathrm{NaK}}$ ). Alternans were Ca-alt $>0.1$. Values in brackets consider 2:1 block of action potentials as alternans.

Figure 4.4 contains a graph showing Ca-alt and APD-alt values in circles and a gray scale of all the tissue sets arranged in 9x9 matrixes. The corresponding SERCA, I $\mathrm{CaL}_{\mathrm{L}}, \mathrm{NCX}$, and $\mathrm{I}_{\mathrm{NaK}}$ scaling factors specific to each myocyte variant classify the models in the matrix squares. In $\mathrm{N}$-tissue, alternans mainly occur with reduced SERCA and $\mathrm{I}_{\mathrm{CaL}}$ and high NCX. While Ca-alt can rise to values of up to 0.8 in amplitude ratio, the maximum APD 90 variation between consecutive beats is only $15 \mathrm{~ms}$. The same mechanisms induce alternans in $\mathrm{N}$-Fb-tissue, but most APD-alt become negligible despite the greater incidence of $\mathrm{Ca}$-alt. When the tissue included failing myocytes, the ionic modulation inducing Ca-alt of similar magnitude is different to the one observed in healthy myocytes. In HF-tissue, the repolarization alternans values are higher (up to $30 \mathrm{~ms}$ ), although they are still of considerable magnitude in HF-Fb-tissue. The analysis of the loss of capture of AP in HF-tissue (shown by a cross) reveals that increased NCX, together with low SERCA and low $\mathrm{I}_{\mathrm{NaK}}$ activity lead to this outcome.

Differences were found in $\mathrm{CaT}$ amplitude of the alternans and no alternans groups of the different populations. Since intracellular $\mathrm{Ca}^{2+}$ is linked to the amount of $\mathrm{Ca}^{2+}$ stored and released from the SR, the systolic $\mathrm{Ca}^{2+}$ peak was compared to maximum diastolic $\left[\mathrm{Ca}^{2+}\right]_{\text {JSR }}$ (see Figure 4.5 ). The linear correlation confirmed that cytosolic and sarcoplasmic $\mathrm{Ca}^{2+}$ content are related and also indicated that Ca-alt occurs within a specific range of $\left[\mathrm{Ca}^{2+}\right]_{\text {JSR }}$ values. This range (shaded area) was very similar for all four groups, but the normal myocytes (N-tissue and N-Fb-tissue) had the lowest values of $\left[\mathrm{Ca}^{2+}\right]$, while HF (HF-tissue and HF-Fb-tissue) had the highest $\mathrm{Ca}^{2+}$ levels of the interval covered by the different models. 

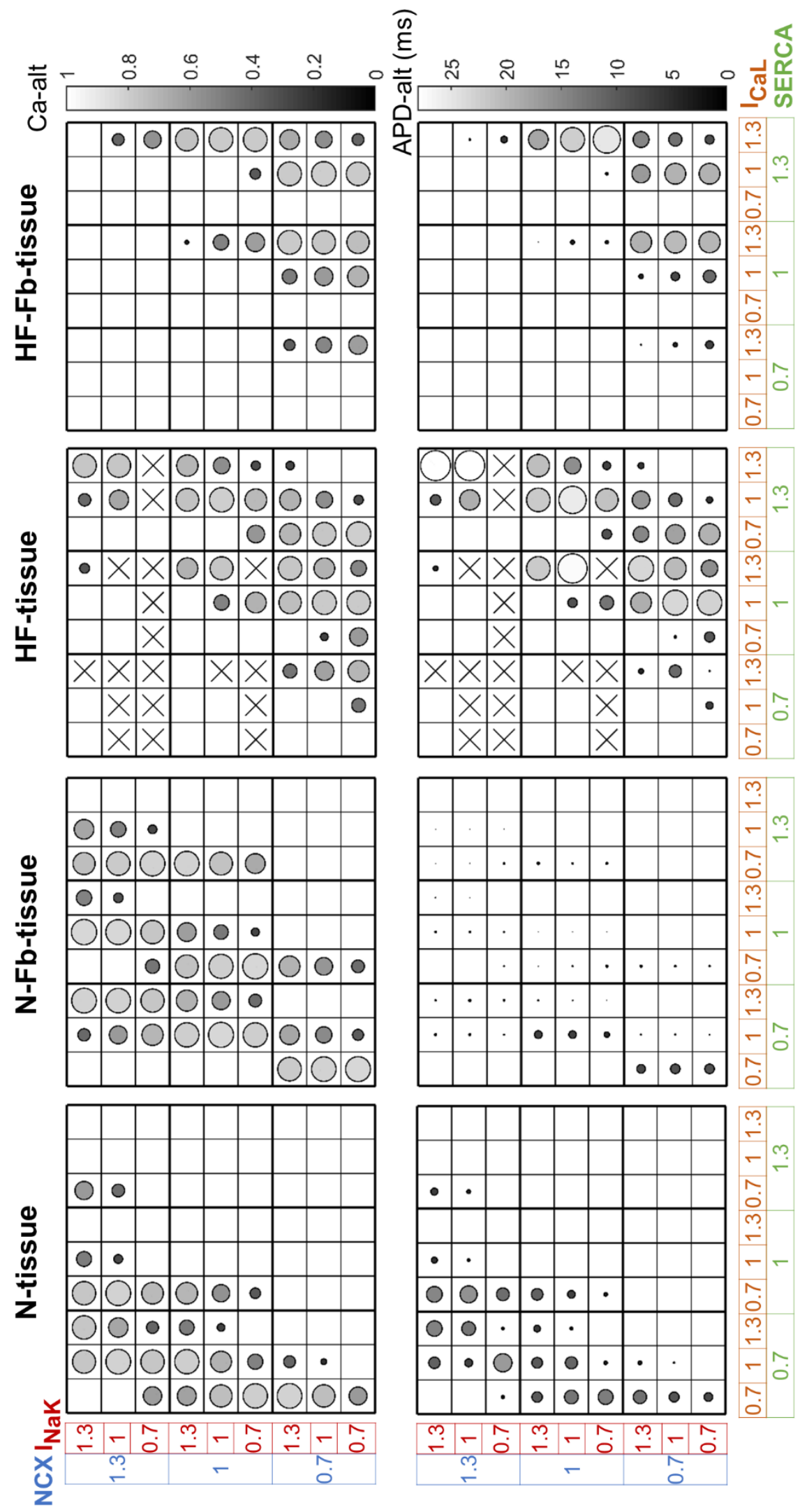

Figure 4.4. $\mathrm{Ca}^{2+}$ and APD alternans (Ca-alt and APD-alt) in tissues. Ca-alt (upper panels) and APD-alt (lower panels) of every model variant is classified according to the parameter values that lead to those results. The four tissue configurations are: normal myocytes (N-tissue), failing myocytes (HF-tissue), normal myocytes and fibroblasts ( $\mathrm{N}-\mathrm{Fb}$ tissue), and failing myocytes and fibroblasts (HF-Fb-tissue). Alternans magnitude is proportional to circle size and gray scale. Crosses represent 2:1 block. 
A

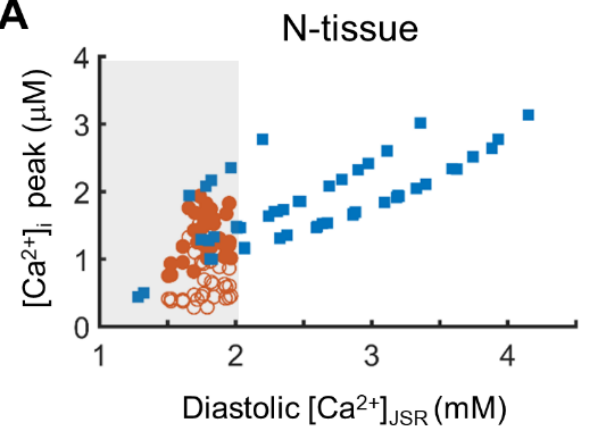

C

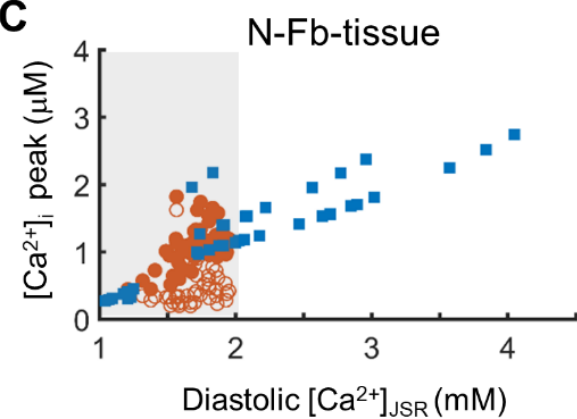

B HF-tissue

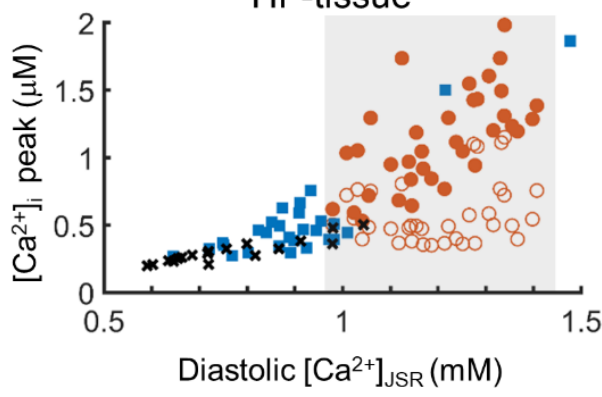

D

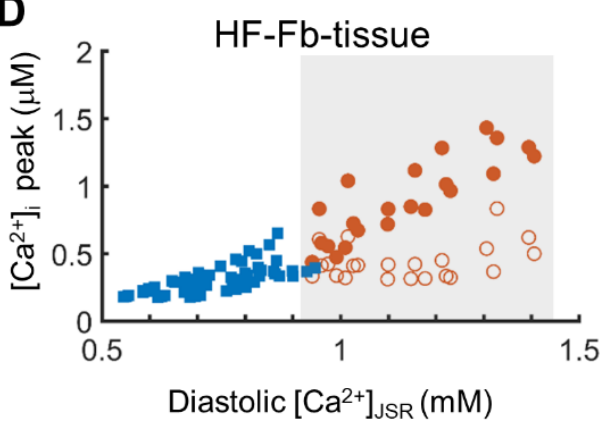

- $\mathrm{CaT}_{\mathrm{L}}$

- $\mathrm{CaT}_{\mathrm{S}}$

- CaT $_{\text {no alternans }}$

× Block 2:1

Figure 4.5. Relation between $\mathrm{SR} \mathrm{Ca}^{2+}$ content, $\mathbf{C a}^{2+}$ peak and alternans. The $\mathrm{CaT}$ peak (systolic $\left[\mathrm{Ca}^{2+}\right]_{\mathrm{i}}$ ) is related to the maximum junctional sarcoplasmic reticulum $\mathrm{Ca}^{2+}$ content (diastolic $\left[\mathrm{Ca}^{2+}\right]_{\mathrm{JSR}}$ ) of the myocyte. Comparison of 4 populations obtained in cardiac tissue: A) normal myocytes (N-tissue), B) failing myocytes (HF-tissue), C) normal myocytes and fibroblasts (N-Fb-tissue), and D) failing myocytes and fibroblasts (HF-Fb-tissue). Shaded areas highlight regions where alternans cases prevail.

\section{Spatial and mechanical discordance}

As cardiac alternans can become arrhythmogenic and the impact depends on the spatial distribution of the electrical fluctuations, we analyzed the evolution of alternans along the strand. Figure 4.6 shows $\mathrm{APD}_{90}$ and $\left[\mathrm{Ca}^{2+}\right]_{i}$ peak for two consecutive beats (blue for even and red for odd beats) in a representative case from each population, quantified in the central nodes of the tissue along the longitudinal axis (x). APD-alt patterns are long-short (L-S) and Ca-alt patterns are large-small (L$\mathrm{S}$ ). When a long APD is concomitant with a large CaT (same color) there is positive V-Ca coupling or electromechanical concordance, otherwise there is electromechanical discordance. Consecutive dots with the same color show that alternans between adjacent myocytes are in phase (spatially concordant), while changes in color indicate a change in alternans patterns between consecutive myocytes (spatially discordant). Spatial concordance in APD alternans is predominant in the four populations because all the myocytes are in phase following the same pattern in APs. This can be seen in both N-tissue (Figure 4.6A) and HF-tissue (Figure 4.6C), where spatial concordance is found in APD and Ca alternans. The $\mathrm{CV}$ in $\mathrm{N}$-tissue was $0.65 \mathrm{~m} / \mathrm{s}$ and the characteristic cellular uncoupling in HF reduced it to $0.4 \mathrm{~m} / \mathrm{s}$ in HF-tissue but the alternans electrical propagation does not seem to be affected. In some cases, discordance can appear in $\mathrm{Ca}^{2+}$ dynamics in normal tissue or in both APD and $\mathrm{Ca}^{2+}$ activity in failing tissue. Of all the N-tissue simulated, only $13 \%$ of tissue variants with Ca-alt are spatially discordant, while in $\mathrm{N}-\mathrm{Fb}$-tissue all the $\mathrm{Ca}$-alt become discordant. In these tissues with fibroblasts, APD 90 alternans are concordant, so that electromechanical discordance occurs (Figure 4.6B). However, in failing tissues, discordant Ca-alt do not increase significantly from HF-tissue (7.5\% alternans) to $\mathrm{HF}$-Fb-tissue (12.5\% alternans). What distinguishes $\mathrm{HF}-\mathrm{Fb}$-tissue from $\mathrm{N}-\mathrm{Fb}$-tissue is that spatial discordance 
occurs in both Ca-alt and APD-alt and is less chaotic (Figure 4.6D), which could be related to a slower $\mathrm{CV}(0.34 \mathrm{~m} / \mathrm{s}$ vs $0.44 \mathrm{~m} / \mathrm{s}$ in normal tissue with fibroblasts $)$.

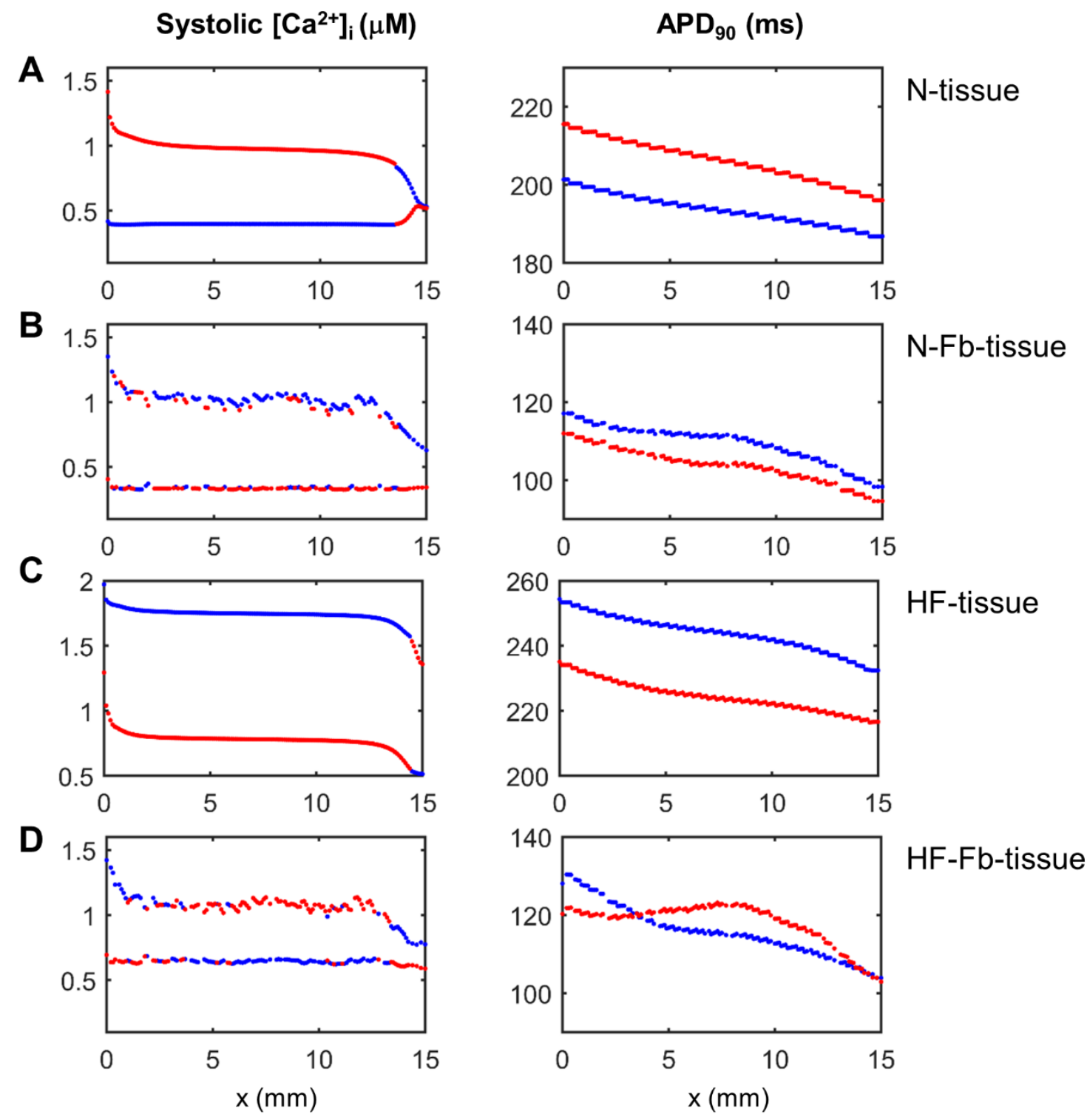

Figure 4.6. Spatial distribution of $\mathrm{Ca}^{2+}$ peak and APD90 in tissues. Node values (myocytes) are given for the central fiber of the strand for 2 consecutive beats (red and blue). The four tissue configurations are: A) normal myocytes (N-tissue), B) normal myocytes with fibroblasts (N-Fb-tissue), C) failing myocytes (HF-tissue), and D) failing myocytes with fibroblasts (HF-Fb-tissue). Y-axis has the same scale in $\mathrm{Ca}^{2+}$ and APD graphs, respectively but values can vary for the sake of clarity.

In addition to spatial differences, Figure 4.6 shows maximum and minimum APD 90 and systolic $\left[\mathrm{Ca}^{2+}\right]_{\mathrm{i}}$ values. Although these values also depend on the modulation of ionic parameters, the figures show that although there are differences in APD90, small and large CaTs from different myocytes with alternating activity can become similar in magnitude. The APD 90 prolongation characteristic of HF appears in HF-tissue and affects APD-alt, but there is also a significant reduction in APD $_{90}$ in fibrotic tissues (N-Fb-tissue and HF-Fb-tissue) due to myocyte-fibroblast interactions. 
Since fibroblasts seem to contribute to a more chaotic spatial distribution of Ca-alt, the whole tissue is represented in Figure 4.7. Black squares indicate the specific location of disperse fibroblasts and the color scale represents alternans magnitude. Alternans of opposite signs, i.e. L-S and S-L, in both CaT (upper panels) and APD (lower panels) are shown in red and blue. As in Figure 4.6B, Figure 4.7A shows that in $\mathrm{N}-\mathrm{Fb}$-tissue the spatially discordant $\mathrm{Ca}$-alt affect the entire tissue but are not translated to APD-alt. Discordant areas vary between tissue variants of the $\mathrm{N}$-Fb-tissue population, but all show a similar chaotic Ca-alt distribution (results not shown) with no patterns around the fibroblast locations. When spatial Ca-alt occur in HF-Fb-tissue (Figure 4.7B), they are confined to certain tissue regions in which APD-alt also appear, enhancing electromechanical concordance. Figure 4.7B also shows that there is a gradual transition between positive and negative APD-alt where there is no alternation (white areas in upper panel separate blue and red areas), although Ca-alt change abruptly from one myocyte to another (blue nodes next to red nodes).

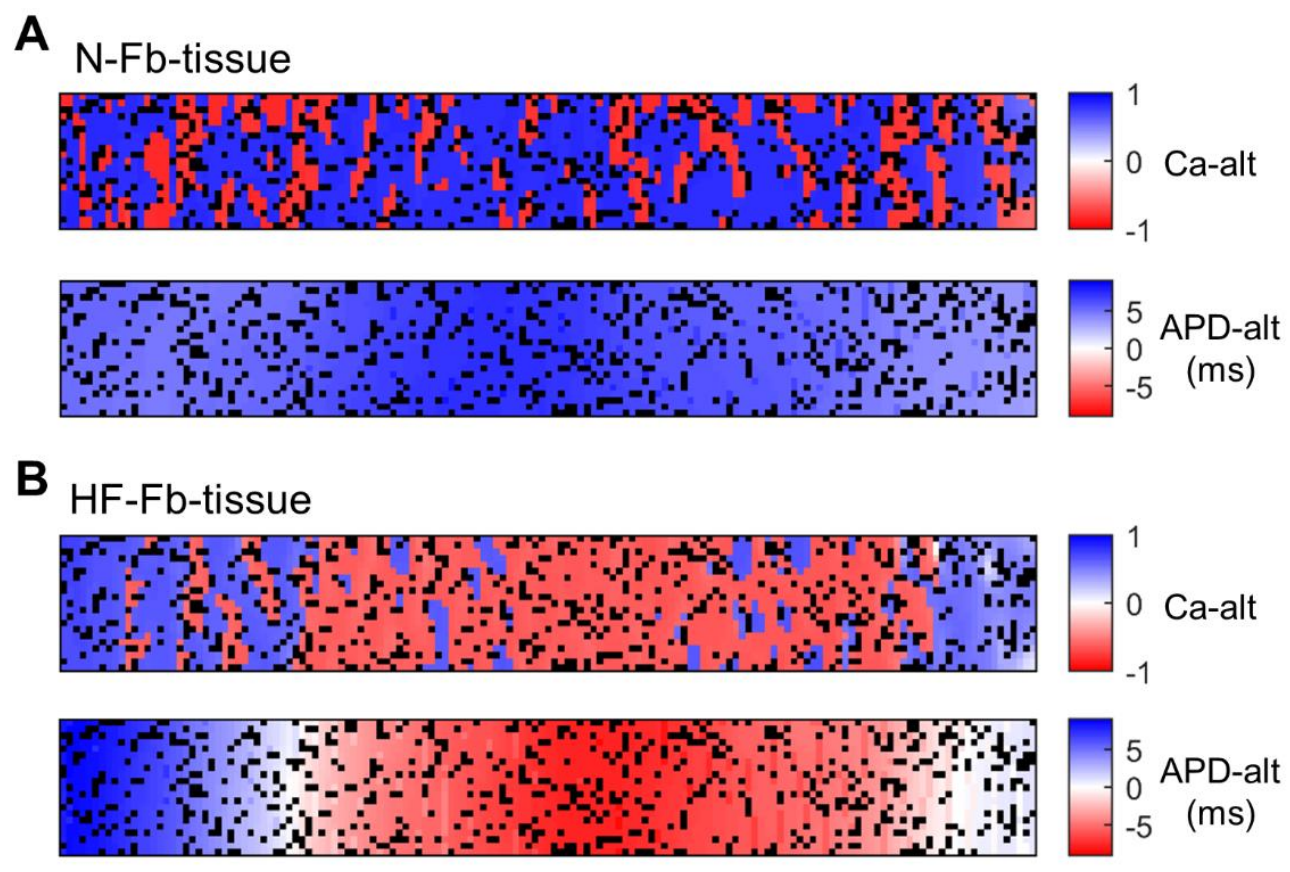

Figure 4.7. Spatial concordance of alternans (Ca-alt and APD-alt) along the tissue. A) Tissue with normal myocytes and fibroblasts (N-Fb-tissue), and B) tissue with failing myocytes and fibroblasts (HF-Fb-tissue). Opposite signs (red vs blue) indicate out-of-phase alternans. Fibroblasts are represented in black.

Electrically discordant alternans are the most arrhythmogenic type, but concordant alternans often precede discordant alternans and play an important role. Ca-alt help in the identification of APDalt, as they are concomitant, but also indicate dysfunctional contraction behavior. Discordant Ca-alt could aggravate the situation by increasing the number of myocytes that do not contract synchronously.

\subsection{Discussion}

\subsubsection{Main findings}

Mechanical and electrical alternans, which are known to be bidirectionally coupled, may compromise cardiac function. This study shows that alternans have their origin in $\mathrm{Ca}^{2+}$ alterations and 
reveals how $\mathrm{Ca}^{2+}$ impairment in $\mathrm{HF}$ or fibroblast interaction influences the development of cellular alternans and how they appear in cardiac tissue. Our main findings are as follows: (i) $\mathrm{Ca}^{2+}$ mechanisms, involving SERCA, $\mathrm{I}_{\mathrm{CaL}}$, and NCX, are responsible for the occurrence of cellular alternans by modulating $\mathrm{Ca}^{2+}$ cycling to threshold levels; these mechanisms act differently in normal and failing mocytes, (ii) the degree of $\mathrm{Ca}^{2+}$ impairment, given by $\left[\mathrm{Ca}^{2+}\right]_{\mathrm{JSR}}$, determines the myocyte susceptibility to Ca-alt development, (iii) fibroblasts induce discordant $\mathrm{Ca}$-alt in normal cardiac tissues, (iv) the high number of alternans in failing tissue with myocyte-fibroblast interaction is reduced due to exacerbated $\mathrm{Ca}^{2+}$ impairment, and (v) discordant Ca-alt are more prone to be translated into discordant APD-alt in failing tissue with fibroblasts than in normal tissue with fibroblasts. Fibroblasts and HF can therefore promote alternans because they alter $\mathrm{Ca}^{2+}$ dynamics, deteriorate contractility and increase the risk of cardiac arrhythmia. Restoring $\mathrm{Ca}^{2+}$ dynamics could thus potentially be used to prevent alternans and improve cellular contraction and cardiac function, although the differences between normal and failing tissues underline the need to consider HF when developing new pharmacological treatments.

\subsubsection{Origin of cellular alternans}

Although cardiac alternans usually occur at fast pacing rates, the threshold for the onset of fluctuations can vary between individuals. It is also a characteristic outcome in heart disease. The first cellular theory for cardiac alternans was based on the relationship between APD alternans and the APD restitution slope [26]. Alternation was generated and sustained when the slope was higher than 1, so steeper restitution curves led to alternans at a longer PCL. However, we found that myocyte-fibroblast coupling, which shortens APD, promotes alternans at a longer PCL, despite a flatter restitution curve. These results indicate that there are other factors that contribute to generating alternans and that the analysis of the restitution curve has some limitations. If alternans are voltage-driven, as Xie et al. [45] found in the Phase I of the Luo and Rudy model [46], fibroblasts that shorten APD can induce alternans at a lower PCL. But when the electrophysiological model incorporates detailed $\mathrm{Ca}^{2+}$ cycling (as in our case) myocytes-fibroblast coupling promotes alternans because the alternans onset is then driven by $\mathrm{Ca}^{2+}$ cycling instabilities [45]. In fact, $\mathrm{Ca}^{2+}$ dynamics, which also oscillates from beat to beat, is one of the most important factors in alternans research. The bidirectional coupling between membrane voltage and intracellular $\mathrm{Ca}^{2+}$ explains why APD-alt and Ca-alt occur concomitantly [47], as can be seen in the restitution curves obtained for $\mathrm{APD}_{90}$ and $\mathrm{Ca}^{2+}$. However, there is still controversy about the origin and underlying causes of these fluctuations, due to the $\mathrm{Ca}^{2+}$ dependence of ion channels, which also control $\mathrm{Ca}^{2+}$ cycling [23,47-49].

In the present computational study, in which the ORd model was used [36], the alternans found in single-cell pairs and tissue are similar to the alternans in the initial isolated myocytes. The ORd model was validated to reproduce human APD alternans (around $10 \mathrm{~ms}$ ) with beat-to-beat alternans in the $\mathrm{Ca}^{2+}$ subsystem at high frequencies (PCL $<300 \mathrm{~ms}$ ). They also occur in a 100-endo-cell strand, and pacing rates faster than $230 \mathrm{~ms}$ cause 2:1 block [36], which agrees with our results in tissue. This type of conduction block can also be observed in cellular simulations, usually at fast frequencies, under conditions that prolong APs. The difference is that a second short AP is developed after an AP longer than the cycle length. In previous studies focusing on alternans mechanisms, these cases were considered as alternans because of their long-short pattern [50]. In tissue simulations, we found that the short APs developed in the externally stimulated myocytes did not propagate through the tissue because the myocytes were in a refractory period, leading to $2: 1$ block. Figure $4.2 \mathrm{~A}$ shows that the 
long APD in failing myocytes causes loss of capture at higher PCLs and this explains why, at a fixed PCL of $300 \mathrm{~ms}, 2: 1$ block cases were only observed in HF tissue without fibroblasts. Despite the different mechanisms of alternans and the conduction block, both were included in the study due to their potential arrhythmogenic consequences.

Our first simulations at different PCLs determined that Ca-alt were easier to identify than APDalt and so this was used as the criterion to detect cellular alternans. In previous studies, AP amplitude alternans have also been used to explain T-wave alternans instead of APD variations and were able to predict malignant arrhythmias in patients with systolic dysfunction [51]. However, the link between mechanical and electrical alternans has also proved that mechanical fluctuations are more visible than T-wave alternans, so that research on these factors could be useful for managing HF patients [21].

\subsubsection{Alternans mechanisms}

Introducing natural electrophysiological variability into ionic channel conductances and transporters provides a population of coupled cells with different electrophysiological characteristics. The analysis of the model variants prone to alternans revealed the electrophysiological mechanisms that promote these fluctuations, i.e. the $\mathrm{Ca}^{2+}$-handling proteins (SERCA, ICaL, NCX, and J $\mathrm{J}_{\text {rel }}$ ). This agrees with the findings of Zhou et al. [31] and Walmsley et al. [50] for non-failing single myocytes. Walmsley et al. [50] associated the appearance of alternans to APD prolongation in failing myocytes when $\mathrm{I}_{\mathrm{Kr}}$ was low, but not to other parameters, since the alternans were measured as differences in AP and $\mathrm{CaT}$ duration. As a novelty, we introduced fibroblast coupling to normal and failing myocytes and then compared them to myocyte-myocyte coupling. The results indicated that although the mechanisms driving alternans in the different populations were similar they had opposite effects on normal conditions and HF.

CaMK appears to play an important role in alternans generation as it controls $\mathrm{Ca}^{2+}$ cycling $[36,52]$. This could partially explain the fact that HF enhances cellular alternans, since a 50\% increase in the CaMK active fraction is a characteristic alteration of failing myocytes (Table 4.1). $\mathrm{Ca}^{2+}$-handling proteins help to maintain normal $\mathrm{Ca}^{2+}$ cycling in myocytes to ensure contractility and their disruption can lead to impaired $\mathrm{Ca}^{2+}$ dynamics in the different cell compartments. This has been linked to beatto-beat $\mathrm{Ca}^{2+}$ oscillations [53], including fluctuations in the $\mathrm{SR} \mathrm{Ca}^{2+}$ content [30], which are the root cause of cardiac alternans. Recent studies have reported that the SR imbalance between $\mathrm{Ca}^{2+}$ reuptake and $\mathrm{Ca}^{2+}$ release explains the genesis of Ca-alt [30,31]. We found that the SERCA pump, which uptakes $\mathrm{Ca}^{2+}$ into the sarcoplasmic reticulum (SR), is involved in alternans-prone myocytes, while SERCA overexpression may possibly suppress cardiac alternans, as has been shown by Cutler et al. [33]. However, unlike previous studies, in HF we found that alternans were not eliminated by increasing $\mathrm{Ca}^{2+}$ uptake into the SR [54-56]. Our results indicate that in HF, when CaT is strongly depressed alternans are not generated. However, if SERCA activity increases, $\mathrm{Ca}^{2+}$ cycling improves although it still remains at failure levels and can lead to alternans. These levels are mainly determined by junctional SR $\mathrm{Ca}^{2+}$ maximal content. Normal myocytes can also reach these failing $\mathrm{Ca}^{2+}$ levels when mechanisms like $\mathrm{I}_{\mathrm{CaL}}$, SERCA, NCX, and $\mathrm{I}_{\mathrm{NaK}}$ are altered, after which Ca-alt may occur. With reduced $\mathrm{I}_{\mathrm{CaL}}, \mathrm{Ca}^{2+}$-induced $\mathrm{Ca}^{2+}$ release (CICR) tends to fail, high NCX contributes to intracellular $\mathrm{Ca}^{2+}$ imbalance by extruding $\mathrm{Ca}^{2+}$ out of the cell, and the higher $\mathrm{I}_{\mathrm{NaK}}$ could indirectly facilitate inward NCX. 
Many experimental studies have also highlighted the role of RyR in alternans generation due to RyR refractoriness and a failure in the CICR process $[28,29,57]$. Computer simulations with a spatially distributed $\mathrm{Ca}^{2+}$ cycling model integrated in the AP model could explain how $\mathrm{Ca}^{2+}$ sparks can lead to cellular alternans due to the randomness, refractoriness and recruitment properties of the couplon network [58]. However, in a less detailed $\mathrm{Ca}^{2+}$ cycling model, such as the one formulated in the ORd model, RyRs cannot show refractoriness, which could explain why we found that, unlike other parameters, changes in RyR hardly affected CaT. However, Tomek et al. [59] showed that slow dynamics and depressed SR $\mathrm{Ca}^{2+}$ release through $\mathrm{RyR}$ can also affect vulnerability to alternans. We therefore believe that incomplete JSR recovery is the factor that affects $\mathrm{Ca}^{2+}$ release and generates alternans [52].

\subsubsection{Alternans spatial distribution}

Regarding the spatiotemporal patterns in cardiac tissue, we found that alternans entail different degrees of risk that depend on individual conditions. Electrical propagation runs smoothly in normal tissue, which explains the tissue's spatial and electromechanical concordance. However, we found that cellular uncoupling in HF may promote the formation of alternans, in agreement with Hammer et al. [60], who found that myocytes with reduced intercellular coupling had higher alternans occurrence and amplitude, with a concordant pattern between neighboring cells. Fibroblasts also reduce intercellular coupling but can lead to spatially discordant alternans in normal tissue with fibroblasts, because, apart from reducing the CV they alter the myocytes' electrical activity. Majumder et al. [61] observed discordant APD-alt preceding reentries in cultured monolayers of neonatal rat ventricular myocytes with $\mathrm{Cx} 43$ inactivation and myofibroblasts. Both slow $\mathrm{CV}$ and interstitial fibrosis were critical to the formation of such arrhythmogenic alternans at fast pacing. This agrees with our simulated $\mathrm{HF}$ and HF with fibroblast results, in which $\mathrm{CV}$ is depressed and discordant APD-alt are prone to occur. Despite the cellular uncoupling with fibroblasts we did not detect APD discordance in normal fibrotic fibers, but Ca-alt became spatially asynchronous due to the slow diffusion of $\mathrm{Ca}^{2+}$ ions [62] in comparison to the fast diffusion of membrane potential. As a consequence, cardiac tissue can present adjacent myocytes with both in-phase and out-of-phase V-Ca ${ }^{2+}$ coupling, which reduces APD-alt [63]. Electromechanically discordant alternans were also found by Xie et al. [45] when passive fibroblasts were inserted into a 2D tissue of rabbit ventricular myocytes. According to MacCannell et al. [38], the use of a passive fibroblast model hardly modulates myocyte AP or CaT, whereas the electrophysiological model does have a strong effect. As our objective was to analyze the most critical conditions only active fibroblasts were studied.

Electrophysiological remodeling of $\mathrm{Ca}^{2+}$-handling proteins is the main cause of $\mathrm{Ca}$-alt in $\mathrm{HF}$, which is then translated to APD-alt. Although we found spatially concordant alternans in HF tissue, they could become discordant at lower PCL, as was shown in [64]. There is also experimental evidence to show that HF enhances susceptibility to arrhythmogenic cardiac alternans, since ventricular fibrillation is only inducible after spatial discordance appears, which is more common in failing wedge preparations and occurs at a slower heart rate [54]. It is difficult to say whether or not these tissues included fibroblasts, but as optical mapping can be hampered by fibrotic areas, many experimental measurements avoid tissues with a high proportion of fibroblasts. In any case, of the computational alternans studies, this is the first to consider myocyte-fibroblast coupling in HF tissue. Apparently, fibroblasts do not increase discordance in failing tissues, since we did not find any differences with 
tissues without fibroblasts. Compared to normal tissue, $\mathrm{HF}$ involves more $\mathrm{Ca}^{2+}$ impairment and reduced $\mathrm{CV}$, which may contribute to the positive APD-alt and Ca-alt coupling. Failing myocytes become susceptible to $\mathrm{Ca}$-alt with unstable $\mathrm{Ca}^{2+}$ dynamics provided that $\mathrm{CaT}$ is not very depressed, and the resultant repolarization alternans can be high. If the tissue properties were to trigger spatial discordance, these alternans could become arrhythmogenic.

Arrhythmogenic activity in cardiac tissue can have a non-electric origin if Ca-alt is the initial cause. In contrast to normal hearts, the attempt to restore $\mathrm{Ca}^{2+}$ dynamics in $\mathrm{HF}$ could not improve cardiac function but did contribute to Ca-alt development and its associated effects. The conclusion is therefore that mechanisms that restore $\mathrm{Ca}^{2+}$ instabilities produced by fibroblasts and/or HF help to recover normal myocyte electrophysiological activity and avoid heart problems only if they are applied to specific heart conditions.

\subsubsection{Limitations}

Mathematical models can help in the mechanistic analysis of alternans onset and complement experimental findings, although computational results may be limited by a number of uncertainties. Only one fibroblast model and one configuration for myocyte-fibroblast coupling were considered. The electrophysiological fibroblast model is thought to be more accurate, as it represents the ion currents in the fibroblasts, but using a different model (eg. passive fibroblast) or variations in the parameters could change the results. In our simulations in particular the fibroblast model does not take into account the potential $\mathrm{Ca}^{2+}$ cycling pathways in non-myocytes because of the lack of data related to cardiac fibroblasts, and this could contribute to $\mathrm{Ca}^{2+}$ dynamics in myocytes and therefore to developing alternans. Myofibroblasts, the contractile fibroblast activated form, arise in response to injury and present a different phenotype from fibroblasts. However, as no specific electrophysiological models of these contractile cells have been developed to date, in the present study we used the same mathematical fibroblast model in both normal conditions and HF, in spite of the fact that fibroblast electrophysiology may be altered in response to HF. We implemented the most critical of the different configurations for myocyte-fibroblast coupling, in which fibroblasts form conduction pathways and act as an electrotonic load. Representing fibroblasts as the same size as myocytes in a continuous mesh still has certain limitations.

Another limitation was the scarcity of human electrophysiological data, which would have been very useful to validate our findings. Our results were thus compared to animal models, including some species with a different electrophysiology to that of humans.

Despite its limitations, this study provides information that plausibly explains the response of myocytes to HF and fibroblast coupling in humans and can thus be used as a guide in the design of HF treatments. 


\section{REFERENCES}

1. Glukhov A V., Fedorov V V., Kalish PW, Ravikumar VK, Lou Q, Janks D, et al. Conduction remodeling in human end-stage nonischemic left ventricular cardiomyopathy. Circulation. 2012;125: 1835-1847. doi:10.1161/CIRCULATIONAHA.111.047274

2. Lou Q, Fedorov V V., Glukhov A V., Moazami N, Fast VG, Efimov IR. Transmural heterogeneity and remodeling of ventricular excitation- contraction coupling in human heart failure. Circulation. 2011;123: 1881-1890. doi:10.1161/CIRCULATIONAHA.110.989707

3. Gomez JF, Cardona K, Trenor B. Lessons learned from multi-scale modeling of the failing heart. J Mol Cell Cardiol. 2015;89: 146-159. doi:10.1016/j.yjmcc.2015.10.016

4. Kohl P, Gourdie RG. Fibroblast-myocyte electrotonic coupling: does it occur in native cardiac tissue? J Mol Cell Cardiol. 2014;70: 37-46. doi:10.1016/j.yjmcc.2013.12.024

5. Gaudesius G, Miragoli M, Thomas SP, Rohr S. Coupling of cardiac electrical activity over extended distances by fibroblasts of cardiac origin. Circ Res. 2003;93: 421-428. doi:10.1161/01.RES.0000089258.40661.0C

6. Kohl P, Camelliti P, Burton FL, Smith GL. Electrical coupling of fibroblasts and myocytes: relevance for cardiac propagation. J Electrocardiol. 2005;38: 45-50. doi:10.1016/J.JELECTROCARD.2005.06.096

7. Camelliti P, Green CR, LeGrice I, Kohl P. Fibroblast Network in Rabbit Sinoatrial Node. Circ Res. 2004;94: 828835. doi:10.1161/01.RES.0000122382.19400.14

8. Rook MB, van Ginneken AC, de Jonge B, el Aoumari A, Gros D, Jongsma HJ. Differences in gap junction channels between cardiac myocytes, fibroblasts, and heterologous pairs. Am J Physiol Physiol. 1992;263: C959-C977. doi:10.1152/ajpcell.1992.263.5.C959

9. Mahoney VM, Mezzano V, Mirams GR, Maass K, Li Z, Cerrone M, et al. Connexin43 contributes to electrotonic conduction across scar tissue in the intact heart. Sci Rep. 2016;6: 26744. doi:10.1038/srep26744

10. Quinn TA, Camelliti P, Rog-Zielinska EA, Siedlecka U, Poggioli T, O’Toole ET, et al. Electrotonic coupling of excitable and nonexcitable cells in the heart revealed by optogenetics. Proc Natl Acad Sci. 2016;113: 14852-14857. doi:10.1073/PNAS.1611184114

11. Rubart M, Tao W, Lu X-L, Conway SJ, Reuter SP, Lin S-F, et al. Electrical coupling between ventricular myocytes and myofibroblasts in the infarcted mouse heart. Cardiovasc Res. 2018;114: 389-400. doi:10.1093/cvr/cvx163

12. Miragoli M, Gaudesius G, Rohr S. Electrotonic modulation of cardiac impulse conduction by myofibroblasts. Circ Res. 2006;98: 801-810. doi:10.1161/01.RES.0000214537.44195.a3

13. Jacquemet V, Henriquez CS. Loading effect of fibroblast-myocyte coupling on resting potential, impulse propagation, and repolarization: insights from a microstructure model. Am J Physiol Circ Physiol. 2008;294: H2040 H2052. doi:10.1152/ajpheart.01298.2007

14. Li Y, Asfour H, Bursac N. Age-dependent functional crosstalk between cardiac fibroblasts and cardiomyocytes in a 3D engineered cardiac tissue. Acta Biomater. 2017;55: 120-130. doi:10.1016/j.actbio.2017.04.027

15. Maleckar MM, Greenstein JL, Giles WR, Trayanova NA. Electrotonic coupling between human atrial myocytes and fibroblasts alters myocyte excitability and repolarization. Biophys J. Biophysical Society; 2009;97: 2179-2190. doi:10.1016/j.bpj.2009.07.054

16. Zlochiver S, Muñoz V, Vikstrom KL, Taffet SM, Berenfeld O, Jalife J. Electrotonic myofibroblast-to-myocyte coupling increases propensity to reentrant arrhythmias in two-dimensional cardiac monolayers. Biophys J. 2008;95: 4469-80. doi:10.1529/biophysj.108.136473

17. Nguyen TP, Xie Y, Garfinkel A, Qu Z, Weiss JN. Arrhythmogenic consequences of myofibroblast-myocyte coupling. Cardiovasc Res. 2012;93: 242-251. doi:10.1093/cvr/cvr292

18. Greisas A, Zlochiver S. The Multi-Domain Fibroblast/Myocyte Coupling in the Cardiac Tissue: A Theoretical Study. Cardiovasc Eng Technol. 2016;7: 290-304. doi:10.1007/s13239-016-0266-X

19. Sridhar S, Vandersickel N, Panfilov A V. Effect of myocyte-fibroblast coupling on the onset of pathological dynamics in a model of ventricular tissue. Sci Rep. 2017;7: 40985. doi:10.1038/srep40985

20. Gomez JF, Cardona K, Martinez L, Saiz J, Trenor B. Electrophysiological and Structural Remodeling in Heart Failure Modulate Arrhythmogenesis. 2D Simulation Study. PLoS One. 2014;9: e103273. doi:10.1371/journal.pone.0103273

21. Kodama M, Kato K, Hirono S, Okura Y, Hanawa H, Yoshida T, et al. Linkage Between Mechanical and Electrical Alternans in Patients with Chronic Heart Failure. J Cardiovasc Electrophysiol. 2004;15: 295-299. doi:10.1046/j.1540-8167.2004.03016.x 
22. Rosenbaum DS, Jackson LE, Smith JM, Garan H, Ruskin JN, Cohen RJ. Electrical Alternans and Vulnerability to Ventricular Arrhythmias. N Engl J Med. 1994;330: 235-241. doi:10.1056/NEJM199401273300402

23. Jordan PN, Christini DJ. Action Potential Morphology Influences Intracellular Calcium Handling Stability and the Occurrence of Alternans. Biophys J. 2006;90: 672-680. doi:10.1529/biophysj.105.071340

24. Cherry EM. Distinguishing mechanisms for alternans in cardiac cells using constant-diastolic-interval pacing. Chaos An Interdiscip J Nonlinear Sci. 2017;27: 093902. doi:10.1063/1.4999354

25. Groenendaal W, Ortega FA, Krogh-Madsen T, Christini DJ. Voltage and calcium dynamics both underlie cellular alternans in cardiac myocytes. Biophys J. 2014;106: 2222-32. doi:10.1016/j.bpj.2014.03.048

26. Nolasco JB, Dahlen RW. A graphic method for the study of alternation in cardiac action potentials. J Appl Physiol. 1968;25: 191-196.

27. Qu Z, Liu MB, Nivala M. A unified theory of calcium alternans in ventricular myocytes. Sci Rep. 2016;6: 1-14. doi:10.1038/srep35625

28. Díaz ME, Eisner DA, O’Neill SC. Depressed ryanodine receptor activity increases variability and duration of the systolic $\mathrm{Ca} 2+$ transient in rat ventricular myocytes. Circ Res. 2002;91: 585-593. doi:10.1161/01.RES.0000035527.53514.C2

29. Picht E, DeSantiago J, Blatter LA, Bers DM. Cardiac alternans do not rely on diastolic sarcoplasmic reticulum calcium content fluctuations. Circ Res. 2006;99: 740-748. doi:10.1161/01.RES.0000244002.88813.91

30. Díaz ME, O’Neill SC, Eisner DA. Sarcoplasmic Reticulum Calcium Content Fluctuation Is the Key to Cardiac Alternans. Circ Res. 2004;94: 650-656. doi:10.1161/01.RES.0000119923.64774.72

31. Zhou X, Bueno-Orovio A, Orini M, Hanson B, Hayward M, Taggart P, et al. In vivo and in silico investigation into mechanisms of frequency dependence of repolarization alternans in human ventricular cardiomyocytes. Circ Res. 2016;118: 266-278. doi:10.1161/CIRCRESAHA.115.307836

32. Xie LH, Sato D, Garfinkel A, Qu Z, Weiss JN. Intracellular Ca alternans: Coordinated regulation by sarcoplasmic reticulum release, uptake, and leak. Biophys J. 2008;95: 3100-3110. doi:10.1529/biophysj.108.130955

33. Cutler MJ, Wan X, Laurita KR, Hajjar RJ, Rosenbaum DS. Targeted SERCA2a Gene Expression Identifies Molecular Mechanism and Therapeutic Target for Arrhythmogenic Cardiac Alternans. Circ Arrhythmia Electrophysiol. 2009;2: 686-694. doi:10.1161/CIRCEP.109.863118

34. Kanaporis G, Blatter LA. The Mechanisms of Calcium Cycling and Action Potential Dynamics in Cardiac Alternans. Circ Res. 2015;116: 846-856. doi:10.1161/CIRCRESAHA.116.305404

35. Pastore JM, Girouard SD, Laurita KR, Akar FG, Rosenbaum DS. Mechanism Linking T-Wave Alternans to the Genesis of Cardiac Fibrillation. Circulation. 1999;99: 1385-1394. doi:10.1161/01.CIR.99.10.1385

36. O'Hara T, Virág L, Varró A, Rudy Y. Simulation of the undiseased human cardiac ventricular action potential: model formulation and experimental validation. PLoS Comput Biol. 2011;7: e1002061. doi:10.1371/journal.pcbi.1002061

37. Mora MT, Ferrero JM, Romero L, Trenor B. Sensitivity analysis revealing the effect of modulating ionic mechanisms on calcium dynamics in simulated human heart failure. PLoS One. 2017;12: e0187739. doi:10.1371/journal.pone.0187739

38. MacCannell KA, Bazzazi H, Chilton L, Shibukawa Y, Clark RB, Giles WR. A mathematical model of electrotonic interactions between ventricular myocytes and fibroblasts. Biophys J. 2007;92: 4121-4132. doi:10.1529/biophysj.106.101410

39. Spach MS, Heidlage JF, Dolber PC, Barr RC. Electrophysiological effects of remodelling cardiac gap junctions and cell size: experimental and model studies of normal cardiac growth. Circ Res. 2000;86: 302-311.

40. Kieval RS, Spear JF, Moore EN. Gap junctional conductance in ventricular myocyte pairs isolated from postischemic rabbit myocardium. Circ Res. 1992;71: 127-136. doi:10.1161/01.RES.71.1.127

41. Gomez JF, Cardona K, Romero L, Ferrero JM, Trenor B. Electrophysiological and structural remodeling in heart failure modulate arrhythmogenesis. 1D simulation study. PLoS One. 2014;9: e106602. doi:10.1371/journal.pone.0106602

42. Taggart P, Sutton PM, Opthof T, Coronel R, Trimlett R, Pugsley W, et al. Inhomogeneous transmural conduction during early ischaemia in patients with coronary artery disease. J Mol Cell Cardiol. 2000;32: 621-630 doi:10.1006/jmcc.2000.1105

43. Heidenreich E. Algoritmos para ecuaciones de reacción difusión aplicados a electrofisiología. Ph.D. Thesis. Universidad de Zaragoza. 2009. Available from: https://institutoi4.net/wp-content/uploads/2017/08/TesisEAH.pdf

44. Heidenreich EA, Ferrero JM, Doblaré M, Rodríguez JF. Adaptive Macro Finite Elements for the Numerical Solution 
of Monodomain Equations in Cardiac Electrophysiology. Ann Biomed Eng. 2010;38: 2331-2345. doi:10.1007/s10439-010-9997-2

45. Xie Y, Garfinkel A, Weiss JN, Qu Z. Cardiac alternans induced by fibroblast-myocyte coupling: mechanistic insights from computational models. Am J Physiol Circ Physiol. 2009;297: H775-H784. doi:10.1152/ajpheart.00341.2009

46. Luo CH, Rudy Y. A model of the ventricular cardiac action potential. Depolarization, repolarization, and their interaction. Circ Res. 1991;68: 1501-26.

47. Pruvot EJ, Katra RP, Rosenbaum DS, Laurita KR. Role of calcium cycling versus restitution in the mechanism of repolarization alternans. Circ Res. 2004;94: 1083-90. doi:10.1161/01.RES.0000125629.72053.95

48. Kanaporis G, Blatter LA. Membrane potential determines calcium alternans through modulation of SR Ca 2+ load and L-type Ca 2+ current. J Mol Cell Cardiol. 2017;105: 49-58. doi:10.1016/j.yjmcc.2017.02.004

49. Goldhaber JI, Xie L-H, Duong T, Motter C, Khuu K, Weiss JN. Action Potential Duration Restitution and Alternans in Rabbit Ventricular Myocytes. Circ Res. 2005;96: 459-466. doi:10.1161/01.RES.0000156891.66893.83

50. Walmsley J, Rodriguez JF, Mirams GR, Burrage K, Efimov IR, Rodriguez B. mRNA expression levels in failing human hearts predict cellular electrophysiological remodeling: A population-based simulation study. PLoS One. 2013;8: e56359. doi:10.1371/journal.pone.0056359

51. Narayan SM, Bayer JD, Lalani G, Trayanova NA. Action Potential Dynamics Explain Arrhythmic Vulnerability in Human Heart Failure. J Am Coll Cardiol. 2008;52: 1782-1792. doi:10.1016/j.jacc.2008.08.037

52. Livshitz LM, Rudy Y. Regulation of $\mathrm{Ca} 2+$ and electrical alternans in cardiac myocytes: role of CAMKII and repolarizing currents. Am J Physiol Circ Physiol. 2007;292: H2854-H2866. doi:10.1152/ajpheart.01347.2006

53. Wilson LD, Wan X, Rosenbaum DS. Cellular alternans: A mechanism linking calcium cycling proteins to cardiac arrhythmogenesis. Ann N Y Acad Sci. 2006;1080: 216-234. doi:10.1196/annals.1380.018

54. Wilson LD, Jeyaraj D, Wan X, Hoeker GS, Said TH, Gittinger M, et al. Heart failure enhances susceptibility to arrhythmogenic cardiac alternans. Hear Rhythm. 2009;6: 251-259. doi:10.1016/j.hrthm.2008.11.008

55. Cutler MJ, Wan X, Plummer BN, Liu H, Deschenes I, Laurita KR, et al. Targeted sarcoplasmic reticulum Ca2+ ATPase 2a gene delivery to restore electrical stability in the failing heart. Circulation. 2012;126: 2095-2104. doi:10.1161/CIRCULATIONAHA.111.071480

56. Bayer JD, Narayan SM, Lalani GG, Trayanova NA. Rate-dependent action potential alternans in human heart failure implicates abnormal intracellular calcium handling. Hear Rhythm. 2010;7: 1093-1101. doi:10.1016/j.hrthm.2010.04.008

57. Wang L, Myles RC, De Jesus NM, Ohlendorf AKP, Bers DM, Ripplinger CM. Optical mapping of sarcoplasmic reticulum $\mathrm{Ca} 2+$ in the intact heart: Ryanodine receptor refractoriness during alternans and fibrillation. Circ Res. 2014;114: 1410-1421. doi:10.1161/CIRCRESAHA.114.302505

58. Rovetti R, Cui X, Garfinkel A, Weiss JN, Qu Z. Spark-Induced Sparks As a Mechanism of Intracellular Calcium Alternans in Cardiac Myocytes. Circ Res. 2010;106: 1582-1591. doi:10.1161/CIRCRESAHA.109.213975

59. Tomek J, Tomková M, Zhou X, Bub G, Rodriguez B. Modulation of Cardiac Alternans by Altered Sarcoplasmic Reticulum Calcium Release: A Simulation Study. Front Physiol. 2018;9: 1306. doi:10.3389/fphys.2018.01306

60. Hammer KP, Ljubojevic S, Ripplinger CM, Pieske BM, Bers DM. Cardiac myocyte alternans in intact heart: Influence of cell-cell coupling and $\beta$-adrenergic stimulation. J Mol Cell Cardiol. 2015;84: 1-9. doi:10.1016/j.yjmcc.2015.03.012

61. Majumder R, Engels MC, de Vries AAF, Panfilov A V., Pijnappels DA. Islands of spatially discordant APD alternans underlie arrhythmogenesis by promoting electrotonic dyssynchrony in models of fibrotic rat ventricular myocardium. Sci Rep. 2016;6: 24334. doi:10.1038/srep24334

62. Shiferaw Y, Karma A. Turing instability mediated by voltage and calcium diffusion in paced cardiac cells. Proc Natl Acad Sci. 2006;103: 5670-5675. doi:10.1073/pnas.0511061103

63. Sato D, Shiferaw Y, Garfinkel A, Weiss JN, Qu Z, Karma A. Spatially discordant alternans in cardiac tissue: Role of calcium cycling. Circ Res. 2006;99: 520-527. doi:10.1161/01.RES.0000240542.03986.e7

64. Ponnaluri AVS, Perotti LE, Liu M, Qu Z, Weiss JN, Ennis DB, et al. Electrophysiology of Heart Failure Using a Rabbit Model: From the Failing Myocyte to Ventricular Fibrillation. PLoS Comput Biol. 2016;12: 1-25. doi:10.1371/journal.pcbi.1004968 


\title{
Chapter 5
}

\section{The role of $\beta$-adrenergic system remodeling in human heart failure: A mechanistic investigation}

\author{
Maria T. Mora ${ }^{\mathrm{a}}$, Jingqi Q.X. Gong ${ }^{\mathrm{b}}$, Eric A. Sobie ${ }^{\mathrm{b}}$, Beatriz Trenor ${ }^{\mathrm{a}}$
}

\begin{abstract}
$\beta$-adrenergic receptor antagonists ( $\beta$-blockers) are extensively used to improve cardiac performance in heart failure $(H F)$, but the electrical improvements with these clinical treatments are not fully understood. The aim of this study was to analyze the electrophysiological effects of $\beta$ adrenergic system remodeling in heart failure with reduced ejection fraction and the underlying mechanisms. We used a combined mathematical model that integrated $\beta$-adrenergic signaling with electrophysiology and calcium cycling in human ventricular myocytes. HF remodeling, both in the electrophysiological and signaling systems, was introduced to quantitatively analyze changes in electrophysiological properties due to the stimulation of $\beta$-adrenergic receptors in failing myocytes. We found that the inotropic effect of $\beta$-adrenergic stimulation was reduced in HF due to the altered $\mathrm{Ca}^{2+}$ dynamics resulting from the combination of structural, electrophysiological and signaling remodeling. Isolated cells showed proarrhythmic risk after sympathetic stimulation because early afterdepolarizations appeared, and the vulnerability was greater in failing myocytes. When analyzing coupled cells, $\beta$-adrenergic stimulation reduced transmural repolarization gradients between endocardium and epicardium in normal tissue, but was less effective at reducing these gradients after $H F$ remodeling. The comparison of the selective activation of $\beta$-adrenergic isoforms revealed that the response to $\beta 2$-adrenergic receptors stimulation was blunted in $H F$ while $\beta 1$-adrenergic receptors downstream effectors regulated most of the changes observed after sympathetic stimulation. In conclusion, this study was able to reproduce an altered $\beta$-adrenergic activity on failing myocytes and to explain the mechanisms involved. The derived predictions could help in the treatment of HF and guide in the design of future experiments.
\end{abstract}

\footnotetext{
Mora MT, Gong JQX, Sobie EA, Trenor B. The role of $\beta$-adrenergic system remodeling in human heart failure: A mechanistic investigation. Journal of Molecular and Cellular Cardiology. (Under review)

aCentro de Investigación e Innovación en Bioingeniería, Universitat Politècnica de València, Valencia, Spain.

bepartment of Pharmacological Sciences, Icahn School of Medicine at Mount Sinai, New York, NY, USA.
} 


\subsection{Introduction}

Heart failure (HF) is a major health problem. Patients with reduced ejection fraction present weak cardiac performance and have a high risk of sudden cardiac death due to ventricular arrhythmias. Many alterations to the myocardium that occur in HF can promote the electrical instabilities observed. These include electrophysiological and structural remodeling of cardiac tissue, such as changes in the expression and function of membrane ion channels and $\mathrm{Ca}^{2+}$-handling proteins. These changes can alter action potentials and $\mathrm{Ca}^{2+}$ dynamics and lead to the electrical and contractile dysfunction that characterizes failing myocytes $[1,2]$. Remodeling of signaling cascades, such as $\mathrm{Ca}^{2+} /$ calmodulindependent protein kinase II (CaMKII) and $\beta$-adrenergic receptor ( $\beta$-AR) pathways, also plays a crucial role $[3,4]$.

Several neurohormonal mechanisms are activated during HF to maintain cardiac output, including the sympathetic nervous system, and a continuous release of catecholamines provokes a sustained activation of cardiac $\beta$-ARs. Catecholamine binding to membrane $\beta$-AR, a type of G-proteincoupled receptor (GPCR), initiates the adenylyl cyclase (AC)/ cyclic AMP (cAMP)/ protein kinase A (PKA) signaling cascade. PKA phosphorylates several electrophysiological proteins and modulates the electrical activity of the heart [5]. In the normal myocardium, this sympathetic stimulation increases heart rate and the force of contraction to enhance cardiac performance in demanding situations. In the failing heart, however, prolonged stimulation becomes detrimental and ultimately contributes to the pathogenesis of HF [6-8].

Malignant arrhythmias are the major cause of death among patients with HF, and the use of $\beta$ blocker agents has demonstrated efficacy in reducing mortality rate and improving clinical outcomes $[9,10]$. Although changes in $\beta$-ARs and other proteins of the signaling cascade have been reported in failing myocytes, most clinical trials quantify the survival benefits of $\beta$-blocker therapy without going into depth regarding the mechanisms by which these drugs prevent arrhythmogenesis [11]. The existence of $\beta$-AR isoforms ( $\beta 1$ and $\beta 2$-ARs are the major subtypes) with different pathways (e.g. only $\beta 2$-AR subtypes activate inhibitory G-proteins, and $\beta 1$ receptors are the only direct effectors on cytosolic protein phosphorylation) has raised questions related to variable effectiveness of $\beta$-blockers depending on drug affinity to the receptors. For instance, non-selective pharmacological agents or even partial agonists appear to have greater benefits than selective $\beta 1$ antagonists [12-14].

Investigations about cAMP signaling have given rise to detailed mathematical models of the adrenergic pathways, including signaling compartmentation and the interaction with electrophysiological proteins [15-17]. Simulations including these models can improve mechanistic insight into HF pathophysiology, but investigations performed to date have generally focused on effects of electrical remodeling rather than on HF-induced alterations in the $\beta$-AR system. The aim of this study was to apply $\beta$-adrenergic signaling changes according to experimental observations of protein function and expression in failing myocytes to reproduce the electrophysiological response to $\beta$-AR stimulation in HF. This approach allows the investigation of the altered signaling mechanisms that trigger electrical instabilities and contractile dysfunction in patients with $\mathrm{HF}$ with reduced ejection fraction. We integrated existing cellular models of signaling and electrophysiology and introduced changes in protein expression and localization according to available data. These initial results will be useful to understand mechanisms and guide future experimental studies aimed at improving clinical HF treatments. 


\subsection{Methods}

\subsubsection{Baseline cellular models}

The mathematical model representing a human ventricular myocyte included the Heijman et al. $\beta$-adrenergic signaling pathway [17] integrated into the ORd action potential model [18], which also considers the CaMKII signaling cascade. The complete formulation was initially described in [19] to represent a normal epicardial cell. We used an improved version of the model [20] which maintained the main characteristics, such as cAMP signal compartmentation and the PKA-mediated phosphorylation of eight electrophysiological proteins: L-type $\mathrm{Ca}^{2+}$ channel $\left(\mathrm{I}_{\mathrm{CaL}}\right)$, slow delayed rectifier $\mathrm{K}^{+}$channel $\left(\mathrm{I}_{\mathrm{Ks}}\right)$, phospholamban $(\mathrm{PLB})$, troponin $\mathrm{I}(\mathrm{TnI})$, ryanodine receptor $(\mathrm{RyR})$, fast $\mathrm{Na}^{+}$ channel $\left(\mathrm{I}_{\mathrm{Na}}\right), \mathrm{Na}^{+} / \mathrm{K}^{+}$pump $\left(\mathrm{I}_{\mathrm{NaK}}\right)$, and background $\mathrm{K}^{+}$current $\left(\mathrm{I}_{\mathrm{Kb}}\right)$.

To simulate HF with reduced ejection fraction phenotype (referred only as HF from now on), several changes were introduced in the model. The electrophysiological part was modified to represent the characteristic HF modifications at the cellular level, such as ion channel remodeling and the loss of T-tubular cellular domains. Heterogeneous HF remodeling was implemented as indicated in Gomez et al. [2]: upregulation of the late $\mathrm{Na}^{+}$current, the $\mathrm{Na}^{+} / \mathrm{Ca}^{2+}$ exchanger, the sarcoplasmic reticulum (SR) $\mathrm{Ca}^{2+}$ leak, and the CaMKII, and downregulation of the $\mathrm{SR} \mathrm{Ca}^{2+}$ uptake (SERCA), the transient outward and inward rectifier $\mathrm{K}^{+}$currents, the $\mathrm{Na}^{+} / \mathrm{K}^{+}$ATPase current, and the $\mathrm{Ca}^{2+}$ release sensitivity via RyRs. Regarding detubulation, several changes were introduced following Sanchez-Alonso et al. [21] methodology: (i) L-type calcium channels (LTCC), which are predominant in the subspace (submembrane space near T-tubules), were redistributed into the crest, (ii) half of the dyadic $\mathrm{Na}^{+} / \mathrm{Ca}^{2+}$ exchangers (NCX) were relocated to the surface membrane, and (iii) $\mathrm{Ca}^{2+}$ release from the $\mathrm{SR}$ was reduced to reproduce orphaned RyRs.

\subsubsection{Signaling remodeling in heart failure}

The formulation of the $\beta$-AR signaling model was also modified to reproduce the alterations in HF. An extensive review of experimental observations is summarized in supplemental Table 5.3. Despite the general agreement on the increased or decreased expression and function of proteins, we found a wide range of variation and considered it instead of taking a fixed value. A better adjustment was performed in several steps, described below.

Figure 5.1 summarizes the remodeling in $\beta$-adrenergic signaling: $\beta 1$-ARs are downregulated, which reduces $\beta$-AR responsiveness; $\beta 2$-ARs migrate from caveolar (cav) to extracaveolar (ecav) domain due to detubulation without causing receptor loss; there is $\mathrm{G}$ protein-coupled receptor kinase (GRK) upregulation, which phosphorylates $\beta$-ARs and this desensitization implies $\beta$-AR loss of function; phosphodiesterase type 4 (PDE4) is downregulated, inhibiting less cAMP and promoting PKA-phosphorylation; the downregulation of the cytosolic (cyt) inhibitor1 increases phosphatase type 1 (PP1) activity, which further dephosphorylates PLB, decreasing SERCA function. T-tubule degradation causing $\beta 2$-ARs signaling disruption affects $\mathrm{I}_{\mathrm{CaL}}$ phosphorylation leading to new ecav signaling pathways for subsarcolemmal LTCC $\left(\mathrm{I}_{\mathrm{CaLe}}\right)$. 


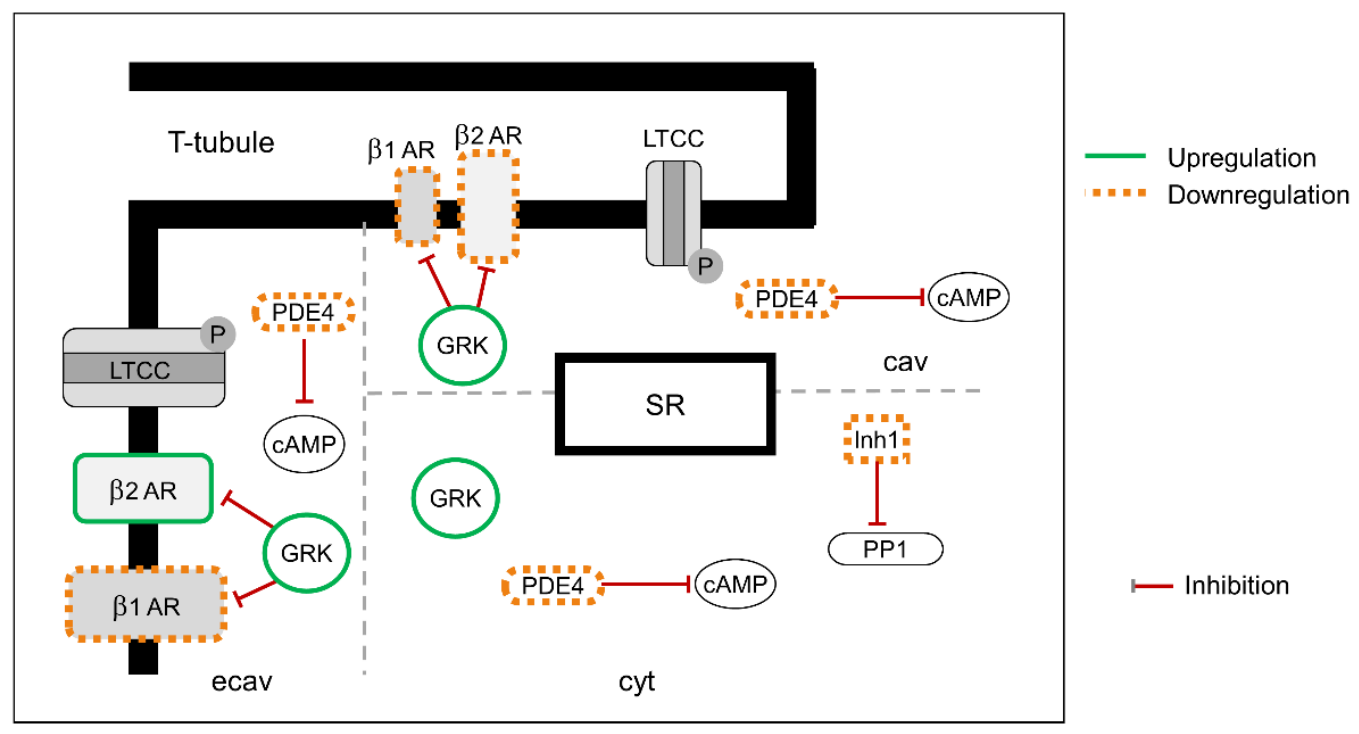

Figure 5.1. $\beta$-adrenergic signaling remodeling in heart failure (HF). Downregulated proteins: isoform $\beta 1$ adrenoreceptor ( $\beta 1-\mathrm{AR})$, phosphodiesterase 4 (PDE4) and inhibitor 1 (Inh1); upregulated proteins: G protein-coupled receptor kinase (GRK). Other changes: redistribution of $\beta 2$ adrenoreceptor ( $\beta 2-\mathrm{AR}$ ) activity from caveolar (cav) to extracaveolar (ecav), L-type $\mathrm{Ca}^{2+}$ channels (LTCC) that migrate to the crest are phosphorylated by ecav signaling pathways. Molecules of cytosolic (cyt) compartment are also affected.

Additional modifications were performed to differentiate between myocardium layers. ORd model already considers transmural heterogeneity. We applied different $\beta 2-\mathrm{AR}$ protein expression along the transmural wall cells, as quantified by Lang et al. [22], to simulate endocardial cells in addition to epicardial cells (supplemental Table 5.4). There were also transmural differences between normal $\left(\beta 2-\mathrm{AR}_{\mathrm{epi}}<\beta 2-\mathrm{AR}_{\mathrm{endo}}\right)$ and failing myocytes $\left(\beta 2-\mathrm{AR}_{\mathrm{epi}}>\beta 2-\mathrm{AR}_{\text {endo }}\right)$. Further details of the model can be found in the supplemental material.

The modifications implemented in the signaling model were first of all calibrated with experiments [22]. From the literature (supplemental Table 5.3), we had a qualitative knowledge about the 5 important HF remodeling changes in the $\beta$-AR system. To quantify the molecular changes that led to HF phenotype, a population of human epicardial failing cells was constructed with uniform variability in the signaling parameters. We selected the cells that underwent the same electrophysiological variations as in experiments [22] according to the following criteria: action potential duration (APD) and CaT duration (CaTD) in epicardial cells upon $\beta$-AR stimulation with isoproterenol were reduced compared to the non-stimulated cells in a specific range $\left(-25 \%<\Delta \mathrm{APD}_{80}\right.$ $<-13.2 \%$ and $\left.\Delta \mathrm{CaTD}_{80}<0 \%\right)$.

\subsubsection{Single cell simulations}

$\boldsymbol{\beta}$-adrenergic stimulation protocol. $\beta$-AR stimulation was simulated with saturated dose of agonists, i.e. the concentration at which the activation of the receptors is maximal so that results were dose independent $(1 \mu \mathrm{M})$. Besides, model equations were run until achieve steady-state conditions to ensure the stability of signaling variables modulating the electrophysiology. Heijman et al. $\beta$ adrenergic model [17] was defined for the non-selective agonist isoproterenol, although in the formulation the activation of $\beta 1$ and $\beta 2$-ARs isoforms was differentiated. We performed selective 
simulations in which only one receptor subtype was stimulated as if the other was blocked. The use of isoproterenol and specific antagonists is the common approach in most of experiments, facilitating the comparison.

Population of models. Biological variability is known to be a feature that can vary the response of different individuals to the same perturbation such as a drug or pathology. For this reason, we considered in this study populations of cells instead of only the baseline models. We applied parameter variability to electrophysiological and $\beta$-adrenergic remodeling variables with scaling factors following a log-normal distribution (59\%-169\%). A total of 300 different cells were initially generated and calibrated to match physiological biomarkers ranges [23]. Medians and interquartile ranges were measured and EADs cases were excluded from calculations because of the repolarization abnormalities.

The statistical analysis was performed using the Wilcoxon rank sum test in MATLAB. Parameters differences were statistically significant for $\mathrm{p}$-values $<0.01$.

Phosphorylation of electrophysiological substrates. The phosphorylation of each substrate was represented by a fraction ranging from 0 (basal PKA-phosphorylation) to 1 (maximum). To study the individual electrophysiological effects of phosphorylated proteins, we performed a univariate contribution analysis, in which one substrate was completely phosphorylated while the others remained at basal levels. APD and CaT peak sensitivities to each parameter were then quantified for both the $\mathrm{N}$ and HF baseline model. Phosphorylation fractions resulting from each baseline model with the different modes of $\beta$-AR stimulation were also analyzed to compare the contribution of phosphorylated proteins in each case.

Electrophysiological indicators. The last AP and CaT of 300 beats were examined, after assuring the stabilization of both the $\beta$-adrenergic system and the electrophysiological activity. Cellular biomarkers were APD, calculated at $80 \%$ and $90 \%$ of repolarization ( $\mathrm{APD}_{80}$ and $\mathrm{APD}_{90}$ ), CaT peak $\left(\mathrm{CaT}_{\max }\right)$, CaT duration from maximum upstroke to $80 \%$ recovery $\left(\mathrm{CaTD}_{80}\right)$, and the interval between electrical and mechanical termination computed as the difference $\mathrm{CaTD}_{80}-\mathrm{APD}_{80}$. All simulations were run at $1 \mathrm{~Hz}$ and biomarkers were obtained for this frequency.

\subsubsection{Transmural strand simulations}

A one-dimensional cable composed of 166 myocytes was used to study the electrical activity and propagation in coupled cells [18] and was simulated in Elvira, a software to solve the monodomain equation by using the finite element technique of the operator splitting. One half of the strand was composed of endocardial cells and the other half of epicardial cells. Midmyocardial cells were not used because of their controversial behavior [24,25]. Instead, we applied a gradient of 20 cells between endocardial and epicardial to smooth the transition. An additional HF remodeling change considered is the reduction of intercellular coupling modeled by a 50\% decrease in the diffusion coefficient [2]. To avoid edge effects, only the 146 central nodes were considered for calculations. Besides cellular biomarkers, we measured repolarization time (RT) along the fiber as time to $90 \%$ of repolarization since the initiation of the stimulus for each cell. The difference between the maximum and minimum $\mathrm{RT}$ values indicated the transmural dispersion of repolarization (TDR). 


\subsection{Results}

\subsection{1 $\beta$-adrenergic stimulation in heart failure}

In failing myocytes, in addition to the electrophysiological remodeling, changes in $\beta$-adrenergic signaling proteins may contribute to the altered electrophysiology. Therefore, the initial goal was to obtain insight into this signaling remodeling by establishing specific changes that may best represent the HF phenotype. From previous experimental studies, we selected 5 model parameters commonly reported to be altered in $\mathrm{HF}$ and generated a population in which these were upregulated or downregulated within a defined variability range (Table 5.3). Figure 5.2A, showing APs and CaTs from these $\mathrm{HF}$ populations, illustrates that $\beta$-adrenergic stimulation with isoproterenol modulated differently the electrophysiological phenotype depending on parameter combinations applied for signaling remodeling (blue traces). The same remodeling also affected, to a lower extent, APs and CaTs of cells with no $\beta$-stimulation (green traces). From these populations we selected cells that showed consistency with experiments [22] in the degree of APD and CaTD shortening following $\beta$ stimulation (Figure 5.2B), as described in the Methods section. This calibration step was used to define the signaling HF remodeling.
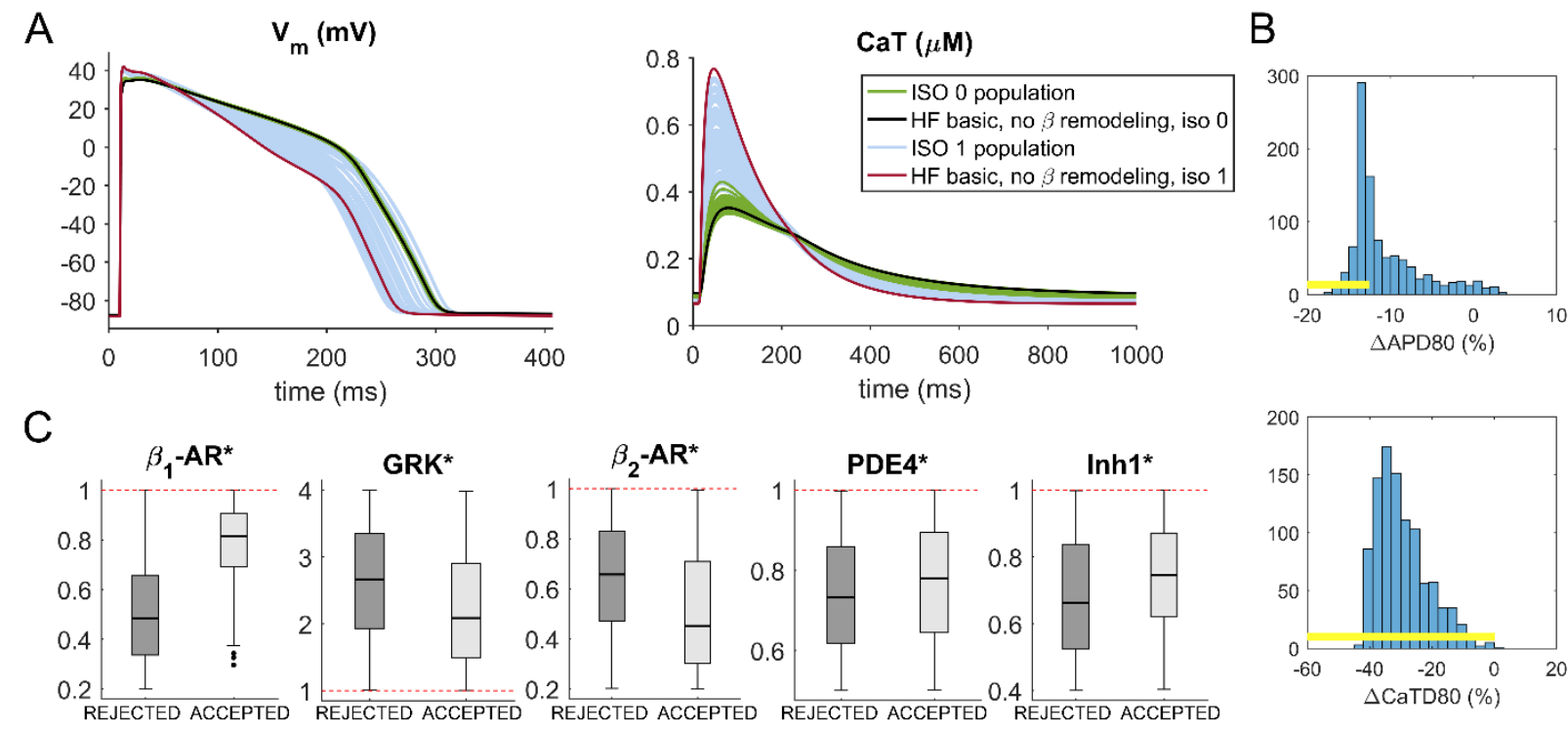

Figure 5.2. Experimental calibration of a $\beta$-population of failing (HF) myocytes stimulated with isoproterenol (iso). A) Action potential (AP) and $\mathrm{Ca}^{2+}$ transient (CaT) traces of some representative cells of the population with fixed electrophysiological remodeling and variable signaling. The basic HF models (black and red, for iso 0 and iso 1 respectively) represent the APs and CaT of myocytes without modifications in the $\beta$-adrenergic system. B) Biomarker histograms of the population show $\triangle \mathrm{APD}_{80}$ and $\triangle \mathrm{CaTD}_{80}$ ranges accepted. C) Signaling parameter distributions divided in accepted and rejected models $(* \mathrm{p}<0.01)$. Results from epicardial cells stimulated at $1 \mathrm{~Hz}$.

During the calibration, 324 out of the initial 1000 models were within the accepted group. Ranges of the 5 signaling parameters in the accepted and rejected sets are shown in Figure 5.2C. Since differences between groups were all statistically significant $(\mathrm{p}<0.01)$, we chose the median values of the 5 parameters from the accepted models, shown in Table 5.1 as scale factors relative to normal myocytes, to define the basic $\beta$-adrenergic remodeling in HF. Specifically, this analysis quantitatively 
predicts downregulation of $\beta 1-\mathrm{ARs}$, PDE4 and Inh1, upregulation of GRK upregulation, and a decrease in $\beta 2$-ARs in the cav compartment due to their migration to the ecav domain. These changes, together with the electrophysiological and structural remodeling in myocytes, constituted our baseline HF model.

Table 5.1. $\beta$-adrenergic system remodeling in heart failure.

\begin{tabular}{cc}
\hline Molecule & $\begin{array}{c}\text { Median } \\
\text { (scale factors) }\end{array}$ \\
\hline$\beta 1-\mathrm{AR}$ & 0.82 \\
GRK & 2.09 \\
$\beta 2-\mathrm{AR}$ & 0.45 \\
PDE4 & 0.78 \\
Inhibitor1 & 0.75 \\
\hline
\end{tabular}

\subsubsection{Comparison of $\beta$-adrenergic stimulation in normal and failing myocytes}

In Figure 5.3, the effects of $\beta$-adrenergic stimulation with isoproterenol are compared in normal and failing myocytes. Figure 5.3A represents the AP and CaT traces for the baseline models under the four different conditions: $\mathrm{N}$ or $\mathrm{HF}$, and with or without isoproterenol. When comparing the electrophysiology between normal and failing cells, the characteristic long AP and reduced systolic $\mathrm{Ca}^{2+}$ in $\mathrm{HF}$ were also observed following sympathetic stimulation. In HF, $\beta$-adrenergic stimulation produced slightly less $\mathrm{APD}_{90}$ shortening (reduction of $12 \%$ versus $15 \%$ in normal myocytes) and a smaller relative increase of CaT amplitude (increase of $89 \%$ versus $108 \%$ ).

Population simulations were then conducted to evaluate variability in the response to $\beta$ stimulation in $\mathrm{N}$ and HF myocytes. Inter-individual variability in signaling and electrophysiological parameters introduced dispersion to each of the studied biomarkers (supplemental Figure 5.8) and allowed us to quantify the vulnerability to repolarization abnormalities in the different cases (Figure 5.3B). Whereas cells without $\beta$-adrenergic stimulation were not prone to develop EADs, isoproterenol caused repolarization abnormalities.

Transmural dispersion of repolarization is strongly related to arrhythmogenesis, and we therefore analyzed whether there were differential effects of $\beta$-stimulation in epicardial versus endocardial cells. Our simulations showed that endocardial cells were more vulnerable to EADs under $\beta$-stimulation than epicardial cells, and failing conditions increased the probability of EADs development in both types of cells. The repolarization difference between endocardial and epicardial cells, shown in Figure 5.3C and measured as $\mathrm{APD}_{90}$ dispersion $\left(\triangle \mathrm{APD}_{90 \text { endo-epi }}\right.$ ), decreased with isoproterenol for $\mathrm{N}$ and $\mathrm{HF}$ myocytes similarly. In the case of $\mathrm{HF}, \beta$-adrenergic stimulation counteracted the increase caused by failing conditions. Regarding $\mathrm{CaT}$, the increase of $\mathrm{Ca}^{2+}$ peak caused by sympathetic stimulation depended on the maximum $\mathrm{Ca}^{2+}$ in control conditions. In $\mathrm{HF}$, the depressed $\mathrm{CaT}$ was slightly enhanced and the increase was smaller in endocardial cells, which have less systolic $\mathrm{Ca}^{2+}$ than epicardial cells. 

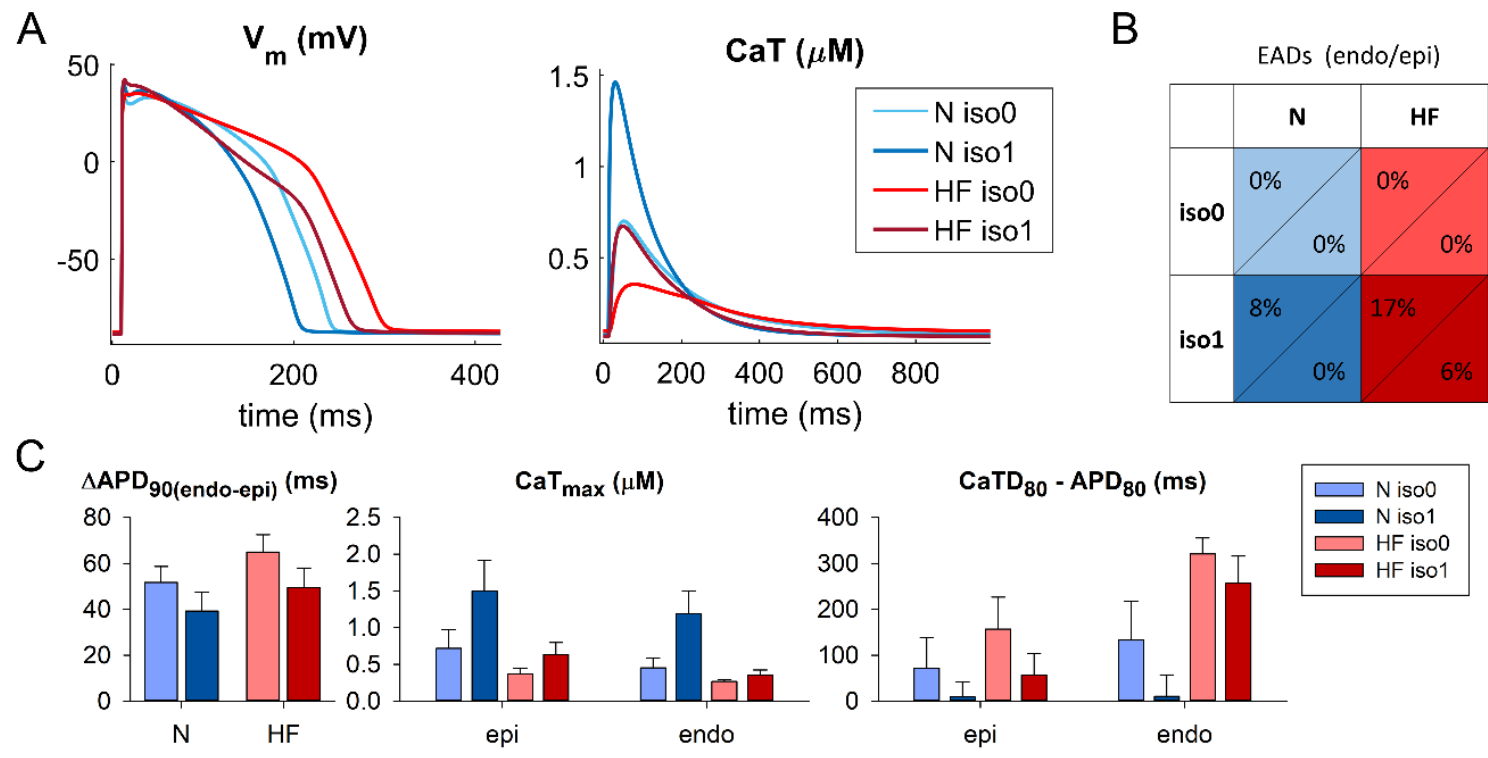

Figure 5.3. $\beta$-adrenergic modulation of action potential (AP) and $\mathrm{Ca}^{2+}$ transient $(\mathrm{CaT})$ in normal $(\mathrm{N})$ and failing (HF) myocytes. A) Comparison of AP and CaT traces of the baseline epicardial models. B) Quantification of early afterdepolarizations (EADs) cases in N and HF populations of endocardial (endo) and epicardial (epi) cells. C) Comparison of transmural APD dispersion ( $\mathrm{APD}_{90 \text { endo-epi }}$ ), $\mathrm{CaT}$ peak $\left(\mathrm{CaT}_{\max }\right)$ and $\mathrm{CaTD}_{80}-\mathrm{APD}_{80}$ interval in the population (median and interquartile range). Results from cells stimulated at $1 \mathrm{~Hz}$.

The delay between $\mathrm{Ca}^{2+}$ recovery and APD repolarization, quantified as ( $\mathrm{CaTD}_{80}-\mathrm{APD}_{80}$ ), has been proposed as a biomarker of arrhythmia vulnerability [22,23], as delayed afterdepolarizations (DADs) can be triggered by the elevated intracellular $\left[\mathrm{Ca}^{2+}\right]$ after the membrane has already repolarized. Figure 5.3C shows that $\beta$-adrenergic activity shortened CaTD-APD interval, thereby presumably reducing the predisposition to DADs. Compared to normal conditions in which major reductions of CaTD-APD period were obtained after sympathetic stimulation, the reduction effect was smaller in HF, especially in endocardial cells. Electrophysiological HF remodeling was the cause of the elevated CaTD-APD, and this combined to the altered $\beta$-adrenergic regulation led to a smaller reduction compared with normal cells, and potentially increased susceptibility to DADs.

These results highlight the differential effects of $\beta$-AR stimulation on $\mathrm{N}$ and HF myocytes. Although isoproterenol is protective in $\mathrm{N}$ and HF conditions by reducing APD dispersion, the impact on decreasing the probability of DADs is smaller in HF and the arrhythmogenic risk of HF through EADs development increases with $\beta$-AR stimulation. Isoproterenol also improves CaT in HF but the increase is far from the effect in $\mathrm{N}$ cells.

\subsubsection{Selective $\beta$-adrenergic stimulation}

The understanding of the relative role of $\beta$-AR isoforms on electrophysiology is crucial to select among a variety of pharmacological agents. In HF, $\beta 1$ isoform is reduced while $\beta 2$ subtype changes its location in the membrane compartments without altering the total number of receptors. The differences in the remodeling of $\beta 1$ and $\beta 2$ pathways help explain the differential roles of both isoforms in the altered electrophysiological behavior of failing cells. The individual influence of the two dominant subtypes on cardiac electrophysiology were examined to evaluate potential differences between them and a non-selective stimulation. Figure 5.4A compares AP and CaT traces in failing myocytes under different signaling conditions. The electrophysiological effect of the activation of both 
receptor subtypes simultaneously $(\beta 1+\beta 2$, equivalent to isoproterenol) was very similar to selective $\beta 1$-AR stimulation, and differed from selective $\beta 2-\mathrm{AR}$ stimulation, which caused only minimal changes to membrane potential or intracellular $\left[\mathrm{Ca}^{2+}\right]$.
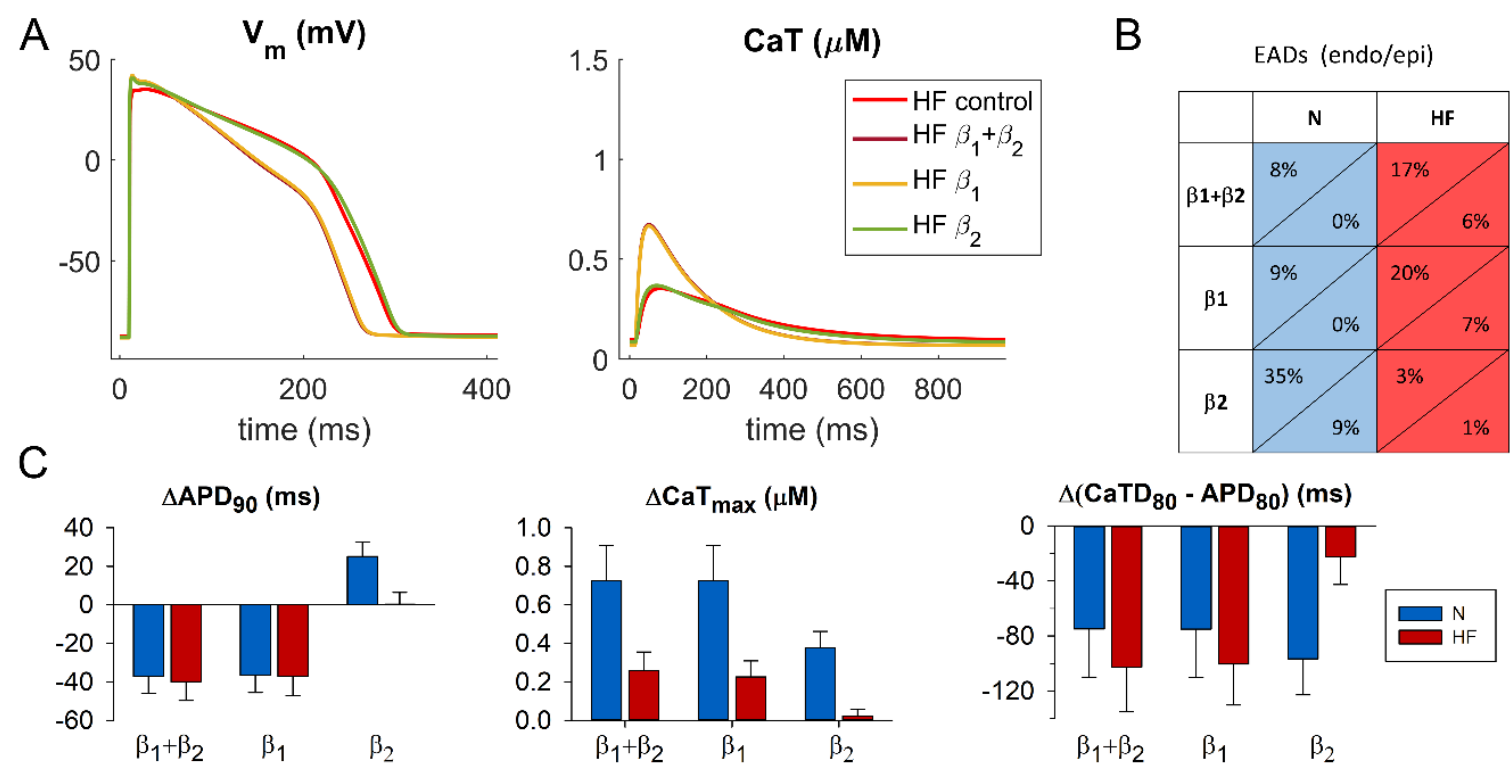

Figure 5.4. Selective $\beta$-adrenergic modulation of action potential (AP) and $\mathrm{Ca}^{2+}$ transient $(\mathrm{CaT})$ in heart failure (HF). A) Comparison of AP and CaT traces of the HF baseline model. B) Quantification of early afterdepolarizations (EADs) cases in N and HF populations of endocardial (endo) and epicardial (epi) cells. C) Comparison of $\beta$-isoform effect on APD90, CaT peak $\left(\mathrm{CaT}_{\max }\right)$ and $\mathrm{CaTD}_{80}-\mathrm{APD}_{80}$ interval in the population (median and interquartile range). Results from epicardial cells stimulated at $1 \mathrm{~Hz}$.

In Figure 5.4C, the population response to $\beta$-adrenergic stimulation was quantified as the median of the difference of biomarkers between $\beta$-ARs stimulation and control (without $\beta$-AR stimulation) for every cell. Negative values indicate a decrease and positive values an increase in the corresponding biomarker. APD reduction, $\mathrm{CaT}$ increase and $\left(\mathrm{CaTD}_{80}-\mathrm{APD}_{80}\right)$ decrease were observed with specific $\beta 1-\mathrm{AR}$ stimulation and this modulation was very similar to the one exerted by isoproterenol. This occurred both in $\mathrm{HF}$ and $\mathrm{N}$ conditions. However, $\beta 2-\mathrm{AR}$ stimulation provoked changes of less or opposite magnitude (shortening instead of prolongation in some cell models). For instance, while $\beta 2$ modulation of $\mathrm{CaT}$ was half of $\beta 1$ effect in $\mathrm{N}$ myocytes, it was blunted in the setting of HF. This minimal impact was also observed in the other biomarkers. Surprisingly, while isoproterenol shortened APD, $\beta 2$ agonists prolonged it in normal myocytes. This prolongation was also related to the increased number of EADs with $\beta 2$-AR stimulation. However, our results suggest that $\beta 2$ becomes less proarrhythmic in HF in terms of EAD generation, whereas $\beta 1$ increases the probability of EADs. Therefore, the arrhythmogenic effects (EADs) of $\beta$-AR stimulation in HF are due to the $\beta 1-A R$ subtype, but the activation of $\beta 1$-AR pathways is also the main way to increase $\mathrm{Ca}^{2+}$ levels and reduce the CaTD-APD interval via the $\beta$-adrenergic system.

\subsubsection{Mechanisms of $\beta$-adrenergic signaling}

The modulation of the electrophysiological activity of cardiomyocytes by $\beta$-AR signaling cascades is mediated by PKA phosphorylation of membrane ion channels and $\mathrm{Ca}^{2+}$-handling proteins. 
A contribution analysis of the eight targets subject to phosphorylation was performed to quantify their individual impact on $\mathrm{APD}_{90}$ and $\mathrm{CaT}_{\max }$. Figure 5.5A shows, as percentages, the univariate contribution of each PKA-phosphorylated target to $\mathrm{APD}_{90}$ and $\mathrm{CaT}_{\max }$. These were obtained through simulations in which the phosphorylation fractions of individual targets were set to 1 while the others were fixed at 0 . $\mathrm{I}_{\mathrm{Ks}}$ turned out to be the main modulator of APD shortening, followed by $\mathrm{I}_{\mathrm{CaL}}$ and $\mathrm{I}_{\mathrm{NaK}}$ with prolongation effects. $\mathrm{I}_{\mathrm{CaL}}$ and PLB were the key factors responsible for $\mathrm{CaT}_{\max }$ increase under $\beta$ AR stimulation. Different values between N and HF highlight that electrophysiological remodeling alters the response to protein phosphorylation. The most remarkable observation is that $\mathrm{I}_{\mathrm{CaL}}$ impact decreased considerably in HF. This is because $\mathrm{I}_{\mathrm{CaL}}$ refers only to channels PKA-phosphorylated in the cav domain, and it was compensated by the contribution of $\mathrm{I}_{\mathrm{CaL}}$ phosphorylation in the ecav domain (I $\mathrm{I}_{\mathrm{CL} e}$ ), as L-type $\mathrm{Ca}^{2+}$ channels distribute in this domain in HF due to loss of T-tubules.
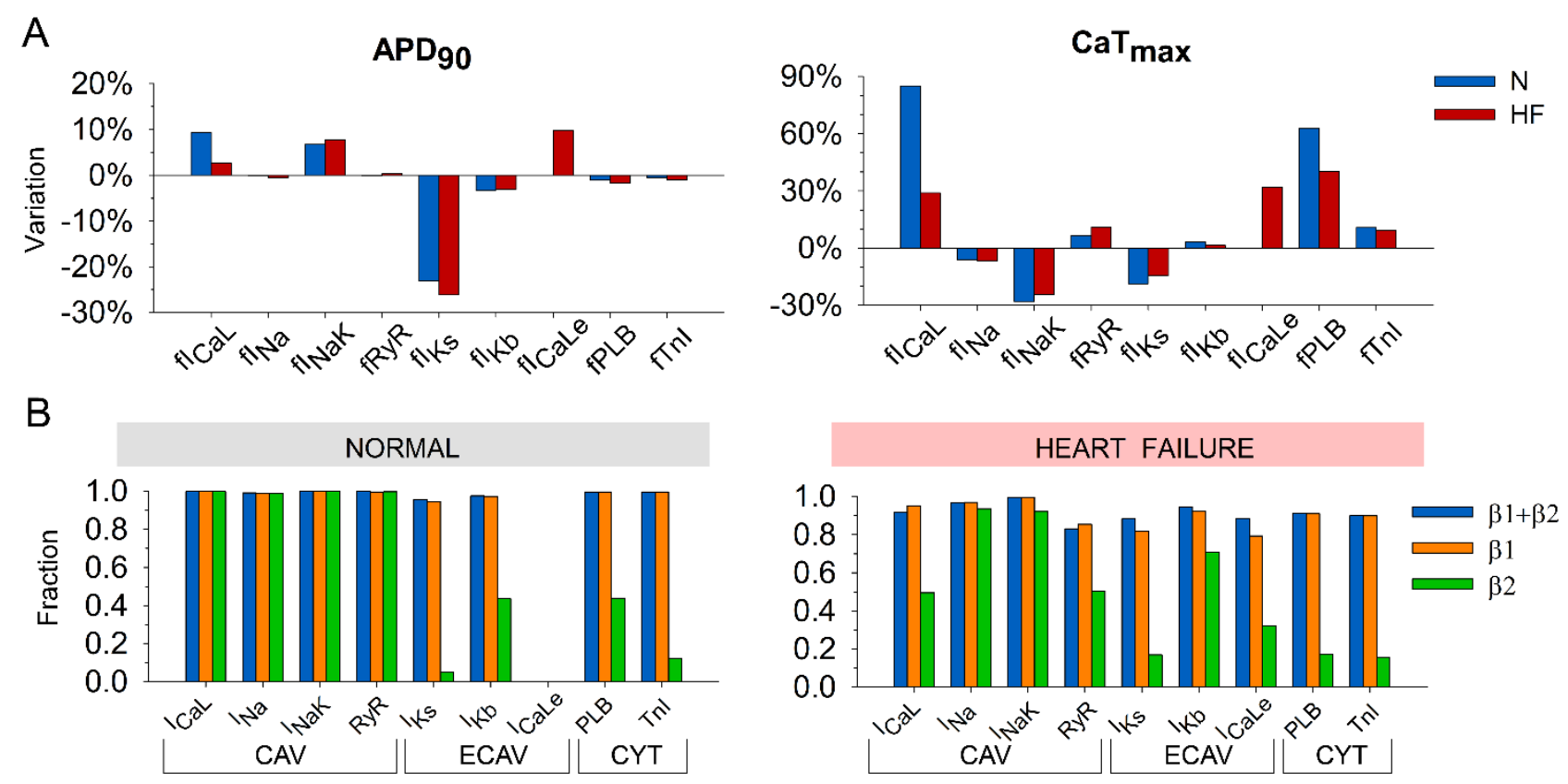

Figure 5.5. Sensitivity analysis of $\beta A R$-mediated PKA-phosphorylation. A) APD and CaT max $_{\text {sensitivities to individual }}$ substrate phosphorylation fraction ( $f_{\text {protein }}$ ) in N and HF. B) Comparison of substrate PKA-phosphorylation under saturated selective and non-selective $\beta$-stimulation. Signaling compartmentation: caveolar (cav), extracaveolar (ecav) and cytosolic (cyt). Results from epicardial cells stimulated at $1 \mathrm{~Hz}$.

Apart from sensitivities, the activating effect of PKA phosphorylation on electrophysiological substrates also depends on the degree of phosphorylation. Figure 5.5B represents the PKAphosphorylation level of each electrophysiological substrate in $\mathrm{N}$ (left) and in HF (right) conditions, differentiating between non-selective stimulation $(\beta 1+\beta 2)$ and selective $\beta$-AR isoform stimulation (blue, orange and green bars respectively). A fraction equal to 1 represents a maximal change in the target protein phosphorylation, while 0 represents the baseline phosphorylated state. Differences between $\mathrm{N}$ and $\mathrm{HF}$ are due to $\beta$-adrenergic protein remodeling in failing myocytes ( $\beta 1$-AR downregulation, GRK upregulation, etc) which alter compartmentalization and PKA-phosphorylation activity. Maximal phosphorylation fractions were computed under non-selective and $\beta 1$-selective stimulation in normal cells. In HF, a slight decrease in the eight original targets was observed, while $\mathrm{I}_{\text {CaLe, }}$ only present in failing cells, increased. In $\mathrm{N}$ conditions, saturated selective $\beta 2-\mathrm{AR}$ stimulation 
only led to maximal phosphorylation of caveolar substrates, highlighting the local PKA activation produced by $\beta_{2}$-ARs. Changes from $\mathrm{N}$ to $\mathrm{HF}$ are more remarkable under $\beta_{2}$-selective stimulation because extracaveolar phosphorylation of substrates increases and the activation tends to be more global.

This analysis highlights on the one hand, that HF electrophysiological remodeling alters phosphorylation impact on AP and $\mathrm{CaT}$, and on the other hand that $\beta$-adrenergic signaling remodeling, as well as selective $\beta$-AR stimulation, changes substrate phosphorylation levels. Both systems contribute to the final electrophysiological phenotype of failing myocytes.

\subsubsection{Variability of $\beta$-adrenergic signaling}

The introduction of interindividual differences to consider all the potential electrophysiological phenotypes provided a wide range of biomarkers variability. Figure 5.6 illustrates the histograms of biomarkers modulation as the difference between $\beta$-ARs stimulation and control.
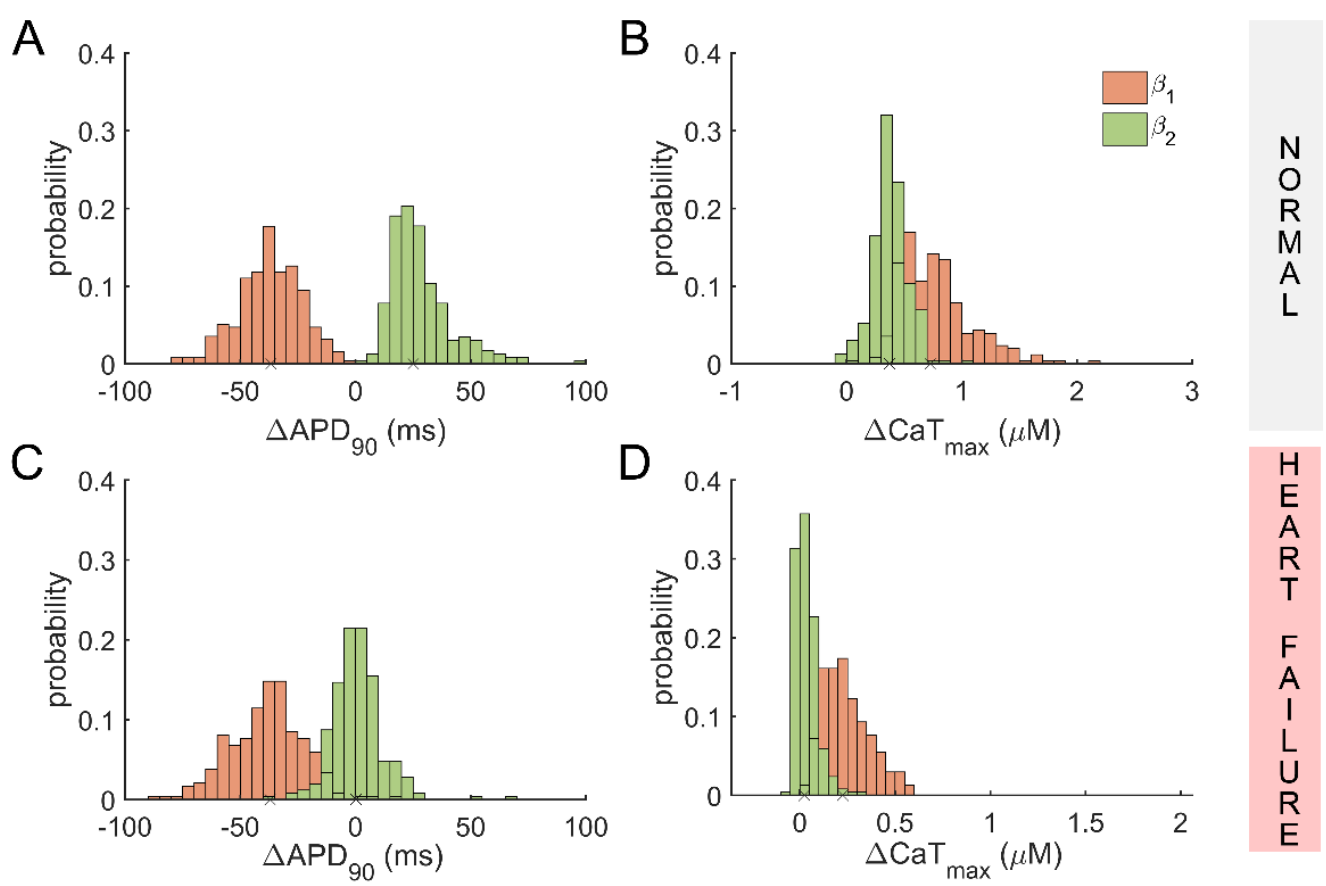

Figure 5.6. Interindividual variability in selective $\boldsymbol{\beta A R}$ stimulation. A) APD and CaT modulation histograms in the normal (N) population. B) APD and CaT modulation histograms in the failing (HF) population. Results from epicardial cells stimulated at $1 \mathrm{~Hz}$.

In this way, all normal myocytes presented APD shortening after $\beta 1$-AR stimulation, but APD prolongation after $\beta 2-\mathrm{AR}$ activation. In the case of $\mathrm{CaT}_{\max }$, it was increased in all models, the only difference between $\beta$-ARs was the range of $\mathrm{CaT}_{\max }$ variation. In HF, $\beta$-adrenergic remodeling caused changes in $\beta 2$-AR modulation effect. Indeed, the increase or decrease of APD and $\mathrm{CaT}_{\max }$ depended on the remodeling degree of the signaling parameters. To go in depth into this phenomenon, populations were separated in two groups according to the increase or decrease of biomarkers after selective $\beta$-AR stimulation (supplemental Figure 5.9). Then, the contribution to this classification of the 5 signaling parameters remodeled in HF was analyzed. Figure 5.9 panel A shows that $\beta 2-\mathrm{AR}$ and PDE4 controlled APD modulation; the strong downregulation of the former shortened it $\left(\triangle \mathrm{APD}_{90}<0\right)$ 
while the strong downregulation of the latter prolonged the duration $\left(\Delta \mathrm{APD}_{90}>0\right)$. The analysis of $\mathrm{CaT}_{\max }$ in Figure 5.9 panel $\mathrm{B}$ indicates that only strong PDE4 downregulation and weak downregulation of inhibitor1 contributed to $\mathrm{CaT}_{\max }$ increase $\left(\Delta \mathrm{CaT}_{\max }>0\right)$.

Figure 5.9 panel $\mathrm{C}$ helps explain the similarities between selective $\beta 1$ and non-selective stimulation (iso) by comparing biomarker differences. As expected, a strong downregulation of this receptor isoform, as can occur in HF, increased the differences between both stimulation protocols, highlighting the dominant role of $\beta 1-\mathrm{AR}$ in human cardiomyocytes.

Populations of models indicate that specific changes in the $\beta$-AR signaling pathway can lead to different $\beta$-AR stimulation responses, especially with $\beta 2$-AR.

\subsubsection{Transmural effects of $\beta$-AR stimulation}

Simulations in a multicellular one-dimensional cable including endocardial and epicardial cells complemented the unicellular simulations in the different types of cells by adding the effect of cellular coupling and transmural electrical propagation. As predicted with APD values in cellular simulations, repolarization time, measured as time to $90 \%$ of repolarization since the initiation of depolarization, decreased with $\beta$-AR stimulation for both $\mathrm{N}$ and HF conditions, except for $\beta 2$-AR in normal myocytes (Figure 5.7). However, the effect on transmural dispersion of repolarization (TDR) differed between strands composed of normal or HF myocytes. While isoproterenol and selective $\beta 1$-AR stimulation reduced TDR in the normal strand, $\beta$-AR stimulation in HF had only minimal effects and would therefore not be beneficial. The control strand shows that the electrophysiological modifications and slow conduction velocity due to reduced intercellular coupling in HF predispose the myocardium to a greater risk of arrhythmia with larger repolarization times and TDR. The only exception was $\beta 2$-AR that became less arrhythmogenic in HF than in normal myocytes. All in all, what these results suggest is that the protective effects of $\beta$-AR stimulation (TDR reduction) observed in $\mathrm{N}$ myocytes disappear in HF.
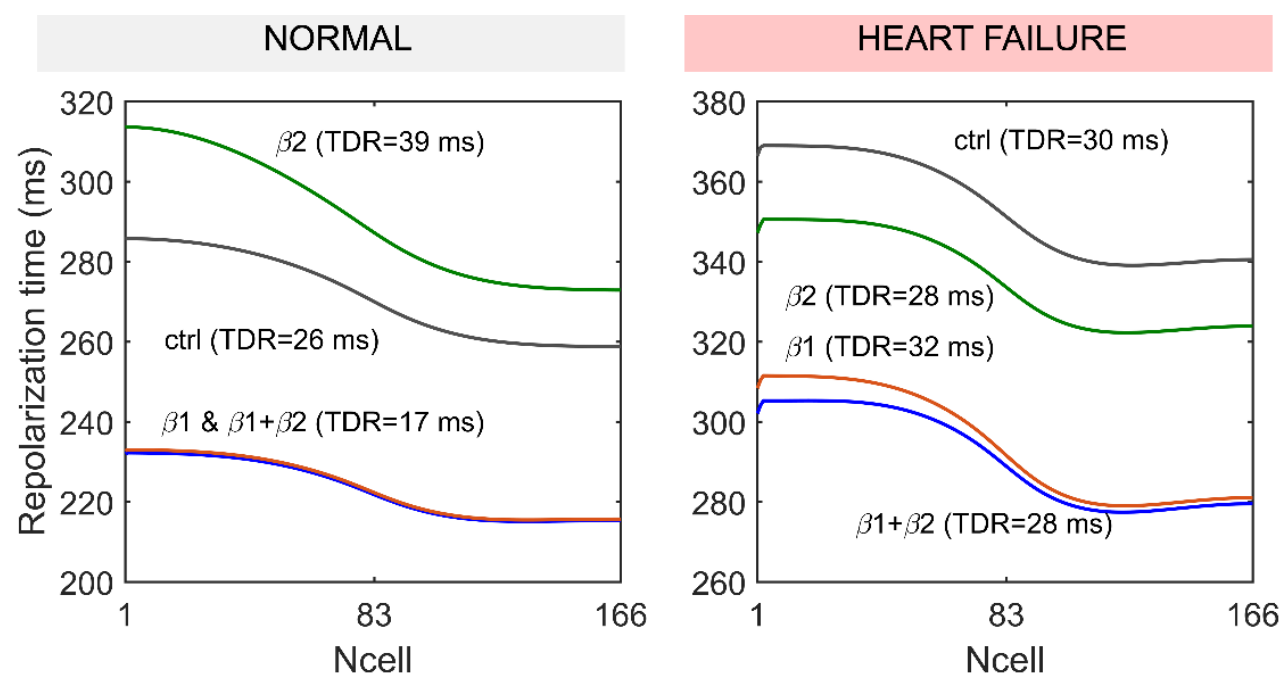

Figure 5.7. Dispersion of repolarization in a transmural strand. Normal $(\mathrm{N})$ vs heart failure (HF) for the different $\beta$ adrenoreceptor isoform stimulation conditions. 


\subsection{Discussion}

\subsubsection{Main findings}

The adverse changes in ventricular myocytes during the progression of HF lead to electrical instabilities and contractile dysfunction. According to this study, the role of the $\beta$-adrenergic system should be considered, since the electrophysiological modulation resulting from signaling protein remodeling might contribute to arrhythmogenesis. Additionally, the electrophysiological response of failing cells to sympathetic stimulation is different to the effects observed with $\beta$-agonists in normal myocytes, which highlights the need to test pharmacological agents under the setting of HF. The present computational study, based on the available data to date, predicts that in HF $\beta$-AR stimulation (i) induces a smaller positive inotropic response compared with that seen in normal myocytes, (ii) increases the vulnerability of myocytes to develop EADs, (iii) decreases the probability of DADs generation by reducing the CaTD-APD interval although, compared to N, HF is less protective, (iv) does not provide a beneficial reduction of TDR as observed in N conditions, and (v) is blunted when only $\beta 2-\mathrm{AR}$ isoforms are activated.

\subsubsection{Compartmented PKA-phosphorylation activated by $\beta$-adrenergic stimulation modulates action potentials and $\mathrm{Ca}^{2+}$ transients}

The $\beta$-AR-mediated modulation of $\mathrm{AP}$ and $\mathrm{CaT}$ determines the electrical activity and contractility of the heart. While the inotropic effect of $\beta$-AR agonists is widely known [26,27], the exact $\beta$-AR-modulation of APD is controversial: APD is prolonged [28,29] or reduced [22,30] depending on the study. It is to be noted that available data in the literature use different experimental protocols, drugs and species, so that a wide variability in the results can be found. In the present study we obtained APD and CaTD shortening with isoproterenol as observed in ventricular wedge preparations of human hearts [22].

The analysis of PKA-phosphorylation degree explained that APD shortening resulted from the dominant effect of phosphorylated $\mathrm{I}_{\mathrm{Ks}}$ while the increase of $\mathrm{Ca}_{\max }$ (equivalent to CaTD shortening) was mainly due to the accumulated contribution of $I_{C a L}$ and PLB phosphorylation. Selective $\beta 2-A R$ isoform stimulation had a moderate inotropic effect due to the low PKA-phosphorylation of PLB compared to $\beta 1$-AR stimulation, and provoked APD prolongation due to the dominant effect of $\mathrm{I}_{\mathrm{CaL}}$ phosphorylation versus minimal $\mathrm{I}_{\mathrm{Ks}}$ phosphorylation. The location of $\beta$-ARs subtypes and the compartmentation of the signaling cascade were therefore critical factors regulating electrophysiological outcomes exerted by $\beta$-adrenergic stimulation. It is known that $\beta 1$-ARs are the prominent subtype in cardiomyocytes and generate global cAMP signals [26,31], which explains that the regulation mediated by isoproterenol and $\beta 1-\mathrm{AR}$ stimulation was identical in $\mathrm{N}$ conditions. It is to be noted that our simulation results showed APD prolongation with $\beta 2$-AR stimulation as opposed to the shortening observed by Lang et al. [22]. This discrepancy could be attributed to the fact that the drugs used (xamoterol and procaterol) as specific ligands for the activation of $\beta$-adrenergic isoforms in [22] could have partial specificity [12]. In fact, the effects of isoproterenol $(\beta 1+\beta 2)$ in our simulations were consistent with the experiments, and discrepancies appeared when comparing the effects of selective agonists.

In failing myocytes, signaling remodeling alters PKA-phosphorylation and consequently has a different impact on AP and CaT, which is also determined by the electrophysiological remodeling. $\mathrm{I}_{\mathrm{Ks}}$ 
phosphorylation seems to be critical to shorten the long APD in failing myocytes, which also explains the blunted effect of selective $\beta 2-\mathrm{AR}$ stimulation. $\beta 2-\mathrm{AR}$ stimulation did not cause maximal LTCC phosphorylation because cAMP signaling was less localized in the caveolar domain after HF remodeling, and part of $\mathrm{I}_{\mathrm{CaL}}$ phosphorylation effect on APD and CaT was translated to the channels relocated in the sarcolemma after detubulation. In a recent study, Loucks et al. [32] studied in silico the degradation of T-tubular domains by redistributing LTCCs and cAMP signaling and showed that channels relocated to the sarcolemmal membrane in HF can produce sustained current that increases the risk of EADs. Regarding CaT, PLB phosphorylation acts as a compensatory mechanism to SERCA downregulation by enhancing SR $\mathrm{Ca}^{2+}$ uptake [33,34], but the increase effect on intracellular $\mathrm{Ca}^{2+}$ appears to be reduced in HF.

\subsubsection{Adverse $\beta$-adrenergic remodeling effects in HF. Desensitization and detubulation}

While sympathetic activity is initially a mechanism to increase contractility and maintain cardiac output in HF, the chronic stimulation becomes detrimental and initiates a protein remodeling process that disrupts the $\beta$-adrenergic signaling cascade [35]. Desensitization, controlled by PKA and GRK, is initially an adaptive mechanism [36] which in HF leads to increased phosphorylation and degradation of $\beta$-ARs [37]. When we incorporated $\beta 1$-AR downregulation and GRK upregulation in the HF model, decreased cellular cAMP levels provoked a reduction in PKA-phosphorylation of substrates with $\beta$ agonists in HF compared to $\mathrm{N}$ and explained the lower inotropy observed [26,38]. A $\beta 1-\mathrm{AR}$ downregulation higher than $19 \%$ (value applied in the baseline model of HF) would be realistic in an aggravated HF condition and could decrease PKA-phosphorylation to a larger extent, increasing differences in the electrophysiological modulation between non-selective and selective $\beta 1$-AR stimulation. The controversial modifications in the inhibitory G-protein $\left(G_{i}\right)$ coupled to $\beta 2-A R$ $[22,39,40]$ during HF were not introduced. However, upregulated GRK, which enhanced protein function, contributed indirectly to reduce $G_{i}$ activation. Both PKA and GRK compete in the phosphorylation of $\beta$-AR. As $\beta 2$-AR coupling to $G_{i}$ depends on GPCR PKA-phosphorylation, a higher GRK-mediated phosphorylation reduced PKA-phosphorylation of receptors and $\beta 2$-ARs coupling to G-protein $\left(\mathrm{G}_{\mathrm{s}}\right)$ dominated over $\mathrm{G}_{\mathrm{i}}$. These results agree with the reduction in PKA-phosphorylation of $\beta 2-A R$ observed in failing myocytes and the consequent switch from $G_{i}$ to $G_{s}$ activation [22]. Nevertheless, the most important remodeling factor altering $\beta 2-\mathrm{AR}$ signaling is detubulation.

Structural and functional remodeling of cellular microdomains leads to changes in cAMP compartmentation. $\beta 2$-AR signaling, which is locally confined in T-tubules and regulates LTCC in healthy myocytes, undergoes substantial changes in HF, presumably due to the loss of T-tubular microdomains $[41,42]$, which can explain the diminished electrophysiological effects in HF. Other studies highlight though that due to the conservation of the total number of $\beta 2-\mathrm{AR}$ in $\mathrm{HF}$, these receptors remain functional and cause positive inotropy and changes in $\mathrm{Ca}^{2+}[26,43,44]$. When we introduced all the changes observed in cAMP signaling compartmentation [45-47], $\beta 2-\mathrm{AR}$ signaling became more global and the modulation of APD and CaT decreased. The tight regulation of $\mathrm{I}_{\mathrm{CaL}}$ by $\beta 2-\mathrm{AR}$ in $\mathrm{N}$ conditions is weakened in failing myocytes because of the reorganization of channels and receptors, contributing to the impairment of $\mathrm{Ca}^{2+}$ dynamics. Besides detubulation, PDE downregulation also causes changes in the compartmented cAMP and PKA signals that affect AP and CaT $[42,48]$. Cytosolic proteins, such as PLB, were not further phosphorylated in HF following $\beta 2$ AR stimulation as DeSantiago et al. observed [43], in part because the enhanced activity of PP1 found 
in failing myocytes due to inhibitor1 downregulation restricts PKA activity $[49,50]$, and because $\beta 2$ ARs still have limited control of cytosolic cAMP signals in the model despite applying caveolar signaling disruption [51,52].

\subsubsection{Arrhythmogenesis in failing myocytes}

Enhanced sympathetic activity has been related to the generation of arrhythmias, especially in $\mathrm{HF}$, where the development of EADs and DADs has been observed [4,22,28,32,43]. Our simulations confirmed that EAD development increased after $\beta$-AR stimulation in HF. With respect to DAD generation, although our simulations did not show DADs, the wider CaTD-APD period in HF compared to control would suggest a higher likelihood of DAD development in HF. Previous studies have suggested that $\mathrm{Ca}^{2+}$ overload plays a role in afterdepolarization formation and that $\beta 2-\mathrm{AR}$ stimulation might be the most arrhythmogenic factor in HF [4,22,32,43]. Triggered activity caused by DADs were observed only during $\beta 2$-AR stimulation in human wedge preparations of failing hearts, which were attributed to transmural differences in CaT and APD generated after HF remodeling [22]. By contrast, in our simulations, both the inotropic effects of $\beta 2-\mathrm{AR}$ stimulation and the apparent arrhythmia susceptibility were reduced in HF compared with normal cells and tissues. These discrepancies could be due to the partial specificity of $\beta$-agonists used in experiments versus the theoretical approach in which only one $\beta$-AR subtype is activated while the other is completely blocked. In $\mathrm{N}$ conditions, EADs resulting from sympathetic stimulation are driven by APD prolongation due to $\mathrm{I}_{\mathrm{CaL}}$ enhancement resulting from PKA-phosphorylation. This finding was also observed in the computational study of Loucks et al. [32], with the mechanistic difference that EADs were induced in failing myocytes after T-tubular disruption and the consequent redistribution of LTCC, which then led to enhanced phosphorylation after $\beta 2$-AR activation. Even though our HF model also considered detubulation, a reduced $\mathrm{I}_{\mathrm{CaL}}$ phosphorylation by $\beta 2$-AR stimulation was observed, and $\beta 1-A R$ was the primary factor responsible for $\mathrm{I}_{\mathrm{CaL}}$ enhancement and EAD development.

\subsubsection{Transmural gradients}

The heterogeneous signaling and electrophysiological HF remodeling in the different transmural myocytes did not result in significant modulation of the different biomarkers in epicardial versus endocardial cells under $\beta$-AR stimulation. Unidimensional cable simulations were then performed to take into account additional factors such as intercellular coupling and electrical propagation in transmural gradients. The initial unicellular study revealed that the main differences between endocardial and epicardial myocytes observed in $\mathrm{N}$ conditions were maintained in HF, despite slight differences in the modulation of some biomarkers, such as CaTD-APD. Contractility seems to be therefore affected throughout the transmural wall in HF. An important difference was the larger propensity of endocardial cells to develop EADs due to their longer APD compared to epicardial cells. These cells might be the origin of triggered activity driven by elevated intracellular $\mathrm{Ca}^{2+}$ and the subsequent reactivation of $\mathrm{I}_{\mathrm{CaL}}$ during a long AP.

The existence of transmural heterogeneities of repolarization, which are common in HF, can create a substrate for arrhythmias [53]. In contrast to the increase of transmural dispersion exerted by $\beta$-adrenergic stimulation in failing myocytes observed by Lang et al. [22], we observed only minimal $\beta$-adrenergic induced changes to TDR in HF. Moreover, $\beta$-AR stimulation TDR reduction benefits obtained in a $\mathrm{N}$ fiber following $\beta 1$-selective and non-selective stimulation were not present in $\mathrm{HF}$. In 
most circumstances, however, TDR was greater in HF strands than in normal strands due to HFinduced electrophysiological remodeling and reduction in intracellular coupling that accompanies HF. In view of these results, it can be concluded that the increase of spatial gradients underlying the development of malignant ventricular arrhythmias in HF patients [54], are mainly due to ionic remodeling rather than to $\beta$-AR stimulation.

\subsubsection{Clinical implications}

Long-term $\beta$-blockers therapy is currently recommended for patients with HF to improve symptoms, reduce hospitalizations, and decrease mortality rate [10]. In addition to $\beta$-AR blockade, antagonist agents can have other properties such as antioxidant, anti-inflammatory, and vasodilating effects that contribute to their efficacy $[13,55]$. Based on the antiarrhythmic impact, which is the main cause of sudden cardiac death in the short term, this study suggests that $\beta 1$-AR blockade in HF, with selective or non-selective drugs, would be protective by reducing EAD events. A decrease in spatial repolarization gradients induced by $\beta$-blockade would also in principle be beneficial, but our results did not show such an effect in HF. Although previous experimental and computational investigations have suggested specific $\beta 2$-AR blockers to stop the detrimental effects of HF $[22,32,43]$, we could not attribute arrhythmogenesis to $\beta 2$-ARs because of the diminished contribution in failing myocytes.

The benefits of $\beta$-AR antagonists have been observed in different cardiac pathologies (atrial fibrillation, long QT syndrome, myocardial infarction, among others) and explain their extended clinical use [56,57]. In atrial fibrillation, $\beta$-blockers are used for ventricular rate control and, despite not being the most effective antiarrhythmic therapy, they may be helpful for atrial fibrillation prevention under certain circumstances, such as reduced ejection fraction [57,58]. A recent exception found is the beneficial effect of $\beta$-AR stimulation restoration to reduce alternans in the postinfarction border zone reported by Tomek et al. [59]. Unlike the response of HF myocytes to $\beta$-AR stimulation, the antiarrhythmic effect of hyperinnervation after myocardial infarction could be due to a different remodeling in the border zone. But apart from the controversy, the aforementioned study, that combined experiments with simulations, also highlighted the potential of computational modeling in investigating mechanistic implications.

An alternative to $\beta$-blocker therapy would be the resensitization of the $\beta$-AR system to restore the beneficial effects of sympathetic stimulation, such as inotropic increase and reduction of TDR. Gene therapy, although in its early stages, can act directly on the known molecular targets that are altered in HF [60]. The observations of $\beta$-AR downregulation in HF led investigators to examine whether $\beta 1-\mathrm{AR}$ or $\beta 2$-AR overexpression was beneficial. Reactivation of $\beta 1$-ARs increases contractility initially but in the long term causes cardiac hypertrophy and fibrosis that contributes to lethal arrhythmias as well as cell death $[35,61]$. Whether $\beta 2-\mathrm{AR}$ overexpression improves cardiac function or not is still debated, but long term stimulation of $\beta 2$-ARs do not have cardiotoxic consequences $[35,62]$. Another approach proposed after finding that elevated GRK activity led to dysfunctional $\beta$-AR in HF is GRK inhibition. At least in transgenic mice, this intervention has reduced ventricular dysfunction and is considered a promising therapy [35,63]. Similarly, the increase of inhibitor1 levels would also constitute a potential target to reduce PP1 inhibition function and ultimately increase SERCA activity. This last strategy, targeted to a specific signaling compartment, could increase therapeutic efficacy compared with drugs that affect global signaling, because different 
pathways and remodeling of the $\beta$-AR microdomains in myocytes determine PKA-phosphorylation and cardiac outcomes in HF [57,64].

\subsubsection{Limitations}

Our HF model reproduced the main changes in the $\beta$-AR system that have routinely been observed experimentally. Human data were included when available, but most data rely on experiments performed in animal models of HF. The comparison with the experimental cardiac response to sympathetic stimulation in human failing preparations highlights that additional experiments would be crucial to confirm our predictions. On the one hand, a consistent methodology for all experiments would facilitate the comparison of selective $\beta$-AR isoform stimulation results. The specificity of $\beta$-AR agonists is under debate and it would be interesting to know if their mechanism of action is equivalent to non-specific stimulation with $\beta$-blockers. On the other hand, despite the increasing research on $\beta$-AR stimulation in patients with HF, clinical trials do not provide enough information to validate signaling mechanisms. The scarcity of human data entails the dependence on other species at the molecular level, which might be the cause of the discrepancies between the mathematical model and experimental observations. $\beta$-AR system model with minor modifications was able to match human $\beta$-AR stimulation results with isoproterenol, but not the results obtained with isoform-specific stimulation. Additional parameters of the model should be readjusted to adapt the original canine $\beta$-AR model to human and for that, reliable electrophysiological responses would be required to confirm the results. Afterwards, additional signaling pathways such as muscarinic receptor interactions or additional proteins prone to PKA-phosphorylation could also help improve the model and the electrophysiological properties following sympathetic stimulation.

Despite some discrepancies with experimental observations, this work presents the most complete relation to date between $\beta$-AR signaling mechanisms and HF remodeling in single cardiac myocytes and transmural cellular strands. The mechanistic investigation of the effects in failing cardiomyocytes can help to predict the critical settings for lethal arrhythmias and guide in the search of potential molecular targets. However, additional experiments to support or refute model predictions would be valuable.

\subsection{Supplemental material}

\subsubsection{Supplementary methods}

References to previous studies that are the basis of our methodology are summarized in Tables 5.2 and 5.3. Table 5.2 shows mathematical models and modifications of the electrophysiological and signaling formulation, and Table 5.3 collects different molecular alterations observed in the $\beta$ adrenergic system in failing myocytes and the possible variability range. 
Table 5.2. Mathematical models and modifications described in previous studies used as a basis for the implementation of a heart failure (HF) model in human ventricular myocytes.

\begin{tabular}{ll}
\hline Formulation & Reference \\
\hline$\beta$-adrenergic signaling model & {$[17]$} \\
\hline Human action potential model (ORd) & {$[18,19]$} \\
\hline PKA-phosphorylation readjustments in ORd & {$[20]$} \\
\hline $\mathrm{I}_{\mathrm{Na}}$ reformulation & {$[65,66]$} \\
\hline HF ion channel remodeling & {$[2]$} \\
\hline Detubulation & {$[21]$} \\
\hline
\end{tabular}

Table 5.3. Variability range of $\beta$-AR remodeling in heart failure

\begin{tabular}{lccc}
\hline Molecule & HF Remodeling & $\begin{array}{c}\text { Variability } \\
\text { range } \\
\text { (\% of change) }\end{array}$ & References \\
\hline $\boldsymbol{\beta 1 - A R}$ & Downregulation & $0 \%$ to $-80 \%$ & {$[26,37,38,67]$} \\
\hline $\boldsymbol{\beta 2 - A R}$ & $\begin{array}{c}\text { "Downregulation" } \\
\text { Redistribution from } \\
\text { cav to ecav }\end{array}$ & $0 \%$ to $-80 \%(*)$ & {$[45,47]$} \\
\hline GRK & Upregulation & $0 \%$ to $+300 \%$ & {$[38,68,69]$} \\
\hline PDE4 & Downregulation & $0 \%$ to $-50 \%$ & {$[70,71]$} \\
\hline Inhibitor1 & Downregulation & $0 \%$ to $-60 \%$ & {$[49,50,72]$} \\
\hline
\end{tabular}

${ }^{*}$ )Changes in $\beta 2$-AR affect caveolar (cav) and extracaveolar (ecav) receptor concentrations, but only [ $\left.\beta 2\right]$ cav variability is shown since [ $\beta 2]$ ecav can be inferred.

\section{Detubulation in the $\beta$-AR system}

As in Sanchez Alonso at al. [21], a small proportion of L-type channels (LTCC) was reorganized in the crest to reproduce the detubulation effect in heart failure (HF). This implied a new sarcolemmal subspace. Although all the electrophysiological changes were described in the former work, it did not include $\beta$-AR pathways. To introduce an altered LTCC modulation by $\beta 2$-AR in HF it was necessary to define a new PKA substrate: $\mathrm{I}_{\mathrm{CaL}}$ in the extracaveolar (ecav) domain ( $\mathrm{I}_{\mathrm{CaLe}}$ ) [47]. The MichaelisMenten formalism for $\mathrm{I}_{\mathrm{CaLe}}$ phosphorylation was equivalent to the formulation for $\mathrm{I}_{\mathrm{CaL}}$ phosphorylation, being a substrate with AKAPS. Affinities and rate constants were adapted to the ecav domain in the steady state:

Rate of I $\mathrm{CaLe}_{\text {phosphorylation: }} k_{P K A}=k_{I C a L, P K A}=5.1 \cdot 10^{-4} \mathrm{~s}^{-1}$

Affinity of $\mathrm{I}_{\mathrm{CaLe}}$ for phosphorylation by PKA: $K_{P K A}=K_{I C a L, P K A}=1.27 \cdot 10^{-6} \mu \mathrm{mol} / \mathrm{L}$ 
Rate of I $\mathrm{I}_{\text {CaLe }}$ dephosphorylation: $k_{P P}=k_{I C a L, P P} \cdot 5=3.45 \cdot 10^{-3} \mathrm{~s}^{-1}$

Affinity of $\mathrm{I}_{\mathrm{CaLe}}$ for phosphorylation by phosphatases: $K_{P P}=K_{I C a L, P P} \cdot 0.1=6.3 \cdot 10^{-4} \mu \mathrm{mol} / \mathrm{L}$

New AKAPs were considered in the ecav domain to mediate in the phosphorylation of $I_{\text {CaLe }}$, interacting with AKAP yotiao. This interaction was analogous to the one existent between AKAPICaL and AKAP ${ }_{\text {RyR }}$ in the caveolar (cav) domain. Binding affinities between PKA and AKAP ICaLe (MICaLe), between PP1 and AKAPICaLe $\left(\mathrm{K}_{\mathrm{ICaLe}}\right)$, and between $\mathrm{I}_{\mathrm{CaLe}}$ and AKAP ( $\left.\mathrm{L}_{\mathrm{ICaLe}}\right)$ were the same that those for $\mathrm{I}_{\mathrm{CaL}}$.

$$
\begin{aligned}
& b_{p p}=[A K A P]_{\text {tot }}^{I C a L e}+[\text { Yotiao }]_{\text {tot }}^{I K S}+K_{\text {ICaLe }}+K_{I K s}-[P P 1]^{e c a v} \\
& c_{p p}=[A K A P]_{\text {tot }}^{I C a L e} \cdot K_{I K s}+\left[Y_{\text {Otiao }}\right]_{\text {tot }}^{I K s} \cdot K_{\text {ICaLe }}+K_{\text {ICaLe }} \cdot K_{I K s}-[P P 1]^{e c a v} \cdot\left(K_{\text {ICaLe }}+K_{I K s}\right) \\
& d_{p p}=[P P 1]^{e c a v} \cdot K_{I C a L e} \cdot K_{I K s} \\
& b_{R}=[A K A P]_{\text {tot }}^{I \text { CaLe }}+[\text { Yotiao }]_{\text {tot }}^{I K S}+M_{\text {ICaLe }}+M_{I K s}-[P K A]^{\text {ecav }} \\
& c_{R}=[A K A P]_{\text {tot }}^{\text {ICaLe }} \cdot M_{I K s}+[\text { Yotiao }]_{\text {tot }}^{I K S} \cdot M_{I C a L e}+M_{I C a L e} \cdot M_{I K s}-[P K A]^{e c a v} \cdot\left(M_{I C a L e}+M_{I K s}\right) \\
& d_{R}=[P K A]^{e c a v} \cdot K_{I C a L e} \cdot K_{I K s}
\end{aligned}
$$

These coefficients are used to calculate $[\mathrm{PP} 1]_{\mathrm{f}}$ and $[\mathrm{PKA}]_{\mathrm{f}}$ in the ecav compartment following Heijman et al. [17] terminology for the different parameters.

\section{Transmural differences}

Initial simulations were performed on epicardial cells. O'Hara et al. [18] ventricular action potential model differentiates between 3 types of myocytes: endocardial (endo), midmyocardial (M) and epicardial (epi), and we wanted to examine the transmural effect of $\beta$-stimulation. Following Lang et al. [22] data, we varied the amount of total $\beta 2-A R$ from endo to epi, which differed between healthy and failing myocytes (Table 5.4). In the study of HF, the electrophysiological remodeling was applied heterogeneously as detailed in Gomez et al. [2]. Finally, we decided not to use midmyocardial cells because of their controversial phenotype: long action potential versus intermediate endo-epi behavior [24,25]. However, in cardiac strand simulations, a gradient of 20 cells with intermediate properties between endo and epi cells did the transmural transition.

Table 5.4. Heterogeneous transmural $\beta 2-A R$ remodeling

\begin{tabular}{lcc}
\hline & epi/endo & epi/M* \\
\hline $\mathbf{N}$ & 0.8 & 0.9 \\
$\mathbf{H F}$ & 1.4 & 1.2 \\
\hline
\end{tabular}

(*) Intermediate variation 


\section{Selective $\beta$-AR isoform stimulation}

The signaling model selected incorporated $\beta 1$ and $\beta 2$ receptor isoforms with specific pathways and activation of cAMP in the different domains. To activate each receptor subtype independently, the ligand (L) was differentiated into $\mathrm{L} 1$ and $\mathrm{L} 2$ for $\beta 1-\mathrm{AR}$ and $\beta 2-\mathrm{AR}$ respectively according to the equations. For instance, equations 5.1 and 5.2 are for $\beta 1$-mediated Gs activation, while equations 5.3 and 5.4 are for $\beta 2$-mediated Gi activation:

$$
\begin{gathered}
{\left[R_{\beta 1}\right]_{n p, f}=\frac{\left[R_{\beta 1}\right]_{n p, t o t}}{1+\frac{[\boldsymbol{L 1}]}{K_{\beta 1, L}}+[G s]_{f} \cdot\left(\frac{1}{K_{\beta 1, C}}+\frac{[\mathbf{L 1}]}{K_{\beta 1, C} \cdot K_{\beta 1, H}}\right)}} \\
{\left[L R_{\beta 1}\right]_{n p}=\frac{[\boldsymbol{L} \mathbf{1}] \cdot\left[R_{\beta 1}\right]_{n p, f}}{K_{\beta 1, L}}} \\
{[G i]_{f}=\frac{[G i]_{\alpha \beta \gamma}}{1+\frac{\left[R_{\beta 2}\right]_{P K A, f}}{K_{\beta 2, A}}+\frac{[\boldsymbol{L 2}] \cdot\left[R_{\beta 2}\right]_{P K A, f}}{K_{\beta 2, A} \cdot K_{\beta 2, F}}}} \\
{\left[L R_{\beta 2} G i\right]_{P K A}=\frac{[\boldsymbol{L 2}] \cdot\left[R_{\beta 2}\right]_{P K A, f} \cdot[G i]_{f}}{K_{\beta 2, A} \cdot K_{\beta 2, F}}}
\end{gathered}
$$

When [L1] was set to $1 \mu \mathrm{M}$, L2 was 0 and vice versa. For further information about parameters refer to [17].

$$
\begin{aligned}
& b_{L R G}=\left[R_{\beta 1}\right]_{n p, t o t}^{x} \\
& +\left(K_{\beta 1, C} \cdot K_{\beta 1, H} \cdot K_{\beta 2, L} \cdot[\mathbf{L 1}] \cdot[\mathbf{L 2}]-[G s]_{\alpha \beta \gamma}^{x}\right. \\
& \cdot\left(K_{\beta 1, L} \cdot K_{\beta 2, L} \cdot[\boldsymbol{L 1}] \cdot[\boldsymbol{L 2}]+K_{\beta 1, H} \cdot K_{\beta 2, H} \cdot K_{\beta 1, L} \cdot K_{\beta 2, L}+K_{\beta 1, H} \cdot K_{\beta 1, L} \cdot K_{\beta 2, L} \cdot[\mathbf{L 2}]\right. \\
& \left.+K_{\beta 2, H} \cdot K_{\beta 1, L} \cdot K_{\beta 2, L} \cdot[\boldsymbol{L 1}]\right)+K_{\beta 2, C} \cdot K_{\beta 2, H} \cdot K_{\beta 1, L} \cdot[\boldsymbol{L 1}] \cdot[\boldsymbol{L 2}]+K_{\beta 1, L} \cdot K_{\beta 2, L} \\
& \cdot[\boldsymbol{L 1}] \cdot[\boldsymbol{L 2}] \cdot\left[R_{\beta 2}\right]_{n p, t o t}^{x}+K_{\beta 1, C} \cdot K_{\beta 1, H} \cdot K_{\beta 1, L} \cdot K_{\beta 2, H} \cdot K_{\beta 2, L}+K_{\beta 1, H} \cdot K_{\beta 1, L} \cdot K_{\beta 2, C} \\
& \cdot K_{\beta 2, H} \cdot K_{\beta 2, L}+K_{\beta 1, C} \cdot K_{\beta 1, H} \cdot K_{\beta 2, H} \cdot K_{\beta 2, L} \cdot[\boldsymbol{L 1}]+K_{\beta 1, H} \cdot K_{\beta 1, L} \cdot K_{\beta 2, C} \cdot K_{\beta 2, H} \cdot[\boldsymbol{L 2}] \\
& +K_{\beta 1, C} \cdot K_{\beta 1, L} \cdot K_{\beta 2, H} \cdot K_{\beta 2, L} \cdot[\mathbf{L 2}]+K_{\beta 1, L} \cdot K_{\beta 2, C} \cdot K_{\beta 2, H} \cdot K_{\beta 2, L} \cdot[\boldsymbol{L 1}]+\left[R_{\beta 2}\right]_{n p, t o t}^{x} \\
& \cdot\left(K_{\beta 1, H} \cdot K_{\beta 1, L} \cdot K_{\beta 2, H} \cdot K_{\beta 2, L}+K_{\beta 1, H} \cdot K_{\beta 1, L} \cdot K_{\beta 2, L} \cdot[\boldsymbol{L 2}]+K_{\beta 1, L} \cdot K_{\beta 2, H} \cdot K_{\beta 2, L}\right. \\
& \cdot[\boldsymbol{L} \mathbf{1}])) \\
& /\left(K_{\beta 1, L} \cdot K_{\beta 2, L} \cdot[\boldsymbol{L 1}] \cdot[\boldsymbol{L 2}]+K_{\beta 1, H} \cdot K_{\beta 1, L} \cdot K_{\beta 2, H} \cdot K_{\beta 2, L}+K_{\beta 1, H} \cdot K_{\beta 1, L} \cdot K_{\beta 2, L} \cdot[\boldsymbol{L 2}]\right. \\
& \left.+K_{\beta 1, L} \cdot K_{\beta 2, H} \cdot K_{\beta 2, L} \cdot[\boldsymbol{L 1}]\right)
\end{aligned}
$$




$$
\begin{aligned}
& c_{L R G}=\left(\left(\left[R_{\beta 2}\right]_{n p, t o t}^{x}-[G s]_{\alpha \beta \gamma}^{x}\right)\right. \\
& \cdot\left(K_{\beta 2, L} \cdot K_{\beta 1, C} \cdot K_{\beta 1, H} \cdot[\boldsymbol{L 1}] \cdot[\boldsymbol{L 2}]+K_{\beta 1, C} \cdot K_{\beta 1, H} \cdot K_{\beta 1, L} \cdot K_{\beta 2, L} \cdot K_{\beta 2, H}\right. \\
& \left.+K_{\beta 1, H} \cdot K_{\beta 1, C} \cdot K_{\beta 2, H} \cdot K_{\beta 2, L} \cdot[\boldsymbol{L 1}]+K_{\beta 1, H} \cdot K_{\beta 1, L} \cdot K_{\beta 1, C} \cdot K_{\beta 2, L} \cdot[\mathbf{L 2}]\right) \\
& +\left(\left[R_{\beta 1}\right]_{n p, t o t}^{x}-[G s]_{\alpha \beta \gamma}^{x}\right) \\
& \cdot\left(K_{\beta 1, H} \cdot K_{\beta 1, L} \cdot K_{\beta 2, H} \cdot K_{\beta 2, L} \cdot K_{\beta 2, C}+K_{\beta 2, H} \cdot K_{\beta 1, L} \cdot K_{\beta 2, C} \cdot K_{\beta 2, L} \cdot[\boldsymbol{L 1}]+K_{\beta 2, C}\right. \\
& \left.\cdot K_{\beta 2, H} \cdot K_{\beta 1, L} \cdot[\boldsymbol{L 1}] \cdot[\boldsymbol{L 2}]+K_{\beta 1, L} \cdot K_{\beta 1, H} \cdot K_{\beta 2, H} \cdot K_{\beta 2, C} \cdot[\mathbf{L 2}]\right)+K_{\beta 1, C} \cdot K_{\beta 1, H} \\
& \cdot K_{\beta 1, L} \cdot K_{\beta 2, H} \cdot K_{\beta 2, L} \cdot K_{\beta 2, C}+K_{\beta 1, H} \cdot K_{\beta 1, C} \cdot K_{\beta 2, C} \cdot K_{\beta 2, H} \cdot K_{\beta 2, L} \cdot[\boldsymbol{L 1}] \\
& +K_{\beta 1, H} \cdot K_{\beta 1, C} \cdot K_{\beta 2, C} \cdot K_{\beta 2, H} \cdot K_{\beta 1, L} \cdot[\mathbf{L 2}]+K_{\beta 1, C} \cdot K_{\beta 1, H} \cdot K_{\beta 2, C} \cdot K_{\beta 2, H} \cdot[\boldsymbol{L 1}] \\
& \cdot[\boldsymbol{L 2}]) /\left(K_{\beta 1, L} \cdot K_{\beta 2, L} \cdot\left(K_{\beta 2, H}+[\boldsymbol{L 2}]\right) \cdot\left(K_{\beta 1, H}+[\boldsymbol{L 1}]\right)\right) \\
& d_{L R G}=\frac{\left([G s]_{\alpha \beta \gamma}^{x} \cdot K_{\beta 1, H} \cdot K_{\beta 1, C} \cdot K_{\beta 2, H} \cdot K_{\beta 2, C} \cdot\left(K_{\beta 2, L}+[\mathbf{L 2}]\right) \cdot\left(K_{\beta 1, L}+[\mathbf{L 1}]\right)\right)}{\left(K_{\beta 1, L} \cdot K_{\beta 2, L} \cdot\left(K_{\beta 2, H}+[\boldsymbol{L 2}]\right) \cdot\left(K_{\beta 1, H}+[\boldsymbol{L 1}]\right)\right)}
\end{aligned}
$$

\section{Population of models}

Biological variability in signaling parameters was only applied to the remodeled factors in heart failure (Table 5.3). Electrophysiological variability was introduced in 17 variables representing maximal current conductance or flux of the following parameters: fast $\mathrm{Na}^{+}$current $\left(\mathrm{I}_{\mathrm{Na}}\right)$, late $\mathrm{Na}^{+}$ current ( $\mathrm{I}_{\mathrm{NaL}}$ ), transient outward $\mathrm{K}^{+}$current $\left(\mathrm{I}_{\mathrm{to}}\right)$, L-type $\mathrm{Ca}^{2+}$ current $\left(\mathrm{I}_{\mathrm{CaL}}\right.$ ), rapid delayed rectifier $\mathrm{K}^{+}$ current $\left(\mathrm{I}_{\mathrm{Kr}}\right.$ ), slow delayed rectifier $\mathrm{K}^{+}$current $\left(\mathrm{I}_{\mathrm{Ks}}\right)$, inward rectifier $\mathrm{K}^{+}$current $\left(\mathrm{I}_{\mathrm{K} 1}\right), \mathrm{Na}^{+} / \mathrm{Ca}^{2+}$ exchange current $\left(\mathrm{I}_{\mathrm{NaCa}}\right), \mathrm{Na}^{+} / \mathrm{K}^{+}$ATPase current $\left(\mathrm{I}_{\mathrm{NaK}}\right)$, background currents ( $\mathrm{I}_{\mathrm{Nab}}, \mathrm{I}_{\mathrm{Cab}}, \mathrm{I}_{\mathrm{Kb}}$ ), sarcolemmal $\mathrm{Ca}^{2+}$ pump current $\left(\mathrm{I}_{\mathrm{pCa}}\right), \mathrm{SR} \mathrm{Ca}{ }^{2+}$ release via $\mathrm{RyR}\left(\mathrm{J}_{\mathrm{rel}}\right), \mathrm{SR} \mathrm{Ca} \mathrm{Ca}^{2+}$ uptake via SERCA pump (J $\mathrm{JSRCA}_{\text {SE }}$, SR $\mathrm{Ca}^{2+}$ leak ( $\left.\mathrm{J}_{\text {leak }}\right)$, and SR $\mathrm{Ca}^{2+}$ translocation from NSR to JSR $\left(\mathrm{J}_{\mathrm{tr}}\right)$. 


\subsubsection{Supplementary figures}

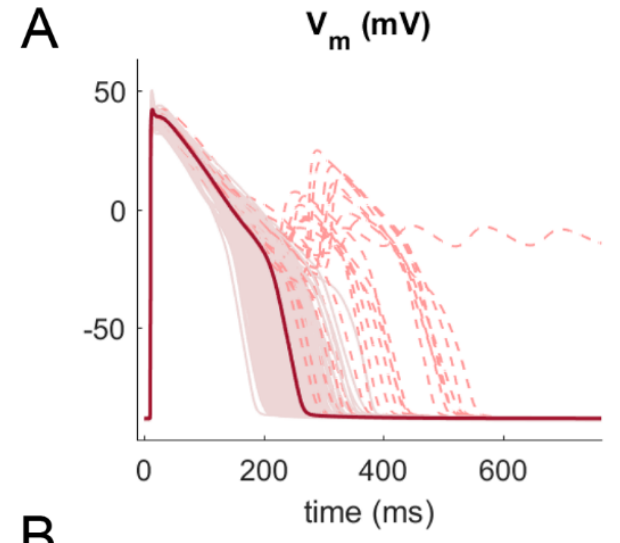

B

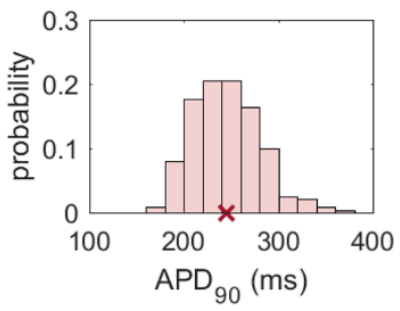

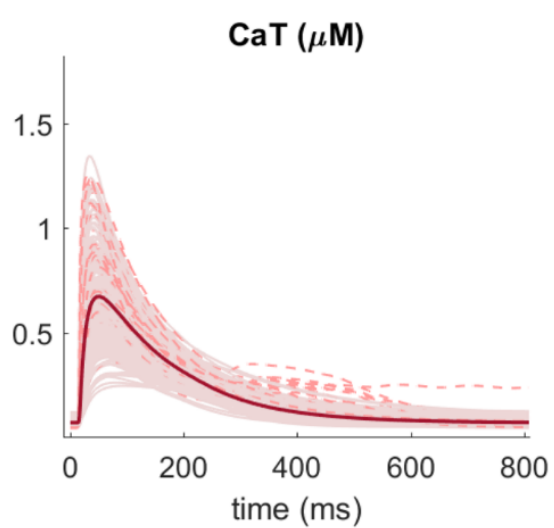
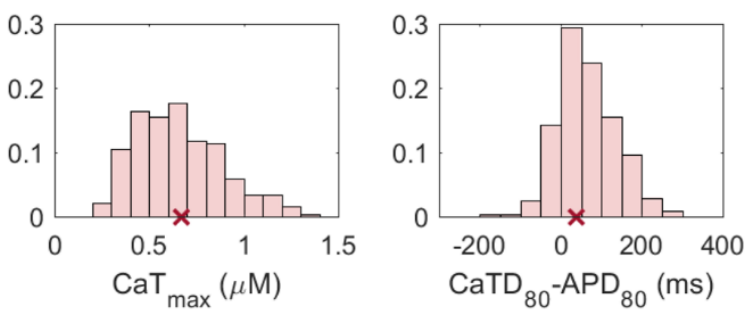

Figure 5.8. Population of cells with $\boldsymbol{\beta}$-AR stimulation in $\mathbf{H F}$ with iso. A) Variability in action potentials and $\mathrm{Ca}^{2+}$ transients, B) Distribution of biomarkers. Dark red lines and markers represent the baseline model. Cells with EADs are represented with dashed lines and were excluded from biomarker calculation. The stimulation frequency was set to $1 \mathrm{~Hz}$. 


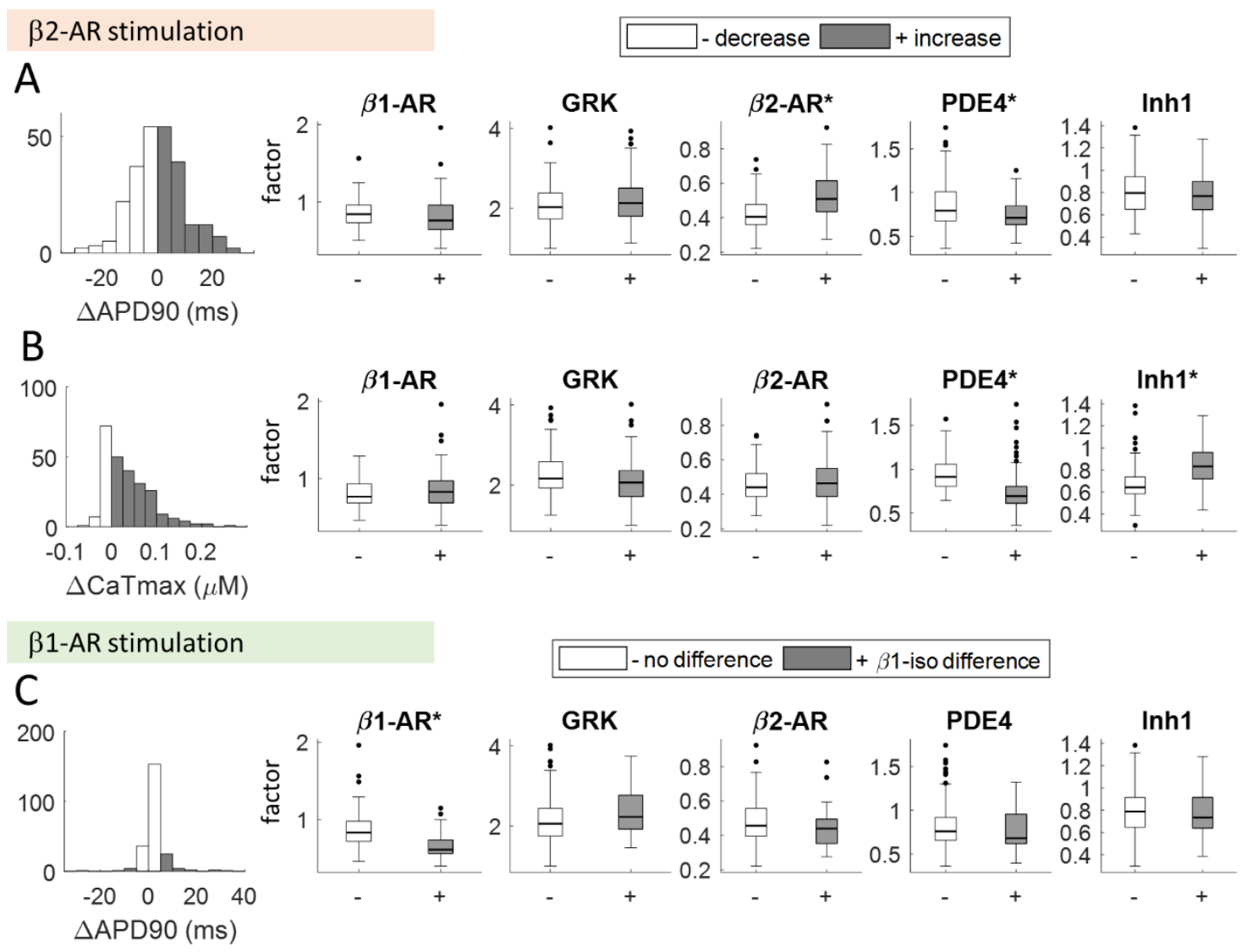

Figure 5.9. Remodeled signaling parameters contribution to $A P D$ and $\mathrm{CaT}_{\max }$ modulation in heart failure depending on $\boldsymbol{\beta}$-AR isoform stimulated. $A$ ) Variation of $\mathrm{APD}_{90}$ between $\beta 2-\mathrm{AR}$ and control, $\mathrm{B}$ ) variation of $\mathrm{CaT}_{\max }$ between $\beta 2-\mathrm{AR}$ and control, and $C$ ) variation of $\mathrm{APD}_{90}$ between $\beta 1-\mathrm{AR}$ and iso. ${ }^{*} \mathrm{p}<0.01$ 


\section{REFERENCES}

1. Coronel R, Wilders R, Verkerk AO, Wiegerinck RF, Benoist D, Bernus O. Electrophysiological changes in heart failure and their implications for arrhythmogenesis. Biochim Biophys Acta - Mol Basis Dis. Elsevier; 2013;1832: 2432-2441. doi:10.1016/J.BBADIS.2013.04.002

2. Gomez JF, Cardona K, Romero L, Ferrero JM, Trenor B. Electrophysiological and structural remodeling in heart failure modulate arrhythmogenesis. 1D simulation study. PLoS One. 2014;9: e106602. doi:10.1371/journal.pone.0106602

3. Antoons G, Oros A, Bito V, Sipido KR, Vos MA. Cellular basis for triggered ventricular arrhythmias that occur in the setting of compensated hypertrophy and heart failure: considerations for diagnosis and treatment. J Electrocardiol. Elsevier; 2007;40: S8-S14. doi:10.1016/j.jelectrocard.2007.05.022

4. Johnson DM, Antoons G. Arrhythmogenic Mechanisms in Heart Failure: Linking $\beta$-Adrenergic Stimulation, Stretch, and Calcium. Front Physiol. 2018;9: 1-23. doi:10.3389/fphys.2018.01453

5. Saucerman JJ, McCulloch AD. Mechanistic systems models of cell signaling networks: A case study of myocyte adrenergic regulation. Prog Biophys Mol Biol. 2004;85: 261-278. doi:10.1016/j.pbiomolbio.2004.01.005

6. William Tank A, Lee Wong D. Peripheral and Central Effects of Circulating Catecholamines. Comprehensive Physiology. Hoboken, NJ, USA: John Wiley \& Sons, Inc.; 2014. pp. 1-15. doi:10.1002/cphy.c140007

7. Lohse MJ, Engelhardt S, Eschenhagen T. What is the role of beta-adrenergic signaling in heart failure? Circ Res. 2003;93: 896-906. doi:10.1161/01.RES.0000102042.83024.CA

8. Port JD, Bristow MR. Altered Beta-adrenergic Receptor Gene Regulation and Signaling in Chronic Heart Failure. J Mol Cell Cardiol. Academic Press; 2001;33: 887-905. doi:10.1006/JMCC.2001.1358

9. Bozkurt B. What Is New in Heart Failure Management in 2017? Update on ACC/AHA Heart Failure Guidelines. Curr Cardiol Rep. Springer US; 2018;20: 39. doi:10.1007/s11886-018-0978-7

10. Kubon C, Mistry NB, Grundvold I, Halvorsen S, Kjeldsen SE, Westheim AS. The role of beta-blockers in the treatment of chronic heart failure. Trends Pharmacol Sci. Elsevier Current Trends; 2011;32: 206-212. doi:10.1016/J.TIPS.2011.01.006

11. Chatterjee S, Biondi-Zoccai G, Abbate A, D'Ascenzo F, Castagno D, Van Tassell B, et al. Benefits of $\beta$ blockers in patients with heart failure and reduced ejection fraction: network meta-analysis. BMJ. British Medical Journal Publishing Group; 2013;346: f55. doi:10.1136/bmj.f55

12. Baker JG. The selectivity of $\beta$-adrenoceptor antagonists at the human $\beta 1, \beta 2$ and $\beta 3$ adrenoceptors. Br J Pharmacol. 2005;144: 317-322. doi:10.1038/sj.bjp.0706048

13. Poole-Wilson PA, Swedberg K, Cleland JG, Di Lenarda A, Hanrath P, Komajda M, et al. Comparison of carvedilol and metoprolol on clinical outcomes in patients with chronic heart failure in the Carvedilol Or Metoprolol European Trial (COMET): randomised controlled trial. Lancet. Elsevier; 2003;362: 7-13. doi:10.1016/S0140-6736(03)138007

14. Heng MK. Beta, partial agonists to treat heart failure: Effects of xamoterol upon cardiac function and clinical status. Clin Cardiol. 1990;13: 171-176. doi:10.1002/clc.4960130305

15. Soltis AR, Saucerman JJ. Synergy between CaMKII substrates and ??-adrenergic signaling in regulation of cardiac myocyte Ca2 handling. Biophys J. Biophysical Society; 2010;99: 2038-2047. doi:10.1016/j.bpj.2010.08.016

16. Rozier K, Bondarenko VE. Distinct physiological effects of $\beta 1$ - and $\beta 2$-adrenoceptors in mouse ventricular myocytes: insights from a compartmentalized mathematical model. Am J Physiol Physiol. 2017;312: C595-C623. doi:10.1152/ajpcell.00273.2016

17. Heijman J, Volders PGA, Westra RL, Rudy Y. Local control of beta-adrenergic stimulation: Effects on ventricular myocyte electrophysiology and Ca2+-transient. J Mol Cell Cardiol. 2011;50: 863-871. doi:10.1016/j.yjmcc.2011.02.007

18. O’Hara T, Virág L, Varró A, Rudy Y. Simulation of the undiseased human cardiac ventricular action potential: model formulation and experimental validation. PLoS Comput Biol. 2011;7: e1002061. doi:10.1371/journal.pcbi.1002061

19. O’Hara T, Rudy Y. Arrhythmia formation in subclinical (“silent”) long QT syndrome requires multiple insults: Quantitative mechanistic study using the KCNQ1 mutation Q357R as example. Hear Rhythm. Elsevier Inc.; 2012;9: 275-282. doi:10.1016/j.hrthm.2011.09.066

20. Gong JQX, Susilo ME, Sher A, Musante CJ, Sobie EA. Quantitative analysis of variability in an integrated model of human ventricular electrophysiology and $\beta$-adrenergic signaling. J Mol Cell Cardiol. Academic Press; 2020; 
doi:10.1016/J.YJMCC.2020.04.009

21. Sanchez-Alonso JL, Bhargava A, O’Hara T, Glukhov A V, Schobesberger S, Bhogal N, et al. Microdomain-Specific Modulation of L-Type Calcium Channels Leads to Triggered Ventricular Arrhythmia in Heart Failure. Circ Res. 2016;119: 944-945. doi:10.1161/CIRCRESAHA.116.308698

22. Lang D, Holzem K, Kang C, Xiao M, Hwang HJ, Ewald GA, et al. Arrhythmogenic remodeling of $\beta 2$ versus $\beta 1$ adrenergic signaling in the human failing heart. Circ Arrhythmia Electrophysiol. 2015;8: 409-419. doi:10.1161/CIRCEP.114.002065

23. Passini E, Trovato C, Morissette P, Sannajust F, Bueno-Orovio A, Rodriguez B. Drug-induced shortening of the electromechanical window is an effective biomarker for in silico prediction of clinical risk of arrhythmias. Br $\mathrm{J}$ Pharmacol. John Wiley \& Sons, Ltd (10.1111); 2019; bph.14786. doi:10.1111/bph.14786

24. Glukhov A V., Fedorov V V., Lou Q, Ravikumar VK, Kalish PW, Schuessler RB, et al. Transmural dispersion of repolarization in failing and nonfailing human ventricle. Circ Res. 2010;106: 981-991. doi:10.1161/CIRCRESAHA.109.204891

25. Antzelevitch C. M cells in the human heart. Circ Res. NIH Public Access; 2010;106: 815-7. doi:10.1161/CIRCRESAHA.109.216226

26. Bristow MR, Ginsburg R, Umans V, Fowler M, Minobe W, Rasmussen R, et al. $\beta 1$ - and $\beta 2$-adrenergic-receptor subpopulations in nonfailing and failing human ventricular myocardium: Coupling of both receptor subtypes to muscle contraction and selective $\beta 1$-receptor down-regulation in heart failure. Circ Res. 1986;59: 297-309. doi:10.1161/01.RES.59.3.297

27. Bers DM. Cardiac excitation-contraction coupling. Nature. Nature Publishing Group; 2002;415: 198-205. doi:10.1038/415198a

28. Veldkamp M. Norepinephrine induces action potential prolongation and early afterdepolarizations in ventricular myocytes isolated from human end-stage failing hearts. Eur Heart J. 2001;22: 955-963. doi:10.1053/euhj.2000.2499

29. Wang Y, Yuan J, Qian Z, Zhang X, Chen Y, Hou X, et al. $\beta 2$ adrenergic receptor activation governs cardiac repolarization and arrhythmogenesis in a guinea pig model of heart failure. Sci Rep. 2015;5: 7681. doi:10.1038/srep07681

30. Lowe MD, Rowland E, Brown MJ, Grace AA. Beta(2) adrenergic receptors mediate important electrophysiological effects in human ventricular myocardium. Heart. 2001;86: 45-51.

31. Nikolaev VO, Bünemann M, Schmitteckert E, Lohse MJ, Engelhardt S. Cyclic AMP Imaging in Adult Cardiac Myocytes Reveals Far-Reaching $\beta 1$-Adrenergic but Locally Confined $\beta 2$-Adrenergic Receptor-Mediated Signaling. Circ Res. 2006;99: 1084-1091. doi:10.1161/01.RES.0000250046.69918.d5

32. Loucks AD, O’Hara T, Trayanova NA. Degradation of T-Tubular Microdomains and Altered cAMP Compartmentation Lead to Emergence of Arrhythmogenic Triggers in Heart Failure Myocytes: An in silico Study. Front Physiol. 2018;9: 1-12. doi:10.3389/fphys.2018.01737

33. Rocchetti M, Alemanni M, Mostacciuolo G, Barassi P, Altomare C, Chisci R, et al. Modulation of sarcoplasmic reticulum function by PST2744 [istaroxime; (E,Z)-3-((2-aminoethoxy)imino) androstane-6,17-dione hydrochloride)] in a pressure-overload heart failure model. J Pharmacol Exp Ther. 2008;326: 957-965. doi:10.1124/jpet.108.138701

34. Dong X, Thomas DD. Time-resolved FRET Reveals the Structural Mechanism of SERCA-PLB Regulation. Biochem Biophys Res Commun. NIH Public Access; 2014;449: 196. doi:10.1016/J.BBRC.2014.04.166

35. de Lucia C, Eguchi A, Koch WJ. New Insights in Cardiac $\beta$-Adrenergic Signaling During Heart Failure and Aging. Front Pharmacol. 2018;9: 1-14. doi:10.3389/fphar.2018.00904

36. Freedman NJ, Lefkowitz RJ. Desensitization of G protein-coupled receptors. Recent Prog Horm Res. 1996;51: 31951; discussion 352-3.

37. Brodde OE. $\beta 1$ - and $\beta 2$-adrenoceptors in the human heart: properties, function, and alterations in chronic heart failure. Pharmacol Rev. 1991;43: 203-42.

38. Ungerer M, Böhm M, Elce JS, Erdmann E, Lohse MJ. Altered expression of beta-adrenergic receptor kinase and beta 1-adrenergic receptors in the failing human heart. Circulation. 1993;87: 454-463. doi:10.1161/01.CIR.87.2.454

39. Böhm M, Eschenhagen T, Gierschik P, Larisch K, Lensche H, Mende U, et al. Radioimmunochemical Quantification of Gi $\alpha$ in Right and Left Vehicles from Patients with Ischaemic and Dilated Cardiomyopathy and Predominant Left Ventricular Failure. J Mol Cell Cardiol. Academic Press; 1994;26: 133-149. doi:10.1006/JMCC.1994.1017

40. Woo AY-H, Song Y, Xiao R-P, Zhu W. Biased $\beta 2$-adrenoceptor signalling in heart failure: pathophysiology and drug discovery. Br J Pharmacol. 2015;172: 5444-56. doi:10.1111/bph.12965 
41. Schobesberger S, Wright P, Tokar S, Bhargava A, Mansfield C, Glukhov A V., et al. T-tubule remodelling disturbs localized $\beta 2$-adrenergic signalling in rat ventricular myocytes during the progression of heart failure. Cardiovasc Res. 2017;113: 770-782. doi:10.1093/cvr/cvx074

42. Bhogal N, Hasan A, Gorelik J. The Development of Compartmentation of cAMP Signaling in Cardiomyocytes: The Role of T-Tubules and Caveolae Microdomains. J Cardiovasc Dev Dis. Multidisciplinary Digital Publishing Institute; 2018;5: 25. doi:10.3390/jcdd5020025

43. Desantiago J, Ai X, Islam M, Acuna G, Ziolo MT, Bers DM, et al. Arrhythmogenic effects of $\beta 2$-adrenergic stimulation in the failing heart are attributable to enhanced sarcoplasmic reticulum Ca load. Circ Res. 2008;102: 1389-1397. doi:10.1161/CIRCRESAHA.107.169011

44. Altschuld RA, Starling RC, Hamlin RL, Billman GE, Hensley J, Castillo L, et al. Response of Failing Canine and Human Heart Cells to $\beta_{2}$-Adrenergic Stimulation. Circulation. 1995;92: 1612-1618. doi:10.1161/01.CIR.92.6.1612

45. Nikolaev VO, Moshkov A, Lyon AR, Miragoli M, Novak P, Paur H, et al. Beta2-Adrenergic Receptor Redistribution in Heart Failure Changes cAMP Compartmentation. Science (80- ). 2010;327: 1653-1657. doi:10.1126/science. 1185988

46. Bryant SM, Kong CHT, Cannell MB, Orchard CH, James AF. Loss of caveolin-3-dependent regulation of I Ca in rat ventricular myocytes in heart failure. Am J Physiol Circ Physiol. 2018;314: H521-H529. doi:10.1152/ajpheart.00458.2017

47. Wright PT, Nikolaev VO, O’Hara T, Diakonov I, Bhargava A, Tokar S, et al. Caveolin-3 regulates compartmentation of cardiomyocyte beta2-adrenergic receptor-mediated cAMP signaling. J Mol Cell Cardiol. The Authors; 2014;67: 38-48. doi:10.1016/j.yjmcc.2013.12.003

48. Surdo NC, Berrera M, Koschinski A, Brescia M, Machado MR, Carr C, et al. FRET biosensor uncovers cAMP nanodomains at $\beta$-adrenergic targets that dictate precise tuning of cardiac contractility. Nat Commun. Nature Publishing Group; 2017;8: 15031. doi:10.1038/ncomms15031

49. Neumann J, Eschenhagen T, Jones LR, Linck B, Schmitz W, Scholz H, et al. Increased Expression of Cardiac Phosphatases in Patients with End-stage Heart Failure. J Mol Cell Cardiol. 1997;29: 265-272. doi:10.1006/jmcc.1996.0271

50. El-Armouche A, Pamminger T, Ditz D, Zolk O, Eschenhagen T. Decreased protein and phosphorylation level of the protein phosphatase inhibitor-1 in failing human hearts. Cardiovasc Res. Narnia; 2004;61: 87-93. doi:10.1016/j.cardiores.2003.11.005

51. MacDougall DA, Agarwal SR, Stopford EA, Chu H, Collins JA, Longster AL, et al. Caveolae compartmentalise $\beta 2$ adrenoceptor signals by curtailing cAMP production and maintaining phosphatase activity in the sarcoplasmic reticulum of the adult ventricular myocyte. J Mol Cell Cardiol. Academic Press; 2012;52: 388-400. doi:10.1016/J.YJMCC.2011.06.014

52. Calaghan S, Kozera L, White E. Compartmentalisation of cAMP-dependent signalling by caveolae in the adult cardiac myocyte. J Mol Cell Cardiol. Academic Press; 2008;45: 88-92. doi:10.1016/J.YJMCC.2008.04.004

53. Akar FG, Rosenbaum DS. Transmural electrophysiological heterogeneities underlying arrhythmogenesis in heart failure. Circ Res. 2003;93: 638-45. doi:10.1161/01.RES.0000092248.59479.AE

54. Antzelevitch C. Heterogeneity and cardiac arrhythmias: An overview. Hear Rhythm. 2007;4: 964-972. doi:10.1016/j.hrthm.2007.03.036

55. Briasoulis A, Palla M, Afonso L. Meta-Analysis of the Effects of Carvedilol Versus Metoprolol on All-Cause Mortality and Hospitalizations in Patients With Heart Failure. Am J Cardiol. Excerpta Medica; 2015;115: 11111115. doi:10.1016/J.AMJCARD.2015.01.545

56. M.J. Shen, D.P. Zipes, Role of the autonomic nervous system in modulating cardiac arrhythmias, Circ. Res. 114 (2014) 1004-1021. https://doi.org/10.1161/CIRCRESAHA.113.302549.

57. Grandi E, Ripplinger CM. Antiarrhythmic mechanisms of beta blocker therapy. Pharmacol Res. 2019;146: 104274. doi:10.1016/j.phrs.2019.104274

58. Nasr IA, Bouzamondo A, Hulot J-S, Dubourg O, Le Heuzey J-Y, Lechat P. Prevention of atrial fibrillation onset by beta-blocker treatment in heart failure: a meta-analysis. Eur Heart J. Narnia; 2007;28: 457-462. doi:10.1093/eurheartj/ehl484

59. Tomek J, Hao G, Tomková M, Lewis A, Carr C, Paterson DJ, et al. $\beta$-Adrenergic Receptor Stimulation and Alternans in the Border Zone of a Healed Infarct: An ex vivo Study and Computational Investigation of Arrhythmogenesis. Front Physiol. Frontiers; 2019;10. doi:10.3389/fphys.2019.00350 
60. Vinge LE, Raake PW, Koch WJ. Gene therapy in heart failure. Circ Res. 2008;102: 1458-70. doi:10.1161/CIRCRESAHA.108.173195

61. Engelhardt S, Hein L, Wiesmann F, Lohse MJ. Progressive hypertrophy and heart failure in $\beta 1$-adrenergic receptor transgenic mice. Proc Natl Acad Sci U S A. National Academy of Sciences; 1999;96: 7059-7064. doi:10.1073/pnas.96.12.7059

62. Xiao RP. Beta-adrenergic signaling in the heart: dual coupling of the beta2-adrenergic receptor to $G(s)$ and $G(i)$ proteins. Sci STKE. American Association for the Advancement of Science; 2001;2001: re15. doi:10.1126/stke.2001.104.re15

63. Rengo G, Perrone-Filardi P, Femminella GD, Liccardo D, Zincarelli C, de Lucia C, et al. Targeting the $\beta$-adrenergic receptor system through G-protein-coupled receptor kinase 2: a new paradigm for therapy and prognostic evaluation in heart failure: from bench to bedside. Circ Heart Fail. 2012;5: 385-91. doi:10.1161/CIRCHEARTFAILURE.112.966895

64. Xiang YK. Compartmentalization of $\beta$-Adrenergic Signals in Cardiomyocytes. Rockman H, editor. Circ Res. 2011;109: 231-244. doi:10.1161/CIRCRESAHA.110.231340

65. Passini E, Mincholé A, Coppini R, Cerbai E, Rodriguez B, Severi S, et al. Mechanisms of pro-arrhythmic abnormalities in ventricular repolarisation and anti-arrhythmic therapies in human hypertrophic cardiomyopathy. J Mol Cell Cardiol. 2016;96: 72-81. doi:10.1016/j.yjmcc.2015.09.003

66. Mora MT, Ferrero JM, Romero L, Trenor B. Sensitivity analysis revealing the effect of modulating ionic mechanisms on calcium dynamics in simulated human heart failure. Csernoch L, editor. PLoS One. 2017;12: e0187739. doi:10.1371/journal.pone.0187739

67. Engelhardt S, Böhm M, Erdmann E, Lohse MJ. Analysis of beta-adrenergic receptor mRNA levels in human ventricular biopsy specimens by quantitative polymerase chain reactions: Progressive reduction of beta1-adrenergic receptor mRNA in heart failure. J Am Coll Cardiol. 1996;27: 146-154. doi:10.1016/0735-1097(95)00425-4

68. Yatani A, Shen Y-T, Yan L, Chen W, Kim S-J, Sano K, et al. Down regulation of the L-type Ca2+ channel, GRK2, and phosphorylated phospholamban: protective mechanisms for the denervated failing heart. J Mol Cell Cardiol. 2006;40: 619-628. doi:10.1016/j.yjmcc.2006.02.002

69. Briston SJ, Caldwell JL, Horn MA, Clarke JD, Richards MA, Greensmith DJ, et al. Impaired $\beta$-adrenergic responsiveness accentuates dysfunctional excitation-contraction coupling in an ovine model of tachypacing-induced heart failure. J Physiol. John Wiley \& Sons, Ltd (10.1111); 2011;589: 1367-1382. doi:10.1113/jphysiol.2010.203984

70. Richter W, Xie M, Scheitrum C, Krall J, Movsesian MA, Conti M. Conserved expression and functions of PDE4 in rodent and human heart. Basic Res Cardiol. 2011;106: 249-262. doi:10.1007/s00395-010-0138-8

71. Abi-Gerges A, Richter W, Lefebvre F, Mateo P, Varin A, Heymes C, et al. Decreased Expression and Activity of cAMP Phosphodiesterases in Cardiac Hypertrophy and Its Impact on $\beta$-Adrenergic cAMP Signals. Circ Res. Lippincott Williams \& Wilkins; 2009;105: 784-792. doi:10.1161/CIRCRESAHA.109.197947

72. Gupta RC, Mishra S, Rastogi S, Imai M, Habib O, Sabbah HN. Cardiac SR-coupled PP1 activity and expression are increased and inhibitor 1 protein expression is decreased in failing hearts. Am J Physiol Circ Physiol. American Physiological Society; 2003;285: H2373-H2381. doi:10.1152/ajpheart.00442.2003 



\section{Chapter 6 General discussion}

This chapter summarizes and briefly discusses the main contributions of the present thesis, which go beyond the state of the art in the role and changes of calcium handling in the human failing heart.

Cardiac electrophysiology is a complex biophysical system in which multiple parameters interact in the excitation-contraction process. Computational modeling of the electrical activity is a wellestablished approach because of its capacity to systematically analyze heart function, explain, and complement experimental findings. Over the years, much effort has been done to improve and adapt myocyte models to human properties, by fitting experimental data and validating the model over ranges of healthy conditions [1,2]. Sensitivity analyses have resulted useful in quantifying ionic variability impact, which helps to validate the model and provides information about critical factors $[3,4]$. When applied to failing myocytes, they revealed pro-arrhythmic mechanisms [5,6].

For the sake of simplicity, we initially performed a univariate sensitivity analysis in a heart failure myocyte model and compared it to the results in normal cell in order to study changes in both action potential and $\mathrm{Ca}^{2+}$ transient properties. We considered important to study intracellular $\mathrm{Ca}^{2+}$ for its crucial role in contraction and its potential arrhythmogenic capacity, which should not be underestimated. The first finding was the strong SERCA effect on $\mathrm{Ca}^{2+}$ indicators, in agreement with experimental reports [7,8]. The comparison of sensitivities in both conditions revealed that HF modulates some parameters in a different way: $\mathrm{I}_{\mathrm{Kr}}$ blocking drugs should be avoided in HF, blocking NCX could be beneficial in HF although it worsens relaxation by increasing diastolic $\mathrm{Ca}^{2+}$, and depressed SERCA function in HF highlights the need of a strong enhancement to restore systolic $\mathrm{Ca}^{2+}$.

A tissue-level hallmark of HF is increased fibrosis and proliferation of cardiac fibroblasts. Altered electrophysiological properties of myocytes due to the electrotonic interaction with fibroblasts have shown conduction abnormalities and reentries [9-11]. We introduced this intercellular coupling in our simulations to study the impact of fibroblasts on $\mathrm{Ca}^{2+}$ dynamics in HF. Multivariate sensitivity analyses were performed to evaluate the effects of fibroblast-myocyte coupling but compared to univariate sensitivities, both analysis yield very similar results: despite the exacerbated $\mathrm{Ca}^{2+}$ impairment in $\mathrm{HF}$, fibroblast presence does not alter the role of the main mechanisms regulating $\mathrm{Ca}^{2+}$ dynamics in myocytes, and pharmacological action on $\mathrm{I}_{\mathrm{CaL}}$ and SERCA enhancement and NCX block would help CaT restoration in failing hearts.

Cells prone to $\mathrm{Ca}^{2+}$ alternans can give rise to repolarization alternans and promote arrhythmogenesis. The mechanistic origin of these alternans has been investigated in normal myocytes with fibroblast coupling, and in failing myocytes, but not under the combination of HF condition and fibroblasts [12-14]. We computationally characterized the onset of alternans in HF under the influence of disperse fibroblasts using a virtual two-dimensional human model. The main findings highlighted SERCA, ICaL, and NCX as the relevant factors for the occurrence of cellular alternans by modulating $\mathrm{Ca}^{2+}$ cycling to threshold levels, but the mechanisms acted differently in normal and failing myocytes. We found that $\left[\mathrm{Ca}^{2+}\right]$ in the junctional SR, in contrast to the altered $\mathrm{SR} \mathrm{Ca}^{2+}$ release reported in [15], determined the degree of $\mathrm{Ca}^{2+}$ impairment and the myocyte susceptibility to $\mathrm{Ca}$-alt development. Fibroblasts induced discordant $\mathrm{Ca}^{2+}$ alternans but the exacerbated $\mathrm{Ca}^{2+}$ impairment in $\mathrm{HF}$ reduced the number of alternans. However, there was a major risk in the translation of $\mathrm{Ca}^{2+}$ alternans into discordant APD alternans in failing tissue with fibroblasts than in normal tissue. 
$\beta$-blocker therapy is used in patients with HF due to the improvement of clinical outputs, but the mechanisms by which these drugs prevent arrhythmogenesis is unknown [16-18]. The effects of isoproterenol, a non-specific $\beta$-adrenergic agonist, have been examined in healthy myocytes $[19,20]$. However, an elevated activation of cardiac $\beta$-adrenergic receptors occurs during HF and a prolonged stimulation becomes detrimental. We applied remodeling in signaling proteins and observed electrical instabilities and contractile dysfunction. It was already reported by Loucks et al. [21], but only with $\beta 2$-ARs. As a novelty, we compared the effects of isoproterenol with selective stimulation of $\beta 1$ and $\beta 2$-ARs. We detected differences in the electrophysiological response of failing cells to sympathetic stimulation compared to the effects observed with $\beta$-agonists in normal myocytes: the positive inotropic response was smaller, the vulnerability of myocytes to develop EADs increased, $\beta$ stimulation was less protective against DADs, the response to $\beta 2-\mathrm{AR}$ stimulation was blunted, and $\beta$ stimulation does not provide a beneficial reduction of repolarization dispersion as observed in normal conditions. These predictions suggest again the need to test pharmacological agents under the setting of HF.

\section{REFERENCES}

1. Grandi E, Pasqualini F, Bers D. A novel computational model of the human ventricular action potential and Ca transient. J Mol Cell .... 2010;48: 112-121.

2. O'Hara T, Virág L, Varró A, Rudy Y. Simulation of the undiseased human cardiac ventricular action potential: model formulation and experimental validation. PLoS Comput Biol. 2011;7: e1002061. doi:10.1371/journal.pcbi.1002061

3. Romero L, Pueyo E, Fink M, Rodríguez B. Impact of ionic current variability on human ventricular cellular electrophysiology. Am J Physiol Heart Circ Physiol. 2009;297: H1436-H1445. doi:10.1152/ajpheart.00263.2009

4. Sobie EA. Parameter sensitivity analysis in electrophysiological models using multivariable regression. Biophys J. 2009;96: 1264-1274. doi:10.1016/j.bpj.2008.10.056

5. Trenor B, Cardona K, Gomez JF, Rajamani S, Ferrero JM, Belardinelli L, et al. Simulation and mechanistic investigation of the arrhythmogenic role of the late sodium current in human heart failure. PLoS One. 2012;7: e32659. doi:10.1371/journal.pone.0032659

6. Passini E, Mincholé A, Coppini R, Cerbai E, Rodriguez B, Severi S, et al. Mechanisms of pro-arrhythmic abnormalities in ventricular repolarisation and anti-arrhythmic therapies in human hypertrophic cardiomyopathy. $\mathrm{J}$ Mol Cell Cardiol. 2016;96: 72-81. doi:10.1016/j.yjmcc.2015.09.003

7. Lyon AR, Bannister ML, Collins T, Pearce E, Sepehripour AH, Dubb SS, et al. SERCA2a gene transfer decreases sarcoplasmic reticulum calcium leak and reduces ventricular arrhythmias in a model of chronic heart failure. Circ Arrhythmia Electrophysiol. 2011;4: 362-372. doi:10.1161/CIRCEP.110.961615

8. del Monte F, Harding SE, Schmidt U, Matsui T, Kang ZB, Dec GW, et al. Restoration of contractile function in isolated cardiomyocytes from failing human hearts by gene transfer of SERCA2a. Circulation. 1999;100: 2308-11. doi:10.1161/01.CIR.100.23.2308

9. Xie Y, Garfinkel A, Camelliti P, Kohl P, Weiss JN, Qu Z. Effects of fibroblast-myocyte coupling on cardiac conduction and vulnerability to reentry: A computational study. Hear Rhythm. Elsevier Inc.; 2009;6: 1641-1649. doi:10.1016/j.hrthm.2009.08.003

10. Majumder R, Nayak AR, Pandit R. Nonequilibrium arrhythmic states and transitions in a mathematical model for diffuse fibrosis in human cardiac tissue. Chen X, editor. PLoS One. 2012;7: e45040. doi:10.1371/journal.pone.0045040

11. Sridhar S, Vandersickel N, Panfilov A V. Effect of myocyte-fibroblast coupling on the onset of pathological dynamics in a model of ventricular tissue. Sci Rep. Nature Publishing Group; 2017;7: 40985. doi:10.1038/srep40985

12. Zhou X, Bueno-Orovio A, Orini M, Hanson B, Hayward M, Taggart P, et al. In vivo and in silico investigation into mechanisms of frequency dependence of repolarization alternans in human ventricular cardiomyocytes. Circ Res. 2016;118: 266-278. doi:10.1161/CIRCRESAHA.115.307836 
13. Xie Y, Garfinkel A, Weiss JN, Qu Z. Cardiac alternans induced by fibroblast-myocyte coupling: mechanistic insights from computational models. Am J Physiol Circ Physiol. American Physiological Society; 2009;297: H775-H784. doi:10.1152/ajpheart.00341.2009

14. Walmsley J, Rodriguez JF, Mirams GR, Burrage K, Efimov IR, Rodriguez B. mRNA expression levels in failing human hearts predict cellular electrophysiological remodeling: A population-based simulation study. PLoS One. 2013;8: e56359. doi:10.1371/journal.pone.0056359

15. Tomek J, Tomková M, Zhou X, Bub G, Rodriguez B. Modulation of Cardiac Alternans by Altered Sarcoplasmic Reticulum Calcium Release: A Simulation Study. Front Physiol. 2018;9: 1306. doi:10.3389/fphys.2018.01306

16. Bozkurt B. What Is New in Heart Failure Management in 2017? Update on ACC/AHA Heart Failure Guidelines. Curr Cardiol Rep. Springer US; 2018;20: 39. doi:10.1007/s11886-018-0978-7

17. Kubon C, Mistry NB, Grundvold I, Halvorsen S, Kjeldsen SE, Westheim AS. The role of beta-blockers in the treatment of chronic heart failure. Trends Pharmacol Sci. Elsevier Current Trends; 2011;32: 206-212. doi:10.1016/J.TIPS.2011.01.006

18. Chatterjee S, Biondi-Zoccai G, Abbate A, D'Ascenzo F, Castagno D, Van Tassell B, et al. Benefits of $\beta$ blockers in patients with heart failure and reduced ejection fraction: network meta-analysis. BMJ. British Medical Journal Publishing Group; 2013;346: f55. doi:10.1136/bmj.f55

19. O'Hara T, Rudy Y. Arrhythmia formation in subclinical ("silent") long QT syndrome requires multiple insults: Quantitative mechanistic study using the KCNQ1 mutation Q357R as example. Hear Rhythm. Elsevier Inc.; 2012;9: 275-282. doi:10.1016/j.hrthm.2011.09.066

20. Gong J, Thompson WC, Musante CJ, Sobie EA. An Integrated Model of Human Beta-Adrenergic Signaling and Ventricular Electrophysiology Reveals Contributors to Positive Inotropy. Biophysical Journal. Elsevier; 2017. pp. 403a-404a. doi:10.1016/j.bpj.2016.11.2185

21. Loucks AD, O’Hara T, Trayanova NA. Degradation of T-Tubular Microdomains and Altered cAMP Compartmentation Lead to Emergence of Arrhythmogenic Triggers in Heart Failure Myocytes: An in silico Study. Front Physiol. 2018;9: 1-12. doi:10.3389/fphys.2018.01737 



\section{Chapter 7 Conclusions and future work}

\subsection{Conclusions}

In this final chapter, the findings drawn from the different studies are highlighted. They have contributed to understand the role of $\mathrm{Ca}^{2+}$ handling and related proteins in human heart failure by means of computer simulations and by using the ORd action potential model, variable modifications to represent $\mathrm{HF}$, and other cellular models (fibroblast model or $\beta$-adrenergic signaling system) when needed. The main conclusions corresponding to the specific objectives defined in this thesis are summarized as follows:

\section{Selection and analysis of biomarkers determining $\mathrm{Ca}^{2+}$ dynamics.}

The main quantitative indicator of $\mathrm{Ca}^{2+}$ handling used along the studies has been the systolic CaT peak because it determines contractile force, but also because it can be related to other $\mathrm{Ca}^{2+}$ biomarkers.

In Chapter 2, the sensitivity of multiple biomarkers to parameter variability were analyzed. Intracellular $\mathrm{Ca}^{2+}$ transients were quantified using systolic and diastolic levels, duration and time to peak. Systolic and diastolic concentrations from sarcoplasmic reticulum (SR) were also measured. All of them were different between normal and failing myocytes and also the sensitivities to $\mathrm{Ca}^{2+}$-handling parameters such as SERCA and NCX. As $\mathrm{Ca}^{2+}$ dynamics follows a cycle, it was easy to relate most biomarkers. For instance, CaT fast recovery due to enhanced $\mathrm{Ca}^{2+}$ reuptake into de $\mathrm{SR}$ led to $\mathrm{CaT}$ duration reduction together with lower diastolic $\left[\mathrm{Ca}^{2+}\right]_{\mathrm{i}}$, and elevated diastolic $\mathrm{SR} \mathrm{Ca}^{2+}$ load. Consequently, SR $\mathrm{Ca}^{2+}$ release increased and elevated systolic $\left[\mathrm{Ca}^{2+}\right]_{\mathrm{i}}$ was finally observed.

When considering fibroblast-myocyte coupling, slight $\mathrm{Ca}^{2+}$-dynamics changes occurred due to electrotonic interactions, although not having details about $\mathrm{Ca}^{2+}$-handling in fibroblasts limited the results. In Chapter 4, the study of SR $\mathrm{Ca}^{2+}$ content was crucial to understand the origin of beat-to-beat alternation of CaTs, as only determined $\left[\mathrm{Ca}^{2+}\right]_{\mathrm{JSR}}$ led to intracellular alternans.

2. Quantification and analysis of the modulation of action potentials and $\mathrm{Ca}^{2+}$ transients with variations in model parameters.

Univariate and multivariate sensitivity analyses were performed to study parameter variability. Chapters 2 and 3 illustrated how these analyses contributed to understand ionic mechanisms. For instance, SERCA was highlighted as a potential target to restore the altered $\mathrm{Ca}^{2+}$ homeostasis in $\mathrm{HF}$. The comparison of univariate and multivariate methodologies in chapter 3 showed that discrepancies increased at elevated parameter variability ranges. Although multivariate analyses take into account parameter interactions providing further information, results highly depended on the linearity of electrophysiological properties. While action potential biomarkers, like the APD90, varied linearly with conductances, $\mathrm{Ca}^{2+}$ biomarkers presented a weaker linear fit, especially in HF. Therefore, numerical predictions of transmembrane potential waveform were easier to determine than $\mathrm{Ca}^{2+}$ dynamics, but estimations were still useful to highlight SERCA, NCX and $\mathrm{I}_{\mathrm{CaL}}$ as important regulators in $\mathrm{Ca}^{2+}$ cycling. 
The use of different sets of models also provided a range of phenotypes similar to biological variability. With population of models, some individuals showed outcomes that could not be observed in a single model but were relevant because presented potential electrical instabilities (e.g. EADs) or on the contrary, revealed a desired phenotype. For this reason, one approach consisted in build populations of models to cover and analyze a wide variety of physiological behaviors and predict parameter sets that led to a determined phenotype. In chapter 3, electrophysiological parameters that improved altered action potentials and impaired $\mathrm{Ca}^{2+}$ transients of failing myocytes with and without fibroblast electrocoupling were elucidated. Targeting $\mathrm{I}_{\mathrm{CaL}}$, SERCA and NCX might help CaT restoration in failing myocytes regardless of fibroblast interaction, but $\mathrm{I}_{\mathrm{Kr}}$ enhancement might only be necessary in myocytes without fibroblast coupling. In chapter 5, HF-induced remodeling of signaling parameters was obtained by selecting myocytes fulfilling the modulation effect of $\beta$-adrenergic stimulation from a heterogeneous population.

3. Implementation and study of the main changes in cardiac myocytes and tissues observed in failing hearts to reproduce the HF phenotype: abnormal action potentials and $\mathrm{Ca}^{2+}$ transients, and defective electrical conduction.

$\&$

4. Comparison of normal and failing myocytes in response to different conditions.

HF-induced changes were implemented in all the studies although the specific remodeling depended on the scope of each work. Apart from study failing conditions, the comparison with healthy myocytes allowed to draw conclusions about the variation of ionic mechanisms regulating cardiac electrophysiology.

Initially (Chapters 2 and 3), we focused on cellular electrophysiology and only ionic remodeling was applied. Differences in $\mathrm{Ca}^{2+}$ dynamics between normal and failing cells were linked to SERCA downregulation and NCX upregulation, which also explained the weaker response in HF to pharmacological actions tested in healthy conditions.

In Chapter 3, apart from electrophysiological remodeling, the characteristic increase in fibrotic content was considered by means of fibroblast coupling. We observed that the electrical sink effect of active fibroblasts shortened action potential duration in myocytes. This affected $\mathrm{Ca}^{2+}$ currents and contributed to $\mathrm{Ca}^{2+}$ impairment. However, ionic remodeling compared to fibroblast coupling effect was the major cause of altered $\mathrm{Ca}^{2+}$ transients.

With the aim of widening the study considering additional factors, $\beta$-adrenergic signaling was included in Chapter 5. The electrophysiological modulation exerted by the sustained sympathetic stimulation in failing myocytes was reproduced by applying remodeling to key signaling parameters affected by HF. We found that $\beta 2$-receptor stimulation became unresponsive and that $\beta 1$-receptors were the only sustaining the weak inotropic increase (systolic $\mathrm{Ca}^{2+}$ ). However, results also suggested an increase in arrhythmogenesis (EADs) highlighting the suppression role of $\beta 1$-blockers, but without positive effects in transmural gradients as they could have in healthy conditions. These findings could explain the partial benefit of adrenergic receptors and the additional need to target $\mathrm{Ca}^{2+}$ proteins to restore inotropy and improve cardiac function.

The study of myocyte coupling and electrical propagation in a strand in Chapters 4 and 5 added information to the results at the cellular level. The reduced conduction in HF due to reduced cellular 
coupling as observed experimentally, contributed to electrical instabilities. We observed, for instance, discordant alternans (Chapter 4) and the increase of transmural repolarization dispersion (Chapter 5).

\section{Study of the influence of altered $\mathrm{Ca}^{2+}$ cycling on electrical instabilities.}

Apart from the reduced inotropy directly related to depressed CaTs, it was interesting to study arrhythmogenic electrical events linked to deranged $\mathrm{Ca}^{2+}$ handling.

Chapter 4 showed repolarization alternans concomitant with $\mathrm{Ca}^{2+}$ alternans. Despite the small magnitude of beat-to-beat action potential duration oscillations, failing tissues with fibroblasts were the most vulnerable to spatially discordant alternans, highlighting one potential trigger of ventricular fibrillation in heart failure.

In Chapter 5, a higher incidence of early afterdepolarizations was observed with $\beta$-adrenergic stimulation, a situation enhanced in failing myocytes. The stimulation of $\beta 1$ receptors also showed electrical benefits such as the reduction of repolarization gradients in normal cardiac fibers, but this property was abolished under HF conditions.

\subsection{General conclusion}

All results have shown that intracellular $\mathrm{Ca}^{2+}$ properties are different in $\mathrm{HF}$ and $\mathrm{Ca}^{2+}$-handling protein modifications are the main cause of such alterations. The strong coupling between action potential and $\mathrm{Ca}^{2+}$ dynamics indicates that changes in one affect the other and studies should analyze both electrical and $\mathrm{Ca}^{2+}$ cycling mechanisms. The scarcity of human data complicated the validation of the results but the targets suggested to restore $\mathrm{Ca}^{2+}$-handling or suppress electrical instabilities in HF can guide future experimental investigations. In addition, new experiments can help to improve and develop more accurate cardiac models that propose more specific targets after applying the same mechanistic analysis proposed by this study.

\subsection{Future work}

The next steps are thought on the one hand, to improve the accuracy of the model to represent failing conditions and on the other hand, to extend simulations to the organ level:

Extend the study to new or improved action potential models. Apart from ORd model, there are other human action potential models. When simulated results do not match what has been reported experimentally, one option would be to try with another model that may better represent a determined condition. Although ORd is a widely accepted model, it has been updated recently and it would be valuable to evaluate the response of the new model to the setting of HF.

Couple a mechanical model and contraction force. In HF, it is critical to evaluate the mechanical force of the heart to pump blood, so another model that can be integrated with the electrophysiological system is the mechanical model. Although $\mathrm{Ca}^{2+}$ transient provides an estimation of cellular contraction, calculating contractile force magnitude may be more realistic. Mathematical 
formulation for myofilament contraction can be found in the literature and we already initiated a project which integrates electrical, mechanical and signaling models to study HF.

Improve the compartmentalization in the electrophysiological and $\boldsymbol{\beta}$-adrenergic models. Regarding CICR, detailed models have been created to focus on the study of $\mathrm{Ca}^{2+}$ dynamics in the membrane subspace and could be integrated in the cellular model. In a similar way, $\beta$-adrenergic receptors and the PKA signaling cascade vary within subcellular microdomains, and the compartmented effects on ion channels need to be validated.

Integrate a myofibroblast model. When considering fibrosis, the main limitation of the fibroblast model was the lack of $\mathrm{Ca}^{2+}$ dynamics and contractility. If new experiments provide these data, new simulations will consider the interactions between myofibroblast and myocytes.

Include additional conditions. Computation time limits the selection of conditions in simulations, but the design of future studies can incorporate more heart rates, include drugs that block channels or even drugs to regulate $\beta$-adrenergic stimulation.

Extend simulations to the whole organ. 3D simulations show the performance of the entire heart. They can also be more realistic with the use of cardiac images to adjust size, shape and structural remodeling (e.g. fibrotic regions). The inclusion of a mechanical model can also allow the study of cardiac contraction apart from the electrical activity and analyze how changes at the subcellular level affect heart function. Personalized simulations, adapted to patient characteristics from genetics to heart anatomy, is the final goal of computational modeling studies. 


\section{Publications}

The contributions of the present thesis have been published in international journals and presented in national and international conferences.

\section{International Journal}

1. Mora MT, Ferrero JM, Romero L, Trenor B. Sensitivity analysis revealing the effect of modulating ionic mechanisms on calcium dynamics in simulated human heart failure. PLoS One. 2017;12: e0187739. doi:10.1371/journal.pone.0187739

JIF 2017: 2.766; Q1

2. Mora MT, Ferrero JM, Gomez JF, Sobie EA, Trenor B. $\mathrm{Ca}^{2+}$ cycling impairment in heart failure is exacerbated by fibrosis: insights gained from mechanistic simulations. Front Physiol. 2018;9: 1-15. doi:10.3389/fphys.2018.01194

JIF 2018: 3.201; Q2

3. Mora MT, Gomez JF, Morley G, Ferrero JM, Trenor B. Mechanistic investigation of $\mathrm{Ca}^{2+}$ alternans in human heart failure and its modulation by fibroblasts. PLoS One. 2019;14: 1-19. doi:10.1371/journal.pone.0217993

JIF 2018: 2.776; Q2

4. Mora MT, Gong JQX, Sobie EA, Trenor B. The role of $\beta$-adrenergic system remodeling in human heart failure: A mechanistic investigation. Journal of Molecular and Cellular Cardiology. (Under review)

\section{Conferences}

1. Mora MT, Ferrero JM, Trenor B. Sensitivity analysis revealing the modulation of calcium dynamics in simulated human heart failure. 2017 Gordon Research Conference (GRC) on Cardiac Arrythmia Mechanisms, Ventura (California, USA).

2. Mora MT, Ferrero JM, Trenor B. Ionic modulation of calcium dynamics in simulated human heart failure. $44^{\text {th }}$ Computing in Cardiology Conference (CinC 2017), Rennes (France), doi:10.22489/CinC.2017.248-074

3. Mora MT, Ferrero JM, Trenor B. Univariate vs multivariate sensitivity analysis of calcium dynamics in simulated human heart failure. XXXV Congreso Anual de la Sociedad Española de Ingeniería Biomédica (CASEIB 2017), Bilbao (Spain).

4. Mora MT, Dasi A, Saiz J, Trenor B, Ferrero JM. Fibroblasts induce calcium alternans when coupled to cardiomyocytes: A simulation study. $45^{\text {th }}$ Computing in Cardiology Conference (CinC 2018), Maastricht (Netherlands), doi:10.22489/CinC.2018.140 
5. Mora MT, Gong J, Efimov I, Ferrero JM, Sobie EA, Trenor B. Modulation of action potentials and intracellular $\mathrm{Ca}^{2+}$ by isoform specific $\beta$-adrenergic receptor stimulation in human ventricular myocyte. 63 ${ }^{\text {rd }}$ Biophysical Society Annual Meeting (BPS 2019), Baltimore (Maryland, USA).

6. Mora MT, Gong J, Efimov I, Ferrero JM, Sobie EA, Trenor B. Isoform-specific $\beta$-adrenergic receptor stimulation modulates action potentials and intracellular $\mathrm{Ca}^{2+}$ in healthy and failing human ventricular myocytes. 2019 Gordon Research Conference (GRC) on Cardiac Arrythmia Mechanisms, Lucca (Italy).

7. Carpio EF, Mora MT, Gomez JF, Ferrero JM, Trenor B. Multiscale modeling of human heart failure to optimize treatments. 2019 Cardiac Physiome Meeting, Maastricht (Netherlands). 


\section{ACKNOWLEDGMENTS AGRADECIMIENTOS}

Over the last four years not only did I have educational support, but also personal, friendly and emotional. It is long the list of people I would like to thank and I would not like to forget any person, so I preferred to express my grateful without using names:

If you have contributed to this thesis, thank you.

If you have revised the manuscript version, thank you.

If you have read (part of) this thesis, thank you.

Si has intentado leer el documento sin saber inglés, gracias.

Si sólo has ojeado las páginas porque te importa, gracias.

Si te emociona ver el trabajo terminado, gracias.

\section{Thank you}

\section{Gracias}

\section{Gràcies}

